\title{
Fossil amphibians and reptiles from the Neogene locality of Maramena (Greece), the most diverse European herpetofauna at the Miocene/Pliocene transition boundary
}

\author{
Georgios L. Georgalis, Andrea Villa, Martin Ivanov, \\ Davit Vasilyan, and Massimo Delfino
}

\begin{abstract}
We herein describe the fossil amphibians and reptiles from the Neogene (latest Miocene or earliest Pliocene; MN 13/14) locality of Maramena, in northern Greece. The herpetofauna is shown to be extremely diverse, comprising at least 30 different taxa. Amphibians include at least six urodelan (Cryptobranchidae indet., Salamandrina sp., Lissotriton sp. [Lissotriton vulgaris group], Lissotriton sp., Ommatotriton sp., and Salamandra sp.), and three anuran taxa (Latonia sp., Hyla sp., and Pelophylax sp.). Reptiles are much more speciose, being represented by two turtle (the geoemydid Mauremys aristotelica and a probable indeterminate testudinid), at least nine lizard (Agaminae indet., Lacertidae indet., ?Lacertidae indet., aff. Palaeocordylus sp., ?Scincidae indet., Anguis sp., five morphotypes of Ophisaurus, Pseudopus sp., and at least one species of Varanus), and 10 snake taxa (Scolecophidia indet., Periergophis micros gen. et sp. nov., Paraxenophis spanios gen. et sp. nov., Hierophis cf. hungaricus, another distinct "colubrine" morphotype, Natrix aff. rudabanyaensis, and another distinct species of Natrix, Naja sp., cf. Micrurus sp., and a member of the "Oriental Vipers" complex). The autapomorphic features and bizarre vertebral morphology of Periergophis micros gen. et sp. nov. and Paraxenophis spanios gen. et sp. nov. render them readily distinguishable among fossil and extant snakes. Cryptobranchids, several of the amphibian genera, scincids, Anguis, Pseudopus, and Micrurus represent totally new fossil occurrences, not only for the Greek area, but for the whole southeastern Europe. The four different types of serration within the Varanus teeth from Maramena raise questions on the taxonomic importance or the variability of this feature. The large number of distinct amphibian and reptile taxa in Maramena makes this Greek locality by far the most diverse and speciose among all European localities across the latest Miocene and earliest Pliocene. An estimation of the palaeoprecipitation value of the locality is provided. The biogeographic origins of the Maramena herpetofauna are not fully resolved, though certain of its elements were previously only known from the early and middle Miocene of Central Europe.
\end{abstract}

http://zoobank.org/5857474C-1265-4443-8938-BC37420561F1

Georgalis, Georgios L., Villa, Andrea, Ivanov, Martin, Vasilyan, Davit, and Delfino, Massimo. 2019. Fossil amphibians and reptiles from the Neogene locality of Maramena (Greece), the most diverse European herpetofauna at the Miocene/Pliocene transition boundary. Palaeontologia Electronica 22.3.68 1-99. https://doi.org/10.26879/908 palaeo-electronica.org/content/2019/2797-fossil-herpetofauna-maramena 
Georgios L. Georgalis. Dipartimento di Scienze della Terra, Università di Torino, Via Valperga Caluso 35, 10125 Torino, Italy. dimetrodon82@gmail.com

Department of Geosciences, University of Fribourg / Freiburg, Chemin du Musée 6, 1700 Fribourg,

Switzerland.

Department of Ecology, Laboratory of Evolutionary Biology, Faculty of Natural Sciences, Comenius University in Bratislava, Mlynská dolina, 84215 Bratislava, Slovakia.

Andrea Villa. Bayerische Staatssammlung für Paläontologie und Geologie, Richard-Wagner-Straße 10, 80333 Munich, Germany. a.villa@unito.it

Dipartimento di Scienze della Terra, Università di Torino, Via Valperga Caluso 35, 10125 Torino, Italy.

Martin Ivanov. Department of Geological Sciences, Faculty of Science, Masaryk University, Kotlářská 2, 61137 Brno, Czech Republic. mivanov@sci.muni.cz

Davit Vasilyan. JURASSICA Museum, Fontenais 21, 2900 Porrentruy, Switzerland.

Department of Geosciences, University of Fribourg / Freiburg, Chemin du Musée 6, 1700 Fribourg,

Switzerland. davitvasilyan@gmail.com

Massimo Delfino. Dipartimento di Scienze della Terra, Università di Torino, Via Valperga Caluso 35, 10125

Torino, Italy. massimo.delfino@unito.it

Institut Català de Paleontologia Miquel Crusafont, Universitat Autònoma de Barcelona, Edifici ICTA-ICP, Carrer de les Columnes s/n, Campus de la UAB, 08193 Cerdanyola del Vallès, Barcelona, Spain.

Keywords: amphibians; reptiles; Neogene; biogeography; new species; new genus

Submission: 26 July 2018. Acceptance: 14 October 2019.

\section{INTRODUCTION}

The latest Miocene/earliest Pliocene transition in Europe is characterized by important climatic changes, geographic alterations, and faunal turnovers, which affected the palaeoenvironments of the continent (Cerling et al., 1997; Snel et al., 2006; Carnevale et al., 2008; Harzhauser et al., 2015; Suc et al., 2015; Carnevale et al., 2017; Karakitsios et al., 2017). One of the major dramatic events of the Cenozoic Era, the Messinian Salinity Crisis (hereafter MSC), took place at the latest Miocene (Messinian), a period during which the Mediterranean Sea became isolated from the Atlantic Ocean through a closure of the Strait of Gibraltar, resulting in a significant amount of drying and severe environmental perturbations (Hsü, 1972; Krijgsman et al., 1999; Snel et al., 2006; Carnevale et al., 2008; Ivanovic et al., 2014; Harzhauser et al., 2015; Suc et al., 2015; Carnevale et al., 2017; Karakitsios et al., 2017; Carnevale et al., 2019).

Although the main focus of palaeontological interest for this time lapse has been, as usual, fossil mammals (e.g., Koufos et al., 2005; Fortelius et al., 2006; Koufos and Vasileiadou, 2015), studies on fossil amphibians and reptiles have demonstrated a general impoverishement of post-Miocene European herpetofaunas, with certain clades being locally extinct from the continent and others gradually shrinking their ranges towards the south- ern portions of the continent (Szyndlar, 1991a, b, 2012; Ivanov et al., 2000; Rage, 2013).

To fully comprehend the mechanisms around these extinctions, probable dispersals, distribution ranges alterations, and faunal turnovers of amphibian and reptile assemblages during the latest Miocene/earliest Pliocene transition, it is essential to comprehend and document in detail the exact diversity, taxonomic composition, and affinities of palaeoherpetofaunas across European localities of this time interval. Here we describe in detail the fossil amphibians and reptiles from the locality of Maramena, northern Greece. A large number of amphibian and reptile lineages are described from the fossil record of southeastern Europe for the first time. Two new "colubrine" snake genera and species are established to accommodate new taxa with bizarre autapomorphic features. With an age around the boundary of latest Miocene/earliest Pliocene (MN 13/14), Maramena offers a unique insight about the biogeography and taxonomic diversity of European herpetofaunal assemblages during that time interval. The high abundance and diversity of taxa surpasses all contemporary faunas of the continent and raises questions about the negative effect of the Miocene/Pliocene transition on European herpetofaunas, implying a much more complex biogeographic pattern. 


\section{GEOLOGICAL AND PALAEOECOLOGICAL SETTINGS}

The locality of Maramena is situated a few kilometers from the city of Serres, in the administrative region of Central Macedonia, in northern Greece (Figure 1). Maramena, along with the adjacent localities Ano Metochi-2 and Ano Metochi-3, belongs to the Lefkon Formation (Bruijn, 1989). Maramena is situated in the uppermost part of the Lefkon Formation, which consists of arkosic sands, clays, marls, and lignites (Schmidt-Kittler et al., 1995). The geology of the Lefkon Formation and the adjacent ones (Georgios Formation and Spilia Formation) within the Strymon (or Strimon or Serres) Basin is described in detail by Karystineos (1984), Bruijn (1989), and Schmidt-Kittler et al. (1995). Further information regarding the Strymon Basin has been recently provided in detail by Karakitsios et al. (2017). Maramena is considered to pertain either to the latest Miocene (latest Messinian) or the earliest Pliocene (earliest Zanclean), lying somewhere at the boundary between MN 13/ 14 (Schmidt-Kittler et al., 1995), although the associated macromammal fauna indicates that a latest Miocene age is the most probable (Koufos, 2006). A latest Miocene age allocated to the locality is also supported by the lithological position of the Pontian malacofauna in the marine incursion in the Strymon Basin below a granite breccia (mass transport from the Ana Vrodou massif) (Hans de Bruijn, pers. comm. to GLG, February 2019). The adjacent localities of Ano Metochi-2 and Ano Metochi-3 are both slightly older than Maramena, pertaining to a late Miocene (Messinian, MN 13) age

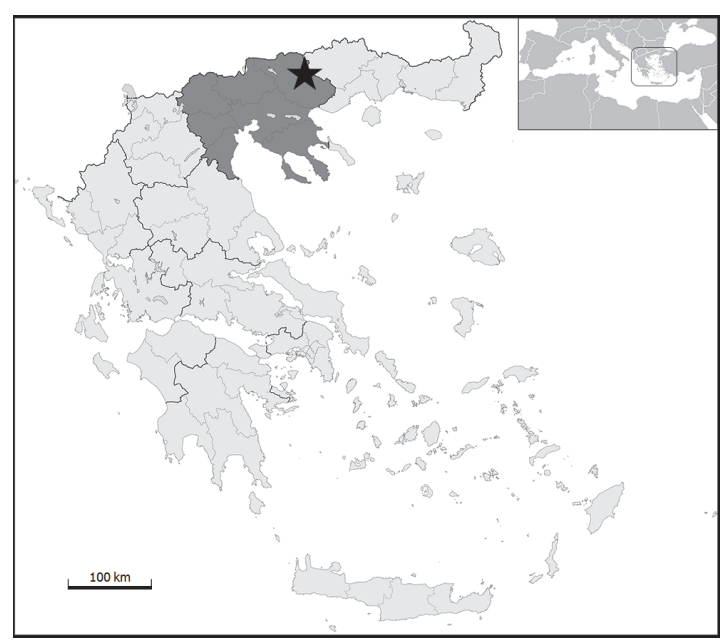

FIGURE 1. Map of Greece, with star indicating the latest Miocene/earliest Pliocene (MN 13/14) locality of Maramena.
(Koufos, 2006). Three approximate and coeval sites in Maramena have produced fossil vertebrates, namely Maramena-1 (M1), Maramena-2 (M2), and Maramena-3 (M3). The majority of the herpetofaunal material described herein, as also the most complete specimens, originates from the M1 site.

Maramena is so far mostly known for its abundant and diverse micromammal fauna, comprising erinaceomorphs, soricomorphs, lagomorphs, and numerous rodents, though large mammals have also been found, consisting of primates, carnivorans, proboscideans, perissodactyls, and artiodactyls (Bruijn, 1995; Schmidt-Kittler et al., 1995; Koufos, 2006). No fossils of amphibians have been so far formally described from Maramena. As far as it concerns reptiles, previous studies conducted in the past three decades have documented the presence of fragmentary remains of turtles (Gad, 1990), lizards (Richter, 1995), and snakes (Szyndlar, 1995).

On the basis of the previous fossil finds, it has been suggested that Maramena represented a lake, surrounded by different environments: a subtropical forest with humid and dense vegetation and a relatively dry and open landscape (SchmidtKittler et al., 1995). This palaeoenvironmental interpretation is also supported by the lithological content, as the sands and lignites present in Maramena probably indicate an alluvial fan or a lake (Schmidt-Kittler et al., 1995).

\section{MATERIAL AND METHODS}

All specimens described herein belong to the collection of the Department of Earth Sciences of the University of Utrecht, Utrecht, The Netherlands (UU). The material was collected during three field excavations in Maramena, in 1981 and 1983 (both collected by Hans de Bruijn), and 1988 (collected by Hans de Bruijn, Norbert Schmidt-Kittler, Constantin Doukas, Gudrun Hock, Lars van den Hoek Ostende, and several students). Fossil specimens were photographed with the digital microscopes Leica M205 and Leica DVM5000. Comparative material includes multiple skeletons of extant frogs, salamanders, turtles, lizards, and snakes hosted in the following collections: HNHM, MDHC, MJSN, MNCN, MNHN, NHMW, NMP, PRIF UK, SMF, ZFMK, and ZZSiD. The mean annual precipitation has been estimated using the bioclimatic analysis of the herpetofaunal assemblage (Böhme et al., 2006). The anatomical terminology of the skeletal elements follows Estes (1981) for urodelans, Roček (1994b) and Sanchíz (1998a) for frogs, 
Joyce and Bell (2004) and Danilov (2005) for turtles, Estes (1983), Evans (2008), and Rage and Augé (2010) for lizards, and Auffenberg (1963), Rage (1984), Szyndlar (1984), and LaDuke (1991) for snakes. Ecophysiological indices follow Böhme et al. (2006).

Geographical/geological Abbreviations. M1, Maramena 1; M2, Maramena 2; M3, Maramena 3. Institutional Abbreviations. HNHM, Hungarian Natural History Museum, Budapest, Hungary; IPUW, Institut für Paläontologie, University of Vienna, Vienna, Austria; MDHC, Massimo Delfino Herpetological Collection, University of Torino, Italy; MFGI, Magyar Földtani és Geofizikai Intézet, Budapest, Hungary; MGPT-PU, Museo di Geologia e Paleontologia, Università degli Studi di Torino, Turin, Italy; MJSN, JURASSICA Museum (formerly Musée jurassien des science naturelle), Porrentruy, Switzerland; MNCN, Museo Nacional de Ciencias Naturales, Madrid, Spain; MNHN, Muséum national d'Histoire naturelle, Paris, France; NHMW, Naturhistorisches Museum, Vienna, Austria; NMP, Národní Muzeum Praha, Prague, Czech Republic; PRIF UK, Faculty of Natural Sciences, Comenius University, Bratislava, Slovakia; SMF, Senckenberg Naturmuseum, Frankfurt am Main, Germany; ZFMK, Zoologisches Forschungsmuseum Koenig, Bonn, Germany; ZZSiD, Polish Academy of Sciences, Krakow, Poland.

\section{SYSTEMATIC PALAEONTOLOGY}

AMPHIBIA Linnaeus, 1758

URODELA Duméril, 1806

PANCRYPTOBRANCHA Vasilyan, Böhme,
Chkhikvadze, Semenov, and Joyce, 2013

CRYPTOBRANCHIDAE Fitzinger, 1826

Cryptobranchidae indet.

Figure 2

Material. M1: an atlas (UU MAA 7441), probably also a second atlas (UU MAA 7530).

Description. The incomplete, opisthocoelous atlas UU MAA 7441 has a preserved centrum length of $6.4 \mathrm{~mm}$ and pertains to a subadult individual, with an estimated approximate body length of $50-55 \mathrm{~cm}$ (Figure 2). The atlas lacks the neural arch. In ventral view, the atlas centrum has concave surface and it is wider than long (Figure 2.4). The articular surfaces of the odontoid process are not fused. Their width is nearly equal to that of the articular cotyle (Figure 2.1). The cotyle is nearly round in outline and tilted posterodorsally (Figure 2.2). The foramen for the first spinal nerve is located in a large lateral groove (Figure 2.2).

Remarks. The general morphology, as well as the large size of the atlas, allows its assignment to the clade of giant salamanders Cryptobranchidae (Westphal, 1958; Vasilyan et al., 2013). Further identification of the atlas is difficult due to the lack of diagnostic morphological characters enabling the determination of interspecific and/or intrageneric differences among recent giant salamander species (Westphal, 1958). Moreover, the study of extant comparative material (Andrias davidianus [Blanchard, 1871] [ZFMK 90469 and ZFMK 76996], Andrias japonicus [Temminck, 1836] [SMF 69133], and Cryptobranchus alleganiensis [Sonnini de Manoncourt and Latreille, 1801] [ZFMK 5245

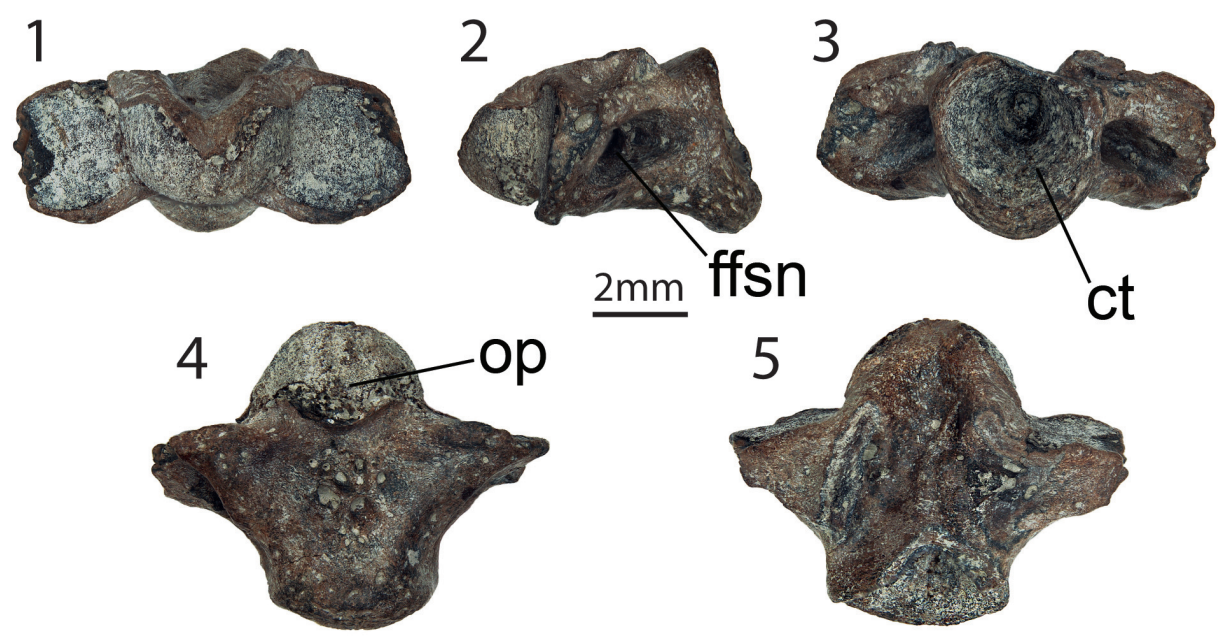

FIGURE 2. Cryptobranchidae indet. from Maramena: atlas (UU MAA 7441) in anterior (1), left lateral (2), posterior (3), ventral (4), and dorsal (5) views. Abbreviations: ct, cotyle; ffsn, foramen for the first spinal nerve; op, odontoid process. 
and SMF 70439]) did not allow any further identification as well.

SALAMANDRIDAE Goldfuss, 1820

SALAMANDRINA Fitzinger, 1826

Type species. Salamandra perspicillata Savi, 1821.

\section{Salamandrina sp.}

Figure 3.1-5

Material. M1: two vertebrae (UU MAA 7483 and UU MAA 7484).

Description. Both vertebrae have small dimensions. In lateral view, the opisthocoelous centrum is straight (Figure 3.1-5). The neural arch is low (Figure 3.2) but possesses a high neural crest, which has "lips" on its dorsal edge (Figure 3.1, 3.5). Posteriorly, it is bifurcated. The posterior laminae (posterior alar process) of the parapophyses reach the cotyle. The ventral lamina is well developed. The anterior edge connecting the prezygapophysis with the centrum is nearly vertical. The zygosphene-zygantrum articulation is present.

Remarks. The combination of the above described characters, observable on these two vertebrae, allows their assignment to the genus Salamandrina (Pitruzzella et al., 2008). Further identification is not possible due to the insufficient preservation of the vertebrae. Moreover, the vertebrae of the two extant Salamandrina species are apparently not diagnostic at the species level (Pitruzzella et al., 2008).

Genus LISSOTRITON Bell, 1839

Type species. Salamandra punctata Latreille, 1800.

LISSOTRITON VULGARIS (Linnaeus, 1758) Lissotriton sp. (Lissotriton vulgaris group)

Figure 3.6-15

Material. M1: two vertebrae (UU MAA 7517 and UU MAA 7518).

Description. The two available vertebrae are relatively large (centrum lengths: $2.15 \mathrm{~mm}$ for UU MAA 7517 and $2.5 \mathrm{~mm}$ for UU MAA 7518) and can be distinguished from Lissotriton spp. and Ommatotriton spp. by their larger size (Figure 3.6-15). The centrum is opisthocoelus. The anterior opening of the neural canal has a pentagonal outline (Figure 3.6, 3.11). The neural arch is high and posteriorly vaulted. The neural spine is high. Its dorsal surface is damaged (Figure 3.7, 3.12). The preserved parapophysis is short and most probably, the vertebrae belong to the anterior trunk region. The ventral lamina has a rhomboid shape with two small subcentral foramina (Figure 3.9, 3.14).
Remarks. The characters observable on the vertebrae (e.g., the overall large size of vertebrae, the small subcentral foramina, high neural spine and neural arch) suggest their assignment to the Lissotriton vulgaris group (Hodrová, 1984). However, due to the poor preservation of both vertebrae, any further identification is not possible.

\section{Lissotriton sp. \\ Figure 3.16-20}

Material. M1: two vertebrae (UU MAA 7486 and UU MAA 7487).

Description. The two small-sized vertebrae have length of less than $2 \mathrm{~mm}$ (Figure 3.16-20). The vertebral centrum is opisthocoelous. The condyle and cotyle are rounded.The condyle displays a welldeveloped pericondylar constriction. The neural canal has a rounded outline. The neural arch is vaulted posteriorly and bifurcated slightly posteriorly. It is not high and possesses a low neural spine. The neural spine has a narrow ridge, without any ornamentation or extensions. The prezygapophyses project dorsolaterally. Posteriorly, they connect with the diapophyses by a moderately developed accessory alar process. The diapophyses and parapophyses are close to each other and connected with osseous laminae, which do not reach the distal end of the transverse process. The anterior and posterior ventral laminae connect the parapophyses with the condyle and cotyle, respectively, forming a broad rhomboid ventral lamina. It is pierced by several large subcentral foramina. The anterior beginning of the anterior lamina (anterior alar process) is pierced by a paracondylar foramen.

Remarks. The combination of certain characters (the general small size of vertebrae, the degree of development of the neural spine, and the rhomboid structure at the ventral surface of the centrum, and the lack of dorsally widening on the neural spine [with tubercles]) observable on the Maramena specimens is characteristic of Lissotriton aff. rohrsi from the early Miocene of Mokrá-Western Quarry, Czech Republic (Ivanov, 2008). Note that the correct spelling of the species epithet of this species should be "rohrsi" and not "roehrsi" (contra Sanchíz, 1998b and Böhme, 2008), as the diacritics in the original spelling of Herre (1955), "röhrsi", have to be removed following ICZN (1999:Article 32.5.2.1). The vertebrae from the Czech locality were distinguished from the respective nominotypical material of Lissotriton rohrsi (Herre, 1955) from the middle Miocene of Devínska Nová Ves, Slovakia, by the lack of the dorsal widening on the neural spine (Ivanov, 2008). The same can be stated also 


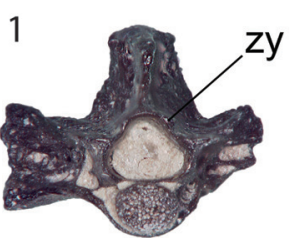

$1 \mathrm{~mm}$

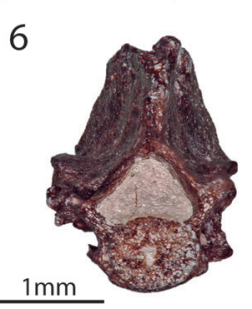

11
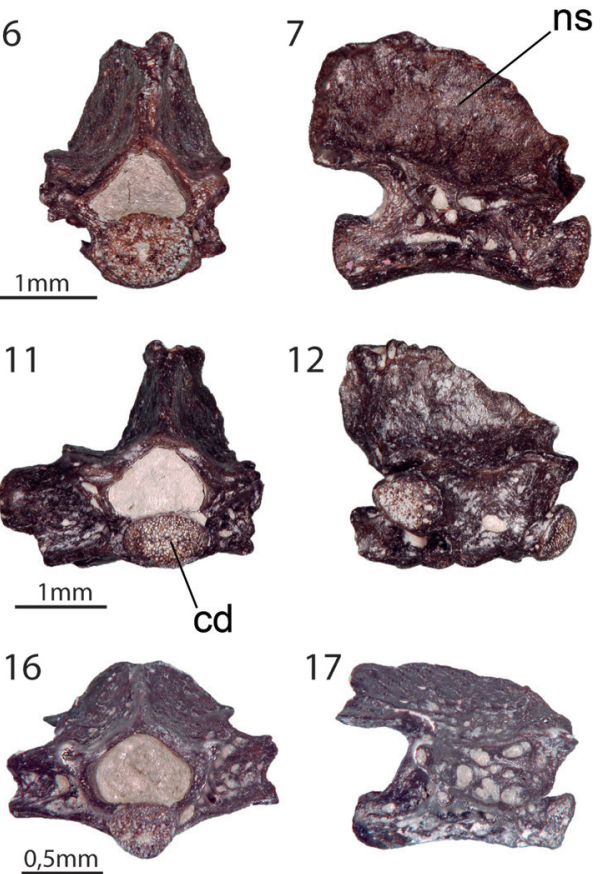

12
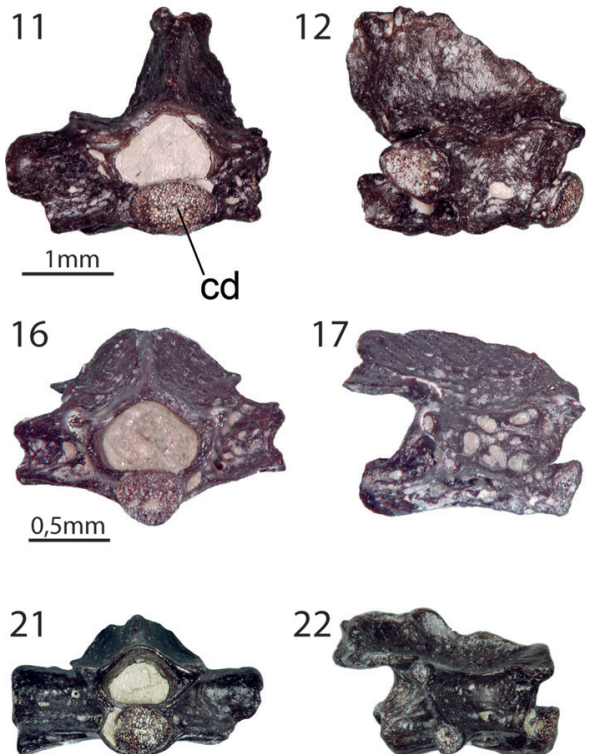

$1 \mathrm{~mm}$

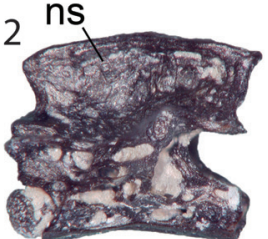

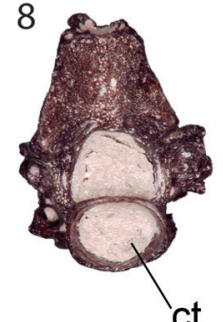
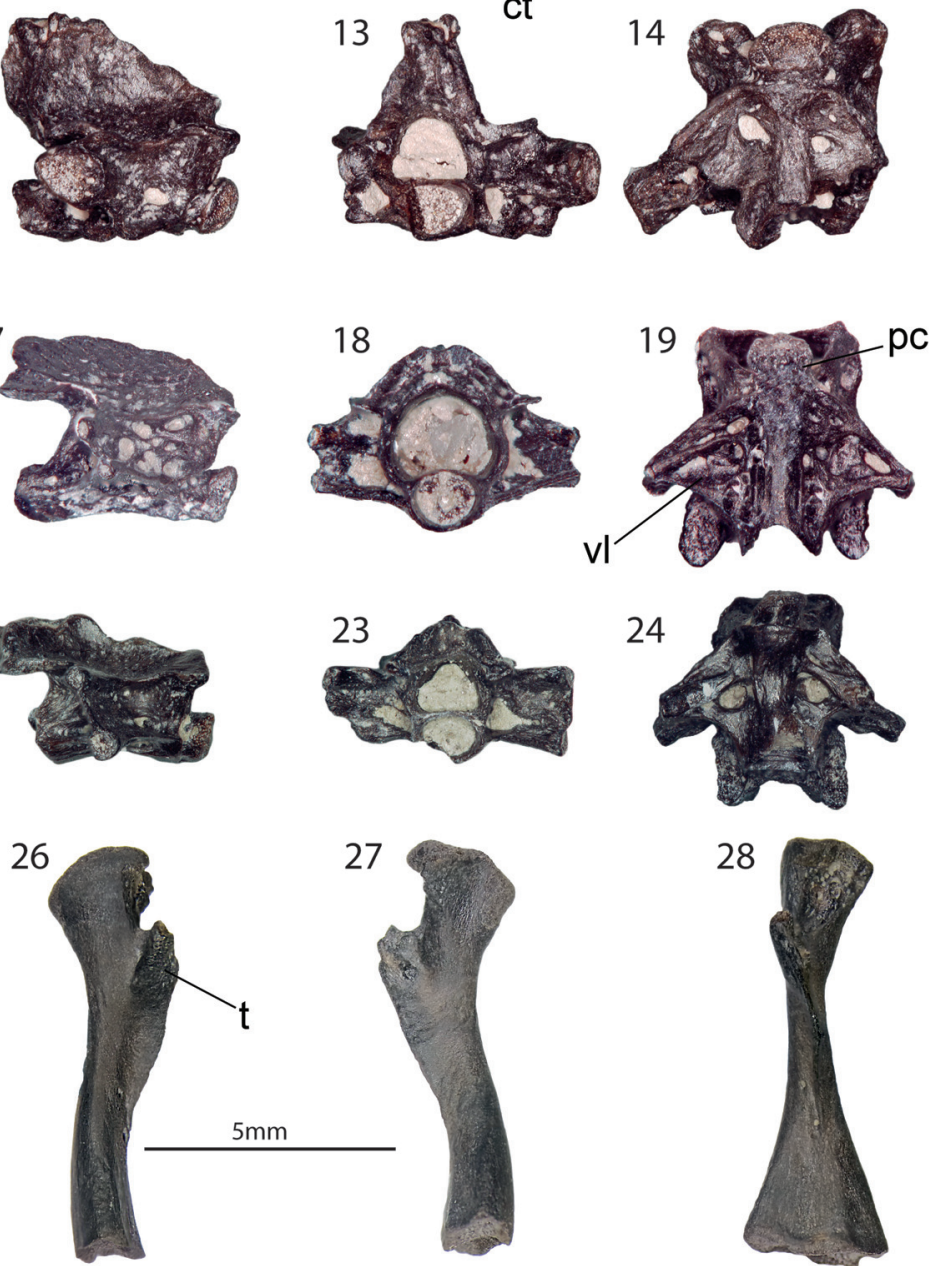
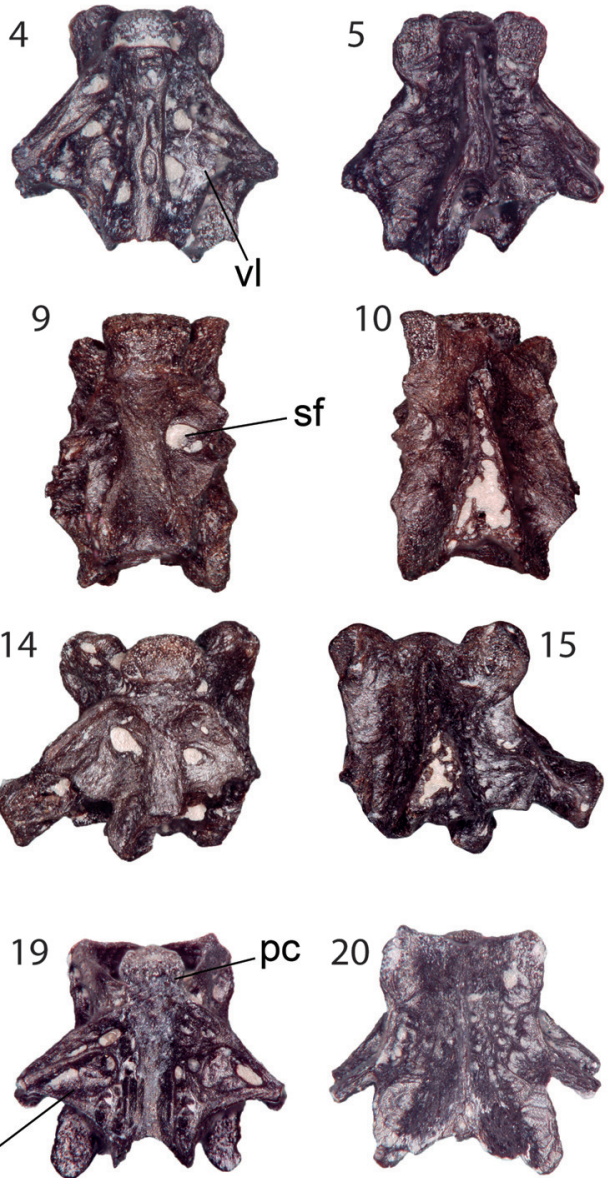

28

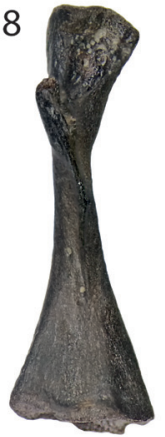

FIGURE 3. Various salamandrids from Maramena. Salamandrina sp. (1-5): trunk vertebra (UU MAA 7483) in anterior (1), left lateral (2), posterior (3), ventral (4), and dorsal (5) views. Lissotriton sp. (Lissotriton vulgaris group) (6-15): trunk vertebra (UU MAA 7518) in anterior (6), right lateral (7), posterior (8), ventral (9), and dorsal (10) views; trunk vertebra (UU MAA 7517) in anterior (11), right lateral (12), posterior (13), ventral (14), and dorsal (15) views. Lissotriton sp.(16-20): trunk vertebra (UU MAA 7486) in anterior (16), right lateral (17), posterior (18), ventral (19), and dorsal (20) views. Ommatotriton sp. (21-28): trunk vertebra (UU MAA 7489) in anterior (21), right lateral (22), posterior (23), ventral (24), and dorsal (25) views; right femur (UU MAA 7248) in anterior (26), posterior (27), and medial (28) views. Abbreviations: cd, condyle; ct, cotyle; ns, neural spine; pc, pericondylar constriction; pt, pterygapophysis; sf, subcentral foramen; t, trochanter; vl, ventral lamina; zy, zygosphene. 
for the Maramena vertebrae. In any case, it is clear that the Maramena vertebrae can be attributed to the genus Lissotriton, on the basis of their small size and the presence of the ventral lamina on their vertebral centrum (DV, pers. observation). The Maramena vertebrae can be further distinguished from the extant Lissotriton spp. by the following features: from Lissotriton boscai (Lataste in Tourneville, 1879) and Lissotriton montandoni (Boulenger, 1880) by the lack of the dorsal widening on the neural spine, and from Lissotriton helveticus (Razoumovsky, 1789) and Lissotriton vulgaris by possessing a lower neural spine. Any further identification seems to be currently vague, pending a solid study of the skeletal anatomy of the recent species and revision of the published fossil material. Thus, we prefer to assign the remains at the generic level, but nevertheless, identify them as a distinct Lissotriton species than the ones described above as Lissotriton sp. (Lissotriton vulgaris group).

\section{Genus OMMATOTRITON Gray, 1850}

Type species. Triturus vittatus Gray in Jenyns, 1835.

Ommatotriton sp.

Figure 3.21-28

Material. M1: a vertebra (UU MAA 7489) and two femurs (UU MAA 7248 and UU MAA 7509).

Description. Vertebra: the only preserved vertebra has a total length of about $3 \mathrm{~mm}$ (Figure 3.21-25). The opisthocoelous centrum is relatively short and compact. In ventral view, a ventral lamina of triangular shape is observable (Figure 3.24). Its posterior ventral lamina is smaller than the anterior one. Two medium-sized subcentral foramina are observable at the posterior corner of the parapophyses and the centrum. In anterior view, the neural canal is rounded but dorsoventrally flattened. The neural arch is low and dorsoventrally compressed (Figure 3.21). Posteriorly, it increases in height and is vaulted. The pterygapophyses are bifurcated. Between the postzygapophyses, a horizontal flange is present, forming the posterodorsal wall of the neural canal. In lateral view, a well-pronounced interzygapophyseal ridge is present (Figure 3.22). The diapophyses and parapophyses are short and connected with a high osseous lamina. The neural spine is not high, though it is slightly higher than the highest point of the neural arch (Figure 3.22). Femurs: they are bent at their mid-diaphyseal part, which is located slightly above the midpoint of the bone (Figure 3.26-28). The distal and proximal articulation surfaces of the femur are filled with mineralized cartilage. The trochanteric crest and trochanter itself are well developed and proximally separate from the bone, projecting anteroproximally (Figure 3.26-28). The latter element has a thin margin, with its anteroposterior surface being covered by tubercles. The intertrochanteric groove, located at the medial side of the proximal head, is broad and moderately deep. The posterior wall is higher than the anterior one.

Remarks. To date, no fossil remains of the genus Ommatotriton have been described or figured. As such, we based our identification of the fossil material on the basis of the study of skeletons of the extant Ommatotriton ophryticus (Berthold, 1846) (collection of MJSN). Based on the following characters, the vertebra is here assigned to this genus: the ventral lamina is triangular, with two mediumsized subcentral foramina; lower and bifurcated neural arch; and low neural spine which is slightly higher than the neural arch. The femur morphology resembles that of Ommatotriton, in terms of general shape and size, as well as the size and dimensions of the trochanteric crest and intertrochlanteric groove.

Genus SALAMANDRA Garsault, 1764

Type species. Lacerta salamandra Linnaeus, 1758.

\section{Salamandra sp. \\ Figure 4.1-5}

Material. M1: 12 trunk vertebrae (UU MAA 7494UU MAA 7505) and six caudal vertebrae (UU MAA 7117, UU MAA 7491-UU MAA 7493, UU MAA 7506, and UU MAA 7507).

Description. Trunk vertebrae: they have dorsoventrally flattened, slightly or strongly curved opisthocoelous centra. The length of the largest vertebra (UU MAA 7495) measures around $6 \mathrm{~mm}$ (Figure 4.2). In all specimens, two small subcentral foramina are present on the ventral surface of the centrum, but only in UU MAA 7495 (the largest vertebra) a small central foramen is observable. Both cotyle and condyle are oval in outline (Figure 4.13 ). The neural arch is low, broad, and flattened. Posteriorly, it increases in height and becomes moderately vaulted. The posterior margin of the neural arch has three lobes. The neural spine is low, slightly higher at its midpoint, and does not reach the anterior and posterior margins of the neural arch (Figure 4.3). The prezygapophyses and postzygapophyses are rounded to oval in outline and tilted laterodorsally. The anterior zygapophyseal ridges that are connecting the prezygapophyses with the diapophyses are weakly 


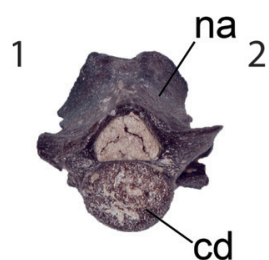

6

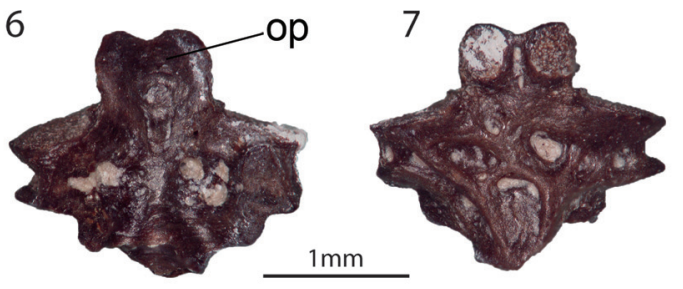

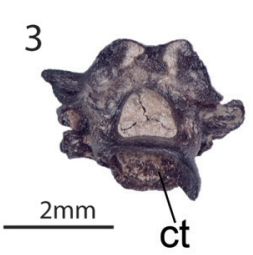

8

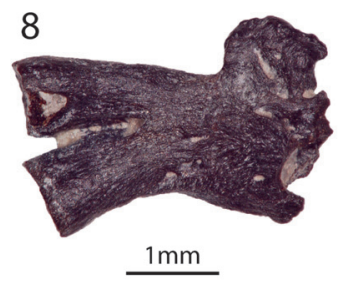

4

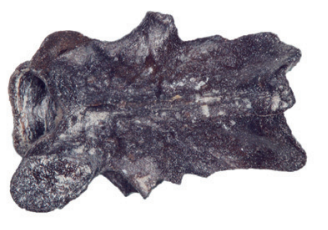

9
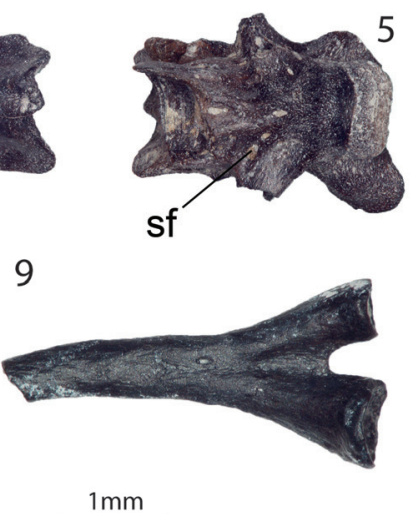

$1 \mathrm{~mm}$

FIGURE 4. Salamandrids from Maramena: Salamandra sp. (1-5): trunk vertebra (UU MAA 7495) in anterior (1), right lateral (2), posterior (3), dorsal (4), and ventral (5) views. Salamandridae indet. (6-9): atlas (UU MAA 7490) in dorsal (6) and ventral (7) views; rib (UU MAA 7508) in anterior view (8); rib (UU MAA 7519) in posterior view (9). Abbreviations: cd, condyle; ct, cotyle; na, neural arch; neural spine; op, odontoid process; sf, subcentral foramen.

pronounced or nearly absent (Figure 4.3). The diapophyses and parapophyses are connected with an osseous lamina.

Caudal vertebrae: they are slightly smaller in size than the above described trunk vertebrae. They belong to different parts of the caudal portion of the skeleton. In comparison with the anterior caudal vertebrae, the posterior ones are smaller in size, their neural arch is much flattened, and their neural spine is reduced, being nearly invisible. The bases of the transverse processes are present. The haemapophyses are either broken or, when present, they are low and project strongly posteriorly (UU MAA 7507).

Remarks. The morphology observable on the preserved vertebrae (i.e., small size, general dorsoventrally flattened centrum, and low neural spine and neural arch) cannot distinguish the Maramena material from both extant or fossil specimens of the recent species Salamandra salamandra (Sanchíz and Młynarski, 1979; Venczel and Hír, 2015), as well as from the extinct taxon Salamandra sansaniensis Lartet, 1851 (Estes and Hoffstetter, 1976). However, the osteology of the genus is, as yet, not adequately studied in detail, except for few exceptions dealing with particular species (e.g., Villa et al., 2014), and as such, the diagnostic characters for each species are not adequately known. Therefore, we prefer to describe these remains only up to the genus level, as Salamandra sp.

\section{Salamandridae indet.}

Figure 4.6-9
Material. M1: an atlas (UU MAA 7490), four vertebrae (UU MAA 7153, UU MAA 7485, UU MAA 7488, and UU MAA 7243), and two ribs (UU MAA 7508 and UU MAA 7519).

Description and remarks. Atlas: only the centrum of the atlas is preserved. Its dorsal surface is relatively flat and bears few large depressions. The odontoid process is "bilobed". The condylar facets are separated and located on the ventral surface of the process. The articular cotyles are slightly posterodorsally tilted. The transverse process has a secondary ridge (Figure 4.6-7).

Vertebrae: the vertebral centra of the trunk and caudal vertebrae are opisthocoelous. The remaining parts of the vertebrae are highly damaged.

Ribs: both ribs are bicapitate. The distal part of the rib UU MAA 7508 (Figure 4.8) is not slender as UU MAA 7519 (Figure 4.9) and it possesses a bulbshaped structure. A comparable rib morphology can be observed in different vertebral positions of salamandrids (Estes, 1981).

$$
\begin{gathered}
\text { ANURA Fischer von Waldheim, } 1813 \\
\text { ALYTIDAE Fitzinger, } 1843 \\
\text { Genus LATONIA Meyer, } 1843
\end{gathered}
$$

Type species. Latonia seyfriedi Meyer, 1843.

\section{Latonia sp. \\ Figure 5}

Material. M1: two fragmentary frontoparietals belonging to a single individual (UU MAA 7445 and UU MAA 7462), three premaxillae (UU MAA 7130), 66 maxillae (UU MAA 7120, UU MAA 7128, UU MAA 7131, UU MAA 7156, UU MAA 7249, UU MAA 7250, UU MAA 7458, and UU MAA 7464-UU 

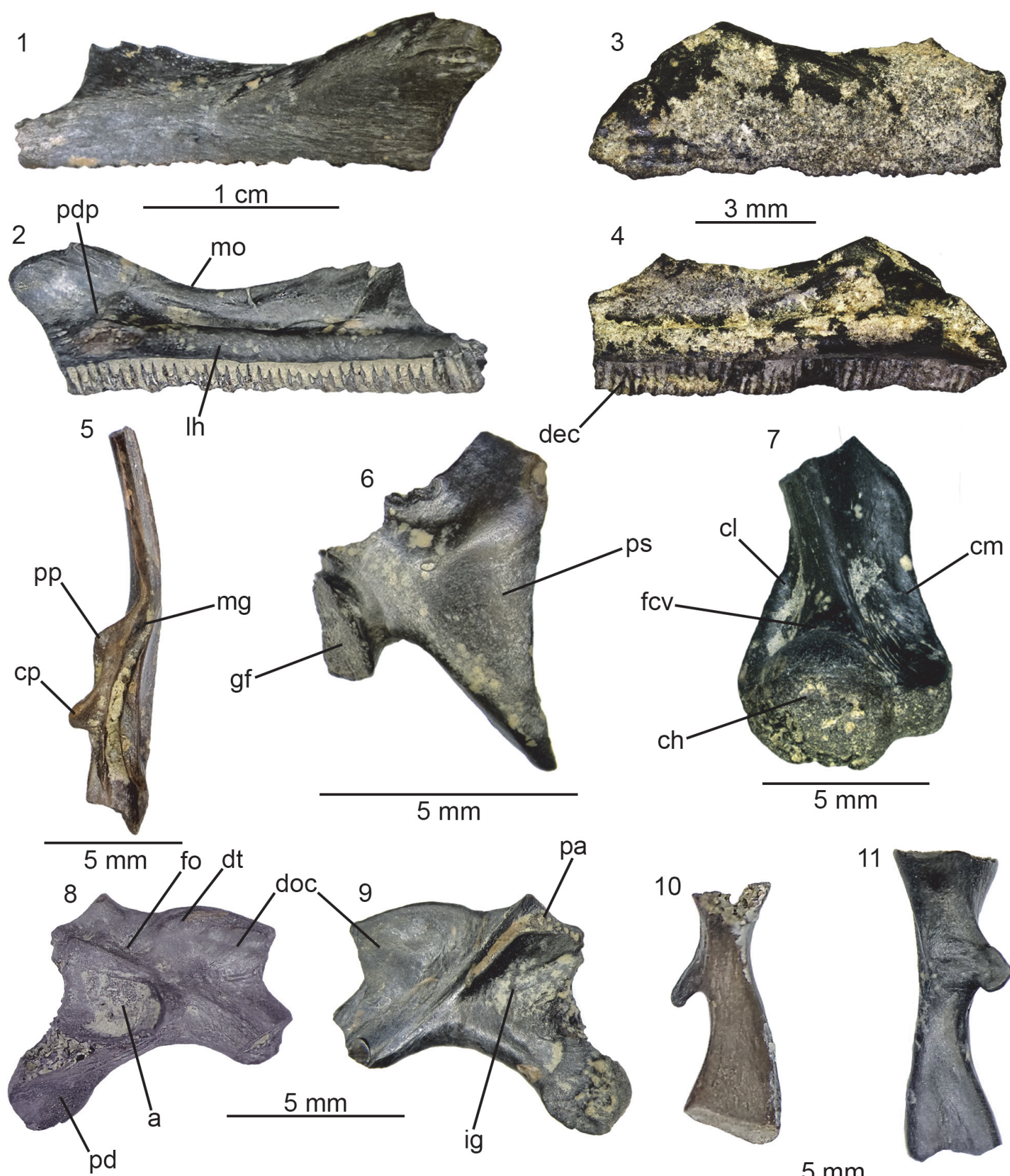

11

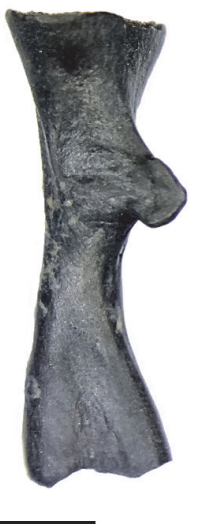

FIGURE 5. Latonia sp. from Maramena: left maxilla (UU MAA 7227) in labial (1) and lingual (2) views; right maxilla (UU MAA 7223) in labial (3) and lingual (4) views; right angular (UU MAA 7154) in dorsal view (5); left scapula (UU MAA 7520) in externalview (6); right humerus (UU MAA 7225) in ventral view (7); right ilium (UU MAA 7528) in lateral (8) and medial (9) views; costa (UU MAA 7523) in lateral (10) and ventral (11) views. Abbreviations: a, acetabulum; $\mathrm{ch}$, caput humeri; $\mathrm{cl}$, crista lateralis; $\mathrm{cm}$, crista medialis; $\mathrm{cp}$, coronoideus portion of the coronoid process; dec, dental crest; doc, dorsal crest; dt, dorsal tubercle; fcv, fossa cubitalis ventralis; fo, supra-acetabular fossa; gf, glenoid fossa; ig, interiliac groove; Ih, lamina horizontalis; mg, Meckelian groove; mo, margo orbitalis; pa, pars ascendens; pd, pars descendens; pdp, posterior depression; pp, paracoronoideus portion of the coronoid process; ps, pars suprascapularis. 
MAA 7472), seven angulars (UU MAA 7154 and UU MAA 7529), an atlas (UU MAA 7459), 17 presacral vertebrae (UU MAA 7125, UU MAA 7158a, UU MAA 7442-UU MAA 7444, UU MAA 7452, UU MAA 7454, UU MAA 7457, UU MAA 7460, and UU MAA 7461), three sacral vertebrae (UU MAA 7455 and UU MAA 7522), four urostyles (UU MAA 7446, UU MAA 7450, and UU MAA 7521), a scapula (UU MAA 7520), four costae (UU MAA 7523), 14 humeri (UU MAA 7155, UU MAA 7158b, UU MAA 7453, and UU MAA 7463), and nine ilia (UU MAA 7447-UU MAA 7449, UU MAA 7456, and UU MAA 7528); M2: a fragmentary frontoparietal (UU MAA 7192); M3: seven maxillae (UU MAA 7223, UU MAA 7224, UU MAA 7227, UU MAA 7238, UU MAA 7239, UU MAA 7240, and UU MAA 7241), a presacral vertebra (UU MAA 7228), a humerus (UU MAA 7225), and an ilium (UU MAA 7229).

Description. Frontoparietals: these elements are represented by rather fragmentary material. The dorsal surface of the bone is characterized by a dermal sculpture with pits and rather sharp, isolated or closely located tubercles. The ventral surface of the bone is smooth.

Maxillaries: all available maxillary bones, belonging to both small and large individuals, have smooth lateral surfaces and no dermal ossification is observable (Figure 5.1, 5.3). In medial view, the lamina horizontalis is well pronounced. It is thick and has rounded medial surface in its middle portion. Both anteriorly and posteriorly from the midpoint, it is reduced in height and its medial surface is flattened. The posterior depression is shallow but broad. The dental crest possesses tooth pedicles and it heightens slightly anteriorly. The margo orbitalis is concave (Figure 5.2). Anteriorly from the posterior depression, between the margo orbitalis and lamina horizontalis, a moderately shallow groove is observable, running anteriorly along the lamina horizontalis.

Angular: this is an elongated bone. In dorsal view, a distinct Meckelian groove is observable, exposed dorsally along its length (Figure 5.5). The posterior portion of the bone, possessing the coronoid process, is robust, whereas the anterior portion is slender. The coronoid process is composed of two separate (paracoronoideus and coronoideus) parts.

Atlas: a large centrum of the atlas is present. In ventral and dorsal views, the centrum is triangular in shape. The ventral surface of the bone possesses a distinct crista ventralis. In anterior view, the occipital fossae are distinctly separated. The cotyle has a rounded outline. The neural arch is missing.

Presacral vertebrae: these have opisthocoelous, cylindrical and slightly dorsoventrally compressed centra. Laterally from the centrum, thin walls of the neural canal are projecting dorsolaterally. The neural canal is large, rounded in outline and dorsoventrally slightly compressed. In lateral view, the neural arch is bent and possesses a longitudinal, but not high, neural spine. It is longer than the posterior margins of the postzygapophyses.

Sacral vertebrae: anteriorly, these vertebrae possess a condyle, whereas posteriorly they are bicondylar. Their neural arch is short and the neural canal is not high. The transverse processes expand and project posterolaterally.

Urostyles: anteriorly, the urostyles show two condyloid fossae for the articulation. The neural canal is round. Its dorsal wall possesses a small neural carina. Posteriorly from the neural carina, the transversal processes arise and incline posterolaterally. A narrow anteroposteriorly running dorsal fissure is observable.

Ribs (costae): these are rather elongated bones possessing a dorsal spine (Figure 5.10-11), though its orientation varies within the available elements.

Scapula: this element is fragmentary, with the pars acromialis being broken (Figure 5.6). In lateral view, the bone is sharply curved. The pars suprascapularis is short and nearly triangular in shape. The margo anterior possesses a thin lamina, which is partially damaged. The glenoid fossa is oval in shape and its surface is bent at a sharp angle.

Humeri: only the distal portions of the humeri with the caput are preserved. The latter is asymmetrically placed in respect to the bone axis. The fossa cubitalis ventralis is shallow. The crista medialis, prominently bent in its upper portion, is broader than the crista lateralis (Figure 5.7).

llia: they are fragmentary. In lateral view, the ilia show a rather low and oval, in outline, dorsal tubercle. Anteriorly, it flows into a weakly-pronounced short dorsal crest. The supra-acetabular fossa is expanded and located posteriorly to the dorsal tubercle, dorsally to the deepest point of the acetabulum. The pars ascendens projects posterodorsally and narrows sharply at its tip. The acetabulum has an outline of an irregular circle. The acetabular rim is highest at its anteroventral ridge, where it projects also over the reduced pars descendens (Figure 5.8). In medial view, the corpus ossi possesses a posteriorly expanding, rather well defined, interiliac groove (Figure 5.9). 
Remarks. The remains described herein can be assigned to the genus Latonia on the basis of the following cranial and postcranial features: the pattern of the dermal ossification of the frontoparietals; the overall morphology of maxillae, vertebrae, and urostyle; the presence of two coronoid processes on the angular; the humeral crista medialis being extended in its distal part; a weakly-pronounced dorsal tubercle and crest on the ilium; and the presence of a depression on the medial surface of the corpus ossi (Roček, 1994b). The species level identification within the genus is mainly based on either the presence (Latonia gigantea [Lartet, 1851]) or the absence (Latonia ragei Hossini, 1993, and Latonia vertaizoni [Friant, 1944]) of dermal sculpturing on the lateral surface of the maxilla, as well as other features, such as the shape of the zygomatico-maxillary process of the maxilla and the shape of scapula (see characters in detail in Roček, 1994b). Moreover, the comparative diagnosis of the several species of Latonia is hindered by the fact that some of them are currently represented only by specimens preserved on slabs, whereas others solely by disarticulated elements. Interestingly, the only extant species, Latonia nigriventer (Mendelssohn and Steinitz, 1943), does not display any kind of sculpturing pattern on its maxillae (Biton et al., 2016). Thus, taking into consideration the interspecific variability within the genus, as well as the lack of further elements useful for a more precise identification, we refer the present material from Maramena to Latonia sp.

HYLIDAE Rafinesque, 1815

Genus HYLA Laurenti, 1768

Type species. Hyla viridis Laurenti, 1768.

$$
\begin{gathered}
\text { Hyla sp. } \\
\text { Figure 6.1-2 }
\end{gathered}
$$

Material. M1: seven humeri (UU MAA 7119, UU MAA 7244, UU MAA 7251, and UU MAA 7474-UU MAA 7476) and an ilium (UU MAA 7118); M2: three humeri (UU MAA 7193).

Description. Humeri: they are represented by their distal portions with the caput humeri, which is located radially to the longitudinal axis of the bone. The lateral and medial cristae are short and thin. They have an equal length on both sides of the bone (Figure 6.2).

Ilium: UU MAA 7118 is a relatively well-preserved left ilium (Figure 6.1). The posteroventral portions of the acetabulum and pars descendens are missing. The iliac shaft is moderately curved. Posteriorly, a rather low but broad dorsal tubercle is present on the dorsal margin of the corpus ossi, above the anterior rim of the acetabulum. The pars ascendens is short. Most probably, the acetabulum has a rather triangular shape. The preacetabular zone and the pars descendens are broad and build a thin flange observable in ventral view. The medial surface of the bone is flat.

Remarks. The general morphology of the ilium, the degree of the development of the pars descendens, as well as the location and the shape of the tuber superior agree with the morphology of the genus Hyla (Böhme, 1977). The fragments of humeri are congruent with the morphology of $\mathrm{Hyla}$ (Bailon, 1999; pers. observation on Hyla specimens housed in MDHC and MJSN), but due to the lack of comparison with other hylid genera, they cannot be confidently assigned to the genus level. Nevertheless, taking into consideration the presence of Hyla in the Maramena material, we herein assign also these humeri to the same genus. Furthermore, applying a biogeographic rationale, it seems most plausible that the Maramena fossil material belongs to the species complex of Hyla arborea (Linnaeus, 1758), extant species of which currently inhabit the area (Sillero et al., 2014). This is further consistent with the overall morphology of the fossil material, which is most similar to members of $H$. arborea complex in comparison with other Hyla spp.

$$
\begin{gathered}
\text { RANIDAE Batsch, } 1796 \\
\text { Genus PELOPHYLAX Fitzinger, } 1843
\end{gathered}
$$

Type species. Rana esculenta Linnaeus, 1758 , by original designation.

Pelophylax sp.

Figure 6.3-6

Material. M2: an angular (UU MAA 7194); M3: a coracoid (UU MAA 7233) and three ilia (UU MAA 7232).

Description. Angular: this element is slender and curved. The coronoid process is small and represented by a process of semilunar shape. Its dorsal surface is convex. Its medial margin possesses few radially projecting tubercles. The Meckelian groove is shallow. It is exposed dorsally in the posterior portion of the bone and laterally in its anterior portion (Figure 6.6).

Coracoid: only its distal portion is preserved (Figure 6.3). Its most distal portion is widened. Both cranial (anterior) and caudal (posterior) margins are curved. The cranial margin is strongly curved. Ilia: only the ventral half of the robust tuber superior is preserved. The large supra-acetabular fossa is observable at the posterior bases of the tuber superior, whereas the corner of the tuber superior 

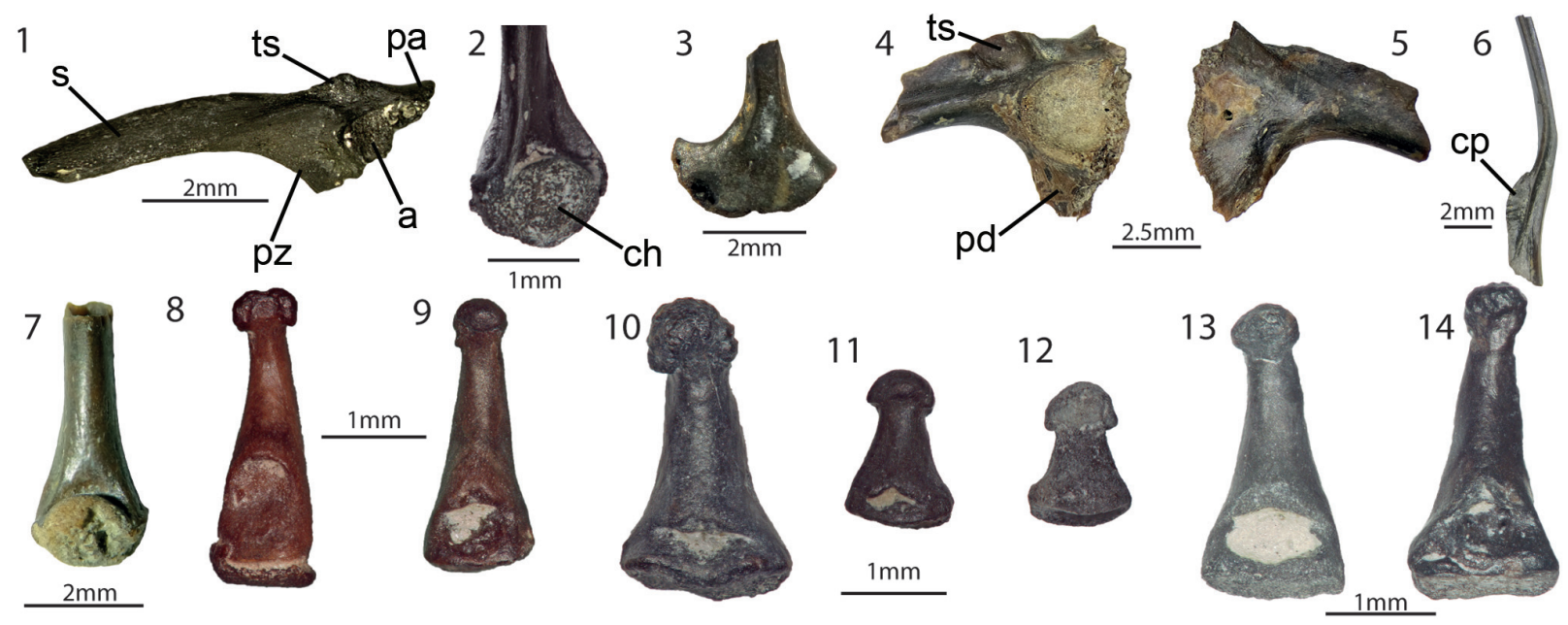

FIGURE 6. Various frogs from Maramena. Hyla sp. (1-2): left ilium (UU MAA 7118) in lateral view (1); left humerus (UU MAA 7474) in ventral view (2). Pelophylax sp. (3-6): right coracoid (UU MAA 7233) in internal view (3); left ilium (UU MAA 7232) in lateral (4) and medial (5) views; right angular (UU MAA 7194) in dorsal view (6). Ranidae indet. (7): right humerus (UU MAA 7231) in ventral view (7). Anura indet., different morphotypes (8-14). Anura indet. (morphotype A) (8-9): phalanx (UU MAA 7527) in ventral view (8); phalanx (UU MAA 7514) in ventral view (9). Anura indet. (morphotype B) (10-12): phalanx (UU MAA 7515) in ventral view (10); two phalanges (UU MAA 7524) in ventral view (11-12). Anura indet. (morphotype C) (13-14): phalanx (UU MAA 7516a) in ventral view (13); phalanx (UU MAA $7516 b$ ) in ventral view (14). Abbreviations: a, acetabulum; ch, caput humeri; cp, coronoid process; pa, pars ascendens; pd, pars descendens; pz, preacetabular zone; s, shaft; ts, tuber superior.

and iliac shaft is pierced by a small tubercular fossa. The acetabulum is rounded. Its ventral wall is high. The pars descendens is narrow at the preacetabular zone and extends moderately posteriorly. The base of the pars ascendens is preserved, allowing us to conclude that its base was broader than that of the pars descendens (Figure 6.4). The medial surface of the corpus ossi is slightly depressed, but it is smooth and does not produce any depression or interiliac groove (Figure 6.5).

Remarks. Despite the poor preservation of the bones, the characteristic features of the genus Pelophylax, such as a robust tuber superior, large supra-acetabular fossa, and flat medial surface of the corpus ossi (Böhme, 1977) are observable in the Maramena specimens. Also, the angular with a semilunar coronoid process with tubercles shows the morphology of the genus Pelophylax (Venczel and Hír, 2015). The coracoid morphology resembles the one of the family Ranidae (Bailon, 1999). Direct comparison with available skeletons of Rana and Pelophylax housed at the MJSN shows that Pelophylax is characterized by a higher degree of curvature of the cranial margin of the distal portion of the coracoid.

Ranidae indet.

Figure 6.7
Material. M2: three ilia (UU MAA 7195); M3: three humeri (UU MAA 7231).

Description and remarks. The distal portion of the humerus is preserved. The caput humeri is rounded and situated in the center of the bone axis. The crista medialis is weakly pronounced. The lateral margin of the humerus is flat and does not show any structure. Its base extends into the epicondylus lateralis, which is regularly damaged in the available material (Figure 6.7). This morphology is observable in members of the family Ranidae (Bailon, 1999). All three ilia are small and damaged. They have a distinct tuber superior. The dorsal crest is preserved in most cases. The supraacetabular fossa is large. The medial surface of the corpus ossi is flat, without any depression or groove. Based on these characters, the bones can be assigned to the family Ranidae (Böhme, 1977). Any further identification of the bones is impossible due to theirpoor preservation.

Anura indet.

Figure 6.8-14

Material. M1: a premaxilla (UU MAA 7473), an urostyle (UU MAA 7510), four maxillae (UU MAA 7246, UU MAA 7247, and UU MAA 7512), 17 fragmentary radio-ulnae (UU MAA 7513), 23 terminal phalanges (UU MAA 7514-UU MAA 7516 and UU 
MAA 7524-UU MAA 7527), and numerous extremity bones (UU MAA 7132 and UU MAA 7511); M2: seven fragmentary maxillae (UU MAA 7197); M3: a maxilla (UU MAA 7237) and several long bones and phalangeal fragments (UU MAA 7242).

Description and remarks. Besides the phalanges, the remaining material is too fragmentary for any further identification. The preserved phalanges are of different size ranges and can be assigned to three different morphotypes, which are characterized as follows:

Morphotype A (eight phalanges; UU MAA 7514, UU MAA 7525, and UU MAA 7527): the phalange bones are slender, long, and thin (Figure 6.8-9). The phalanges narrow extremely towards the distal end. The latter possesses a small, rounded, and nearly smooth bulb or in few of them, the tip possesses two distinct pads. The lateral edges of the bones are smooth.

Morphotype B (11 phalanges; UU MAA 7515 andUU MAA 7524): the bone is robust, significantly shorter and broader than the morphotype A (Figure $6.10-12)$. The bulb is larger as well, with well-developed rugosities on its surface. The lateral edges of the phalanges bear weakly-pronounced lateral ridges.

Morphotype C (four phalanges; UU MAA 7516 and UU MAA 7526): the bone morphology shows somewhat intermediate conditions of the character states between the morphotypes A and B (Figure 6.13-14). The phalanges are long and narrow to the tip of the bone gradually and not sharply as in the morphotype $A$, and not as strongly as in the morphotype $\mathrm{B}$. The bulb is small, but possesses rugosities.

Amphibian phalanges are so far not considered useful for identification of fossil frog and salamander remains, apparently due to the insufficient knowledge of the taxonomic reliability of these elements. Nevertheless, certain studies used the phalangeal morphology for taxonomic purposes (e.g., Raninae [Clarke, 1981]; the plethodontid Speleomantes Dubois, 1984 [Lanza et al., 1995]) or for the correlation of the locomotion types (Kamermans and Vences, 2009). However, no solid study and / or review of the systematic importance of these elements has ever been conducted. Thus, the morphologies described herein can only be tentatively considered as different frog taxa, though it cannot be shown whether they pertain to any of the above described anurans (Latonia sp., Hyla sp., and Pelophylax sp.) or a distinct species currently not known by other fossil elements.

\author{
REPTILIA Laurenti, 1768 \\ TESTUDINES Batsch, 1788 \\ PAN-TESTUDINOIDEA Joyce, Parham, and \\ Gauthier, 2004 \\ GEOEMYDIDAE Theobald, 1868 \\ Genus MAUREMYS Gray, 1869
}

Type species. Emys fuliginosus Gray, 1860.

Mauremys aristotelica Vlachos, Sterli, Vasileiadou, and Syrides, 2018

Figure 7

Material. M1: three incomplete unidentified neurals (UU MAA 7143, UU MAA 7144, and UU MAA 7146); M3: a nuchal (UU MAA 7283), a fragmentary unidentified neural (UU MAA 7253), a left costal VI (UU MAA 7284), unidentified costals (UU MAA 7286 and UU MAA 7288), a left peripheral III (UU MAA 7289), a right peripheral III (UU MAA 7290), unidentified peripherals (UU MAA 7285, UU MAA 7287, UU MAA 7291, UU MAA 7292, UU MAA 7293, UU MAA 7295, and UU MAA 7297), and a right hyoplastron (UU MAA 7296).

Description. Nuchal: UU MAA 7283 is a nearly complete nuchal, missing just a small portion of the right posterolateral edge (Figure 7.1-2). Since there are no vertebro-pleural sulci, it was entirely covered by the first vertebral shield. The cervical shield, clearly expressed also on the ventral side of the nuchal, was broad, with its posterior edge being about one third of the width of the nuchal at that level. The posterior margin of the cervical was nearly straight (not deeply notched; see Hervet, 2004). The nuchal is constricted in the area corresponding to the marginal shields.

Neurals: four juvenile, fragmentary neurals (UU MAA 7143, UU MAA 7144, UU MAA 7146, and UU MAA 7253) are present in the collection (Figure 7.3-5). They are thickened sagittally. Due to their preservation, their precise position within the neural column cannot be evaluated with confidence.

Costals: UU MAA 7284 is tentatively considered to represent a sixth left costal (Figure 3.6-7). Despite missing the proximal portion, it clearly shows paralled sides (as also UU MAA 7286, see Figure 7.89 ) and vertebro-pleural sulci characterized by forming an acute angle in correspondence of the junction with the transverally oriented interpleural sulcus. The tip of the acute angle is rather close (closer than in extant Mauremys) to the costoperipheral suture. The anterior margin is much thicker than the posterior one. The ventral edge hosts a robust costal process whose tip is broken. Specimen UU MAA 7288 is a paired costal preserving only the distal area and showing the corre- 

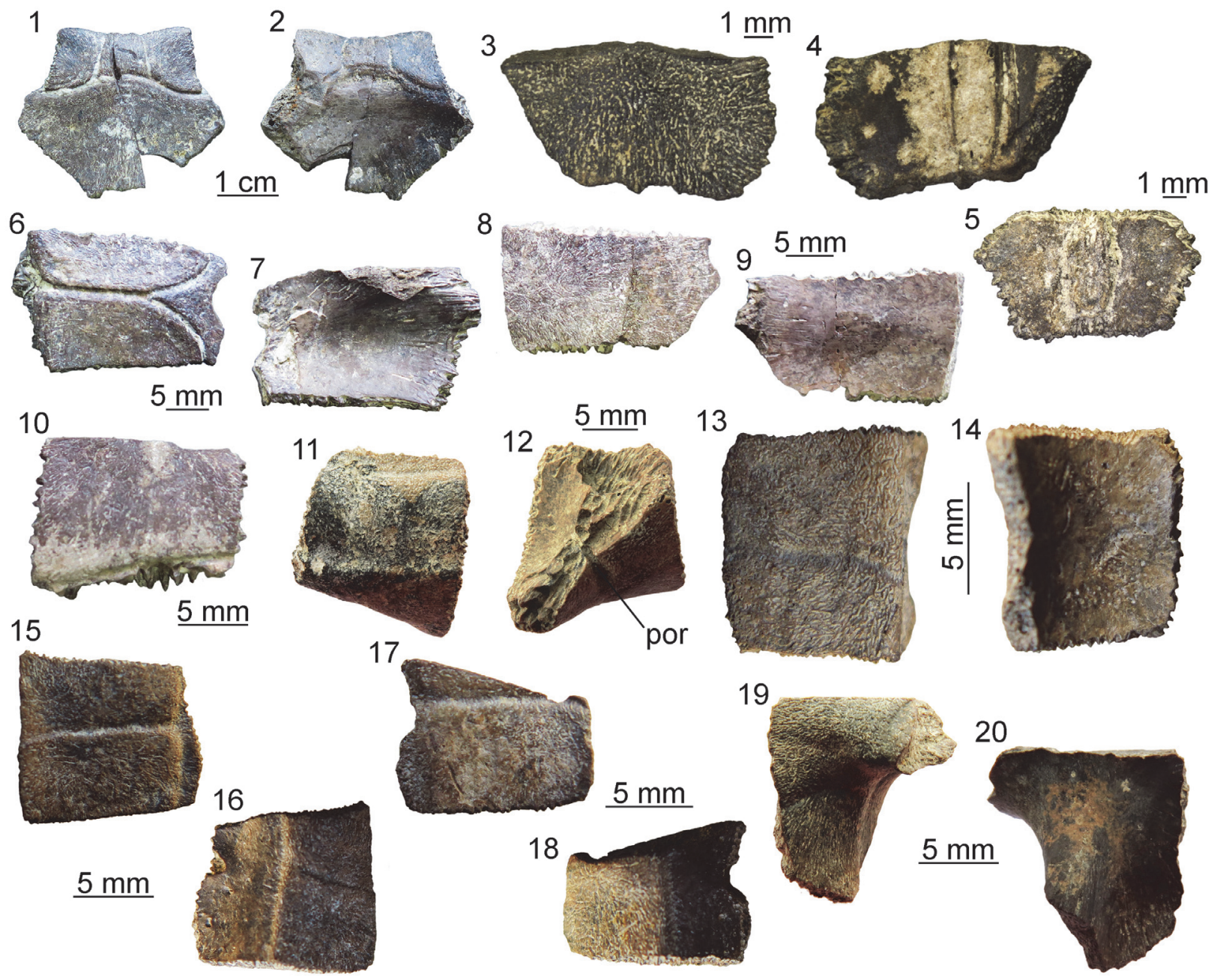

$\underline{5 \mathrm{~mm}}$

FIGURE 7. Mauremys aristotelica from Maramena: nuchal (UU MAA 7283) in dorsal (1) and visceral (2) views; neural (UU MAA 7146) in dorsal (3) and visceral (4) views; neural (UU MAA 7253) in visceralview (5); left costal VI (UU MAA 7284) in dorsal (6) and visceral (7) views; costal (UU MAA 7286) in dorsal (8) and visceral (9) views; costal (UU MAA 7288) in dorsal view (10); left peripheral III (UU MAA 7289) in dorsal (11) and visceral (12) views; bridge peripheral (UU MAA 7297) in dorsal (13) and visceral (14) views; peripheral (UU MAA 7293) in dorsal (15) and visceral (16) views; peripheral (UU MAA 7295) in dorsal (17) and visceral (18) views; right hyoplastron (UU MAA 7296) in visceral (19) and dorsal (20) views. Abbreviation: por, musk pore.

spondence of the pleuro-marginal sulcus with the costo-peripheral suture (Figure 7.10).

Peripherals: the third left peripheral UU MAA 7289 is fully preserved and characterized by a thick anterior edge and an evident foramen, the musk pore, clearly piercing the bone at the level of the suture with the plastron (Figure 7.11-12). The foramen opens within the limits of the axillary shield. The dorsal suture with the corresponding costal hosts a pit for the ventral costal process. The pleuro-marginal sulcus runs slightly ventral to the costo-peripheral suture. The external surface shows a modest but evident ridge anteroposteriorly directed. The pleuro-marginal sulcus of the third right peripheral UU MAA 7290 is placed signifi- cantly ventral to the costo-peripheral suture; the lateral edge of the element is raised in a ridge. The ridge of a fragmentary element, herein interpreted as a bridge peripheral (UU MAA 7297) of a juvenile individual, is particularly developed (Figure 7.1314). The dorsal suture of the three best preserved, juvenile peripherals (UU MAA 7285, UU MAA 7293, and UU MAA 7295) hosts a deep pit for the reception of the costal process (Figure 7.15-18). Such pit is not present in the juvenile eleventh left peripheral UU MAA 7294.

Hyoplastron: the fragmentary right hyoplastron UU MAA 7296 does not offer any relevant morphological detail, besides the fact that it preserves the humero-pectoral sulcus reaching laterally the 
axilla, and the sulcus of the axillary shield (Figure 7.19-20). The ventral surface of the bone is slighly concave.

Remarks. The assignment of the Maramena material to Geoemydidae is supported by the presence of a musk pore in a peripheral element, a character considered to be a synapomorphy of this clade by Hirayama (1985) and, accordingly, this feature has been variously applied to identify fossil specimens (among others, Chesi et al., 2009; Colombero et al., 2017; Vlachos et al., 2019). The referral of the material to Mauremys is suggested by the morphology of the nuchal and its scute sulci, which is fully congruent with that of extant members of this genus (e.g., Holman, 1995; Hervet, 2000, 2004). The three juvenile neurals are also referred to the same genus on the basis of the sagittal thickening (Ernst and Barbour, 1989). The shape of the fifth vertebral, as shown by the sixth left costal UU MAA 7284 , is rather rare for published specimens of extant (e.g., Hervet, 2000) or extinct Mauremys (e.g., Chesi et al., 2009) because of the markedly acute lateral angle of that elementand the lateral extension of the vertebral shield. In fact, this feature is highly reminiscent of the recently described species Mauremys aristotelica, which is known from the latest Miocene and Pliocene of northern Greek localities rather close to Maramena, and characterized by rather wide vertebral scutes (Vlachos et al., 2019). A (still undescribed) costal of Mauremys sp. (MGPT-PU 142091) from the early Pleistocene of Pirro Nord, in southern Italy (Delfino and Bailon, 2000; Delfino and Atzori, 2013) possesses an acute lateral angle of the vertebral scute, in contrast to the standard morphology shown by the rest of the material from this locality, therefore suggesting that this character could also sporadically appear in other Mauremys spp. It is worth noting, however, that, besides Mauremys aristotelica, this costo-vertebral morphology of sulci is also reminiscent of that of Promalacoclemmys laharpi (Pictet and Humbert, 1856) from the late Oligocene of Switzerland (see Hervet, 2004, plates 8, 9) and Clemmydopsis sopronensis (Boda, 1927) from Hungary (Williams, 1954, figure 2). Up to that date, the only chelonian remains from Maramena that had formally been described was a specimen tentatively referred by Gad (1990) to the extant Mauremys caspica (Gmelin, 1774). The same material was referred to as Mauremys sp. by Georgalis and Kear (2013). Although rather incomplete, Gad's (1990) material is herein referred to the same taxon identified on the basis of the new specimens described herein.
TESTUDINIDAE Batsch, 1788

?Testudinidae indet.

Figure 8

Material. M1: an isolated ?limb osteoderm (UU MAA 7135).

Description and remarks. Specimen UU MAA 7135 is a relatively elongated osteoderm, with a maximum length of slightly less than $5 \mathrm{~mm}$ (Figure 8). It is much thickened at one edge and becomes significantly thinner towards its other edge. Its main surfaces are rugose, with distinct holes and small cavities across both surfaces. The overall morphology of the specimen resembles that of a testudinid limb osteoderm. Nevertheless, it still differs significantly from the respective elements of extant small-sized testudinids that occur in Greece, i.e., Testudo graeca Linnaeus, 1758, Testudo hermanni Gmelin, 1789, and Testudo marginata Schoepff, 1792. On the other hand, the Maramena specimen is proportionally smallerthan various limb osteoderms of the giant testudinid Titanochelon PérezGarcía and Vlachos, 2014, that have been described from the Neogene of Greece (e.g., Bachmayer, 1967; Lapparent de Broin, 2002; Vlachos et al., 2014), however, we still cannot preclude the possibility that it pertains to a rather young individual of the latter genus. On the basis of this single element, it is difficult to further assess the taxonomic assignment of this specimen and we prefer to treat it as a probable indeterminate testudinid.

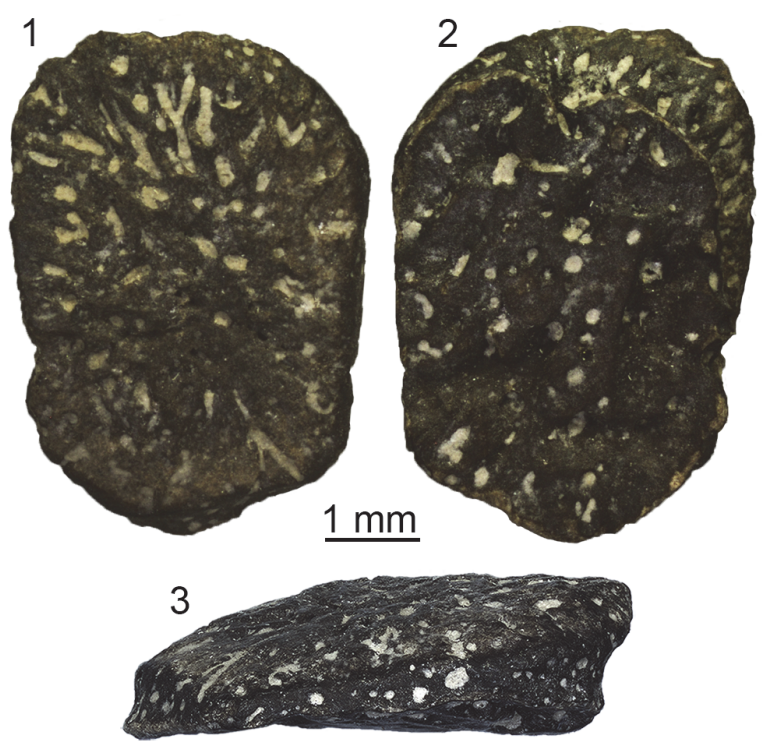

FIGURE 8. ?Testudinidae indet. from Maramena: ?osteoderm (UU MAA 7135) in dorsal (1), ventral (2), and lateral (3) views. 
Testudines indet.

Material. M1: an incomplete unidentified neural (UU MAA 7136), three unidentified peripherals (UU MAA 7137, UU MAA 7140, and UU MAA 7142), and several shell fragments (UU MAA 7138, UU MAA 7139, UU MAA 7147 [five fragments]); M3: an unidentified peripheral (UU MAA 7254), a shell fragment (UU MAA 7252), and several fragments of different elements (one caudal vertebra, one pelvic fragment, three neurals, four costals, one peripheral, and 24 shell fragments) (UU MAA 7255).

Remarks. This material is so fragmentary that it cannot be attributed with confidence to any chelonian clade. Most probably, all of this material could pertain to any of the above described Mauremys aristotelica or the probable indeterminate testudinid, though such an assumption cannot be confirmed.

SQUAMATA Oppel, 1811

IGUANIA Cuvier, 1817 (sensu Estes et al., 1988)

ACRODONTA Cope, 1864

AGAMIDAE Spix, 1825

AGAMINAE Spix, 1825

Agaminae indet.

Figure 9

Material. M1: a premaxilla (UU MAA 7076), three maxillae (UU MAA 7043-UU MAA 7045); five dentaries (UU MAA 7041, UU MAA 7042, UU MAA 7075, UU MAA 7276, and UU MAA 7305); 15 fragments of tooth bearing bones (UU MAA 7063, UU MAA 7065-UU MAA 7074, UU MAA 7264, UU MAA 7303, UU MAA 7304, and UU MAA 7394); five caudal vertebrae (UU MAA 7062, UU MAA 7064, and UU MAA 7302); M2: a frontal (UU MAA 7191); M3: a premaxilla (UU MAA 7341), a maxilla (UU MAA 7208), and a left dentary (UU MAA 7207).

Description. Frontal: UU MAA 7191 is a fragment of an unpaired and robust frontal, preserving part of the anterior end of the bone (Figure 9.1-2). The anteriormost part (the medial and lateral processes) is missing. The dorsal surface displays a distinctly sunken area in the middle and towards the posterior end of the preserved portion and a faint ornamentation made by low irregularities. Anteriorly, two poorly distinct and U-shaped surfaces may represent the articulation surfaces with the nasals. Their outline is marked by very low ridges that laterally separate each of them from the wide articulation surfaces with maxillae and prefrontals. The prefrontals cover entirely the lateral surface of the preserved portion of the specimen, being marked both dorsally and ventrally by distinct ridges. Ventrally, the anterior end of the cristae cranii is visible. The cristae are wide and robust posteriorly, but they narrow towards the anterior end of the bone. There are no anterior processes and therefore the cristae remain low. The ventral surface between the cristae is smooth.

Premaxillae: the small premaxillae have a $1.8 \mathrm{~mm}$ (UU MAA 7341) or 2 mm-wide (UU MAA 7076) alveolar plate (Figure 9.3-6). They preserve only the alveolar portion of the bone, lacking the entire ascending nasal process and the palatal lamina. Two sub-pleurodont and stocky teeth are present. They have a distinctly swollen and bulbous base, but shrink towards the tip, taking a sub-conical shape. The anterior surface of the bone is smooth, displaying only a small foramen near the right side of the base of the ascending nasal process.

Maxillae: the small maxillae are fragmentary: only part of the middle portion of the tooth row is preserved in UU MAA 7044, UU MAA 7045, and UU MAA 7208, whereas UU MAA 7043 preserves part of the anterior end. The latter specimen carries two sub-pleurodont and canine-like teeth, slightly curved in posterior direction by their tip, followed by two small, acrodont and closely spaced teeth. The other specimens, on the other hand, carry five (UU MAA 7044), six (UU MAA 7045) or seven (UU MAA 7208) acrodont and closely spaced teeth, whose tooth base is slightly developed towards the medial surface of the alveolar border. In all specimens, the acrodont teeth are triangular and display small accessory cusps anteriorly and posteriorly to the main one. The lateral process is partially preserved in UU MAA 7043, showing a hint of dorsal development towards the anterior end (Figure 9.7-8). Two ventrolateral foramina are visible on the otherwise smooth lateral surface in all specimens except for UU MAA 7044.

Dentaries: UU MAA 7042 and UU MAA 7305 represent the anterior portions of dentaries (Figure $9.11,9.13)$. They preserve the symphysial region and four (UU MAA 7305) or eight (UU MAA 7042) tooth positions. The mandibular symphysis is subhorizontal in medial view. On the medial surface of the bone, the subdental table originates a mediolaterally short, dorsoventrally high, and robust subdental shelf, which carries a low ridge dorsally (subdental ridge sensu Evans, 2008). Ventrally, a narrow and ventrally open Meckelian groove runs antero-posteriorly. The lateral surface of the bone is smooth, bearing four mental foramina. As in the maxillae, two morphologically different kinds of teeth are present: anteriorly, there are two sub- 


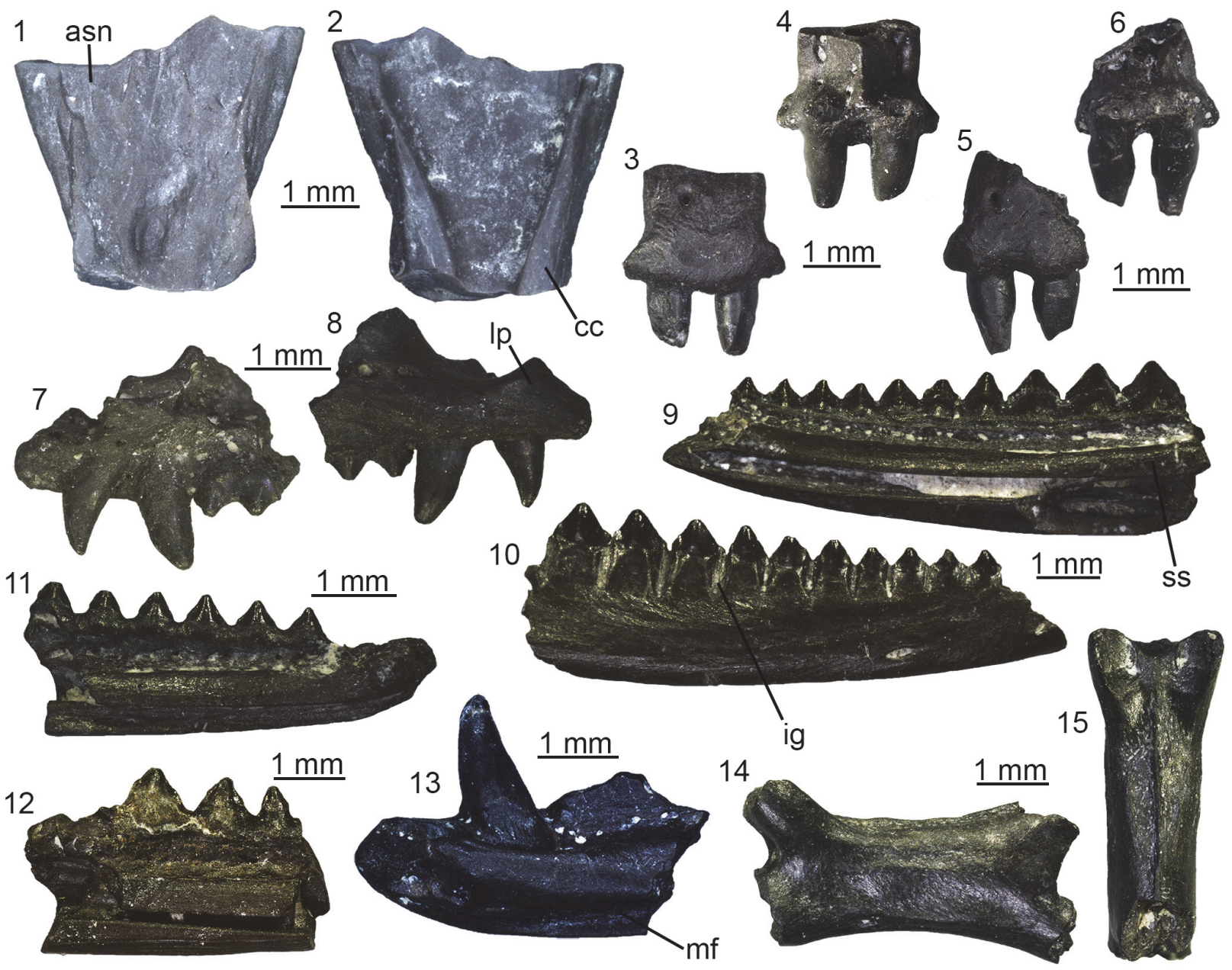

FIGURE 9. Agaminae indet. from Maramena: frontal (UU MAA 7191) in dorsal (1) and ventral (2) views; premaxilla (UU MAA 7076) in anterior (3) and posterior (4) views; premaxilla (UU MAA 7341) in anterior (5) and posterior (6) views; right maxilla (UU MAA 7043) in medial (7) and lateral (8) views; right dentary (UU MAA 7041) in medial (9) and lateral (10) views; left dentary (UU MAA 7042) in medial view (11); left dentary (UU MAA 7207) in medial view (12); right dentary (UU MAA 7305) in medial view (13); caudal vertebra (UU MAA 7062) in left lateral (14) and dorsal (15) views. Abbreviations: asn, articular surface with the nasal; cc, crista cranii; ig, interdental groove; Ip, lateral process; $\mathrm{mf}$, Meckelian groove; ss, subdental shelf.

pleurodont teeth, followed posteriorly by acrodont ones. Among the large sub-pleurodont teeth, only the second one of UU MAA 7305 preserves more than the tooth base: it is conical, with a slightly posteriorly curved tip (Figure 9.13). The acrodont teeth are very small, closely spaced and poorly preserved in UU MAA 7305, but larger, more spaced, slightly developed towards the medial margin of the alveolar crest and triangular in the other specimen. Accessory cusps are present in the teeth of the latter specimen, as well as deep and ventrally directed interdental grooves between them on the lateral surface. Specimens UU MAA 7041 and UU MAA 7207, on the other hand, preserve the middle portion of the dentary (Figure 9.9-10 and 9.12). In medial view, a rather narrow Meckelian groove is visible, opening medially. The groove is partially covered dorsally by a high and ventrally expanded subdental shelf, displaying a ridge as in the former specimens. The straight ventral margin of the dentary bends in medial direction, forming a ventral floor for the fossa. Specimens UU MAA 7041, UU MAA 7075, UU MAA 7207, and UU MAA 7276 bear three to 10 acrodont, triangular and closely spaced teeth, provided with a main cusp and two small accessory cusps located anteriorly and posteriorly. The teeth develop slightly in ventral direction on the medial surface of the alveolar shelf. 
Moreover, they distinctly increase in size posteriorly. The lateral surface is smooth, except for the presence of deep and ventrally directed interdental grooves. Specimens UU MAA 7041, UU MAA 7075, and UU MAA 7276 also display few mental foramina.

Tooth bearing bones: the small fragments of tooth bearing bones carry acrodont and triangular teeth with a pointed tip. Accessory cusps can be either present or absent. The tooth base is slightly expanded in ventro-medial direction, towards the medial surface of the tooth bearing bone. Teeth are usually closely spaced, even if those of UU MAA 7063, UU MAA 7264, and UU MAA 7304 are more spaced. A moderately wide and deep interdental groove separates them in lateral view.

Caudal vertebrae: the caudal vertebrae are procoelous and rather antero-posteriorly elongated (Figure 9.14-15). They have a sub-circular vertebral centrum, a sub-elliptical neural canal, and a dorsally smooth neural arch. The zygapophyses are small, elliptical, and tilted dorsally at $45^{\circ}$. There are no autotomy planes and haemapophyses.

Remarks. Maxillae and dentaries carrying both pleurodont and acrodont teeth can be confidently assigned to Agamidae (Delfino et al., 2008; Blain et al., 2014). Closely spaced acrodont teeth extending onto the lingual side of the alveolar border are usually used as an argument to support such a taxonomic assignment, in contrast with more spaced and apically located teeth in Chamaeleonidae (Evans et al., 2002; Delfino et al., 2008; Georgalis et al., 2016b), although Rage and Bailon (2011) recently cast doubt on this differentiation based on existing variation within the two clades. A certain degree of variation in the spacing between teeth seems to be present in the material from Maramena also, but the general similarity in the morphology of both teeth and tooth bearing bones allows us to allocate all the acrodont tooth bearing remains to the same taxon. Moreover, Maul et al. (2011) stated that the presence of two sub-pleurodont teeth in both maxillae and dentaries distinguishes the subfamily Agaminae (sensu Macey et al., 2000) from other agamids. Furthermore, the sole other biogeographically approximate clade, i.e., Uromastycinae, is characterized by much different cranial anatomy and tooth morphology, and relatively larger size (e.g., Beddard, 1905; El-Toubi, 1945). The other remains (i.e., frontal, premaxillae, and caudal vertebrae) are congruent in terms of morphology with the agamid specimens we used as a comparison and therefore are here attributed to the same taxon as the tooth bearing bones. The single maxilla fragment from Maramena that was previously described and figured by Richter (1995) as pertaining to the extant, once wastebasket, genus Agama Daudin, 1802, is herein also referred to the same taxon with the new agamid material.

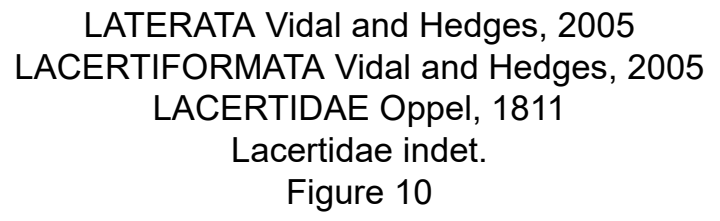

Material. M1: three maxillae (UU MAA 7031, UU MAA 7032, and UU MAA 7438), a quadrate (UU MAA 7096), three pterygoids (UU MAA 7097-UU MAA 7099), 16 dentaries (UU MAA 7048-UU MAA 7061, UU MAA 7095, and UU MAA 7424), 10 fragments of tooth bearing bones (UU MAA 7087-UU MAA 7092, UU MAA 7094, UU MAA 7391, and UU MAA 7802), and an isolated tooth (UU MAA 7392); M3: a dentary (UU MAA 7220).

Description. Maxillae: the maxillae are small-sized and fragmentary (Figure 10.1-2). Except for UU MAA 7438, which is represented by the anterior premaxillary process, they preserve only part of the posterior half of the bone and they are $2.3 \mathrm{~mm}$ (UU MAA 7438), $3.5 \mathrm{~mm}$ (UU MAA 7032) or $4.5 \mathrm{~mm}$ (UU MAA 7031) in length. Specimen UU MAA 7438 has moderately developed lateral and medial processes, defining a wide, deep, and U-shaped anterior concavity. Due to theirpreservation, it is not clear whether the medial process possesses a lappet. A large vomeronasal foramen is present. The wide superior dental foramen is visible on the dorsal surface of the palatal shelf of UU MAA 7031 and UU MAA 7032. Maxillae bear three to eight tooth positions. The preserved teeth are pleurodont, closely spaced, slender and cylindrical; the best preserved ones have a bicuspid crown. The lateral surface of the bone is smooth, with one or two ventrolateral foramina; in the case when a second foramen is present, it is distinctly enlarged.

Quadrate: the quadrate is small-sized, with a length of $3.6 \mathrm{~mm}$ (Figure 10.3-5). It is straight in anterior view and has a rounded anterior outline in medial view. A deep conch, originated by a welldeveloped lateral lamina, is present. The anterior surface of the lamina has a flattened anterodorsal platform, bordered medially by a low ridge. A welldeveloped medial lamina is also present, showing a distinct pterygoid flange by its ventral end. The cephalic condyle is expanded in both posterior and medio-lateral directions. The mandibular one is wide in posterior view and is composed by two similar sized portions. A wide and deep squamosal notch is present laterally to the cephalic condyle. 

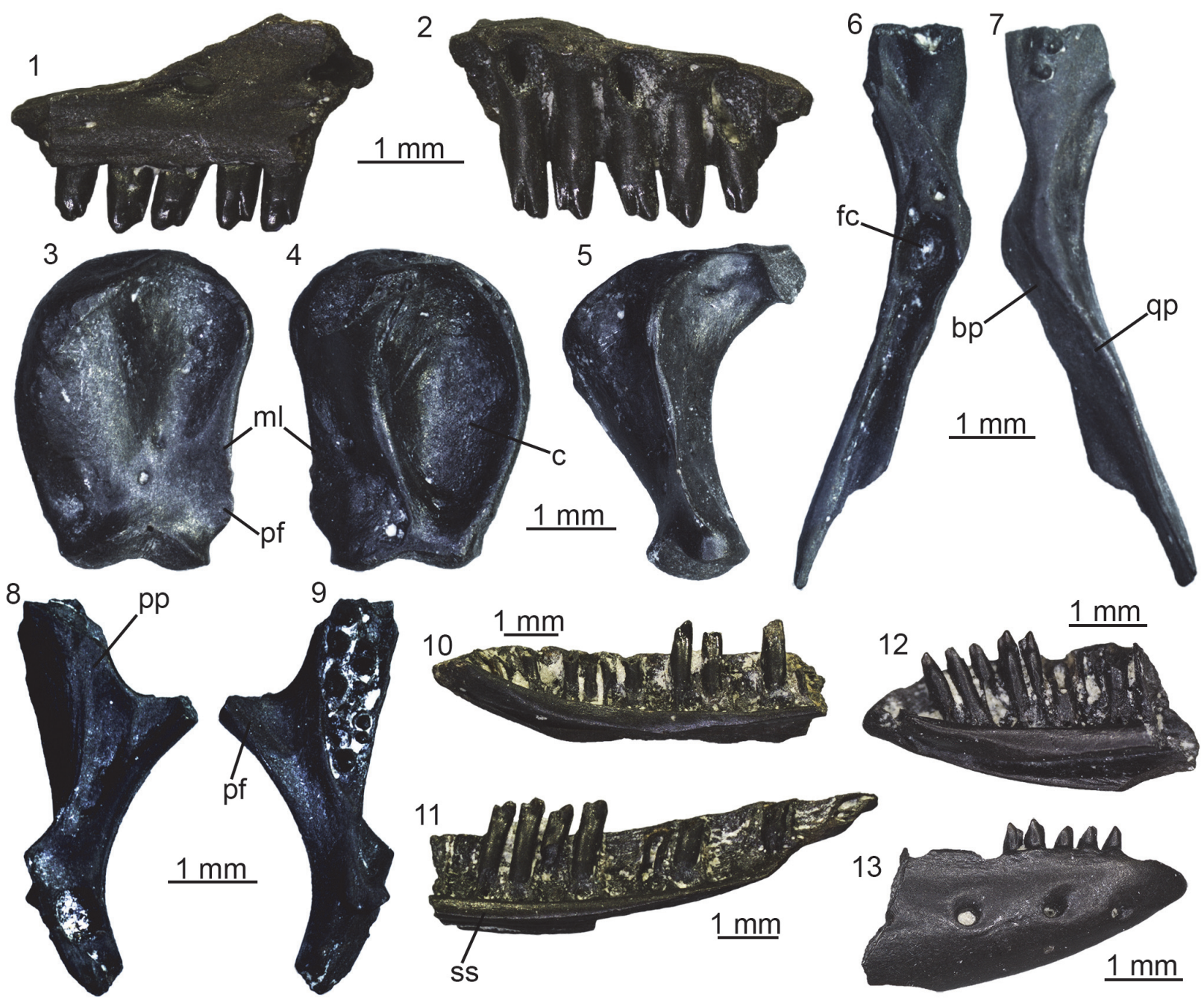

FIGURE 10. Lacertidae indet. from Maramena: right maxilla (UU MAA 7032) in lateral (1) and medial (2) views; right quadrate (UU MAA 7096) in anterior (3), posterior (4) and medial (5) views; left pterygoid (UU MAA 7099) in ventral (6) and dorsal (7) views; right pterygoid (UU MAA 7097) in dorsal (8) and ventral (9) views; right dentary (UU MAA 7048) in medial view (10); right dentary (UU MAA 7049) in medial view (11); right dentary (UU MAA 7050) in medial (12) and lateral (13) views. Abbreviations: bp, basipterygoid fossa;c, conch; fc, fossa columellae; ml, medial lamina; pf, pterygoid flange; pp, palatine process; qp, quadrate process; ss, subdental shelf.

Dorsally to the mandibular condyle, the quadrate is pierced by the quadrate foramen.

Pterygoids: they are incomplete and small-sized. The most complete pterygoid, UU MAA 7099, is $6.7 \mathrm{~mm}$ long (Figure 10.6-7), but the other ones are similar in size. Both the palatine process and the pterygoid flange are regularly incompletely preserved: only their bases are visible, at different degrees of preservation, in the three specimens. The most complete flange is that of UU MAA 7097, which displays the proximal portions of moderately developed dorsal and ventral ridges (Figure 10.89). Similar ridges are recognizable on UU MAA 7098 too, but in both specimens the real degree of development of the ridges cannot be defined because of the preservation. The palatine process, which is better preserved in UU MAA 7097 and UU MAA 7098 in comparison with UU MAA 7099, has a wide patch with numerous pterygoid teeth on its ventral surface. The quadrate process is almost complete in UU MAA 7099 (Figure 10.8-9), partially preserved in UU MAA 7097, and missing in UU MAA 7098. It is straight in dorsal view and displays a wide and circular fossa columellae, from which a well-developed pterygoid ridge starts. The basipterygoid fossa is wide and flat. Specimen UU MAA 7097 possesses a probably pathological tubercle-like osseous proliferation ventrally to the 
fossa and a ridge-like osseous expansion dorsally to it, running anteriorly towards the dorsal surface of the palatine process (Figure 10.6-7).

Dentaries: UU MAA 7049, UU MAA 7051-UU MAA 7057, UU MAA 7095, UU MAA 7220, and UU MAA 7424 are incomplete dentaries, missing both the anterior and posterior ends (Figure 10.11). Specimens UU MAA 7048, UU MAA 7050, and UU MAA 7058-UU MAA 7061 are similar-sized fragmentary dentaries preserving also the symphysial region (Figure 10.10, 10.12-13). The total length of the specimens ranges from a minimum of $3.5 \mathrm{~mm}$ (UU MAA 7055) to a maximum of $7.4 \mathrm{~mm}$ (UU MAA 7048). A moderately high subdental shelf with a distinct subdental ridge is present medially. Specimens UU MAA 7050, UU MAA 7055, UU MAA 7056, UU MAA 7057, and UU MAA 7220 preserve a wide and medially open Meckelian groove also. When preserved, the mandibular symphysis is narrow and sub-horizontal. The bones preserve eight to 17 closely spaced tooth positions. Well-preserved teeth are pleurodont, cylindrical, and slender, with a mono-, bi- or (only in UU MAA 7049) tricuspid crown. The lateral surface of the dentaries is relatively smooth, except for some mental foramina. Specimens UU MAA 7050, UU MAA 7055-UU MAA 7057, and UU MAA 7220 display a convex ventral margin.

Tooth bearing bones and isolated tooth: the small and poorly preserved fragments of tooth bearing bones preserve closely spaced, pleurodont, slender, cylindrical and bicuspid teeth. The same morphology characterizes the isolated tooth, UU MAA 7392.

Remarks. Lacertidae are relatively easily recognizable among Neogene squamates because of the presence of an heterodont dentition composed by mono-, bi- and tricuspid teeth (Bailon, 1991; Augé, 2005). Despite the fragmentary nature of most of the Maramena specimens, their size seems to indicate the presence of a small-sized species. Studies on the quadrate morphology of lacertids from the Eastern Mediterranean are currently lacking, though on the basis of similar research focusing on extant Iberian taxa (Barahona and Barbadillo, 1997), the total length of the best preserved remain from Maramena, the quadrate UU MAA 7096, fits within the maximum value known for Algyroides hidalgoi Boscá, 1916 (note that this is the valid available name for this Iberian taxonand not Algyroides marchi Valverde, 1958, as was until recently thought; see Sánchez-Vialas et al., 2019), Psammodromus hispanicus Fitzinger, 1826, and Zootoca vivipara (Lichtenstein, 1823) (equal to 3.4 $\mathrm{mm}$ ) and the minimum one for Iberolacerta bonnali (Lantz, 1927), Iberolacerta cyreni (Müller and Hellmich, 1937), Iberolacerta monticola (Boulenger, 1905), Podarcis hispanicus (Steindachner, 1870), Podarcis bocagei (Lopez-Seoane, 1885), and Podarcis muralis (Laurenti, 1768) (equal to 3.9 $\mathrm{mm}$ ). This agrees with the clues provided by the best preserved pterygoid, UU MAA 7099, whose length is comparable with the range of the latter group of species (6.4-8.6 mm; Barahona and Barbadillo, 1997). These species, however, do not have pterygoid teeth (Barahona and Barbadillo, 1997), whereas such teeth are present in larger species instead. It might be possible that the pterygoids from Maramena belong to juveniles of a larger species, but this seems unlikely because of the large number of pterygoid teeth, which are usually scarce or even absent in young individuals (Barahona and Barbadillo, 1997, 1998). The fossils from Maramena therefore represent an indeterminate small-sized lacertid possessing pterygoid teeth. Regarding the lacertid material from Maramena previously described by Richter (1995) as belonging to Lacerta, it was never figured and only briefly described, so no further taxonomic conclusions can be made. Furthermore, the genus Lacerta Linnaeus, 1758, commonly served as a wastebasket taxon for multiple distantly related species (see e.g., Arnold et al., 2007). We tentatively consider Richter's (1995) Maramena lacertid material as conspecific with the new specimens described herein.

\section{?Lacertidae indet.}

Figure 11

Material. M1: a fragment of tooth bearing bone (UU MAA 7033).

Description. Specimen UU MAA 7033 is a small fragment of a tooth bearing bone, with a total length of $3.4 \mathrm{~mm}$ (Figure 11). It preserves only a small part of the tooth row with five tooth positions. Two rather well-preserved teeth are present: they are pleurodont, slender, cylindrical, and closely spaced. Though slightly eroded, their crown shows a tricuspid condition, with a large central cusp and two slightly smaller, similar-sized accessory cusps, located anteriorly and posteriorly to the main one. The accessory cusps are separated from the main one by evident grooves lingually, but this cannot be clearly stated labially due to the wear. Because of the presence of the two accessory cusps and of a light constriction at mid-height, the tooth appears slightly antero-posteriorly enlarged at the level of the crown and roughly symmetrical in medial view. 

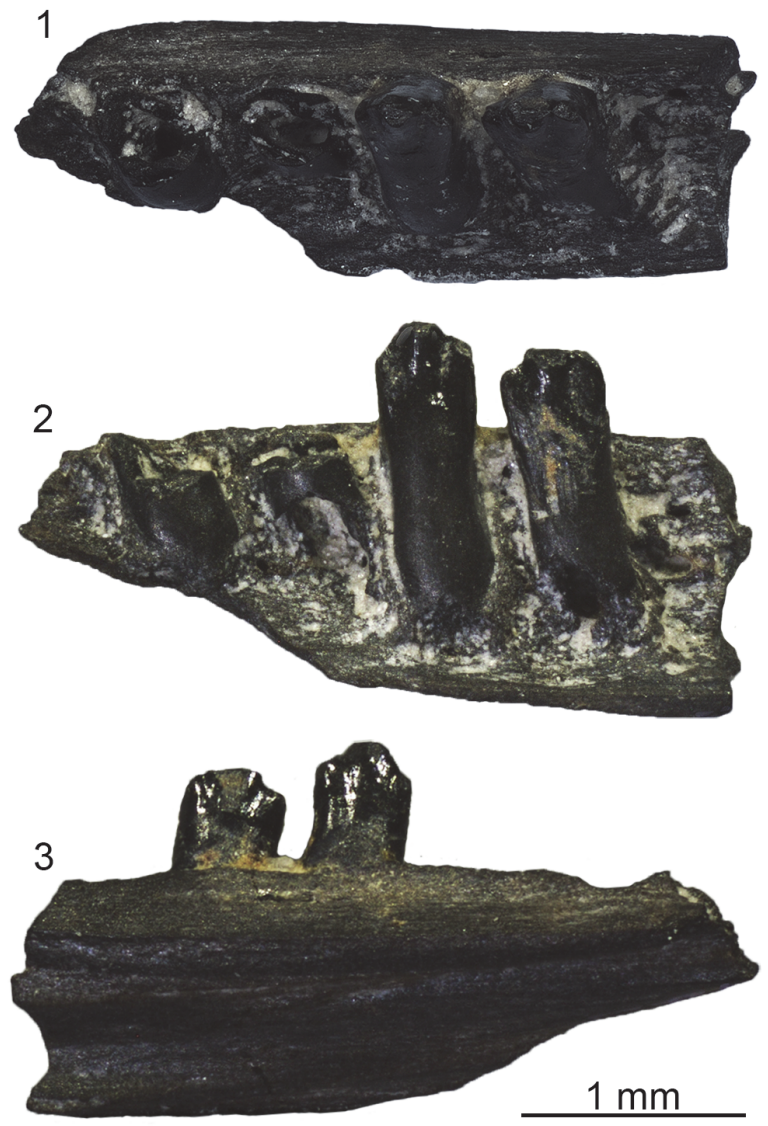

FIGURE 11. ?Lacertidae indet. from Maramena: fragment of a tooth bearing bone (UU MAA 7033) in dorsal (1), medial (2), and lateral (3) views.

Remarks. Pleurodont and tricuspid teeth are present in a number of different lizard groups, such as iguanids, lacertids, and teiids (Montanucci, 1968; Augé, 2005; Smith, 2006, 2009; Augé and Pouit, 2012). According to Smith (2006), tricuspid teeth of iguanids differ from those of other lizards by having developed grooves separating the cusps on the labial surface of the crown. Tricuspid teeth of teiids usually have a mesiodistally enlarged crown and considerable basal cementum (Smith, 2006). Lacertids usually display a difference in the size of the accessory cusps, with the anterior one that is larger than the posterior one, rather than a symmetrical condition. However, this difference might sometimes be less recognizable or even absent (e.g., in some species of Gallotia Boulenger, 1916, and Takydromus Daudin, 1802; see Kosma, 2004). Among Miocene lacertids, a distinct tricuspid condition of some of the teeth is known for Miolacerta tenuis Roček, 1984, from the early Miocene (MN 4) of Dolnice, Czech Republic, this feature being one of those included in its original diagnosis. However, as stated above, symmetrical tricuspidity is not unique to Miolacerta among lacertids and so, assigning poorly preserved remains to this genus based solely on this feature should be considered with caution. Adding to this, teeth of UU MAA 7033 also differ from those of Miolacerta in the light constriction at midheight and the slight expansion of the crown. Moreover, this kind of constriction is currently not known in the dentition of lacertids as a whole, complicating even more the attribution of this specimen to this lizard clade. Nevertheless, lacertids seems to be the clade of tricuspid teeth bearing lizards that is most likely to be present in the Greek region in the late Miocene/early Pliocene based on a biogeographic rationale, considering also that iguanids and teiids are totally absent from the European Neogene. Therefore, we herein tentatively refer UU MAA 7033 to Lacertidae, without pushing further its identification awaiting the discovery of other, better preserved remains bearing unambiguous diagnostic features (e.g., dentaries). It has to be noted, however, that the teeth of this specimen are distinctly different from those of all the other specimens bearing pleurodont and tricuspid teeth from Maramena and it as such, it is clearly distinct from the other lacertid from the locality that was described above.

\section{SCINCIFORMATA Vidal and Hedges, 2005 CORDYLIFORMES Fitzinger, 1826 CORDYLIDAE Fitzinger, 1826 \\ Genus PALAEOCORDYLUS Roček, 1984}

Type species. Palaeocordylus bohemicus Roček, 1984.

\section{aff. Palaeocordylus sp. Figure 12}

Material. M1: 26 maxillae (UU MAA 7046, UU MAA 7047, UU MAA 7077-UU MAA 7086, UU MAA 7101, UU MAA 7273, UU MAA 7358, UU MAA 7362-UU MAA 7365, UU MAA 7370-UU MAA 7372, UU MAA 7395, UU MAA 7396, and UU MAA 7437), 57 dentaries (UU MAA 7001-UU MAA 7025, UU MAA 7034-UU MAA 7036, UU MAA 7039, UU MAA 7040, UU MAA 7104, UU MAA 7108, UU MAA 7266, UU MAA 7267, UU MAA 7270, UU MAA 7279, UU MAA 7359, UU MAA 7366-UU MAA 7369, UU MAA 7397-UU MAA 7401, UU MAA 7425, and UU MAA 7426), and six fragments of tooth bearing bones (UU MAA 7037 and UU MAA 7038); M3: a maxilla (UU MAA 7340), eight dentaries (UU MAA 7199-UU MAA 7205, and UU MAA 7209), and a fragment of tooth bearing bone (UU MAA 7210). 

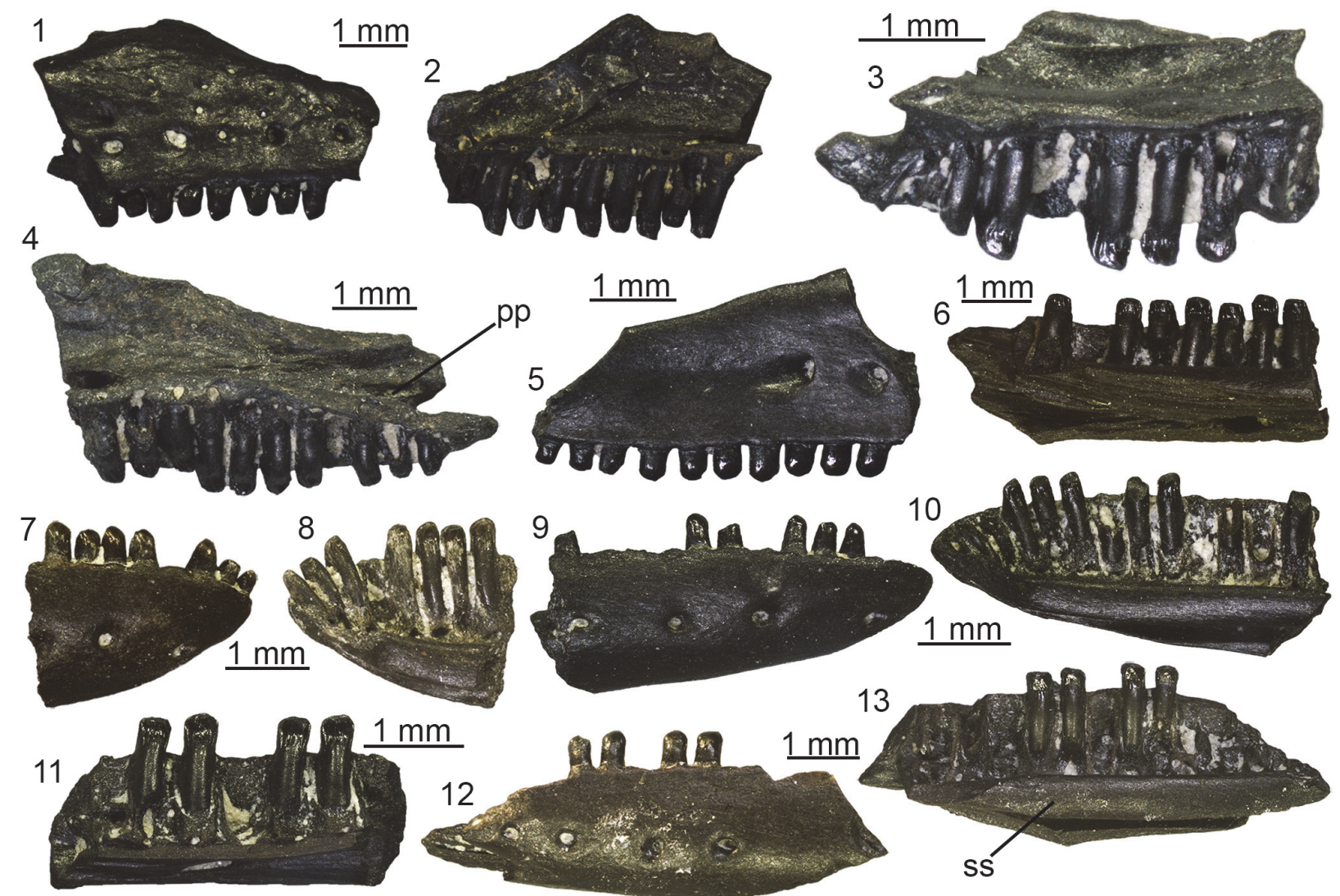

FIGURE 12. aff. Palaeocordylus sp. from Maramena: right maxilla (UU MAA 7046) in lateral (1) and medial (2) views; right maxilla (UU MAA 7047) in medial view (3); right maxilla (UU MAA 7077) in medial view (4); right maxilla (UU MAA 7078) in lateral view (5); left dentary (UU MAA 7003) in medial view (6); right dentary (UU MAA 7004) in lateral (7) and medial (8) views; right dentary (UU MAA 7006) in lateral (9) and medial (10) views; right dentary (UU MAA 7036) in medial view (11); left dentary (UU MAA 7199) in lateral (12) and medial (13) views. Abbreviations: pp, posterior process; ss, subdental shelf.

Description. Maxillae: all elements are relatively small-sized (Figure 12.1-5). Specimens UU MAA 7047, UU MAA 7371, and UU MAA 7372 preserve the anterior end. Specimens UU MAA 7046, UU MAA 7079, UU MAA 7080, UU MAA 7101, UU MAA 7362, and UU MAA 7437 preserve the middle portion of the bone. Specimens UU MAA 7077 and UU MAA 7370 preserve the complete posterior end, whereas the other specimensrepresent only poorly preserved, small portions of the posterior process. The number of preserved tooth positions varies from four to 14 . The preserved teeth are pleurodont, moderately slender, cylindrical, and closely spaced. They have a blunt and strongly postero-medially bending crown, with a labial and a lingual longitudinal cusp. The lingual surface of the crown displays a dense and distinct striation, which is on the other hand absent on the labial side. The tooth row reaches the posterior end of the bone, when the latter is preserved. Specimens UU MAA
7047 and UU MAA 7372 preserve the anterior premaxillary process, which displays a deep anteriorly directed concavity defined by the short lateral and medial processes (Figure 12.3). A short lateral process is also preserved in UU MAA 7371. The vomeronasal foramen opens by the base of the anterior premaxillary process, in a shallow concave area, which is bordered medially by a low ridge. A low arched ridge is present on the medial surface of the preserved remnant of the facial process in UU MAA 7046, UU MAA 7371, and UU MAA 7372 (Figure 12.1). In UU MAA 7077 and UU MAA 7370, the posterior process appears moderately short and high in lateral view and has a forked posterior end, because of the presence of a wide and welldeveloped posterior projection of its dorsal margin (Figure 12.4); the projection is separated by the ventral portion of the process by a deep U-shaped notch. The labial surface is smooth, but UU MAA 7046, UU MAA 7047, UU MAA 7077, UU MAA 
7078, UU MAA 7101, UU MAA 7395, and UU MAA 7396 display some ventrolateral foramina. Other smaller foramina are scattered on the labial surface of the facial process in UU MAA 7046 and UU MAA 7371, whereas UU MAA 7047 displays some grooves.

Dentaries: the dentaries are also small-sized (Figure 12.6-13). A high subdental shelf with a distinct subdental ridge is visible in medial view, covering the narrow Meckelian groove in the anterior half of the bone. In those specimens in which the posterior portion is preserved, the shelf appears to narrow towards its posterior end and the groove widens. A distinct facet for the articulation with the splenial is visible ventrally to the ridge when the posterior portion is preserved, but its anterior extension cannot be defined because of the fragmentary nature of the material. A narrow and slightly dorsally inclined mandibular symphysis is preserved in UU MAA 7004, UU MAA 7005, UU MAA 7006, UU MAA 7020, UU MAA 7021, UU MAA 7022, UU MAA 7023, UU MAA 7024, UU MAA 7025, UU MAA 7108, UU MAA 7205, UU MAA 7266, UU MAA 7267, UU MAA 7366, UU MAA 7367, and UU MAA 7368. Tooth morphology is the same as in the maxillae. The number of preserved tooth positions ranks between five and 18 . In UU MAA 7001, UU MAA 7002, UU MAA 7003, UU MAA 7017, UU MAA 7018, UU MAA 7019, UU MAA 7036, UU MAA 7040, UU MAA 7104, UU MAA 7204, UU MAA 7209, UU MAA 7270, UU MAA 7279, UU MAA 7401, and UU MAA 7426, the wide alveolar foramen is visible in ventral view. The lateral surface of the specimens is smooth, bearing a variable number of mental foramina. The single preserved foramen of UU MAA 7209 and those of UU MAA 7270 are rather large. When preserved, the ventral margin is straight in medial view.

Tooth bearing bones: UU MAA 7037, UU MAA 7038, UU MAA 7210, and UU MAA 7344 are small fragments of indeterminate tooth bearing bones. They bear pleurodont teeth, which are similar in morphology to the ones described above for maxillae and dentaries.

Remarks. The tooth morphology of these remains, with the two parallel cusps, resembles Kosma's (2004) morphotype F, typically present in Cordyliformes (Cordylidae, Gerrhosauridae, and their stem) and Scincidae sensu lato. In this case, the crown is blunt and distinctly bending postero-medially, in contrast with UU MAA 7027 and UU MAA 7107 (see below), and appears to be similar to the cordyliform condition. Among cordylids and gerrhosaurids, the dense and strong striation on the lin- gual surface is a common feature of the former, whereas striae are usually absent or poorly developed in the latter (Kosma, 2004). For several years, Neogene cordylids from Europe were represented by two different genera: "Bavaricordylus" Kosma, 2004 and Palaeocordylus Roček, 1984. However, the genus name "Bavaricordylus" was "introduced" in an unpublished PhD dissertation and should therefore not be considered valid, being unavailable for nomenclatorial purposes. Moreover, Villa et al. (2018c) recently demonstrated that the fossil material assigned to the two known species of "Bavaricordylus" can be referred instead to the lacertid genus Janosikia Čerňanský, Klembara, and Smith, 2016b. In any case, these fossil remains, originating from the early and middle Miocene of Germany (Kosma, 2004; Böhme, 2010), clearly differ from the cordylid from Maramena in having a rough lateral surface of the dentary and striae on the labial surface of the teeth. The type and only named species of Palaeocordylus, Palaeocordylus bohemicus Roček, 1984, from the early Miocene of Czech Republic, is more similar to the herein described specimens in terms of general morphology of the dentary. However, differences are present in the dentition: teeth of Palaeocordylus bohemicus are more swollen lingually than those of the specimens from Maramena and, at least as far as the posterior teeth are concerned, distinctly more robust. Moreover, teeth of $P$. bohemicus can rarely be tricuspid and lightly striated on the labial surface according to Roček (1984). Given that, it appears clear that the cordylid from Maramena shares some affinities with Palaeocordylus, even if some differences are present. It should also be noted that the herein described specimens from Maramena are rather similar in terms of both tooth and general morphology to the right dentary from the early Miocene locality of Merkur-Nord, Czech Republic, attributed to aff. Palaeocordylus bohemicus by Čerňanský (2012). The same applies to the fossils from the nearby and slightly older (MN 13) locality of Ano Metochi, which were assigned to probable cordylids by Georgalis et al. (2017a) and to the indeterminate "scincoid" described by Richter (1995) from Maramena. Accordingly, both the Ano Metochi cordylids (Georgalis et al., 2017a) and the previously described "scincoid" from Maramena (Richter, 1995) are herein also referred to aff. Palaeocordylus sp.

\footnotetext{
SCINCIDAE Oppel, 1811

?Scincidae indet.

Figure 13
} 


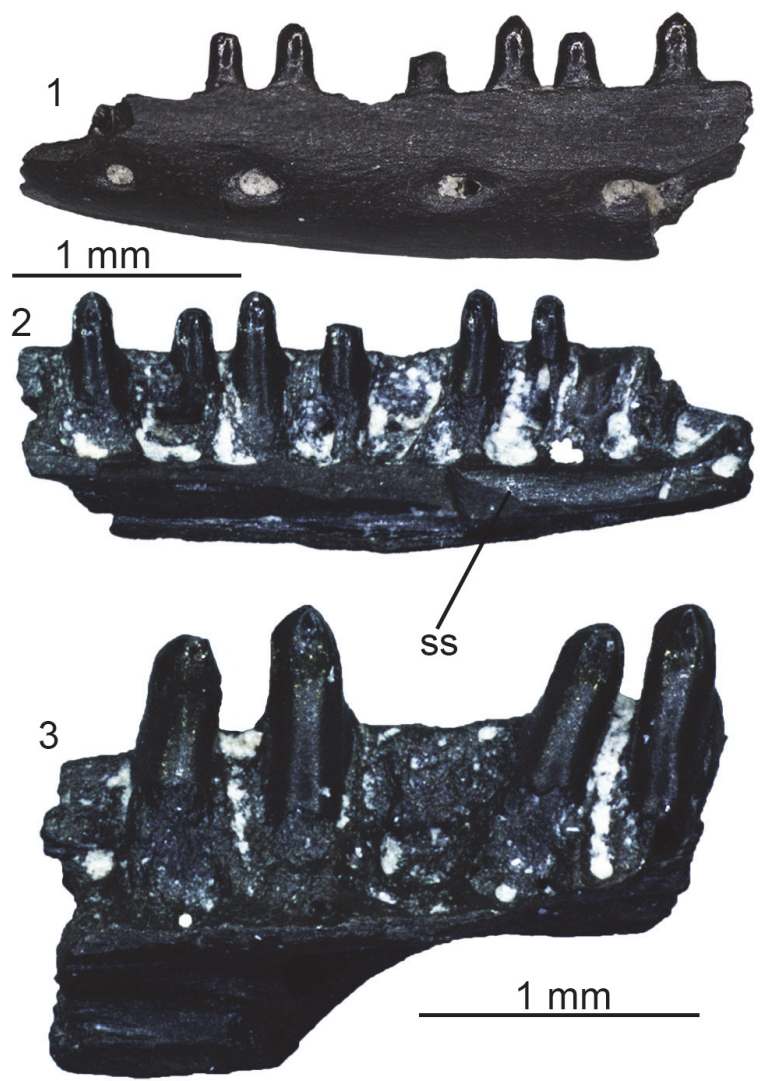

FIGURE 13. ?Scincidae indet. from Maramena: left dentary (UU MAA 7027) in lateral (1) and medial (2) views; right dentary (UU MAA 7107) in medial view (3). Abbreviation: ss, subdental shelf.

Material. M1: two dentaries (UU MAA 7027 and UU MAA 7107).

Description. Specimen UU MAA 7027 is a small and poorly preserved dentary, roughly $3.5 \mathrm{~mm}$ in length (Figure 13.1-2). It misses both the anterior and posterior ends. In medial view, a moderately high subdental shelf and a narrow and ventrally open Meckelian groove are visible. The shelf carries a subdental ridge dorsally. Nine tooth positions are preserved, housing five well-preserved teeth plus some more damaged ones. The teeth are closely spaced, pleurodont, slender, and cylindrical. They have a bicuspid crown, with labial and lingual cusps, and a pointed tip that is very slightly, not distinctly curved in medial direction. Both the labial and the lingual surfaces of the teeth are smooth, lacking evident striation. The ventral margin is straight in medial view. The lateral surface is smooth, bearing four mental foramina. Specimen UU MAA 7107 is also a rather small (total length = $2.5 \mathrm{~mm}$ ) fragment of a dentary (Figure 13.3). It bears four pleurodont teeth that are rather similar to those of UU MAA 7027, even if they show light striae on the labial surface of the crown, plus two empty tooth positions. In this specimen, the wide alveolar foramen is visible in ventral view. The lateral surface is smooth, with a single mental foramen.

Remarks. The tooth morphology of UU MAA 7027 and UU MAA 7107, with the two parallel cusps, recalls the morphotype $\mathrm{F}$ of Kosma (2004), as was also the case with the above described cordylids. According to the latter author, this morphotype is typical of the Scincoidea (sensu Estes et al., 1988 and Gauthier et al., 2012), i.e., Cordyliformes and Scincidae sensu lato. Teeth similar to morphotype $\mathrm{F}$ are also present in gekkotans (Sumida and Murphy, 1987; Villa et al., 2018b), but they lack striae and they are not curved by the tip. Moreover, dentaries of gekkotans have a closed Meckelian groove (Evans, 2008; Villa et al., 2018b). Compared to those of the herein described dentaries, cordyliforms have more robust and blunter teeth (Kosma, 2004), whereas the more slender, pointed and slightly postero-medially curved morphology of the crown of small-sized scincids (Townsend et al., 1999; Caputo, 2004) seems to fit better with the Maramena specimens. The few remains recovered and their poor preservation prevents us from being more confident with this identification.

Laterata indet. or Scinciformata indet.

Material. M1: 29 dentaries (UU MAA 7026, UU MAA 7106, UU MAA 7357, UU MAA 7361, UU MAA 7379, UU MAA 7402-UU MAA 7404, UU MAA 7435, and UU MAA 7436); M3: a dentary (UU MAA 7206).

Description. These dentaries are poorly preserved and fragmentary. All specimens are smallsized and represented by only part of the tooth row. They display a well-developed and high subdental shelf, provided with a distinct subdental ridge. The tooth positions are occupied by pleurodont, slender, cylindrical, and closely spaced teeth. The latter are either absent or they underwent strong wear, preventing a clear recognition of the main features of the crowns.

Remarks. A precise identification of these remains is impossible because of their rather poor preservation. Anyway, the combination of pleurodont dentition, open Meckelian groove, and presence of the subdental ridge suggests that they cannot be assigned to Iguania, Gekkota, or Anguimorpha and rather belong to what was until recently called "scincomorph" lizards (Evans, 2008). "Scincomorpha"is a term often used in the literature for the group uniting scincids and lacertids (Camp, 1923; Estes, 1983; Estes et al., 1988; Augé, 2005; 
Evans, 2008), but this grouping has been recently considered paraphyletic in phylogenetic analyses either based only on or including also molecular data (e.g., Vidal and Hedges, 2005, 2009; Wiens et al., 2012; Pyron et al., 2013; Reeder et al., 2015; Zheng and Wiens, 2016; Streicher and Wiens, 2017), although Gauthier et al. (2012) redefined it as comprising Lacertoidea and Scincoidea. Recent molecular studies suggest that lacertids and scincids are in fact much more distantly related and have instead demonstrated close affinities of lacertids with amphisbaenians, teiids, and gymnophthalmids (grouped altogether into Laterata) and of scincids with cordyliforms and xantusiids (grouped altogether into Scinciformata) (Vidal and Hedges, 2005, 2009). Similar affinities have been also recovered in subsequent phylogenetic analyses (Wiens et al., 2012; Pyron et al., 2013; Reeder et al., 2015; Zheng and Wiens, 2016; Streicher and Wiens, 2017) and have been recently also supported by the fossil record (Müller et al., 2011), whereas the taxonomic arrangement and nomenclature of Vidal and Hedges (2005) has recently appeared also in palaeontological papers (e.g., Codrea et al., 2017b).

\section{ANGUIMORPHA Fürbringer, 1900 \\ ANGUIDAE Gray, 1825 \\ ANGUINAE Gray, 1825 \\ Genus ANGUIS Linnaeus, 1758}

Type species. Anguis fragilis Linnaeus, 1758.
Anguis sp.

Figure 14

Material. M1: 37 trunk vertebrae (UU MAA 7181, UU MAA 7263, UU MAA 7274, UU MAA 7280, UU MAA 7332-UU MAA 7334, UU MAA 7411, UU MAA 7418, and UU MAA 7804), a cloacal vertebra (UU MAA 7269); M3: two trunk vertebrae (UU MAA 7217 and UU MAA 7218).

Description. Trunk vertebrae: they are lightly built and small-sized (Figure 14). Centrum length varies from $2.4 \mathrm{~mm}$ to $3.7 \mathrm{~mm}$. The vertebral centrum is procoelous and dorso-ventrally compressed. There is no precondylar constriction. In ventral view (Figure 14.2, 14.7), the lateral margins are straight and roughly parallel in the posterior portion of the centrum, slightly diverging anteriorly. The ventral surface is flat. The subcentral foramina range from small to moderately large. The synapophyses are dorso-ventrally elongated. The neural canal is subtriangular or subpentagonal. The neural arch bears a well-developed, laminar neural crest, originating a well-developed neural spine posteriorly. The zygapophyses are dorsallytilted of about $45^{\circ}$ and subelliptical.

Cloacal vertebra: this is similar to the trunk vertebrae in both morphology and size. In ventral view, the vertebral centrum has straight and roughly parallel lateral margins in its posterior half.

Remarks. These vertebrae can be allocated to Anguis on the basis of the dorso-ventrally compressed centrum with straight and parallel lateral margins, flat ventral surface, and devoid of precon-

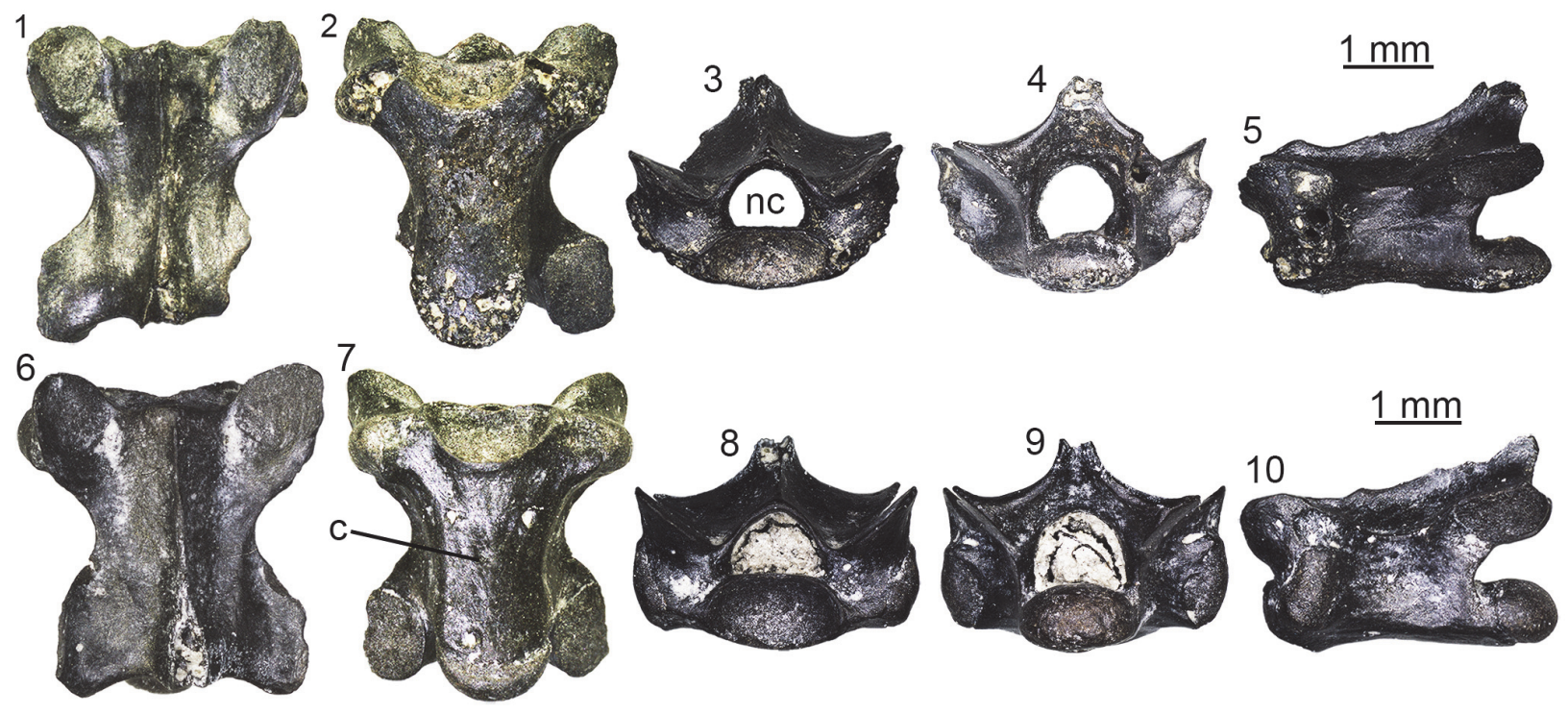

FIGURE 14. Anguis sp. from Maramena: trunk vertebra (UU MAA 7181) in dorsal (1), ventral (2), anterior (3), posterior (4), and left lateral (5) views; trunk vertebra (UU MAA 7263) in dorsal (6), ventral (7), anterior (8), posterior (9), and left lateral (10) views. Abbreviations: c, vertebral centrum; nc, neural canal. 


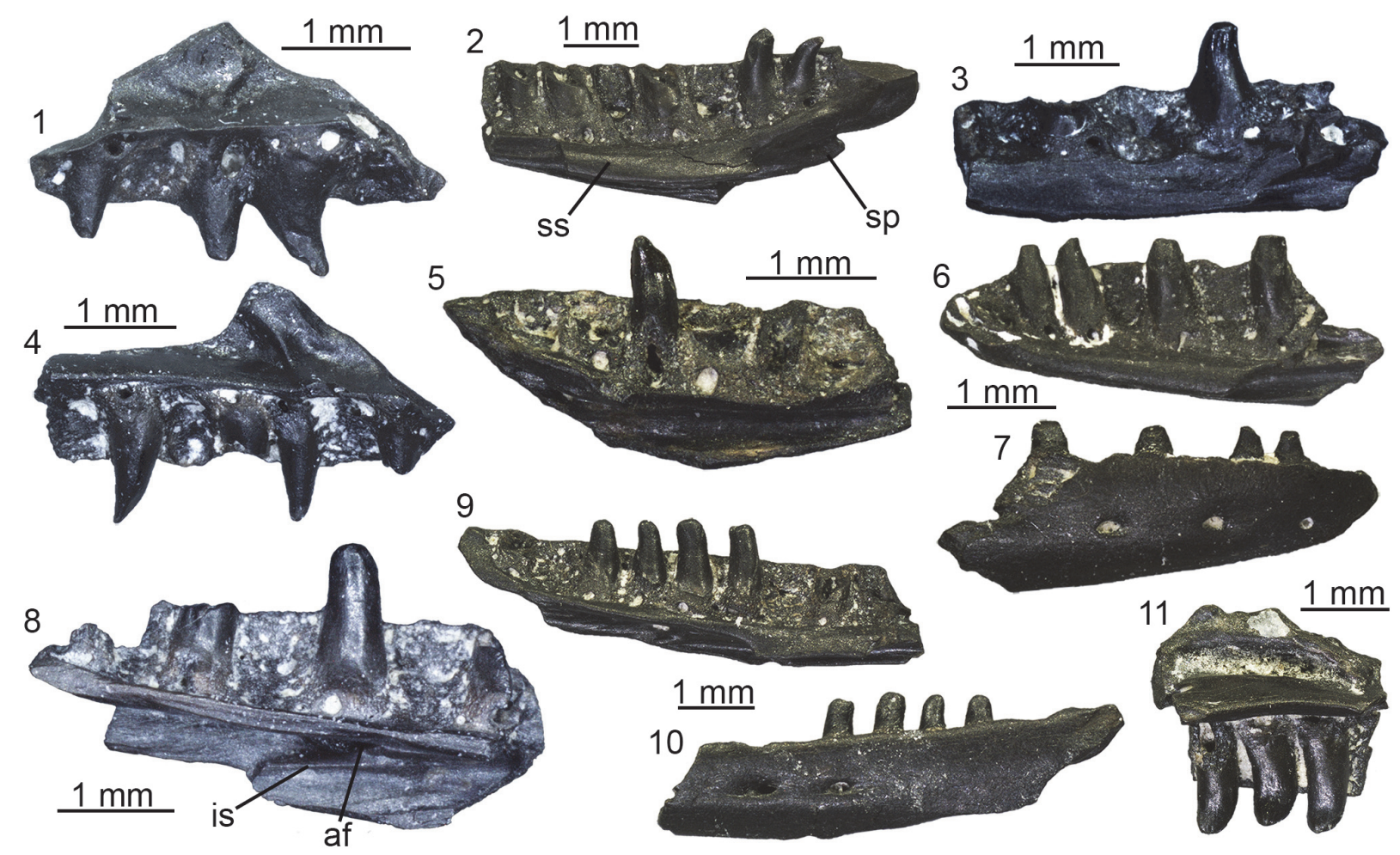

FIGURE 15. Ophisaurus morphotypes from Maramena. Ophisaurus sp. (morphotype 1) (1-3): right maxilla (UU MAA 7324) in medial view (1); right dentary (UU MAA 7176) in medial view (2); right dentary (UU MAA 7177) in medial view (3). Ophisaurus sp. (morphotype 2) (4-7): left maxilla (UU MAA 7180) in medial view (4); left dentary (UU MAA 7100) in medial view (5); right dentary (UU MAA 7186) in medial (6) and lateral (7) views. Ophisaurus sp. (morphotype 3) (8): left dentary (UU MAA 7313) in medial view (8). Ophisaurus sp. (morphotype 4) (9-10): left dentary (UU MAA 7175) in medial (9) and lateral (10) views. Ophisaurus sp. (morphotype 5) (11): left maxilla (UU MAA 7178) in medial view (11). Abbreviations: af, alveolar foramen; is, intramandibular septum; sp, surangular spine; ss, subdental shelf.

dylar constriction (Klembara, 1981; Estes, 1983; Čerňanský et al., 2019). A species level identification is not possible, as all named Anguis species described from the Neogene of Europe are based on cranial material (Klembara and Rummel, 2018). Even more, the extant taxon Anguis fragilis has been recently demonstrated to represent a species complex, with distinct species of the genus currently identified in the European continent, including also the Greek area (Gvoždík et al., 2010, 2013). Nevertheless, such taxonomic allocation of the extant Anguis spp. was made primarily on the basis of molecular data, with their osteology being, however, relatively indistinguishable.

Genus OPHISAURUS Daudin, 1803

Type species. Anguis ventralis Linnaeus, 1766.

Ophisaurus sp. (morphotype 1)

Figure 15.1-3

Material. M1: a maxilla (UU MAA 7324) and two dentaries (UU MAA 7176 and UU MAA 7177).
Description. Maxilla: the specimen is small-sized and fragmentary (Figure 15.1). The total length is 3 $\mathrm{mm}$. It preserves only part of the tooth row, missing part of the anterior end, most of the facial process, and the posterior process. On the medial surface of the preserved portion of the facial process, there is the antero-ventral part of a low but distinct arched ridge. The lateral surface is smooth, except for four ventrolateral foramina. Teeth are sub-pleurodont. Five tooth positions are preserved, with three rather well-preserved teeth. The best preserved tooth is distinctly conical, with a pointed and posteriorly curved tip. Low carinae might be present on the anterior and posterior sides of the crown, but this cannot be confirmed because of its preservation. There are no striae on the crown.

Dentaries: all dentaries are fragmentary. Specimen UU MAA 7177 is represented only by the middle portion of the bone (Figure 15.3), whereas UU MAA 7176 misses the anterior end and part of the posterior one (namely, the angular process and the coronoid process) (Figure 15.2). Both specimens are small-sized, roughly $4 \mathrm{~mm}$ (UU MAA 7177) and 
$6 \mathrm{~mm}$ (UU MAA 7176) in length. Medially, the smooth subdental shelf covers completely the narrow and ventrally opened Meckelian groove in UU MAA 7177, whereas it is almost completely broken in UU MAA 7176. The opening of the alveolar foramen, visible only in UU MAA 7176, is located by the posteriormost tooth position. The intramandibular septum does not develop a clear posterior projection, and its posteroventral margin is fused to the wall of the Meckelian groove. Posteriorly to the opening of the alveolar canal, there is a small surangular spine. The surangular process is short and wide. Specimen UU MAA 7176 displays seven tooth positions, whereas only five are preserved in UU MAA 7177. Teeth are sub-pleurodont and closely spaced, with a non-swollen tooth base. Only the posteriormost two are well preserved in UU MAA 7176, whereas a single rather well-preserved tooth is present in UU MAA 7177. They are moderately slender and conical, displaying a light but distinct posterior curvature by their tip. Except for the single well-preserved tooth of UU MAA 7177 (which displays a light striation on the lingual side), there are no striae on the crown. The last tooth of UU MAA 7176 presents two very poorly recognizable carinae on the anterior and posterior sides. The crown of the other preserved teeth is too eroded to clearly state the presence or absence of such features. The lateral surface of the bone is smooth and displays three (UU MAA 7177) or four (UU MAA 7176) mental foramina. In UU MAA 7176, part of the articulation surface with the surangular is visible in lateral view, ventrally to the surangular process (Figure 15.2). The ventral margin is rather straight.

Remarks. According to Klembara et al. (2014), conical and slightly posteriorly curved teeth and a surangular spine on the dentary are diagnostic features of Ophisaurus among anguines, whereas an intramandibular septum ending by or near the last tooth position (that is, the alveolar foramen opening there) is typical of Anguis. This might cause a certain degree of uncertainty about the possible identification of the above described specimens, taking also into account the fact that both Anguis and Ophisaurus seem to be present in Maramena based on vertebral morphology. However, the fusion of the intramandibular septum with the wall of the Meckelian groove is not present in Anguis, whereas it occurs in at least two extant species of Ophisaurus: Ophisaurus gracilis (Gray, 1845) and Ophisaurus koellikeri (Günther, 1873) (Klembara et al., 2014). Because of this, we favour the assignment of UU MAA 7324, UU MAA 7176, and UU
MAA 7177 to Ophisaurus. Members of the recently defined genus Ophisauromimus Čerňanský, Klembara and Müller, 2016a, from the Oligocene of France and Germany also have conical and slightly posteriorly curved teeth (Čerňanský et al., 2016a), but nevertheless, this genus is clearly different from the herein considered specimens because of the presence of a broad and plate-like intramandibular septum that is posteriorly free and the fact that it develops a large posterior projection. Conical and slightly posteriorly curved teeth are also observed in Ragesaurus medasensis Bailon and Augé, 2012, from the early Pleistocene of Spain (Bailon and Augé, 2012). The fragmentary nature of the specimens, along with the fact that most Neogene species of European Ophisaurus are based on parietals (see Klembara and Rummel, 2018), precludes a more precise identification.

\section{Ophisaurus sp. (morphotype 2)}

Figure 15.4-7

Material. M1: three maxillae (UU MAA 7180, UU MAA 7336, and UU MAA 7337), three dentaries (UU MAA 7100, UU MAA 7186, and UU MAA 7439), and a fragment of a tooth bearing bone (UU MAA 7440).

Description. Maxillae: the maxillae are small and fragmentary, preserving only part of the tooth row. None of the specimens preserve the posterior end, and only UU MAA 7180 preserves part of the anterior end (Figure 15.4). Most of the facial process is lacking too. The total length of the specimen ranges from $2.5 \mathrm{~mm}$ to $3.8 \mathrm{~mm}$. A small vomeronasal foramen located in a shallow concavity is visible anteriorly in UU MAA 7180, whereas UU MAA 7336 preserves the wide superior dental foramen. Specimen UU MAA 7180 displays also part of a sharp and low arched ridge on the medial surface of the facial process (Figure 15.4). Preserved teeth are sub-pleurodont, closely spaced, slender, and conical. They have a pointed and slightly posteriorly curved tip. There are no striae on the crown, but low carinae are present on the anterior and posterior sides at least in UU MAA 7336 and UU MAA 7337. The lingual side of the tooth base is slightly swollen. Specimen UU MAA 7180 carries seven tooth positions with two well-preserved teeth, whereas tooth positions and preserved teeth are respectively five in UU MAA 7336 and three in UU MAA 7337. The lateral surface is smooth in all specimens. Five preserved ventrolateral foramina are visible in UU MAA 7180, whereas only two are preserved in UU MAA 7336.

Dentaries: the dentaries preserve the anterior half (UU MAA 7186), the posterior half (UU MAA 7100), 
or only a portion of the middle part of the bone (UU MAA 7439). They are small-sized, roughly $2.4 \mathrm{~mm}$ (UU MAA 7439) or $4 \mathrm{~mm}$ (other specimens) in total length. In medial view, the narrow and ventrally open Meckelian groove of UU MAA 7186 and UU MAA 7439 is completely covered by a well-developed subdental shelf. Both UU MAA 7186 and UU MAA 7439 preserve only the anterior and middle portions of the bone, respectively, so neither the anterior inferior alveolar foramen nor the splenial spine, which are located in the posterior portion, are preserved (if present). A narrow and sub-horizontal mandibular symphysis is present by the anterior end of the former specimen. On the other hand, the shelf is broken in UU MAA 7100 (Figure 15.5). Four moderately preserved sub-pleurodont teeth are present in UU MAA 7186 (Figure 15.6-7), together with three empty tooth positions, whereas UU MAA 7100 carries five empty tooth positions and a single well-preserved tooth, and UU MAA 7439 bears three empty tooth positions and one well-preserved tooth. Teeth are closely spaced, slender and roughly conical. In UU MAA 7186 and UU MAA 7439, their tip is missing because of their preservation, but the crown appears to slightly curve posteriorly, as shown also by the preserved and pointed tip of the tooth of UU MAA 7100. There are no striae, whereas the anterior and posterior carinae are present only in UU MAA 7100 and UU MAA 7439; however, their absence in the other specimen can also be due to its poor preservation. The tooth base is not distinctly swollen lingually. The alveolar foramen is visible in UU MAA 7100 , located between the last and the second to last tooth positions. The intramandibular septum appears to be fused to the wall of the bone. Because of the preservation, it is not possible to state whether a surangular spine was present or not. The lateral surface is smooth, but carries two (UU MAA 7100 and UU MAA 7439) or three (UU MAA 7186) mental foramina. The ventral margin is straight.

Tooth bearing bone: UU MAA 7440 is a small fragment of tooth bearing bone, carrying four sub-pleurodont, slender, closely spaced and roughly conical teeth. Their tooth base is slightly swollen. There are no striae on the crown, but low carinae are visible both anteriorly and posteriorly at least in the best-preserved teeth.

Remarks. The identification of these specimens as belonging to Ophisaurus is based on the same criteria used for those assigned to morphotype 1 . The two morphotypes are indeed rather similar, in particular as far as the position of the alveolar foramen is concerned, but they are here considered as distinct because of some differences in the tooth morphology (i.e., the less conical and more swollen teeth of the second morphotype). On the other hand, however, we cannot state with confidence that these slightly different morphologies are only due to some kind of individual variation and that morphotypes 1 and 2 might represent the same form. The recently described Ophisaurus cranial remains from the nearby locality of Ano Metochi (Georgalis et al., 2017a) resemble the Maramena Ophisaurus morphotypes 1 and 2, particularly the second one.

\section{Ophisaurus sp. (morphotype 3) \\ Figure 15.8}

Material. M1: a left dentary (UU MAA 7313).

Description. Specimen UU MAA 7313 is a fragmentary left dentary, preserving part of the posterior portion of the bone, but missing the ventral margin and the posterior processes (Figure 15.8). It has a wide and laterally open Meckelian groove, separated from the alveolar shelf by a narrow subdental shelf. The alveolar shelf preserves six tooth positions, with a single well-preserved tooth and only part of a second one. The preserved tooth is sub-pleurodont, cylindrical, and slender; it displays a very slightly enlarged tooth base. The crown is blunt and does not show striae. The alveolar foramen is visible inside the Meckelian groove ventrally to the preserved teeth, being located at least four teeth before the posterior end of the tooth-row. The intramandibular septum is fused to the wall of the bone, but a very small and shallow groove visible in ventral view could be a suture line. A longitudinal ridge starts by the end of the intramandibular septum and runs posteriorly along the wall of the bone; this ridge might represent the base of the surangular spine, but because of a breakage at its posterior end, it is not possible to state whether it is indeed the case. The lateral surface of the specimen is smooth, except for a mental foramen located anteriorly and a small portion of the articulation surface with the surangular. The total length of the specimen is $4.5 \mathrm{~mm}$.

Remarks. The sub-pleurodont, slender, and cylindrical teeth, and the possible presence of a surangular spine suggest that UU MAA 7313 can also be referred to Ophisaurus (Klembara et al., 2014). The different tooth morphology and the more anteriorly located alveolar foramen, however, clearly distinguish this specimen from the previously described ones. 
Ophisaurus sp. (morphotype 4)

Figure 15.9-10

Material. M1: a left dentary (UU MAA 7175).

Description. Specimen UU MAA 7175 is a fragment of a left dentary, missing the anterior portion, most of the posterior end, and the ventral margin (Figure 15.9-10). It is small-sized, with a total length roughly reaching $6 \mathrm{~mm}$. The subdental shelf is ventrally developed anteriorly, but very narrow posteriorly. A very small splenial spine is present by the end of the expanded part of the shelf, though its tip is broken. The alveolar foramen is located between the fourth and the fifth tooth positions, starting from the posterior end of the tooth row. The intramandibular septum projects posteriorly with a small and pointed projection, which is not fused with the wall of the bone. Nine tooth positions are preserved in the tooth row, carrying four rather well-preserved teeth. Teeth are sub-pleurodont, cylindrical, and rather slender, with a blunt and apically flat crown and a not-distinctly enlarged base. The crown displays no striae and is not curved posteriorly. The lateral surface is smooth and bears three mental foramina.

Remarks. Specimen UU MAA 7175 is similar to UU MAA 7313 in tooth morphology and therefore we here assign it to Ophisaurus too. A possibly significant difference between these two specimens, however, is found in the unfused intramandibular septum of the former. It is worth noting that Klembara (2015) seems to treat this difference as individual variation in the description of its Anguine morphotype 1 from Merkur-Nord. The presence of a suture line in UU MAA 7313 can support this view, suggesting that the two specimens might be attributed to the same morphotype.

\section{Ophisaurus sp. (morphotype 5)}

Figure 15.11

Material. M1: a maxilla (UU MAA 7178).

Description. Specimen UU MAA 7178 is a small fragment of maxilla, measuring $2.7 \mathrm{~mm}$ in total length (Figure 15.11). It preserves only a part of the middle portion of the tooth row and of the facial process, carrying three well-preserved teeth. The latter are sub-pleurodont, closely spaced, and cylindrical, with a roughly pointed, labio-lingually compressed, and slightly postero-medially bending crown. The tooth crown displays very light striae on the lingual side, whereas the labial one is smooth. A sharp carina is present on both the anterior and the posterior sides of the teeth. In medial view, the teeth appear slightly thicker than those of the other morphotypes. Their base is not enlarged. On the medial surface of the preserved portion of the facial process, a very robust and well-developed arched ridge is present, defining ventrally a strongly medially concave area. By the posterior end of the preserved portion of the palatal shelf, the outline of the superior dental foramen is recognizable in dorsal view. The lateral surface of the bone carries three large ventrolateral foramina. Dorsally to them, a hint of dermal ornamentation is also visible.

Remarks. As for the other morphotypes described above, tooth morphology suggests that UU MAA 7178 can also be attributed to Ophisaurus. However, the clear differences of its dentition lead to its assignment to a fifth morphotype.

\section{Ophisaurus sp. (indeterminate morphotype) Figure 16}

Material. M1: three dentaries (UU MAA 7179, UU MAA 7312, and UU MAA 7343), 41 trunk vertebrae (UU MAA 7173, UU MAA 7174, UU MAA 7183, UU MAA 7335, UU MAA 7412, and UU MAA 7416); M3: two trunk vertebrae (UU MAA 7215 and UU MAA 7216).

Description. Dentaries: UU MAA 7179 and UU MAA 7312 are represented by the anterior end of small-sized dentaries. Their total length is roughly $3.6 \mathrm{~mm}$ for UU MAA 7179 and roughly $2.5 \mathrm{~mm}$ for UU MAA 7312. Both have a narrow and sub-horizontal mandibular symphysis and a ventrally welldeveloped subdental shelf, which completely covers the narrow Meckelian groove in medial view. In both specimens, the tooth row preserves five tooth positions, with a single well-preserved (UU MAA 7179) or poorly-preserved (UU MAA 7312) tooth, and two other preserved tooth bases. Teeth are sub-pleurodont and closely spaced. The well-preserved one of UU MAA 7179 is slender, cylindrical, and narrows towards the tip, showing an enlarged base. The other preserved bases and the best preserved one of UU MAA 7312 (which misses the crown), however, do not show a clear enlargement. The crown of the well-preserved tooth is rather blunt, smooth, and not posteriorly curved. The lateral surface of the dentaries is smooth, with one (UU MAA 7179) or two (UU MAA 7312) mental foramina. The mental foramen of UU MAA 7179 is very large. Specimen UU MAA 7343is a small fragment of a very poorly preserved dentary. It displays a well-developed subdental shelf and four subpleurodont and closely spaced teeth. The teeth are also very poorly preserved. The lateral surface of the dentary is smooth, with two mental foramina.

Trunk vertebrae: they are procoelous, moderately robust and small- to medium-sized (Figure 16). The length of their vertebral centrum ranges from 


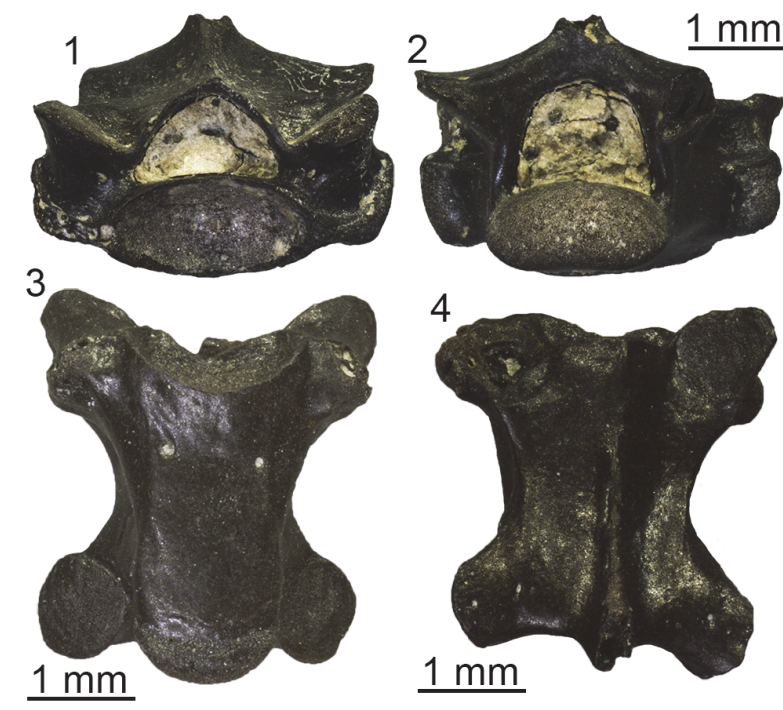

FIGURE 16. Ophisaurus from Maramena (indeterminate morphotype), vertebrae:trunk vertebra (UU MAA 7173) in anterior (1) and posterior (2) views; trunk vertebra (UU MAA 7215) in ventral view (3); trunk vertebra (UU MAA 7216) in dorsal view (4).

$2.3 \mathrm{~mm}$ to $4.9 \mathrm{~mm}$. The centrum is dorsoventrally compressed and has a flat ventral surface, provided with small subcentral foramina. In ventral view, the centrum has a subtriangular shape, with posteriorly converging and laterally concave lateral margins. There is no precondylar constriction. The synapophyses are dorsoventrally elongated. The neural canal is roughly subtriangular or subpentagonal in anterior view. The neural arch displays a high and laminar neural crest, originating a welldeveloped (but often broken) neural spine by its posterior end. Zygapophyses are tilted dorsally of about $45^{\circ}$ and have a subelliptical shape.

Remarks. The trunk vertebrae clearly belong to Ophisaurus because of the dorsoventrally compressed and subtriangular vertebral centrum with concave lateral margins, a flat ventral surface, and the absence of a precondylar constriction (Klembara, 1981; Estes, 1983; Čerňanský et al., 2019). The dentaries are allocated to the same genus because of the presence of sub-pleurodont, slender, and cylindrical or conical teeth (Klembara et al., 2014). The poor preservation of UU MAA 7343 prevents us to confidently assign it to one of the above five recognized morphotypes. Teeth of UU MAA 7179 and UU MAA 7312, on the other hand, are similar to those of both morphotypes 3 and 4, but, since the posterior end is not preserved in these dentaries, and as such the degree of fusion of the intramandibular septum is not definable, they cannot be confidently attributed to either the third or the fourth morphotypes.

Genus PSEUDOPUS Merrem, 1820

Type species. Lacerta apoda Pallas, 1775.

Pseudopus sp.

Figures 17, 18

Material. M1: a maxilla (UU MAA 7171), a dentary (UU MAA 7407), a fragment of tooth bearing bone (UU MAA 7307), two trunk vertebrae (UU MAA 7172 and UU MAA 7328), and a cloacal vertebra (UU MAA 7329); M3: three trunk vertebrae (UU MAA 7212-UU MAA 7214).

Description. Maxilla: UU MAA 7171 is a fragment of a small maxilla (total length $=4.9 \mathrm{~mm}$ ) preserving only part of the posterior process (Figure 17.1$4)$. The posterior tip of the process is missing. The lateral surface is smooth and carries two ventrolateral foramina, with the posteriormost one distinctly larger than the other one. A wide superior dental foramen followed by a shallow longitudinal groove is present on the dorsal surface of the palatal shelf. The alveolar border of UU MAA 7171 carries three large, relatively bulbous, rather robust and subpleurodont teeth, which decrease in size posteriorly. Their crown is blunt and does not display distinct cusps, however, this latter feature could be simply due to weathering or wear. A dense striation surrounds the tip of the teeth.

Dentary: UU MAA 7407 is a poorly preserved dentary, with a total length of $3 \mathrm{~mm}$ (Figure 17.5-8). In medial view, the subdental shelf can be recognized despite the poor preservation. The specimen carries five cylindrical, sub-pleurodont, and rather robust teeth, with flat and blunt crowns. Even if all teeth are distinctly eroded, a single and small cusp is still recognizable in the middle of the apical surface of some of them. A light and dense radial striation surrounds the cusp. The lateral surface of the dentary is smooth.

Tooth bearing bone: UU MAA 7307 is a small fragment of tooth bearing bone, carrying two rather robust, cylindrical, and sub-pleurodont teeth (Figure 17.9-10). Their tip is rounded, with a single, small cusp in the middle surrounded by a dense radial striation covering both the labial and the lingual sides of the tooth crown.

Trunk vertebrae: they are robust and small- to medium-sized. The smallest one, UU MAA 7213, has a centrum length of $2 \mathrm{~mm}$, whereas the largest one, UU MAA 7172, is $4.4 \mathrm{~mm}$ in length (Figure 18.1-5). The vertebral centrum in all specimens is procoelous and dorso-ventrally compressed. In ventral view, it is distinctly triangular and devoid of 

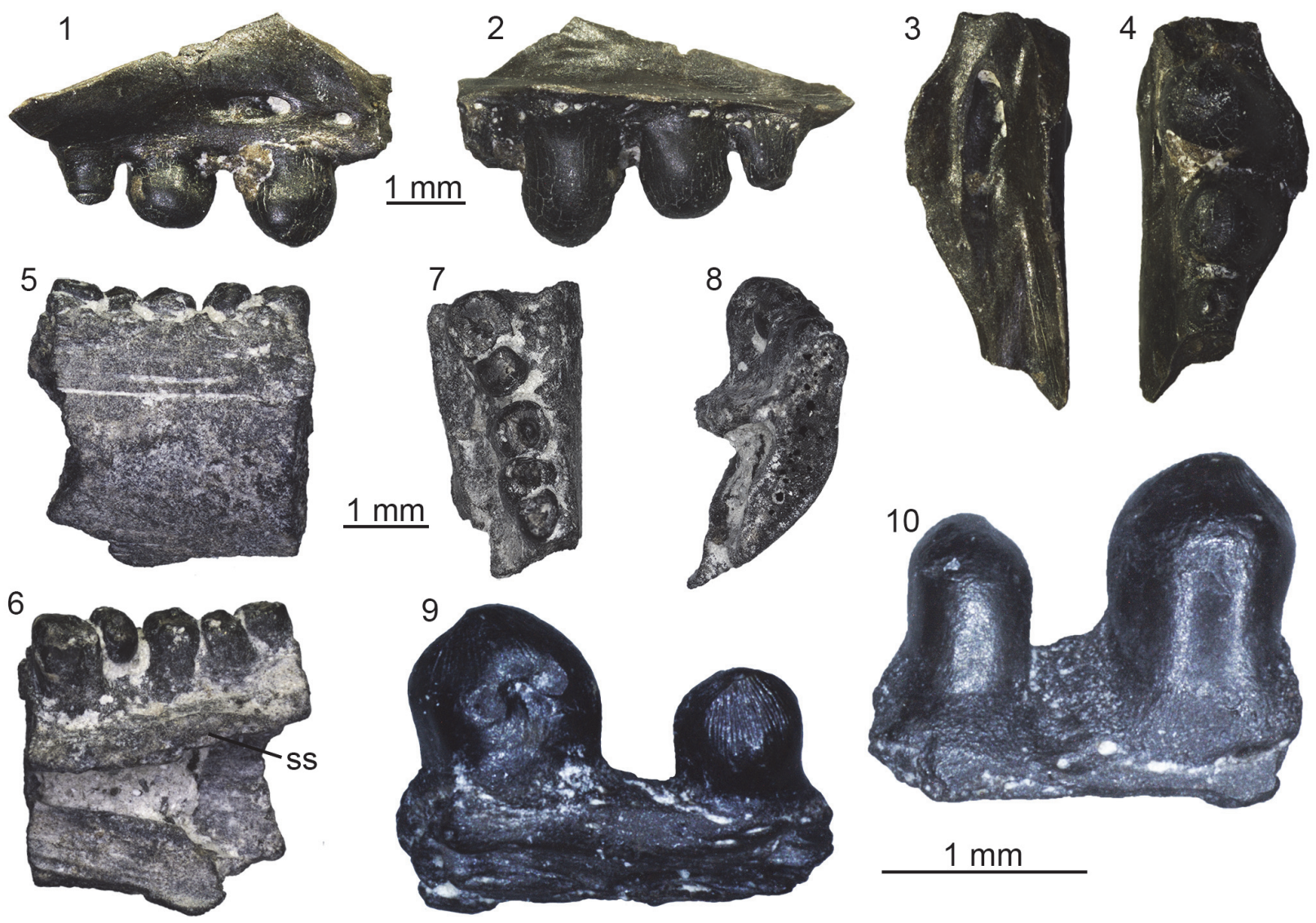

FIGURE 17. Pseudopus sp. from Maramena, cranial elements: right maxilla (UU MAA 7171) in lateral (1), medial (2), dorsal (3), and ventral (4) views; right dentary (UU MAA 7407) in lateral (5), medial (6), dorsal (7), and posterior (8) views; fragment of tooth bearing bone (UU MAA 7307) in lateral (9) and medial (10) views. Abbreviation: ss, subdental shelf.

precondylar constriction. The lateral margins are straight in UU MAA 7328 (Figure 18.6), but slightly concave in the other specimens. The ventral surface of the centrum displays a low and wide convexity. The synapophyses are dorsoventrally elongated. The neural canal is subtriangular or subpentagonal in anterior view. A well-developed neural crest is present on the dorsal surface of the neural arch; it forms a neural spine posteriorly, but the latter is always broken off. The zygapophyses are subellipical and strongly tilted dorsally at around $45^{\circ}$.

Cloacal vertebra: UU MAA 7329 is rather similar to the above described trunk vertebrae in robustness and morphology (Figure 18.7-8). Its centrum length is $4.5 \mathrm{~mm}$.

Remarks. Robust, bulbous, cylindrical, and striated sub-pleurodont teeth are one of the main features of the tooth bearing bones of Pseudopus (Klembara et al., 2014). Trunk vertebrae with a dorsoventrally compressed and triangular vertebral centrum, straight (or concave in small specimens) lateral margins, a convex ventral surface, and no precondylar constriction can be attributed to the same genus (Klembara, 1981; Estes, 1983; Čerňanský et al., 2019). A species level identification is prevented by the poor preservation of the few cranial remains, but the tooth bearing bones from Maramena differ clearly at least from those of Pseudopus ahnikoviensis Klembara, 2012, from the early Miocene (MN 3) of Merkur-Nord, Czech Republic, by the presence of the striated teeth (Klembara, 2012; Klembara and Rummel, 2018). However, the dentary UU MAA 7407 can still provide more diagnostic information for a more precise determination. The subdental shelf of the Maramena dentary is much different from that of Pseudopus laurillardi (Lartet, 1851) from the early and middle Miocene of France and Germany, as in the latter taxon, the position of the subdental shelf is situated much deeper relative to the height of the lower jaw throughout its anteroposterior course, a feature occurring constantly in both small and large-sized specimens of the species (Klembara et 

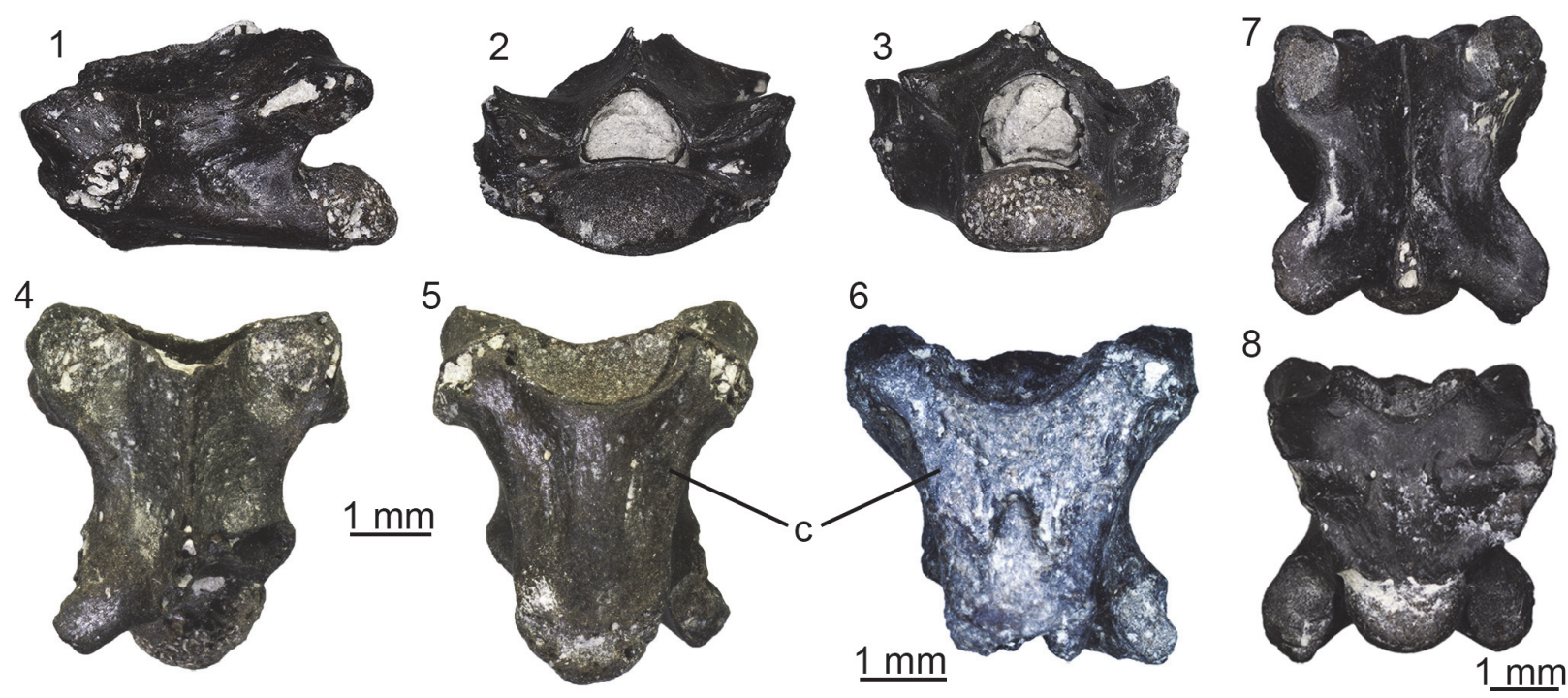

FIGURE 18. Pseudopus sp. from Maramena,vertebrae: trunk vertebra (UU MAA 7172) in left lateral (1), anterior (2), posterior (3), dorsal (4), and ventral (5) views; trunk vertebra (UU MAA 7328) in ventral view (6); cloacal vertebra (UU MAA 7329) in dorsal (7) and ventral (8) views. Abbreviation: c, vertebral centrum.

al., 2010). Instead, UU MAA 7407 is characterized by a dorsal position of the subdental shelf in the posterior section of the dentary relative to height of the dentary. Such feature is present in dentaries of the extant $P$ seudopus apodus and small-sized individuals of the extinct widespread "giant" anguid Pseudopus pannonicus (Kormos, 1911) from the late Miocene and Pliocene of Central and Eastern Europe (Klembara et al., 2010, 2014; Klembara, pers. comm. to GLG, October 2018). As such, this feature could be regarded as a synapomorphy of the clade of $P$ seudopus pannonicus plus the extant Pseudopus apodus. Unfortunately, this character cannot be evaluated for Pseudopus confertus Klembara and Rummel, 2018, another species of that genus from the early Miocene (MN 3) of Merkur-Nord, Czech Republic, as dentaries are currently unknown for that species (Klembara, 2015; Klembara and Rummel, 2018). It therefore seems most probable that the Maramena material pertains to the widespread taxon Pseudopus pannonicus, taking also into consideration a stratigraphic and geographic rationale and the ubiquitous absence of definite specimens of Pseudopus apodus in pre-Quaternary sediments.

non-Anguis Anguinae indet.

Figure 19.1-12

Material. M1: 188 osteoderms (UU MAA 7160-UU MAA 7170, UU MAA 7262, UU MAA 7265, UU MAA 7268, UU MAA 7271, UU MAA 7275, UU MAA 7306, and UU MAA 7314-UU MAA 7318);
M2: eight osteoderms (UU MAA 7187, UU MAA 7188, and UU MAA 7298).

Description. Osteoderms are relatively smallsized and sub-rectangular in shape. The only exceptions are UU MAA 7160, UU MAA 7161, UU MAA 7162, UU MAA 7163, UU MAA 7164, UU MAA 7165, UU MAA 7166, UU MAA 7169, UU MAA 7314, UU MAA 7315, and UU MAA 7316, which are strongly larger and more robust than the other ones. The external surface displays a vermicular ornamentation, absent only anteriorly where the smooth gliding surface is located (Figure 19.112). A low longitudinal keel (sharper in UU MAA 7317 and UU MAA 7318) runs in the middle of the same surface in many specimens. The inner surface, on the other hand, is smooth. As for the position of the osteoderms in the body (sensu Hoffstetter, 1962), certain specimens can be recognized as mediodorsal osteoderms (Figure 19.6, 19.12), others as lateral osteoderms (Figure 19.1$2,19.4,19.7-11)$, others as medioventral osteoderms (Figure 19.5), whereas others are too incomplete to denote an exact origination from the body (Figure 19.3).

Remarks. Sub-rectangular and keeled osteoderms are found in non-Anguis anguines, whereas those of Anguis are more rounded and devoid of any keel (Hoffstetter, 1962; Delfino et al., 2011). Because of the absence of clear diagnostic features, it is not possible to assign these osteoderms to either Ophisaurus or Pseudopus. Regarding the previously described anguids from Maramena that had been 


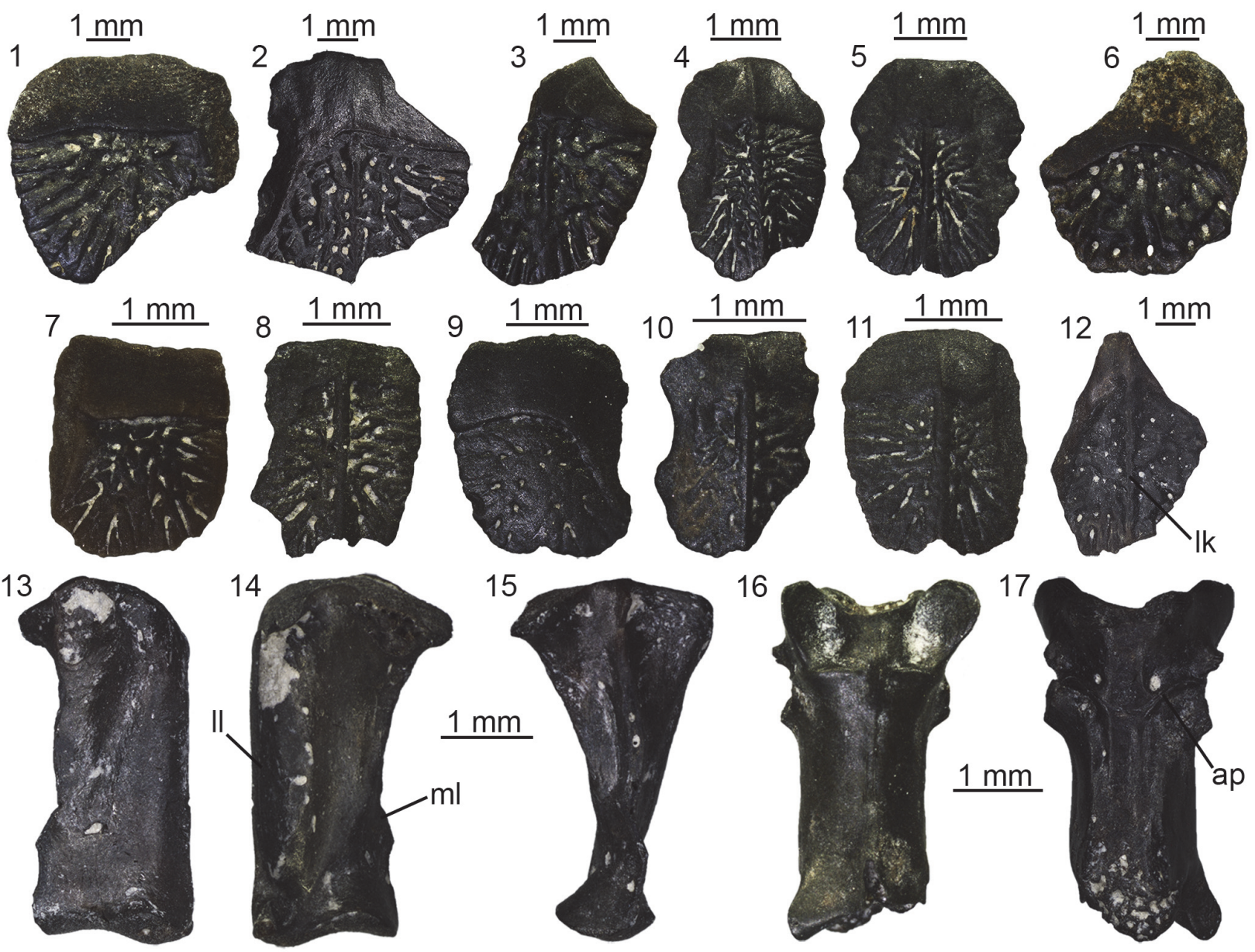

FIGURE 19. Non-Anguis Anguinae indet. from Maramena (1-12): osteoderm (UU MAA 7161) in external view (1); osteoderm (UU MAA 7164) in external view (2); osteoderm (UU MAA 7165) in external view (3); osteoderm (UU MAA 7167) in external view (4); osteoderm (UU MAA 7168) in external view (5); osteoderm (UU MAA 7169) in external view (6); osteoderm (UU MAA 7187) in external view (7); osteoderm (UU MAA 7262) in external view (8); osteoderm (UU MAA 7265) in external view (9); osteoderm (UU MAA 7271) in external view (10); osteoderm (UU MAA 7275) in external view (11); osteoderm (UU MAA 7315) in external view (12). Anguidae indet. (13-17): left quadrate (UU MAA 7408) in anterior (13), posterior (14), and medial (15) views; caudal vertebra (UU MAA 7182) in dorsal (16) and ventral (17) views. Abbreviations: ap, autotomy plane; Ik, longitudinal keel; II, lateral lamina; ml, medial lamina.

referred to Ophisaurus sp. by Richter (1995), this material consisted of a "questionable jaw fragment" (Richter, 1995:37) that was never figured and 30 osteoderms; in any case, it appears that Richter's (1995) material is not informative at the genus level and should only be treated as indeterminate anguines.

\section{Anguidae indet.}

Figure 19.13-17

Material. M1: a quadrate (UU MAA 7408), 13 trunk vertebrae (UU MAA 7323, UU MAA 7410, and UU MAA 7417), 80 caudal vertebrae (UU MAA 7182, UU MAA 7184, UU MAA 7185, UU MAA 7272, UU MAA 7320, UU MAA 7321, UU MAA 7325-UU
MAA 7327, UU MAA 7330, UU MAA 7331, UU MAA 7409, UU MAA 7423, UU MAA 7800, UU MAA 7801, and UU MAA 7803), and four fused caudal vertebrae (UU MAA 7413); M2: a caudal vertebra (UU MAA 7301); M3: four caudal vertebrae (UU MAA 7211, UU MAA 7219, and UU MAA 7338).

Description. Quadrate: this specimen is $4 \mathrm{~mm}$ in length (Figure 19.13-15). In anterior view, it is straight and narrow. The lateral lamina is short and does not develop a deep and wide conch. A medial lamina is also present, but its margin is broken and so it is not possible to define its total development, as well as the presence or absence of a pterygoid flange. The mandibular condyle is wide and 
roughly flat, with two similar-sized portions. A quadrate foramen is visible dorsally to it on the anterior surface of the specimen. The cephalic condyle is strongly anteroposteriorly expanded; in medial view, its dorsal surface is flat and slightly convex. The anterior outline of the quadrate is distinctly angular, with an angle of about $90^{\circ} \mathrm{com}-$ posed by the cephalic condyle and the straight anterior margin of the bone. A deep squamosal notch is visible in dorsal view.

Trunk vertebrae: the small trunk vertebrae are fragmentary and poorly preserved, but they clearly display a dorsoventrally compressed and procoelous vertebral centrum, strongly dorsally tilted (roughly $45^{\circ}$ ) and sub-elliptical prezygapophyses and a sub-triangular neural canal. The synapophyses are dorsoventrally elongated.

Caudal vertebrae: the caudal vertebrae are medium- or small-sized and procoelous (Figure 19.16-17). They have a dorsoventrally compressed centrum and a sub-triangular neural canal. When the posterior portion of the centrum is preserved, the bases of the fused and thin haemapophyses are present on its ventral surface. The zygapophyses are tilted dorsally at $45^{\circ}$ and have a sub-elliptical shape. A long and sub-cylindrical, though often broken, neural spine is present by the posterior end of the neural arch, when preserved. The transverse processes are welded, the anterior process being smaller than the posterior, and placed just behind the prezygapophyses. The autotomy plane is usually present, but sometimes it can be secondarily fused (e.g., UU MAA 7321, UU MAA 7326, and UU MAA 7327). Specimen UU MAA 7413 is represented by the poorly preserved and fused vertebral centra of four small caudal vertebrae. The centra are dorsoventrally compressed and display the bases of fused haemapophyses on the ventral surface.

Remarks. The vertebral remains clearly display anguid features, such as the dorsoventrally compressed centrum and, in the caudal vertebrae, the fused haemapophyses and the autotomy plane. The morphology of the quadrate is also congruent with that of anguid quadrates. These specimens are most probably attributable to one of the above mentioned anguine taxa, but we here treat them as indeterminate anguids because of the absence of clear diagnostic characters allowing for a more precise allocation.

PLATYNOTA Duméril and Bibron, 1839

VARANIDAE Gray, 1827 (sensu Estes et al., 1988) Genus VARANUS Merrem, 1820

Type species. Lacerta varia White, 1790.

\section{Varanus $\mathrm{sp}$.}

Figure 20

Material. M1: six teeth (UU MAA 7029, UU MAA 7030, and UU MAA 7148-UU MAA 7151) and 12 caudal vertebrae (UU MAA 7028, UU MAA 7278, UU MAA 7388, UU MAA 7389, UU MAA 7429-UU MAA 7434, UU MAA 7805, and UU MAA 7806); M3: a caudal vertebra (UU MAA 7198).

Description. Teeth: the isolated teeth are labiolingually compressed, conical, and slightly posteriorly curved by the pointed tip (Figure 20.1-10). The curve is more pronounced in UU MAA 7029 (Figure 20.1-2). A sharp carina runs along the entire posterior margin; this carina is serrated in all specimens except UU MAA 7029 and UU MAA 7148. Another, non-serrated carina is also present along the distal portion of the anterior margin, but it becomes less distinct towards the tooth base. This latter carina is more developed and serrated in UU MAA 7029 (Figure 20.1-2), UU MAA 7030 (Figure 20.3-4), and UU MAA 7151 (Figure 20.9-10). The tooth base is almost always broken off, but well-distinct striae are present on both the labial and the lingual sides, near the proximal end of the preserved portion of the specimens. The striation is rather dense in UU MAA 7030 (Figure 20.3-4). Except for the latter specimen, the striae correspond interiorly to dentine lamellae projecting inside the pulp cavity. Part of the tooth base is preserved only in UU MAA 7029 (Figure 20.1-2) and UU MAA 7148 (Figure 20.5-6): it shows a spongy structure, formed by a strong development of the lamellae.

Caudal vertebrae: the caudal vertebrae are procoelous and medium-sized (Figure 20.11-17). Their centrum is dorsoventrally compressed; the best-preserved and largest ones, those of UU MAA 7198 and UU MAA 7278, are roughly $7 \mathrm{~mm}$ and 8 $\mathrm{mm}$ in length, respectively. In lateral view, the ventral margin of the anterior cotyle is located posteriorly compared to the dorsal one. A distinct precondylar constriction is visible in ventral view. Two robust pedestals for the chevron bone are present on the ventral surface, especially in UU MAA 7198 (Figure 20.14-15). Only a hint of the base of the pedestals is recognizable in UU MAA 7028 (Figure 20.11). The neural canal is subtriangular in anterior view. The neural arch is mostly missing (completely absent in UU MAA 7388, but well preserved in UU MAA 7429), but its anterior end is dorsally flattened. Zygapophyses are subelliptical and tilted dorsally at $45^{\circ}$ in anterior view. There is no sign of autotomy plane.

Remarks. Teeth including a trenchant and keeled morphology, the presence of plicidentine (i.e., the 

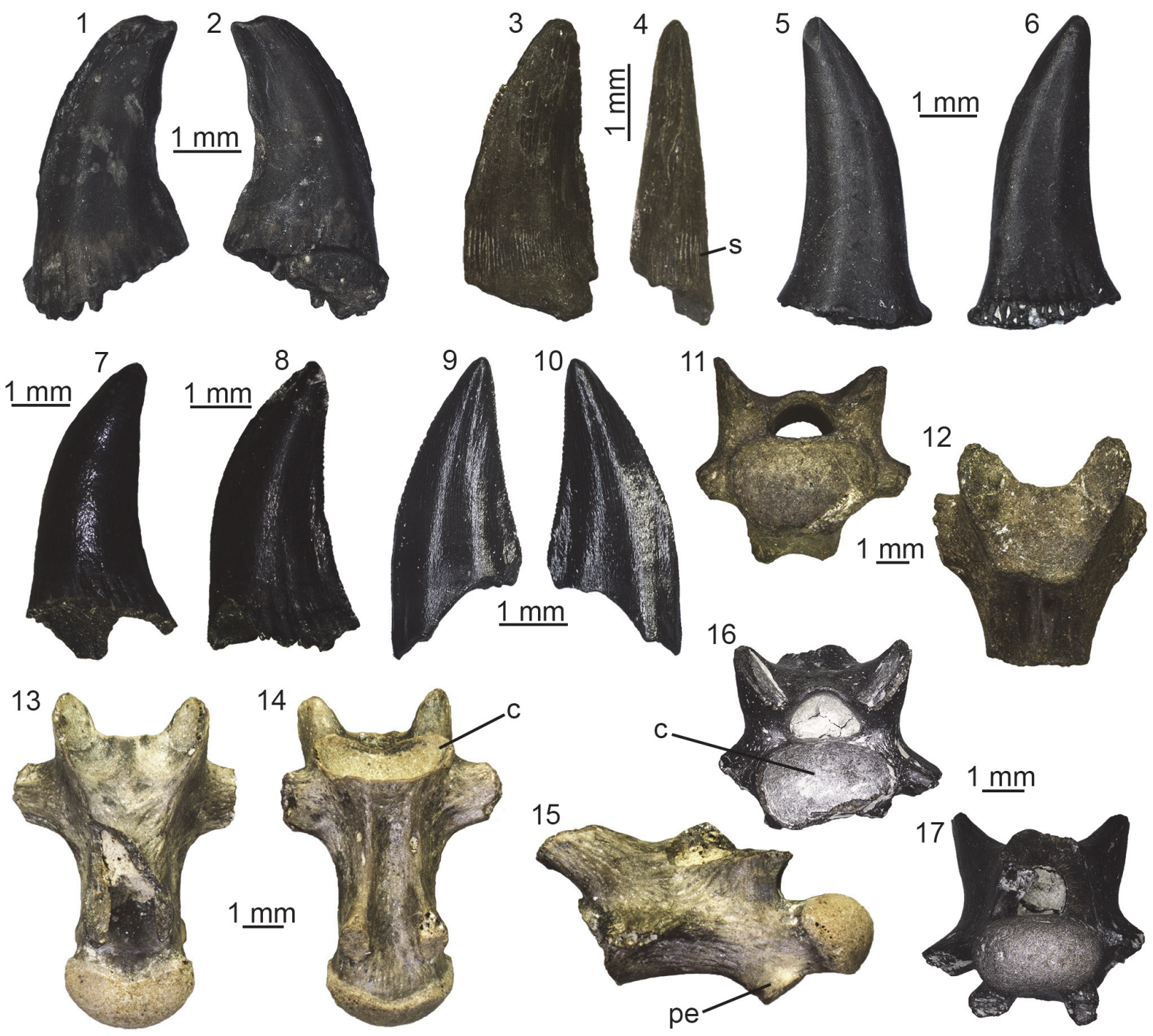

FIGURE 20. Varanus sp. from Maramena: tooth (UU MAA 7029) in labial (1) and lingual (2) views; tooth (UU MAA 7030) in lingual (3) and anterior (4) views; tooth (UU MAA 7148) in labial (5) and lingual (6) views; tooth (UU MAA 7149) in lingual view (7); tooth (UU MAA 7150) in lingual view (8); tooth (UU MAA 7151) in labial (9) and lingual (10) views; caudal vertebra (UU MAA 7028) in posterior (11) and dorsal (12) views; caudal vertebra (UU MAA 7198) in left lateral (13), dorsal (14), and ventral (15) views; caudal vertebra (UU MAA 7278) in anterior (16) and posterior (17) views. Abbreviations: c, cotyle; pe, pedestal; s, striae.

infolding of dentine lamellae in the pulp cavity), basal striae, and spongy tissue at their tooth bases are all diagnostic traits of Varanoidea (Estes, 1983; Bailon, 1991; Pianka et al., 2004; Augé, 2005; Kearney and Rieppel, 2006). Among varanoids, the basal striae are more developed towards the tip in varanids than in helodermatids and lanthanotids (Kearney and Rieppel, 2006; Georgalis et al., 2017b). In this feature, the specimens from Maramena appear to be more congruent with varanids than helodermatids. Moreover, the presence of precondylar constriction on the vertebrae is consid- ered as a synapomorphy of Varanidae (Bailon, 1991; Smith et al., 2008). Two varanid genera are reported from Europe: Saniwa Leidy, 1870, and Varanus. One of the main features distinguishing them is the presence of a pseudozygosphene in the presacral vertebrae of the former genus (Hoffstetter, 1943; Estes, 1983; Smith et al., 2008). The pseudozygosphene, however, is not present in the caudal vertebrae (Estes, 1983) and therefore this feature cannot be used to discriminate specimens of Saniwa and Varanus when only these bones are considered. Furthermore, vertebrae of Saniwa are 
characterized by a lesser degree of precondylar constriction in comparison to those of Varanus (Smith et al., 2008). Besides, European material assigned to Saniwa is strictly restricted to the Paleogene, and Varanus is the only valid varanoid genus currently known from the European Neogene (Delfino et al., 2013; Georgalis et al., 2017b, 2018b; Ivanov et al., 2018; Villa et al., 2018a). Taking all these into consideration, we herein follow this view in assigning the fossils from Maramena to Varanus.

The Varanus specimens from Maramena show a broad variation regarding the presence or absence of toothserration. In fact, the situation is more complex than just a dichotomy between serrated and unserrated teeth, with a mix of different conditions. The teeth are either completely serrated (i.e., both anteriorly and posteriorly; UU MAA 7030 and UU MAA 7051), either completely unserrated (UU MAA 7148), either serrated anteriorly but not posteriorly (UU MAA 7029), and either serrated posteriorly but not anteriorly (UU MAA 7149 and UU MAA 7150). This variability in the tooth serration can be explained by the following hypotheses:

1) The serration on the fossil teeth of Varanus from Maramena is an intraspecifically variable feature among different individuals or even within different teeth of the same individual, maybe linked with factors such as ontogenetic variation or different developmental stage of the tooth;

2) There are more than one different species / morphotypes in our Maramena fossil sample;

3) Some taphonomic process may have been involved, and the serration was originally present in life in the unserrated teeth as well (or also in the unserrated portions of the one-side onlyserrated ones) but was subsequently lost / eroded at some point during fossilization.

However, all these three hypotheses cannot be fully evaluated for the Maramena dental material. Regarding the first hypothesis about intraspecific variation, it is known that serration in extant varanids occurs only in a few large taxa, e.g., the Komodo Dragon Varanus komodoensis Ouwens, 1912 , though the serration in that species is present in all teeth (Hocknul et al., 2009; GLG, pers. observ. specimen NMP 73735). Some smaller extant varanid species have been reported to have also serration on their teeth, only at their posterior sides though (Farlow et al., 1991). Among extinct forms, serration in varanids is most prominent in the largest terrestrial lizard, the "Megalania" Varanus priscus (Owen, 1859) from the Quaternary of Australia (Fejérváry, 1918, 1935; Hocknul et al., 2009). One of the earliest European members of the genus, Varanus mokrensis Ivanov, Ruta, Klembara, and Böhme, 2017, bears no serration on its teeth (Ivanov et al., 2018). In Greek specimens, absence of tooth serration cannot be evaluated on the lectotype skull (IPUW 1888-001-001) of Varanus marathonensis Weithofer, 1888, from the late Miocene (MN 12) of Pikermi, near Athens, due to the preservation of the specimen (Villa et al., 2018a). Unserrated teeth in V. marathonensis have been, however, demonstrated by the recently published Iberian remains assigned to this species (Villa et al., 2018a). The same applies for the youngest record of varanids from the continent, known from the Middle Pleistocene of Tourkobounia-5, also near Athens (Georgalis et al., 2017b). In fact, among European fossil Varanus, tooth serration is, in general, a rare feature. Judging primarily from the published descriptions and figures, these few European varanids with serrated teeth are known only fromthe middle Miocene (MN 6) of Subpiatră, Romania (Venczel et al., 2005), the middle Miocene (MN 7/8) of Gratkorn, Austria (Böhme and Vasilyan, 2014), the late Miocene (MN 13) of Cava Monticino, Italy (AV, pers. observ.), the early Pliocene (MN 15/16) of Balaruc II, France (Bailon, 1991), and probably also the late Pliocene (MN 16) of Beremend, Hungary (referred to Varanus marathonensis by Fejérváry [1918]) and the late Miocene ( $M N$ 11) of Kohfidisch, Austria (referred to Varanus cf. hofmanni by Tempfer [2005]). The second hypothesis, about higher species diversity, appears strange for European standards, considering that there has almost never been more than one species / morphotype of varanids coexisting in a single Neogene or Quaternary European locality (e.g., Böhme and Vasilyan, 2014; Colombero et al., 2014; Georgalis et al., 2017b, 2018b; Ivanov et al., 2018; Villa et al., 2018a). The only exception is the Greek late Miocene locality of Pikermi, from which two species have been named: Varanus marathonensis and Varanus atticus Nopcsa, 1908. However, these were established on non-overlapping material (the former on skull elements [Weithofer, 1888], the latter on a single vertebra [Nopcsa, 1908]), and therefore, no direct comparison can be made, although generally they are still treated as synonyms (e.g., Fejérváry, 1918; Rage and Sen, 1976; Estes, 1983; Villa et al., 2018a). On the other hand, though, the abundance of multitaxic extant varanid assemblages in Australia, Asia, and Africa (Pianka et al., 2004), with as much as 10 species co-occurring sympatrically at certain regions (e.g., Kimberley region in Western Australia; D’Amore et al., 2018), leaves 
open the possibility that more than one species of monitor lizards could have indeed existed in Maramena. The third hypothesis, about taphonomical transformation of the fossils, cannot be fully confirmed or discarded; there are signs of erosion in some of the teeth, also at the serrated portions. This case is mostly apparent in the specimen UU MAA 7029, the only tooth that is serrated anteriorly but not posteriorly, where signs of erosion are visible along both anterior and posterior keels. As such, we cannot be certain whether all the non-serrated portions correspond to some degree of erosion, but we do not consider this as highly plausible, at least for the rest of the teeth other than UU MAA 7029. Taking all the above into consideration and in the absence of other, more taxonomically significant elements (i.e., maxillae, or even dentaries, with more complete dentition), we cannot clearly state whether the four different types of serration in the Maramena varanid assemblage reflect taxonomic diversity or are simply subjected to intraspecific variation. Therefore, for the moment we can only confirm that Maramena was inhabited by at least one species of Varanus.

Anguimorpha indet.

Material. M1: a dentary (UU MAA 7353).

Description. Specimen UU MAA 7353 is a small and rather poorly preserved fragment of dentary. Teeth are not preserved but they were sub-pleurodont in life. A well-developed subdental shelf is visible medially, with no subdental ridge on it.

Remarks. The presence of a subdental shelf devoid of subdental ridge is a distinctive feature of anguimorph lizards (Evans, 2008). A more precise identification of this dentary is impossible because of its poor preservation.

\section{(non-snake) Squamata indet.}

Material. M1: a premaxilla (UU MAA 7093), eight maxillae (UU MAA 7342, UU MAA 7355, UU MAA 7356, UU MAA 7360, and UU MAA 7428), six dentaries (UU MAA 7103, UU MAA 7105, and UU MAA 7427), 14 fragments of tooth bearing bones (UU MAA 7102, UU MAA 7311, UU MAA 7354, UU MAA 7393, UU MAA 7405, and UU MAA 7406), three axes (UU MAA 7346 and UU MAA 7378), three post-axial cervical vertebrae (UU MAA 7322, UU MAA 7348, and UU MAA 7789), 13 trunk vertebrae (UU MAA 7110, UU MAA 7345, UU MAA 7382-UU MAA 7384, UU MAA 7421), two cloacal vertebrae (UU MAA 7380 and UU MAA 7381), eight caudal vertebrae (UU MAA 7347, UU MAA 7385-UU MAA 7387, and UU MAA 7390), a fragment of caudal vertebra (UU MAA 7310), 11 ribs
(UU MAA 7111 and UU MAA 7419), seven humeri (UU MAA 7309 and UU MAA 7352), two pelvic girdles (UU MAA 7349 and UU MAA 7376), 14 femurs (UU MAA 7109, UU MAA 7308, UU MAA 7351, UU MAA 7377, and UU MAA 7420), and a tibia (UU MAA 7350); M2: a fragment of a presacral vertebra (UU MAA 7299) and a caudal vertebra (UU MAA 7300); M3: a fragment of tooth bearing bone (UU MAA 7339) and a caudal vertebra (UU MAA 7221).

Description and remarks. All these remains are either rather fragmentary or lack significant diagnostic features. They can be therefore identified only as indeterminate lizards (i.e., non-snake squamates).

\section{SERPENTES Linnaeus, 1758 \\ SCOLECOPHIDIA Duméril and Bibron, 1844 Scolecophidia indet. \\ Figure 21}

Material. M1: three trunk vertebrae (UU MAA 7373-UU MAA 7375).

Description. All three vertebrae are small with centrum lengths between 1.2 and $1.6 \mathrm{~mm}$ (Figure 21). Specimen UU MAA 7374 is the most complete among the three vertebrae, missing only the left prezygapophysis and part of the left lateral lobe of the zygosphene (Figure 21.7-12). The vertebrae are rather dorsoventrally compressed. No neural spine is present. In anterior view, the zygosphene is either almost straight (UU MAA 7375) or slightly arched (UU MAA 7373 and UU MAA 7374) and the prezygapophyses are only slightly dorsolaterally tilted. The neural canal is rather large, having a greater height than that of the cotyle, and being much wider above the level of the cotyle, than below the level of the zygosphene. Cotyle is elliptical in anterior view and the synapophyses form a single articular surface, and they are prominent, hemisphaerical-shaped, and appear to extend well beyond the vertebral centrum. No paracotylar foramina are present. In posterior view, the neural arch appears to be almost straight or only slightly curved, but this cannot be verified in UU MAA 7373 where the posterior part of the vertebra is not preserved. The zygantrum is completely preserved only in UU MAA 7375 (Figure 21.14), it is incomplete in UU MAA 7374 (Figure 21.8), whereas it is totally damaged in UU MAA 7373 (Figure 21.2). The condyle is elliptical, projective after a distinctive condylar neck, and is smaller than the cotyle in all three specimens. In lateral view, a lateral foramen is present, being rather large and deep especially in UU MAA 7373 (Figure 21.3) and UU MAA 7375 (Figure 21.15). In ventral view, the postzyga- 

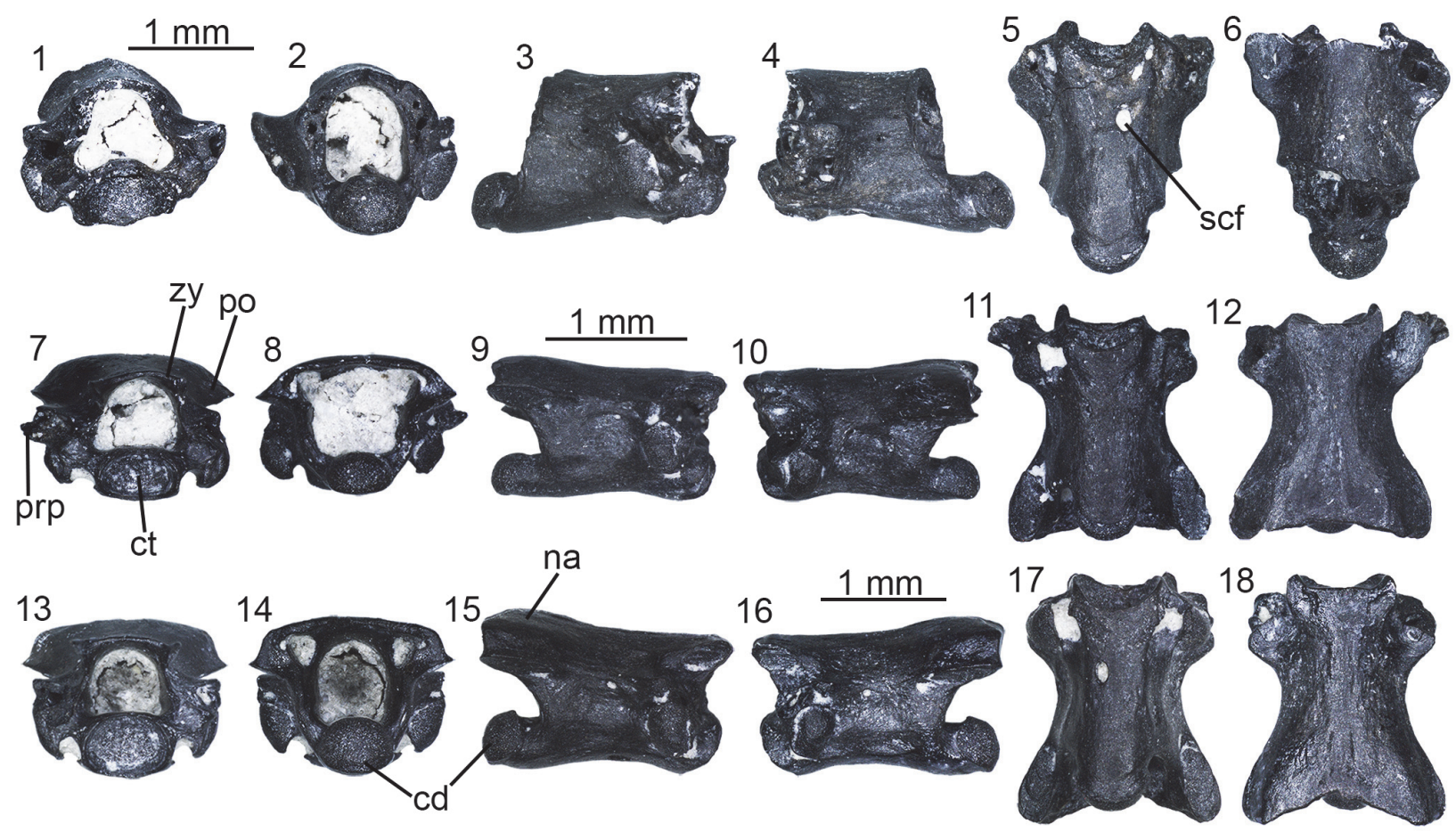

FIGURE 21. Scolecophidia indet. from Maramena: trunk vertebra (UU MAA 7373) in anterior (1), posterior (2), right lateral (3), left lateral (4), ventral (5), and dorsal (6) views; trunk vertebra (UU MAA 7374) in anterior (7), posterior (8), right lateral (9), left lateral (10), ventral (11), and dorsal (12) views; trunk vertrebra (UU MAA 7375) in anterior (13), posterior (14), right lateral (15), left lateral (16), ventral (17), and dorsal (18) views. Abbreviations: cd, condyle; ct, cotyle; nac, neural arch; po, postzygapophysis; prp, prezygapophyseal accessory process; scf, subcentral foramen; zy, zygosphene.

pophyses are significantly enlarged and they extend laterally well beyond the posterior part of the centrum and posteriorly much beyond the tip of the condyle (these structures are not preserved in UU MAA 7373). The surface of the centrum is relatively flattened, though ventral foramina are present, being especially large in UU MAA 7373 (Figure 21.5) and UU MAA 7375 (Figure 21.17). There are no subcentral ridges, haemal keel and/or hypapophysis. Distinct subcentral grooves are present only in UU MAA 7375 (Figure 21.17). In dorsal view, the zygosphene is rather concave and bears two distinct lateral lobes in UU MAA 7374 (Figure 21.12) and UU MAA 7375 (Figure 21.18), but it is not preserved in UU MAA 7373. The right prezygapophysis of UU MAA 7374 is oriented laterally at an angle of around $40^{\circ}$ (Figure 21.12). The prezygapophyses are much damaged in the other two specimens. Prezygapophyseal accessory processes are present in UU MAA 7374 (Figure 21.12).

Remarks. These three specimens from Maramena can be referred to Scolecophidia on the basis of rather small vertebral size, dorsoventrally depressed vertebrae, absence of neural spine, absence of hypapophysis and haemal keel, synapophyses forming a single articular surface without a clear distinction between diapophyses and parapophyses, absence of paracotylar foramina, and both cotyle and condyle being flattened dorsoventrally (characters from Rage, 1984 and Szyndlar, 1991a). Moreover, their absolute size, the shape of the neural canal, and, most importantly, the absence of a hypapophysis denote an origin of UU MAA 7373 and UU MAA 7374 from the midtrunk portion of the skeletal column, whereas the presence of distinct deep subcentral grooves in UU MAA 7375 denotes that it probably originated from the posterior trunk region. The new Maramena scolecophidian can be differentiated from the extant Xerotyphlops vermicularis (Merrem, 1820), but also from all other published fossil scolecophidians (including the sole known European extinct species, "Typhlops" grivensis Hoffstetter, 1946, from the middle Miocene of France), by the rather long and enlarged postzygapophyses that extend well beyond the condyle, the robust synapophyses, the prominent and deep zygantrum, the curvature 
of the prezygapophysis, and different angle between the tips of prezygapophyses and postzygapophyses. However, due to the uniform morphology of scolecophidian vertebrae and the current absence of any diagnostic characters in their postcranial skeleton, it is not possible to evaluate the taxonomic significance of the above mentioned features. As such, it is not easy to identify more accurately the Maramena material, even to the family level (Georgalis et al., 2017a). Such identification is further complicated by the fact that two distinct families of scolecophidians, typhlopids and leptotyphlopids, occur in the modern herpetofauna of the northeastern Mediterranean region (Sindaco and Jeremčenko, 2008; Adalsteinsson et al., 2009), even though only the former clade currently inhabits Greece, represented by Xerotyphlops vermicularis (Valakos et al., 2008; Kornilios, 2017). The recently published scolecophidian from the late Miocene (MN 13) of the nearby locality of Ano Metochi (Georgalis et al., 2017a) strongly resembles the Maramena form in having large postzygapophyses. Accordingly, and following also a geographic and stratigraphic rationale, the two scolecophidians from Ano Metochi and Maramena are probably conspecific.

\section{ALETHINOPHIDIA Nopcsa, 1923 \\ CAENOPHIDIA Hoffstetter, 1939 COLUBRIDAE Oppel, 1811 \\ "COLUBRINAE" Oppel, 1811 (sensu Szyndlar, 1991a)}

Remarks. The presence or absence of a hypapophysis in the mid-trunk and posterior trunk vertebrae has been considered as the most significant character in distinguishing "colubrine" from natricine snakes (Rage, 1984; Szyndlar, 1984, 1991a, b). However, it is known that partial or even total absence of hypapophyses in the mid-trunk and posterior trunk vertebrae is in fact a more widespread feature within snakes. Besides "colubrines", it also occurs in various elapoids (e.g., psammophiids) and dipsadids (Pyron et al., 2013; Head et al., 2016), whereas at least one natricine taxon without hypapophyses on the posterior trunk vertebrae has been documented (Malnate, 1972; Ikeda, 2007; McCartney et al., 2014). Therefore, caution should be taken into consideration when dealing with such taxonomic assignements and the name "Colubrinae" should be more safely placed in quotation marks (e.g., Szyndlar, 2012). Apart from the absence of hypapophyses in the mid-trunk and posterior trunk vertebrae, the following other features have been suggested to characterize "Colubrinae": lightly built morphology, presence of haemal keel, synapophyses clearly divided into diapophyses and parapophyses, presence of lateral foramina, straight interzygapophyseal ridges, and straight subcentral ridges (Szyndlar, 1991a).

Genus PERIERGOPHIS gen. nov.

zoobank.org/56B6CEC0-CC70-4880-BBAC-4CE805BCD746

Type species. Periergophis micros gen. et sp. nov. (by monotypy).

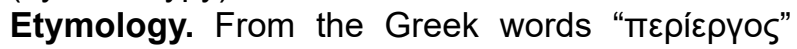
("periergos"), meaning "strange", "bizarre", "curious", in reference to the strange features observed in the vertebrae of this genus, and in particular the anteroventrally directed haemal keel tubercles on the posterior trunk vertebrae, and "öழıऽ" ("ophis"), meaning "snake".

Gender. Gender of the genus Periergophis is masculine.

Diagnosis. As for type and only known species.

Periergophis micros gen. et sp. nov.

Figures 22, 23, 24, 25, 26

zoobank.org/66C2F8A3-9542-4F20-80AD-F584C4A3A7F8

Holotype. Specimen UU MAA 7615 (a posterior trunk vertebra) (Figures 22 and 24.1-2). The holotype originates from M1 site.

Paratypes. Specimen UU MAA 7551 (a cervical vertebra) (Figure 23.1-2); UU MAA 7614 (a midtrunk vertebra) (Figure 23.3-8); UU MAA 7618 (a cloacal vertebra) (Figure 23.9-12); UU MAA 7636 (a caudal vertebra) (Figures 23.13-16, 24.3). All paratypes originate from M1 site.

Type locality. Maramena 1 site, Maramena locality (latest Miocene or earliest Pliocene [MN 13/14]), Central Macedonia, Greece.

Referred material. M1: a cervical vertebra (UU MAA 7552), 113 trunk vertebrae (UU MAA 7553UU MAA 7613, UU MAA 7616, UU MAA 7617, UU MAA 7762, UU MAA 7769, UU MAA 7780, UU MAA 7784, UU MAA 7785, UU MAA 7787, UU MAA 7790, UU MAA 7792, UU MAA 7799, UU MAA 7820, UU MAA 7821, UU MAA 7826, UU MAA 7835, UU MAA 7839, UU MAA 7841, UU MAA 7842, UU MAA 7845, UU MAA 7848-UU MAA 7850, UU MAA 7862, UU MAA 7872, UU MAA 7874, UU MAA 7875, UU MAA 7880, UU MAA 7884, UU MAA 7887, UU MAA 7888, UU MAA 7890, UU MAA 7894, UU MAA 7896, UU MAA 7899, UU MAA 7903, UU MAA 7905, UU MAA 7911, UU MAA 7912, UU MAA 7916, UU MAA 7918, UU MAA 7922, UU MAA 7924, UU MAA 7926, UU MAA 7929, UU MAA 7937, UU MAA 7940, UU MAA 7951, UU MAA 7952, UU MAA 7955, UU MAA 7958, UU MAA 7963, and probably also UU MAA 7112), three cloacal verte- 


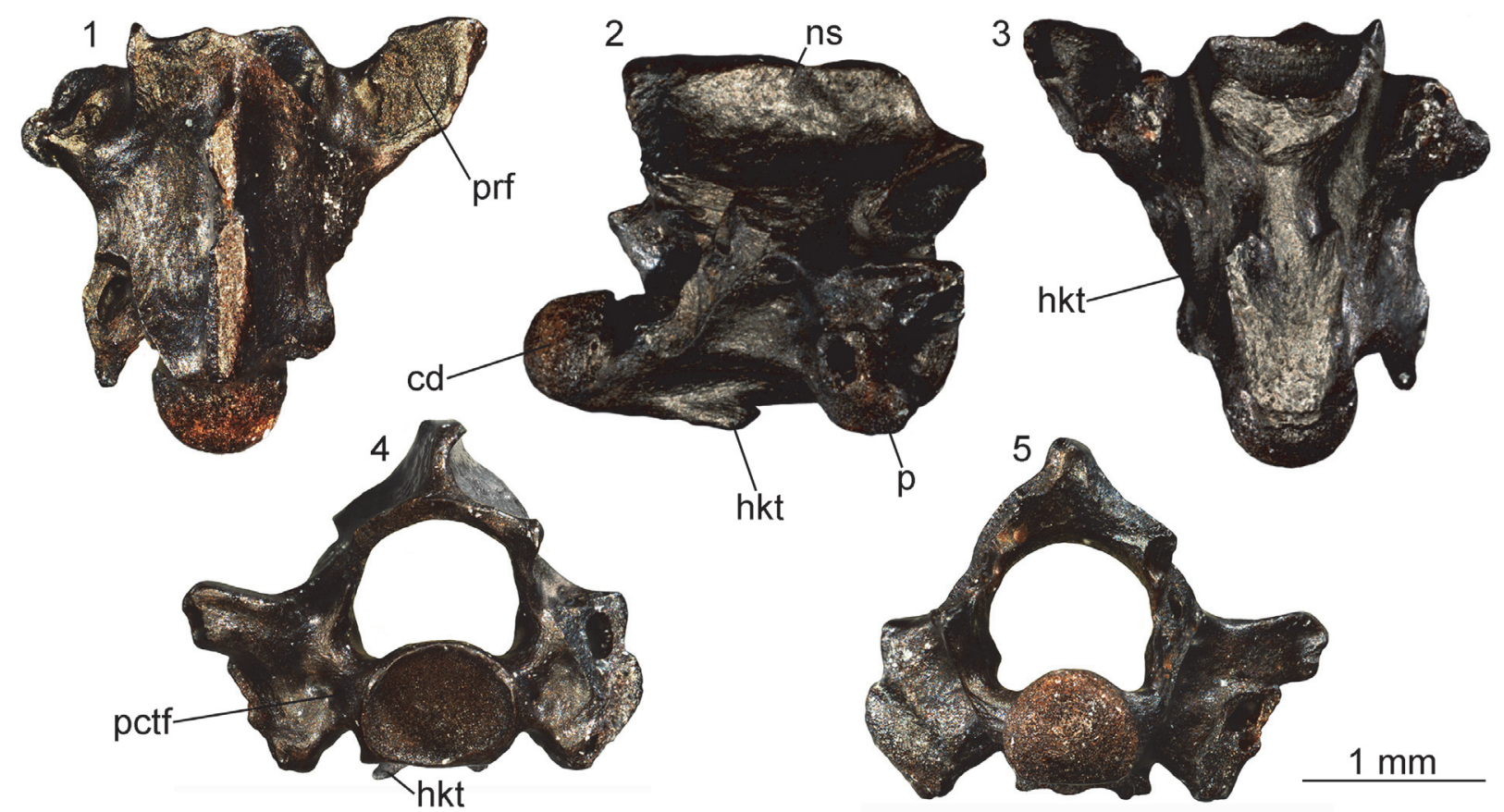

FIGURE 22. Periergophis micros gen. et sp. nov. from Maramena: holotype posterior trunk vertebra (UU MAA 7615) in dorsal (1), right lateral (2), ventral (3), anterior (4), and posterior (5) views. Abbreviations: cd, condyle; hkt, haemal keel tubercles; ns, neural spine; p, parapophysis; pctf, paracotylar foramina; prf, prezygapophyseal articular facet.

brae (UU MAA 7619, UU MAA 7797, and UU MAA 7822), and 25 caudal vertebrae (UU MAA 7620-UU MAA 7635, UU MAA 7637, UU MAA 7779, UU MAA 7827, UU MAA 7907, UU MAA 7915, UU MAA 7921, UU MAA 7928, and UU MAA 7936, and UU MAA 7950); M3: a posterior trunk vertebra (UU MAA 7740).

Distribution and age. Known only from the type locality, Maramena, Central Macedonia, Greece. More specifically, holotype and all paratypes originate from M1 site; nevertheless, the referred material originates from two different sites (M1 and M3) within the locality, even though M3 has yielded only a single vertebra. $\mathrm{M} 1$ and $\mathrm{M} 3$ sites are coeval, having a latest Miocene (MN 13) or earliest Pliocene (MN 14) age, with the latest Miocene being the most probable.

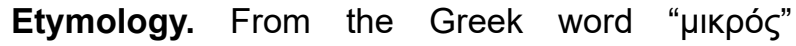
("mikros"), meaning "small", "tiny", in reference to the rather small vertebral size of this snake species.

Descriptive diagnosis. Periergophis micros gen. et sp. nov. can be differentiated from all other "colubrine" taxa, on the basis of one autapomorphy (distinct paired anteroventrally directed tubercles or short processes developed on the wide haemal keel of posterior middle and posterior trunk vertebrae and haemapophyseal tubercles separated from the remaining part of haemapophyses in caudal vertebrae, at least in a portion of the caudal series) and the following combination of characters: 1) posteriorly inclined anterior margin of the neural spine observed in trunk, cloacal, and caudal vertebrae; 2) unusually deep lateral depressions with large lateral foramina developed between the interzygapophyseal and subcentral ridges; 3)parapophyses being twice as long as the diapophyses; 4) rather wide haemal keel in trunk vertebrae, with a constriction present behind the level of the synapophyses; 5) slightly dorsally vaulted zygosphene, with wide medial and more distinct lateral lobes; 6 ) rather depressed neural arch of the midtrunk vertebrae in posterior view; and 7) small size (centrum length of the largest vertebrae not exceeding the $2 \mathrm{~mm}$ ) and rather lightly-built overall structure.

Description of the holotype. The holotype posterior trunk vertebra (UU MAA 7615) is incomplete, missing its left prezygapophysis and large portions of the postzygapophyses (Figure 22). The vertebra is small, with a centrum length of $2 \mathrm{~mm}$. In lateral view (Figures 22.2, 24.1), the neural spine is longer than high; its dorsal margin is straight and its anterior and posterior margins are posteriorly inclined. Deep lateral depressions with large lateral foramina are developed between the interzygapophyseal 

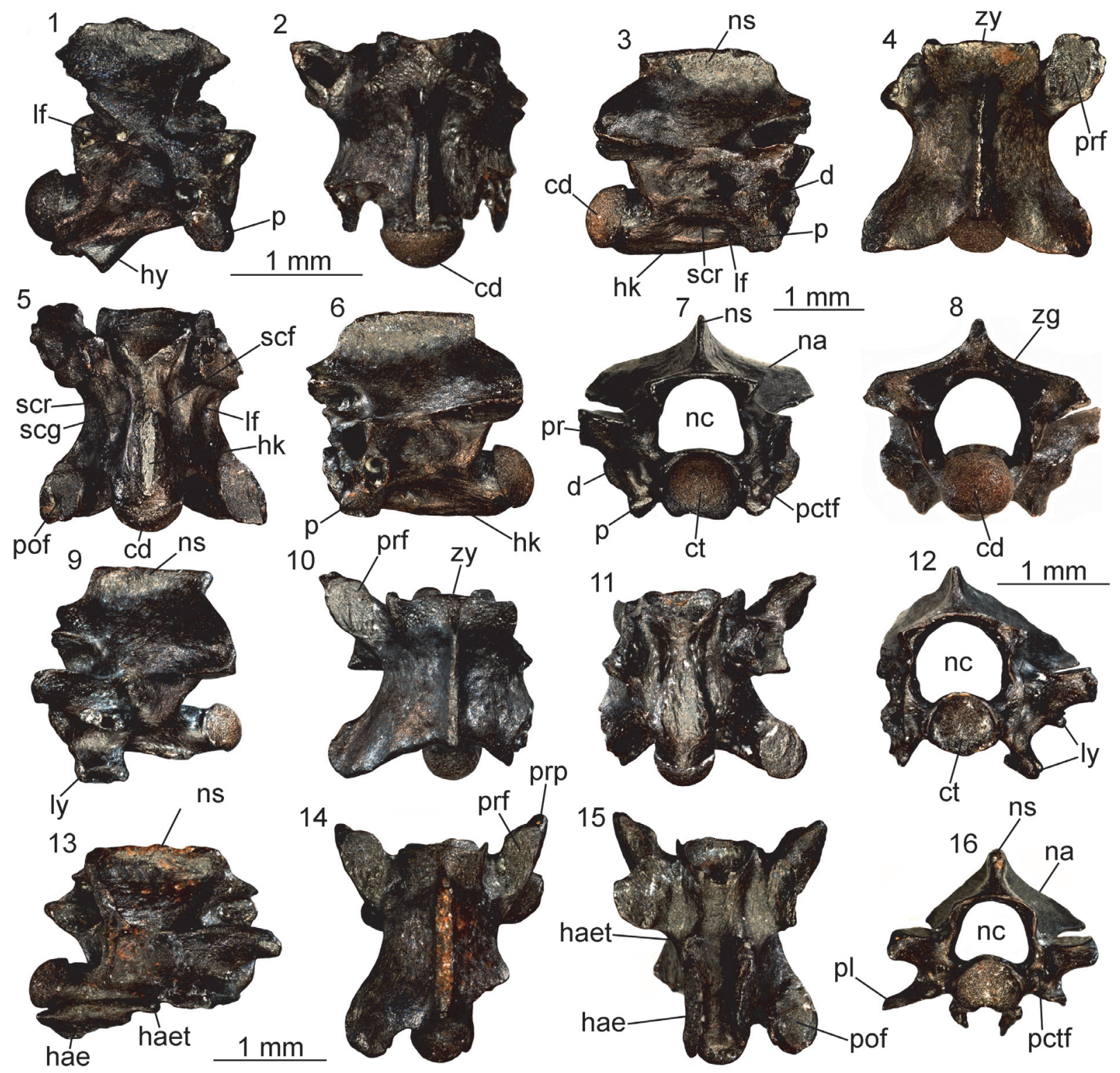

FIGURE 23. Periergophis micros gen. et sp. nov. from Maramena, paratypes: cervical vertebra (UU MAA 7551) in right lateral (1) and ventral (2) views; paratype mid-trunk vertebra (UU MAA 7614) in right lateral (3), dorsal (4), ventral (5), left lateral (6), anterior (7), and posterior (8) views; paratype cloacal vertebra (UU MAA 7618) in left lateral (9), dorsal (10), ventral (11), and anterior (12) views; paratype caudal vertebra (UU MAA 7636) in right lateral (13), dorsal (14), ventral (15), and anterior (16) views. Abbreviations: cd, condyle; ct, cotyle; d, diapophysis; hae, haemapophysis; haet, haemapophyseal tubercles; hy, hypapophysis; If, lateral foramen; ly,lymphapophysis; na, neural arch; nc, neural canal; ns, neural spine; p, parapophysis; pctf, paracotylar foramen; pl, pleurapophysis; pof, postzygapophyseal articular facet; pr, prezygapophysis; prf, prezygapophyseal articular facet; prp, prezygapophyseal accessory process; scf, subcentral foramen; scg, subcentral groove; scr, subcentral ridge; zg, zygantrum; zy, zygosphene.

and subcentral ridges. A condylar neck is present. Distinct anteroventrally directed haemal keel tubercles are present; they become enlarged, while going further from their bases, but their anteriormost parts are pointed. In dorsal view (Figure 22.1), the zygosphenal lip has developed distinct and pointed lateral lobes and a rather wide (almost bilobed) medial lobe. The prezygapophyseal articular facets (only the right is fully preserved) are suboval. The prezygapophyseal accessory process is eroded and not visible. The rather thin neural spine rises in the posterior part of the zygosphene. In ventral view (Figures 22.3, 24.2), a prominent and rather wide haemal keel is present, 
and it becomes even wider towards its posterior termination. The ventral surface of the haemal keel is flattened. There is a distinct constriction of the haemal keel, close behind the level of the synapophyses. Distinct, paired anteroventrally directed haemal keel tubercles (or short processes) are developed onto each of the lateral margins of the haemal keel. The synapophyses are divided into diapophyses and parapophyses, with the latter being twice as long as the former. The subcentral ridges are distinct and rather sharp. In anterior view (Figure 22.4), the zygosphene is thin, convex, and its edges are vaulted dorsally. The zygosphene is wider than the cotyle. The neural canal bears rather large lateral sinuses. The slightly dorsally tilted prezygapophyseal articular facets occur far above the dorsal margin of the cotylar rim at the level of the dorsal termination of lateral sinuses. Paracotylar foramina are present and large (especially the right one) and they occur within deep depressions on either side of the dorsoventrally flattened cotyle. The parapophyses and the anteroventrally directed tubercles of the haemal keel extend below the ventral level of the cotyle. In posterior view (Figure 22.5), the neural arch is moderately vaulted. The postzygapophyses are slightly tilted up dorsally. The condyle is depressed with a relatively straight ventral level.

Description of paratypes and referred specimens - intracolumnar variation. Cervical vertebrae (Figures 23.1-2, 25.1-4): both preserved cervical vertebrae (paratype UU MAA 7551 and referred specimen UU MAA 7552) are incomplete, with broken-off zygosphene, hypapophysis, damaged zygapophyses, and neural spines. In lateral view (Figures 23.1, 25.1), the neural spine was probably as high as long with its posterior margin vertical or slightly inclined posteriorly. The anterior margin of the neural spine is missing in both specimens. Large lateral foramina occur close to the dorsal margin of a large and deep depression, just below the short interzygapophyseal ridges. The synapophyses are eroded. The diapophyses were most probably anteroposteriorly short; the parapophyses are narrow horizontally but rather elongated vertically. The dorsally vaulted distinct subcentral ridges are short and reach about the half of the centrum length. The preserved base of the hypapophysis in the two vertebrae indicates that this element was directed posteroventrally, with its anterior keel being rather flat. In dorsal view, the only preserved right prezygapophyseal articular facet of UU MAA 7552 is rather large and, most probably, had a wide subrectangular or ellipti-

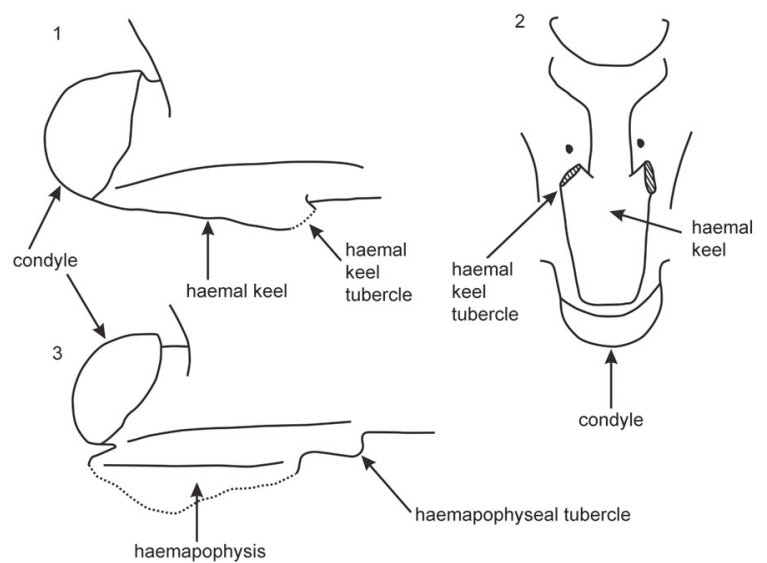

FIGURE 24. Explanatory drawings of the haemal keel tubercles and the haemapophyseal keel tubercles in posterior trunk and caudal vertebrae of Periergophis micros gen. et sp. nov. Holotype posterior trunk vertebra UU MAA 7615 in right lateral (1) and ventral (2) views; paratype caudal vertebra UU MAA 7636 in right lateral view (3).

cal outline (Figure 25.2). In ventral view (Figures 23.2, 25.3), small subcotylar tubercles occur at the base of the cotylar rim. The subcentral grooves are wide and short, developed only in the anterior part of the centrum. In anterior view (Figure 25.4), the neural canal is almost rounded, with wide lateral sinuses. The preserved right prezygapophyseal articular facet of UU MAA 7552 is situated well above the dorsal margin of the cotylar rim, just at the level of the dorsal margin of the right lateral sinus. Paracotylar foramina are present and situated within depressions at both sides of the rounded cotyle with flatten base.

Mid-trunk vertebrae (Figures 23.3-8, 25.5-6, 26.17): the best preserved mid-trunk vertebra is the paratype UU MAA 7614, missing its left prezygapophysis and right prezygapophyseal accessory process (Figure 23.3-8). In lateral view (Figure $23.3,23.6)$, the neural spine is about three times longer than high. Its dorsal margin is almost straight, with its anterodorsal edge rounded. The posterior margin of the neural spine was most probably almost vertical. The zygosphenal facets are narrow. The sharp interzygapophyseal ridges are short. Rather large lateral foramina occur close below the interzygapophyseal ridges, in the vicinity of the dorsal margin of the wide depressions developed behind the synapophyses. These depressions are developed between the interzygapophyseal and the subcentral ridges. The straight and short subcentral ridges are moderately developed. In the completely preserved right syn- 


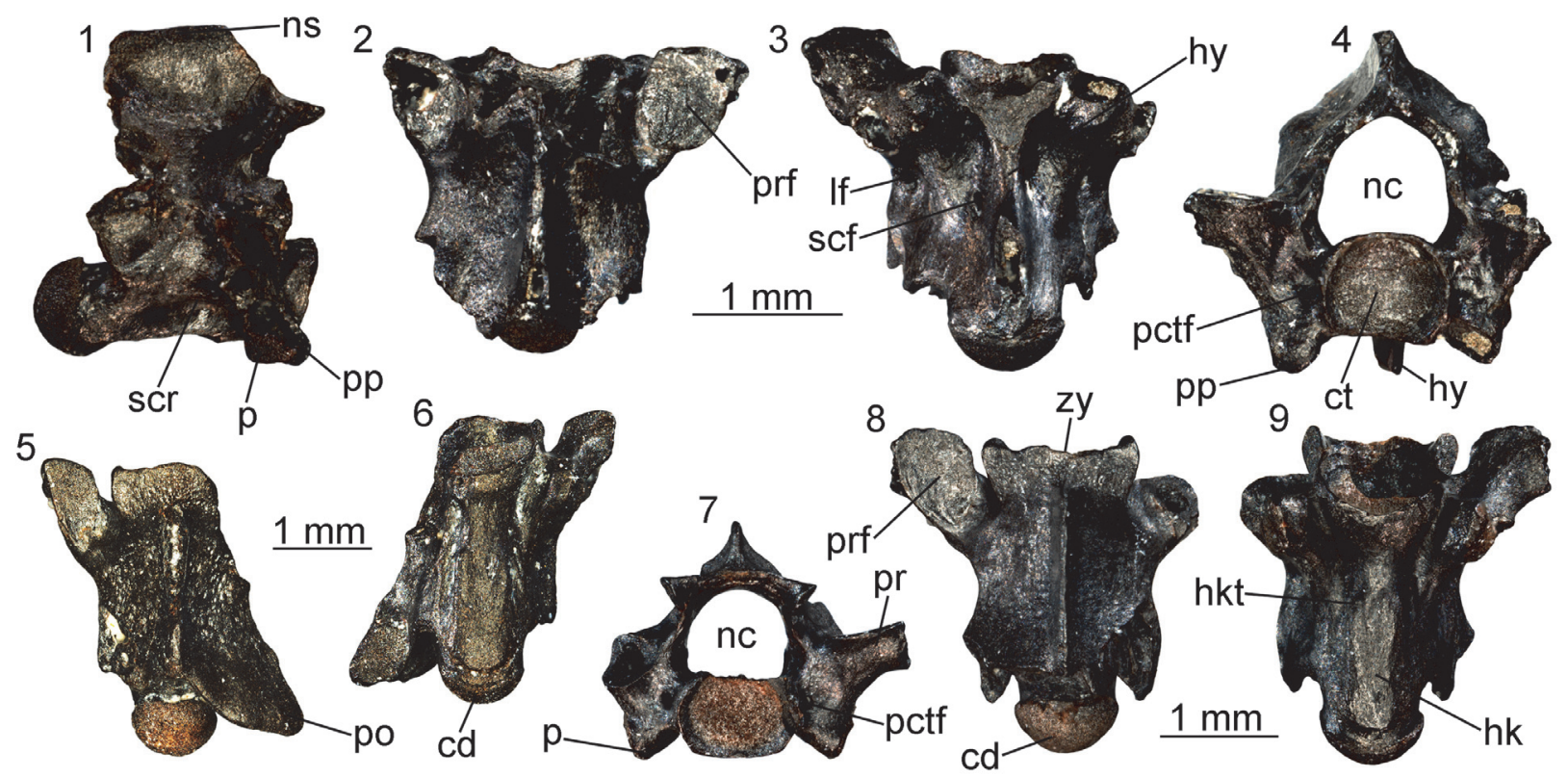

FIGURE 25. Periergophis micros gen. et sp. nov. from Maramena, referred specimens: cervical vertebra (UU MAA 7552) in right lateral (1), dorsal (2), ventral (3), and anterior (4) views;mid-trunk vertebra (UU MAA 7740) in dorsal (5) and ventral (6) views; posterior trunk vertebra (UU MAA 7616) in anterior (7), dorsal (8), and ventral (9) views. Abbreviations: cd, condyle; ct, cotyle; hk, haemal keel; hkt, haemal keel tubercle; hy, hypapophysis; If, lateral foramen; nc, neural canal; ns, neural spine; p, parapophysis; pctf, paracotylar foramen; po, postzygapophysis; pp, parapophyseal process; pr, prezygapophysis; prf, prezygapophyseal articular facet; scf, subcentral foramen; scr, subcentral ridge; zy, zygosphene.

apophysis, the parapophysis is about twice as long as the short diapophysis. In dorsal view (Figure 23.4), the zygosphenal lip has developed small and pointed lateral lobes and a moderately developed, wide medial lobe. The preserved right prezygapophyseal articular facet is suboval to subtriangular. The rather thin neural spine rises in the posterior half of the zygosphene length. The epizygapophyseal spines are moderately developed. In ventral view (Figure 23.5), the haemal keel is prominent and rather wide, with a constriction situated anteriorly close behind the synapophyses. The ventral surface of the haemal keel is slightly flattened. Small subcentral foramina occur at the base of the haemal keel. The slightly damaged postzygapophyseal articular facets are rectangular. In anterior view (Figure 23.7), the zygosphene is wider than the cotyle. The thin zygosphenal lip is slightly vaulted dorsally. The neural canal is rounded, with large lateral sinuses. The prezygapophyses are situated far above the dorsal margin of the cotylar rim, at the level of the dorsal termination of lateral sinuses. Large paracotylar foramina occur within deep depressions on either side of the cotyle. The ventral rim of the cotyle is partially damaged. In posterior view (Figure 23.8), the neural arch is moderately vaulted or almost flat- tened. The postzygapophyses are tilted dorsally. The condyle is slightly depressed with a flat ventral surface.The morphology of the other referred midtrunk vertebrae corresponds to that of the paratype UU MAA 7614, though none is as complete (Figures 25.5-6, 26.1-7). A general trend is that in the mid-trunk vertebrae, the haemal keel tubercles are not present, however, they slightly develop in posterior mid-trunk vertebrae, first appearing on each side of the haemal keel in the form of longitudinal carinae (e.g., Figure 26.7), culminating in size in the posterior trunk ones (see below).

Posterior trunk vertebrae: they are rather similar to the holotype UU MAA 7615. The subcentral ridges of the posterior trunk vertebrae are more distinct and rather sharp in comparison with those of the mid-trunk ones (Figures 25.7-9, 26.8-16). The most peculiar characteristic of the posterior trunk vertebrae is the presence of a pair of distinct anteroventrally directed tubercles or short processes (i.e., haemal keel tubercles) developed along the lateral sides of the haemal keel. These haemal keel tubercles slightly appear first in the posterior mid-trunk vertebrae and they gradually increase in size towards the posterior trunk region. The shape of the prezygapophyseal articular facets varies from suboval to subtriangular. When preserved, the pre- 

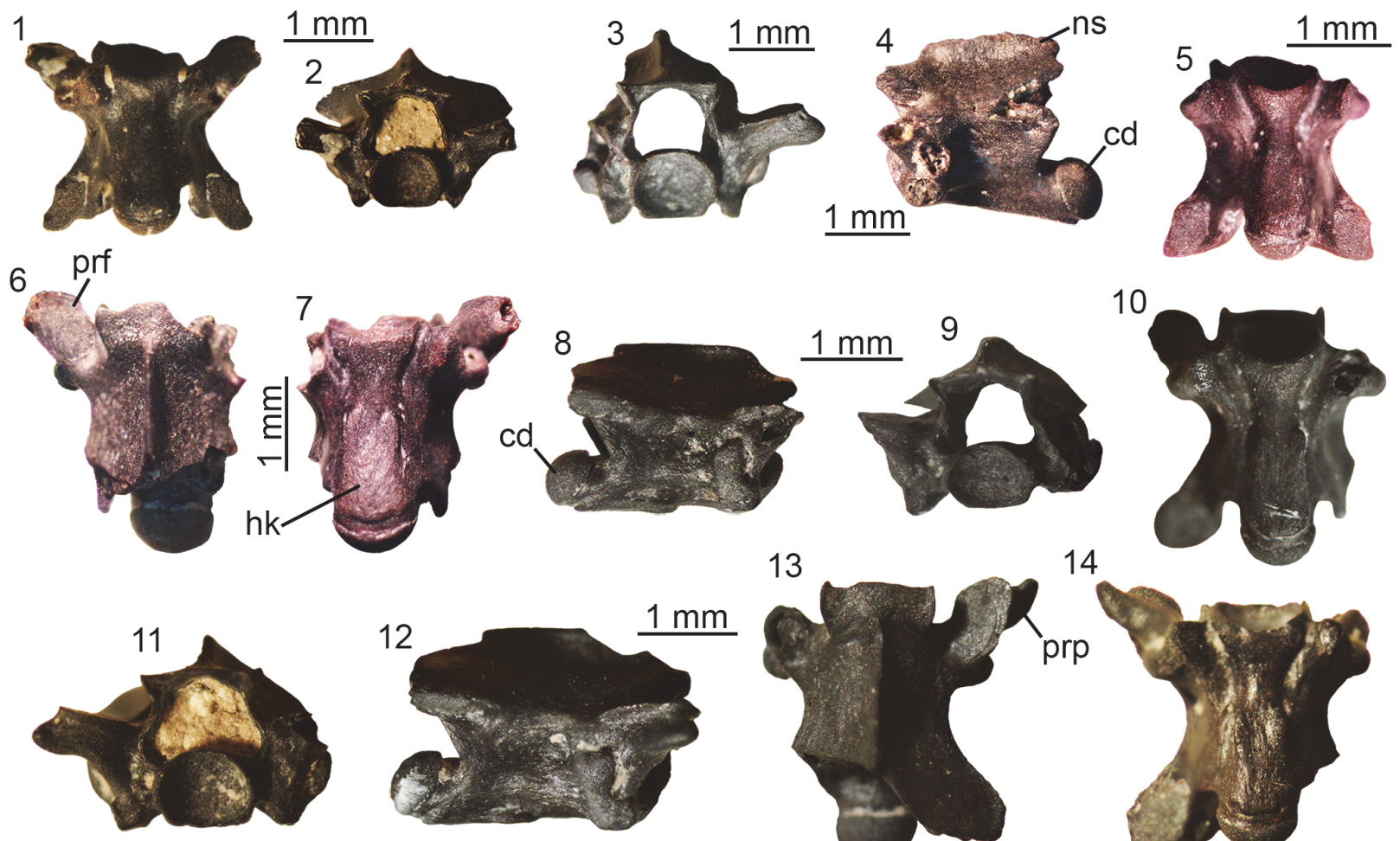

13

14
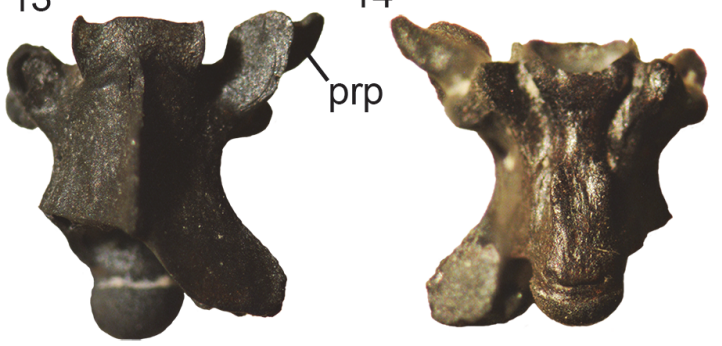

15
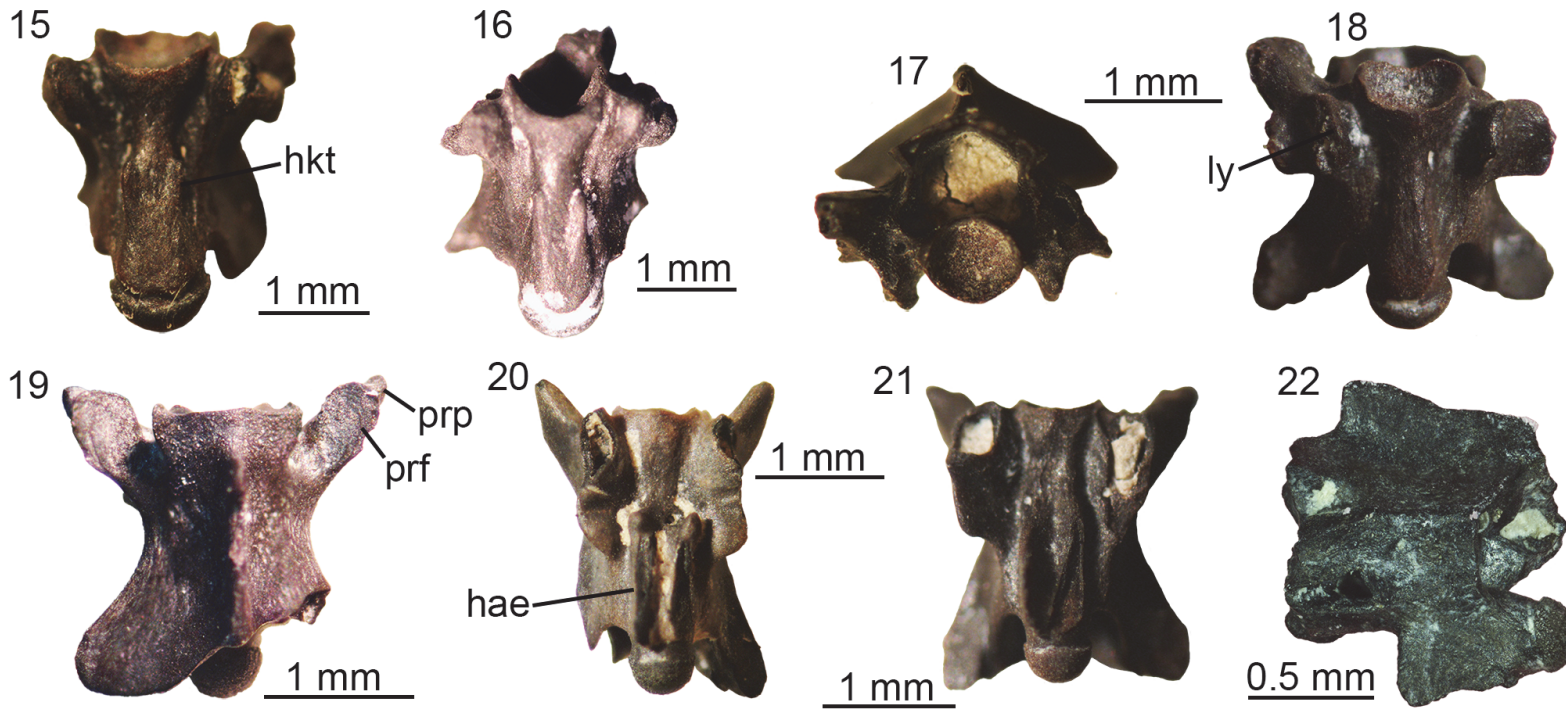

FIGURE 26. Periergophis micros gen. et sp. nov. from Maramena, referred specimens: mid-trunk vertebra (UU MAA 7820 ) in ventral (1) and anterior (2) views; mid-trunk vertebra (UU MAA 7848) in anterior (3) view; mid-trunk vertebra (UU MAA 7903) in left lateral view (4); mid-trunk vertebra (UU MAA 7890) in ventral view (5); mid-trunk vertebra (UU MAA 7922) in dorsal (6) and ventral (7) views; posterior trunk vertebra (UU MAA 7790) in right lateral (8), anterior (9), and ventral (10) views; posterior trunk vertebra (UU MAA 7780) in anterior (11), right lateral (12), dorsal (13), and ventral (14) views; posterior trunk vertebra (UU MAA 7839) in ventral view (15); posterior trunk vertebra (UU MAA 7894) in ventral view (16); cloacal vertebra (UU MAA 7797) in anterior (17) and ventral (18) views; caudal vertebra (UU MAA 7907) in dorsal view (19); caudal vertebra (UU MAA 7779) in ventral view (20); caudal vertebra (UU MAA 7827) in ventral view (21); caudal vertebra (UU MAA 7921) in left lateral view (22). Abbreviations: cd, condyle; hae, haemapophysis; hk, haemal keel; hkt, haemal keel tubercle; ly, lymphapophysis; ns, neural spine; prf, prezygapophyseal articular facet; prp, prezygapophyseal accessory process. 
zygapophyseal accessory processes are relatively pointed, bear a distinct crest on their dorsal surface, and reach about the half of the prezygapophyseal articular facets' length (Figure 26.13-14). The epizygapophyseal spines are moderately developed or absent. The ventral surface of the haemal keel is rounded in anterior mid-trunk vertebrae, whereas in the posterior trunk ones, it becomes flat. When preserved, the postzygapophyseal articular facets are rectangular.

Cloacal vertebrae (Figures 23.9-12, 26.17-18): the four preserved vertebrae (paratype UU MAA 7618 and referred specimens UU MAA 7619, UU MAA 7797, and UU MAA 7822) are partially incomplete, with lymphapophyses broken off close to their bases (with the exception of UU MAA 7797, where the latter structures are relatively much more complete [Figure 26.17-18]). In lateral view, the only preserved complete neural spine (paratype UU MAA 7618) is three times as long as high, with both its anterior and posterior dorsal margins inclined posteriorly (Figure 23.9). Small lateral foramina occur just below the short interzygapophyseal ridges, situated at the dorsal margin of the deep depressions. These depressions are developed close behind the bases of the lymphapophyses. The condyle is developed on a long condylar neck. In dorsal view (Figure 23.10), all cloacal vertebrae are rather short and wide. The zygosphene is wide, with distinct lateral lobes and wide medial lobe. In the paratype UU MAA 7618, a shallow and wide notch occurs on the anterior margin of the medial lobe. The prezygapophyseal articular facets are oval. The distal tips of the slender prezygapophyseal accessory processes are broken. In ventral view (Figures 23.11, 26.18), the haemapophyses are reduced into the distinct anteroposteriorly enlarged and laterally directed laminae. It seems that the peculiar tubercles that were present in the posterior trunk and anterior caudal vertebrae were rather reduced in the cloacal region of the column. The postzygapophyseal articular facets are subcircular in outline. In anterior view (Figure 23.12), the neural arch is moderately vaulted. The neural spine is relatively thick, being proportionally thicker than those of the preceding trunk vertebrae but thinner that those of the succeeding caudal vertebrae. The neural canal is rounded, with rather short and wide lateral sinuses. The zygosphene is vaulted dorsally. Deep depressions occur on either side of the slightly dorsoventrally depressed cotyle. The paracotylar foramina, which are rather large in the paratype UU MAA 7618 (with the right one doubled), occur within these depressions.
Caudal vertebrae (Figures 23.13-16, 24.3, 26.1921): all preserved caudal vertebrae are incomplete, with pleurapophyses and haemapophyses usually broken off close to their bases. The best preserved caudal vertebra is the paratype UU MAA 7636 (Figure 23.13-16), and we base the description on this specimen. In lateral view (Figure 23.13), the neural spine is rather low (three to four times longer than high), with its anterior margin vertical or slightly posteriorly inclined. Large lateral foramina are situated close below the short interzygapophyseal ridges. In dorsal view (Figure 23.14), the zygosphene has a wide medial lobe and small distinct lateral lobes. The prezygapophyseal articular facets are large and oval. They are elongated anteriorly. The prezygapophyseal accessory processes are short and directed anteriorly rather than anterolaterally. In ventral view (Figure 23.15), the base of the haemapophyses protrudes anteriorly into small but distinct processes or tubercles (here termed "haemapophyseal tubercles"). However, the distal termination of haemapophyses is not preserved. In anterior view (Figure 23.16), the zygosphenal lip is thin and arched. The pleurapophyses (the left is partially damaged) are slightly ventrolaterally inclined, extending beyond the level of the lateral edges of the prezygapophyseal articular facets. Rather deep paracotylar foramina are present on either side of the elliptical cotyle. The neural arch is vaulted and triangular-shaped. The neural spine is relatively thick, being proportionally thicker in comparison with the preceding trunk and cloacal vertebrae. An interesting specimen is UU MAA 7921, which is also the only caudal vertebra where haemapophyses are almost complete (even though only the left one is preserved); in lateral view of UU MAA 7921 (Figure 26.22), the haemapophysis is much thickened along its anterior vertical border, extending much ventrally, whereas it gradually decreases in height along the posterior portion of the centrum. Haemapophyseal tubercles cannot be clearly visible in UU MAA 7921. They seem to be strongly reduced or they are eroded, but an alternative explanation would be that in some portion of the caudal series, the haemapophyseal tubercles are substituted by strongly ventrally exposed anterior thickenings of the haemapophyses.

Remarks. Periergophis micros gen. et sp. nov. is referred to "colubrines" on the basis of the following combination of characters: 1) vertebral centrum being longer than wide; 2 ) the slender structure of all vertebrae, with hypapophyses present only in cervical vertebrae and haemal keel developed in the trunk vertebrae; 3 ) the presence of distinct well- 
developed prezygapophyseal accessory processes; and 4) the presence of paracotylar foramina. Periergophis micros gen. et sp. nov. further differs from all other known "Colubrinae" by the presence of a unique (presumed) autapomorphy, i.e., distinct paired anteroventrally directed tubercles or short processes developed on the wide haemal keel of posterior middle and posterior trunk vertebrae and haemapophyseal tubercles separated from the remaining part of haemapophyses in caudal vertebrae (at least a portion of the caudal series). Indeed, these strange features on the posterior trunk and caudal vertebrae seem to be unique, not only for "colubrines" but for all snakes in general. The functional purposes of these tubercles are unknown. Nevertheless, the presence of such structures in the posterior trunk vertebrae of Periergophis micros gen. et sp. nov. probably denotes a non-fossorial life style for this taxon, as in fossorial snakes (e.g., scolecophidians), the ventral surface of mid-trunk and posterior trunk vertebrae is usually flattened and often devoid of haemal keel (Hoffstetter, 1968). The fact that these structures appear to be symmetrical and seem to follow a pattern of increasing size and acuteness of their orientation tips from the posterior mid-trunk to the posterior trunk vertebrae supports the taxonomic utility of these features and precludes the possibility that they could be attributed to taphonomical processes, preservation, or pathology. As such, we decided to select the incomplete posterior trunk vertebra UU MAA 7615 as the holotype of this new species, instead of the rather more complete mid-trunk vertebra UU MAA 7614, considering that the former specimen clearly demonstrates the presumed autapomorphy and further shares common diagnostic features with the well-preserved latter specimen (posteriorly inclined anterior margin of the neural spine, large parapophyses, deep and wide depressions with large lateral foramina situated behind synapophyses, highly depressed neural arch, and small overall vertebral size and lightly built structure). The genuine nature of the peculiar vertebral structures and morphology of Periergophis micros gen. et sp. nov. is further supported by the fact that it seems to be by far the most abundant snake in the Maramena assemblage (at least 140 specimens known) and is recovered from two different sites (M1 and M3) within the locality.

Furthermore, the other diagnostic traits of Periergophis micros gen. et sp. nov. can differentiate it from all other known extinct and extant "colubrines":
1) Posteriorly inclined anterior margin of the neural spine observed in trunk, cloacal, and caudal vertebrae. This character is unusual in "Colubrinae". Most Eurasian "colubrine" snakes have a neural spine which is inclined anteriorly, e.g., members of the genera Elaphe Fitzinger in Wagler, 1833 (sensu lato). Exceptions include the extinct Elaphe paralongissima Szyndlar, 1984, and the extant Elaphe rudoforsata (Cantor, 1842) (currently placed in its own genus Oocatochus Helfenberger, 2001) where the anterior margin of the neural spine is vertical (see Szyndlar, 1991a; Ratnikov, 2004), Coronella Laurenti, 1768, Hierophis Fitzinger in Bonaparte, 1834, most members of Dolichophis Gistel, 1868, and others as well (Szyndlar, 1991a; Ikeda, 2007). A vertical anterior margin of the neural spine occurs in many North American genera, including Cemophora Cope, 1860, Chionactis Cope, 1860, Drymarchon Fitzinger, 1843, Lampropeltis Fitzinger, 1843, Pantherophis Fitzinger, 1843 (including the extinct Pantherophis kansensis [Gilmore, 1938] and Pantherophis pliocenicus [Holman, 1968]), Phyllorhynchus Stejneger, 1890, and Rhinocheilus Baird and Girard, 1853. In contrast, the posteriorly inclined anterior margin has been documented only in the extinct Pseudocemophora antiqua Auffenberg, 1963, from the early Miocene of USA and Lampropeltis vetustum Auffenberg, 1963, from the late Miocene of USA (Auffenberg, 1963; Holman, 2000). However, Pseudocemophora antiqua possesses a vaulted neural arch, more laterally directed prezygapophyses, and relatively smaller parapophyses contrary to Periergophis micros gen. et sp. nov. Moreover, both Pseudocemophora antiqua and Lampropeltis vetustum lack deep wide lateral depressions between interzygapophyseal and subcentral ridges. Lampropeltis vetustum also differs from Periergophis micros gen. et $\mathrm{sp}$. nov. by the distinctly lower neural spine, as well as by the shape of the haemal keel, which is equally wide along its entire length and lacks a constriction behind the level of the synapophyses.

2) The unusually deep lateral depressions with large lateral foramina developed between the interzygapophyseal and subcentral ridges. These rather deep depressions are unusual in "Colubrinae". Although we have not noticed equally wide and deep lateral depressions in other Eurasian or North American taxa (Szyndlar, 1991a; Venczel, 1994, 1998; Holman, 2000; Venczel, 2000; Ratnikov, 2004; Ikeda, 2007), we cannot clearly state that this character is really autapomorphic, especially when it has not been tested in a phylogenetic analysis. Similarly deep lateral depressions posterior to the synapophyses were reported in Ameiseophis robinsoni Holman, 1976, from the late early to middle Miocene of Split Rock Formation, Fremont and Natrona Counties, Wyoming, USA (Holman, 1976, 2000). However, the holotype of $A$. robinsoni, fig- 
ured by Holman (1976) and which apparently originates from the posterior trunk section of the column, lacks the paired tubercles or processes on the haemal keel, which are typical for Periergophis micros gen. et sp. nov.

3) The parapophyses being twice as long as the diapophyses. Among Eurasian "colubrines" this character is characteristic of the genus Telescopus Wagler, 1830, as documented by specimens pertaining to the extant Telescopus fallax (Fleischmann, 1831) (e.g., specimen MDHC 303; specimens from the early Pleistocene of Betfia 9C, Romania [Venczel, 2000]), the extinct Telescopus bolkayi Szyndlar, 2005, from the late Miocene of Rudabánya, Hungary (Szyndlar, 2005) and Telescopus sp. described from the Middle Pleistocene of Varbesnitsa, Bulgaria (Szyndlar, 1991a). In any case, however, Telescopus differs from Periergophis gen. nov. by the less distinct lateral depressions between interzygapophyses and subcentral ridges, and by the different shape of the haemal keel in posterior trunk vertebrae (see below). Concerning North American species, the parapophysis twice as large as the diapophysis occurs in several genera including the extinct Ameiseophis Holman, 1976, as well as the extant Lampropeltis and Pituophis Holbrook, 1842 (Holman, 1976, 2000).

4) The wide haemal keel in trunk vertebrae with a constriction located behind the level of the synapophyses. A wide haemal keel with a distinct constriction is present in the mid-trunk vertebrae of the extinct Telescopus bolkayi (Szyndlar, 2005, figure $4 \mathrm{H}, \mathrm{K}, \mathrm{O}$ ) and Pseudocemophora antiqua (Auffenberg, 1963; Holman, 2000, figure 89), as well as in the posterior trunk vertebrae of Telescopus $\mathrm{sp}$. from the late Miocene (MN 13) of Polgárdi 4 "Upper" fissure filling (Venczel, 1998). However, both the above-mentioned genera lack the deep lateral depressions below the interzygapophyseal ridges, as well as the paired tubercles on the haemal keel, which are typical for Periergophis micros gen. et sp. nov.

5) The slightly dorsally vaulted zygosphene with the wide medial and the more distinct lateral lobes. The wide medial lobe and distinct lateral lobes developed on the dorsally vaulted zygosphenal roof occur in numerous small-sized "colubrines" including the Eurasian Platyceps Blyth, 1860, Hierophis (e.g., the extant Hierophis gemonensis [Laurenti, 1768]), and Eirenis Jan, 1863 (Szyndlar, 1991a). However, these genera still differ from Periergophis gen. nov. by the absence of the deep lateral depressions below the interzygapophyseal ridges as well as paired tubercles developed on the haemal keel.

6 ) and 7) The last two diagnostic features of Periergophis micros gen. et sp. nov. (the rather depressed neural arch of the mid-trunk vertebrae in posterior view and the small size and the rather lightly-built overall shape) are not unique for this Greek taxon and have been documented in other extinct and extant "colubrines", although they are still not common features for these snakes.

As was mentioned above, the haemal keel tubercles present on the posterior trunk vertebrae of Periergophis micros gen. et sp. nov. consist of a unique feature that is not known in any other snake lineage. The rather unique and bizarre vertebral morphology of this new taxon makes a proper familial assignment a challenging issue. A precise taxonomic assignment is further challenged by the fact that "Colubrinae" probably represents a paraphyletic assemblage of distantly related snakes, as relatively similar vertebral morphology with "colubrines" is known to occur in other distantly related clades as well, such as psammophiids and dipsadids. Indeed, the wide haemal keel of the new Greek snake species could indicate affinities with dipsadids (Holman, 1973). Outside America, dipsadids are known by a sole extant Asian taxon, Thermophis Malnate, 1953, from the Tibetan Plateau (He et al., 2009; Huang et al., 2009), though the fossil record suggests that it was probably also present in the Neogene of Europe (Vidal et al., 2009), represented by Paleoheterodon arcuatus Rage and Holman, 1984, from the middle Miocene of France (Rage and Holman, 1984; Augé and Rage, 2000). Furthermore, certain extant dipsadids from South America are known to have a rather extreme vertebral morphology (Bogert, 1964; Fritts and Smith, 1969), though none possesses any kind of haemal keel tubercles, as those observed in the vertebrae of Periergophis micros gen. et sp. nov. Furthermore, the vertebral anatomy of several African lineages, such as lamprophiids, is far from adequately known. Pending a better understanding of the systematics and phylogenetic relationships of fossil "colubrines" and "colubrine"-like forms, and a better comprehension of the vertebral anatomy of certain groups (e.g., psammophiids and lamprophiids), Periergophis micros gen. et sp. nov. is herein tentatively assigned to "Colubrinae".

\section{Genus PARAXENOPHIS gen. nov.}

zoobank.org/0FF649FC-33C1-4C39-A657-F93EB4CCC85D

Type species. Paraxenophis spanios gen. et sp. nov. (by monotypy).

Etymology. From the Greek words "тарá દॄvoऽ" ("paraxenos"), meaning "strange", "bizarre", in reference to the strange features observed in the vertebrae of this genus, and in particular the lateral notches of the haemal keel, and "ǒpıs" ("ophis"), meaning "snake". 
Gender. Gender of the genus Paraxenophis is masculine.

Diagnosis. As for type and only known species.

Paraxenophis spanios gen. et sp. nov. Figures 27, 28, 29, 30, 31

zoobank.org/2BF8DD41-770D-4495-A71F-12C84F58C6AF

Holotype. Specimen UU MAA 7645 (a mid-trunk vertebra) (Figure 27). The holotype originates from M1 site.

Paratypes. Specimen UU MAA 7536 (a posterior trunk vertebra) (Figure 29.1-5); UU MAA 7533 (a posteriormost trunk vertebra) (Figure 29.6-8). Both paratypes originate from $\mathrm{M} 1$ site.

Type locality. Maramena 1 site, Maramena locality (latest Miocene or earliest Pliocene [MN 13/14]), Central Macedonia, Greece.

Referred Material. M1: four cervical vertebrae (UU MAA 7843,UU MAA 7853, UU MAA 7870, and UU MAA 7876), 47 trunk vertebrae (UU MAA 7532, UU MAA 7640-UU MAA 7644, UU MAA 7646, UU MAA 7647, UU MAA 7649, UU MAA 7650, UU MAA 7760, UU MAA 7761, UU MAA 7763, UU MAA 7770, UU MAA 7774, UU MAA 7777, UU MAA 7798, UU MAA 7808-UU MAA 7814, UU MAA 7817, UU MAA 7824, UU MAA 7829, UU MAA 7830, UU MAA 7837, UU MAA 7854, UU MAA 7859, UU MAA 7860, UU MAA 7863, UU MAA 7867- UU MAA 7869, UU MAA 7876, UU MAA 7878, UU MAA 7881, UU MAA 7886, UU MAA 7889, UU MAA 7906, UU MAA 7910, UU MAA 7919, UU MAA 7923, UU MAA 7947, UU MAA 7961, and UU MAA 7962), a cloacal vertebra (UU MAA 7858), and an anterior caudal vertebra (UU MAA 7873).

Distribution and age. Known only from the type locality, Maramena, Central Macedonia, Greece. The holotype, paratypes, and all referred specimens originate from M1 site. Age of the type locality is latest Miocene (MN 13) or earliest Pliocene (MN 14), with the latest Miocene being the most probable.

Etymology. From the Greek word "orá́vios" ("spanios"), meaning "rare", referring to the uniqueness of the vertebral morphology of this snake species.

Descriptive diagnosis. Paraxenophis spanios gen. et sp. nov. can be differentiated from all other "colubrine" taxa on the basis of the following combination of characters: 1) presence of clearly distinct lateral notches on either side of the haemal keel on all vertebrae throughout the trunk region; 2) haemal keel being rather sharp in anterior middle and mid-trunk vertebrae, whereas it is rather flattened and wide in posterior middle and posterior trunk ones 3) rather short parapophyseal processes; 4) blunt subcentral ridges which are almost straight in lateral view; 5) short prezygapophyseal accessory processes; 6) moderately vaulted neural arch; and 7) rather large paracotylar foramina, especially in the mid-trunk vertebrae.

Description of the holotype. The holotype midtrunk vertebra (UU MAA 7645) is incomplete, missing large parts of the right prezygapophysis and postzygapophysis, and dorsal part of the neural spine, whereas the synapophyses are eroded (Figure 27). The vertebra has a centrum length of 5.3 $\mathrm{mm}$. In lateral view (Figure 27.1), the neural spine starts rising rather close to the level of the zygosphene. The interzygapophyseal ridge is moderately developed, and it is short and rather blunt. Lateral foramina are present, they are rather large, and their orifices are usually situated within deep funnel-like depressions. The straight or slightly dorsally vaulted subcentral ridges are moderately developed, and they are rather wide and blunt along their entire length. The synapophyses are eroded but it is clear that they are well divided into diapophyses and parapophyses. The diapophyses appear to have been larger than the rather short parapophyses. The ventral margin of parapophyses is relatively rounded. The condyle is developed on a short condylar neck. In dorsal view (Figure 27.2), the zygosphene is almost straight, but minute lateral lobes are present. The neural spine is thin. The prezygapophyses extend anterolaterally. The prezygapophyseal articular facets are suboval to rhomboid and the distally pointed, anterolaterally directed prezygapophyseal accessory processes reach about the half of the length of the prezygapophyseal articular facets. The interzygapophyseal constriction is situated in the middle of the neural arch length. The posterior median notch of the neural arch is deep. No epizygapophyseal spines are present. In ventral view (Figure 27.3), distinct narrow grooves occur between the cotylar rim and both parapophyses. The base of the haemal keel becomes wider in its posterior portion. There is a sharp keel, situated in the midline of the haemal keel in the ventral surface of the vertebra. Two distinct notches (herein defined under the term "lateral notches of the haemal keel") are present on both lateral sides of the haemal keel, being almost parallel throughout the ventral surface of the vertebra, but diverge laterally in the posterior portion of the centrum and slightly also in its anterior portion. Two distinct subcentral foramina occur within the anterior half of the centrum length, on both sides of the haemal keel. The postzygapophyseal articular 


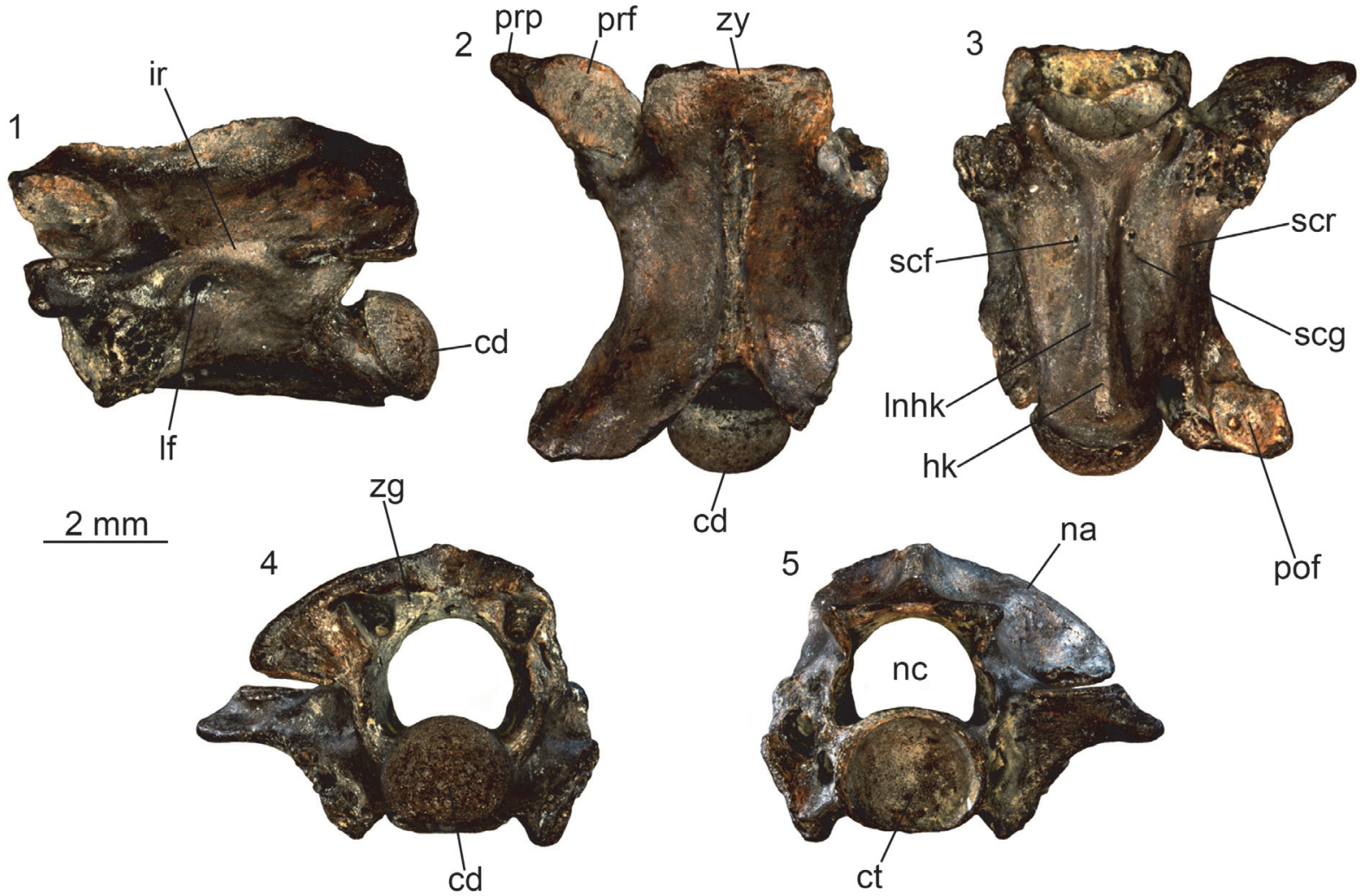

FIGURE 27. Paraxenophis spanios gen. et sp. nov. from Maramena: holotype mid-trunk vertebra (UU MAA 7645) in left lateral (1), dorsal (2), ventral (3), posterior (4), and anterior (5) views. Abbreviations: cd, condyle; ct, cotyle; hk, haemal keel; ir, interzygapophyseal ridge; If, lateral foramen; Inhk, lateral notch of the haemal keel; na, neural arch; nc, neural canal; pof, postzygapophyseal articular facet; prf, prezygapophyseal articular facet; prp, prezygapophyseal accessory process; scf, subcentral foramen; scg, subcentral groove; scr, subcentral ridge; zg, zygantrum; zy, zygosphene.

facet (only the left one is preserved) is rectangular in outline. In anterior view (Figure 27.5), the zygosphene is almost straight to slightly vaulted dorsally. The zygosphene is rather thin and is wider than the cotyle. The neural canal is rounded with distinct lateral sinuses. The prezygapophyses are directed rather laterally but not much dorsally, with their prezygapophyseal facets (only the left one is preserved) situated slightly above the dorsal margin of the cotylar rim. The unusually large paracotylar foramina are situated within depressions on either side of the rounded cotyle. The parapophyses are directed ventrally, extending below the ventral margin of the cotyle. In posterior view (Figure 27.4), the neural arch is vaulted. The ventral margin of the condyle is slightly depressed. There are distinct foramina, situated within deep depressions in the zygantrum.

Description of paratypes and referred specimens - intracolumnar variation. The paratype posterior trunk vertebra UU MAA 7536 is incomplete, missing a large part of its left postzygapoph- ysis and most of the neural spine, whereas the right prezygapophysis is eroded, with only its half prezygapophyseal articular facet preserved (Figure 29.1-5). This vertebra is smaller than the holotype, having a centrum length of $3.9 \mathrm{~mm}$. In dorsal view (Figure 29.1), the zygosphene has a rather indistinct medial lobe, with lateral lobes being present.

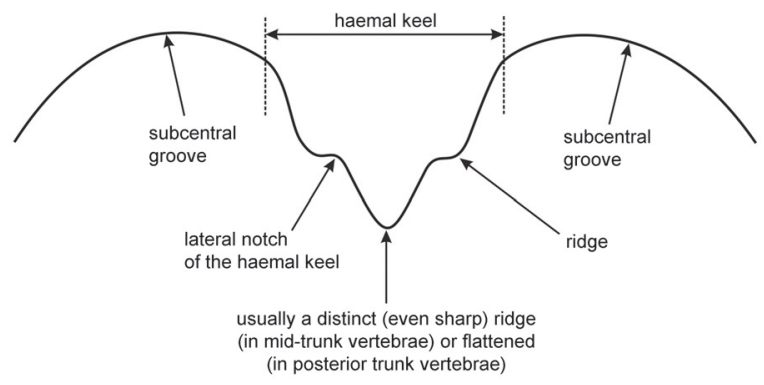

FIGURE 28. Explanatory drawing of a vertical cross section of a trunk vertebra of Paraxenophis spanios gen. et sp. nov., showing the distinctive lateral notches of the haemal keel. 

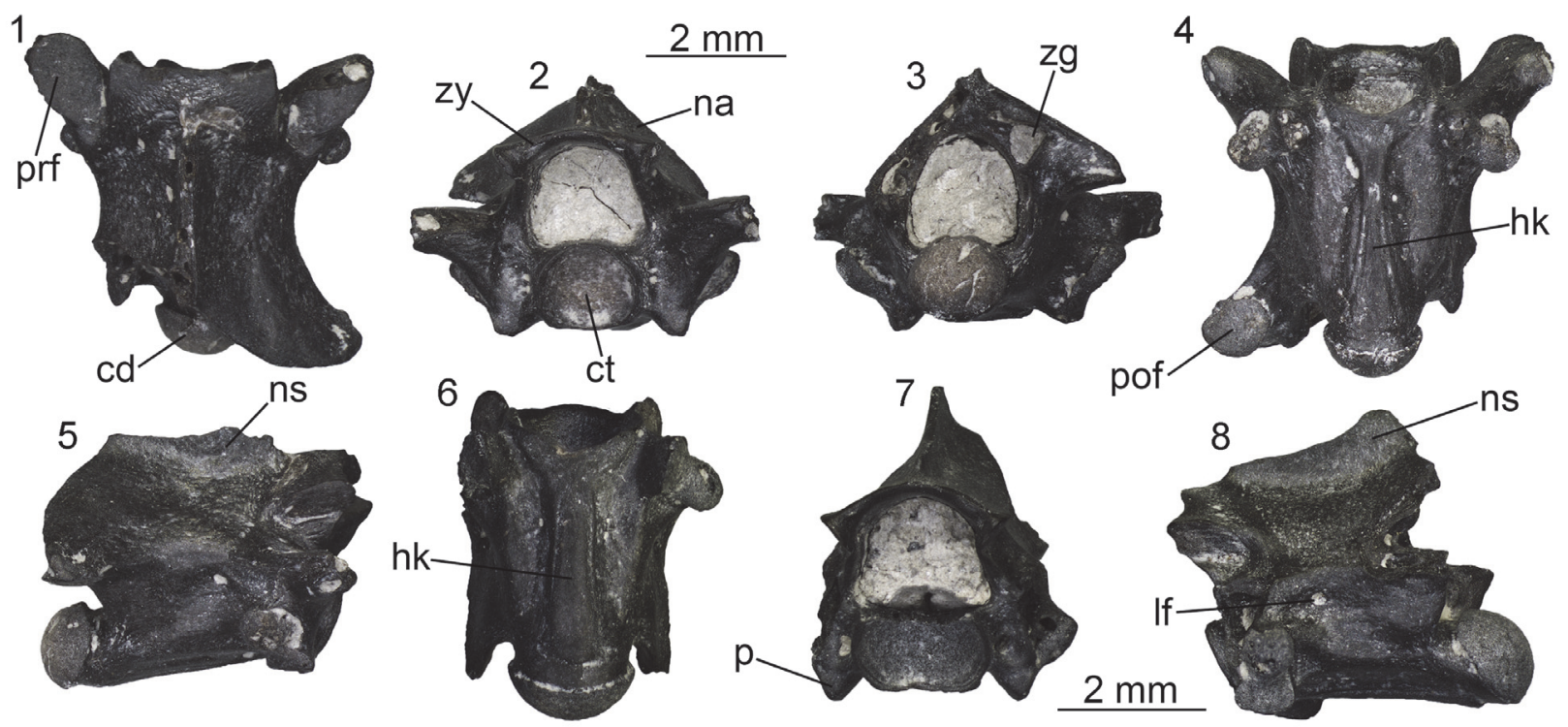

FIGURE 29. Paraxenophis spanios gen. et sp. nov. from Maramena, paratypes: posterior trunk vertebra (UU MAA 7536) in dorsal (1), anterior (2), posterior (3), ventral (4), and right lateral (5) views; posteriormost trunk vertebra (UU MAA 7533) in ventral (6), anterior (7), and left lateral (8) views. Abbreviations: cd, condyle; ct, cotyle; hk, haemal keel; If, lateral foramen; na, neural arch; ns, neural spine; $p$, parapophysis; pof, postzygapophyseal articular facet; prf, prezygapophyseal articular facet; zg, zygantrum; zy, zygosphene.

The prezygapophyses extend beyond the level of the zygosphene. The prezygapophyseal articular facets are oval. In ventral view (Figure 29.4), the synapophyses are massive, clearly divided into diapophyses and parapophyses. The postzygapophyseal articular facet is large and oval-shaped. The haemal keel runs almost throughout the centrum. The haemal keel is not sharp but instead, it is relatively broad and flattened, especially at its posterior portion (broader than the holotype mid-trunk vertebra). There are distinct lateral notches on either side of the haemal keel and they are inclined laterally in the posterior and the anterior parts of the centrum. Subcentral foramina are present. In lateral view (Figure 29.5), lateral foramina are present, with their orifices situated in deep depressions. The neural spine is broken, with its base running throughout most of the neural arch. A distinct condylar neck is present. In anterior view (Figure 29.2), the zygosphene is thin and slightly convex, with its lateral edges slightly inclined dorsally. The cotyle is elliptical. Paracotylar foramina are present. The parapophyses extend below the level of the centrum. In posterior view (Figure 29.3), the neural arch is almost vaulted and triangular-shaped.

The paratype posteriormost trunk vertebra UU MAA 7533 is incomplete, missing most of the posterior portion of the neural arch and the postzygapophyses, and most of both prezygapophyses
(Figure 29.6-8). This vertebra is even smaller than the other paratype described above, with a centrum length of $3.5 \mathrm{~mm}$. In lateral view (Figure 29.8), large lateral foramina are situated in deep depressions. The neural spine is broken but increases distinctly in height in the posterior portion of the neural arch. In ventral view (Figure 29.6), the haemal keel runs througout most of the centrum and becomes rather broad and flattened along its length (much broaded than the holotype mid-trunk and the other paratype posterior trunk vertebra UU MAA 7536), especially in its posterior part. Like the above described specimens, distinct lateral notches of the haemal keel run almost throughout the ventral surface of the vertebra, being relatively parallel in the anterior and middle parts of the centrum but diverging laterally in the posterior portion of the centrum. Subcentral foramina are present. In anterior view (Figure 29.7), the cotyle is rather rounded. The zygosphene is thin and convex, with its lateral edges slightly inclining dorsolaterally. The parapophyses are directed ventrally and are clearly divided from the diapophyses. In posterior view, both postzygapophyses, and most portions of the zygantrum and the posterior part of the neural arch are missing.

Almost all referred vertebrae originate from the trunk region, though two pertain to the cloacal and caudal regions. All specimens are partially incomplete, mostly with not fully preserved neural 

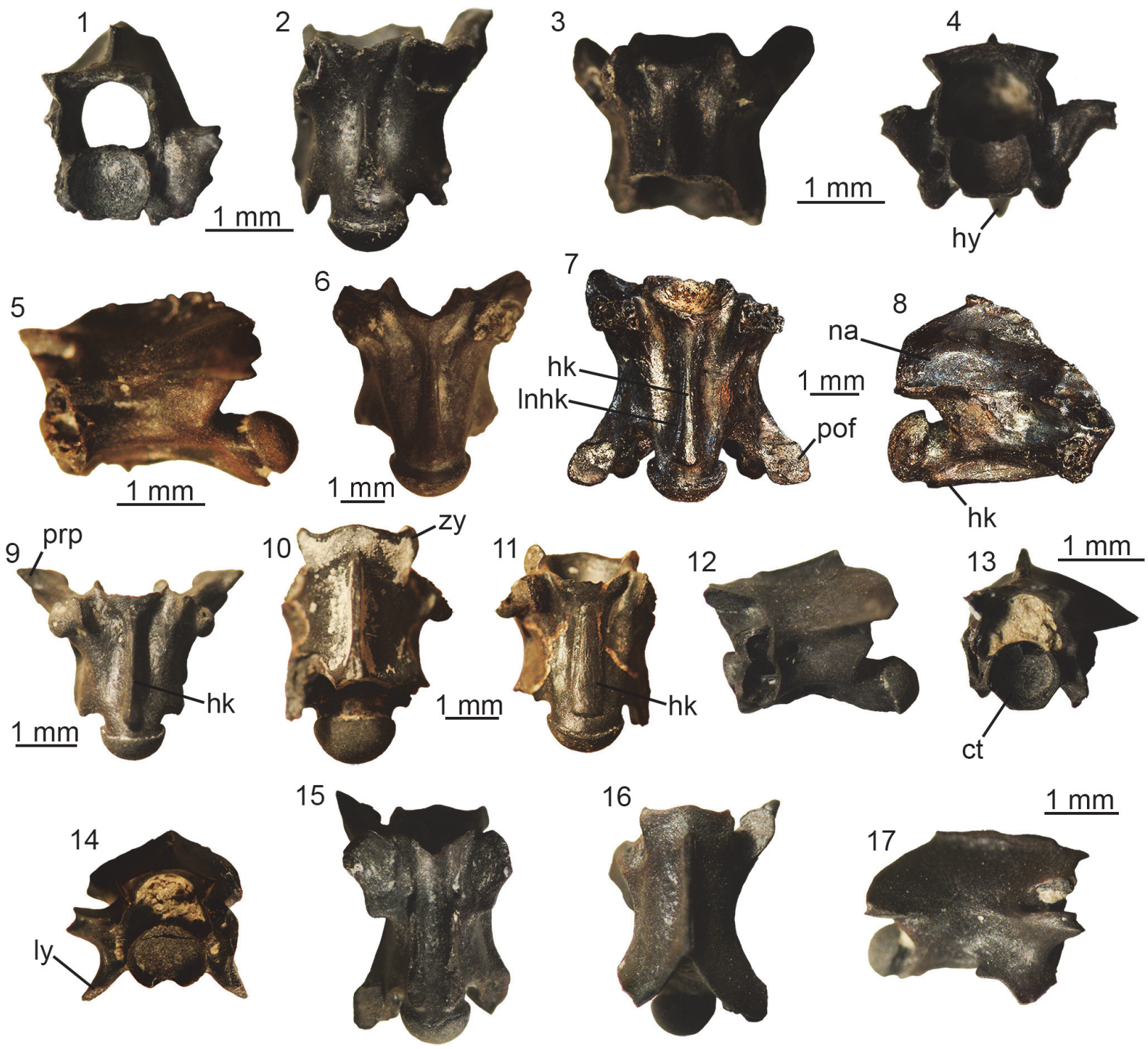

FIGURE 30. Paraxenophis spanios gen. et sp. nov. from Maramena, referred specimens: cervical vertebra (UU MAA 7870) in anterior (1) and ventral (2) views; cervical vertebra (UU MAA 7876) in ventral (3) and anterior (4) views; midtrunk vertebra (UU MAA 7843) in left lateral view (5); mid-trunk vertebra (UU MAA 7808) in ventral view (6); midtrunk vertebra (UU MAA 7650) in ventral (7) and right lateral (8) views; mid-trunk vertebra (UU MAA 7868) in ventral view (9); middle to posterior trunk vertebra (UU MAA 7770) in dorsal (10) and ventral (11) views; cloacal vertebra (UU MAA 7858) in left lateral (12) and anterior (13) views; anterior caudal vertebra (UU MAA 7873) in anterior (14), ventral (15), dorsal (16), and right lateral (17) views. Abbreviations: ct, cotyle; hk, haemal keel; hy, hypapophysis; Inhk, lateral notch of the haemal keel; ly, lymphapophysis; na, neural arch; pof, postzygapophyseal articular facet; prp, prezygapophyseal accessory process; zy, zygosphene.

spines, whereas their synapophyses are damaged (Figures 30, 31). Only four cervical vertebrae are known, all with rather incomplete hypapophyses (Figure 30.1-4). Nevertheless, it seems that hypapophysis was relatively short in height, whereas its posterior tip was probably not projecting beyond the level of the condylar neck or at least it only reached that level. The lateral notches of the haemal keel (that are present and prominent on either side of the haemal keel on the mid-trunk vertebrae) are not so prominent in the cervical vertebrae. Regarding the trunk vertebrae, it seems that, in lateral view, the neural spine was about twice longer than high with its dorsal posterior margin being slightly inclined posteriorly. The anterior margin of the neural spine was most probably vertical, although its anterodorsal termination is not preserved in any of the available specimens. Similarly 

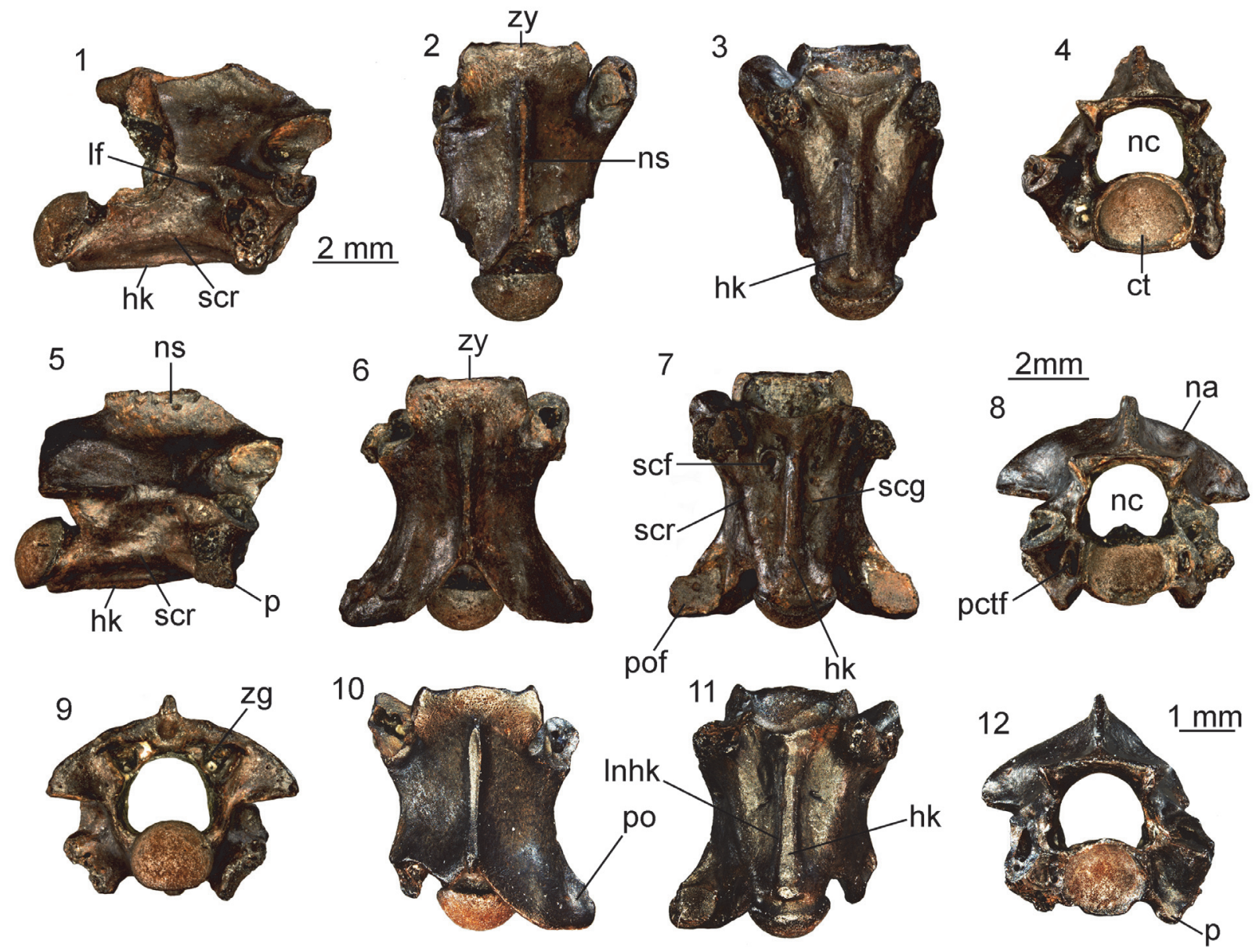

FIGURE 31. Paraxenophis spanios gen. et sp. nov. from Maramena, referred specimens: mid-trunk vertebra (UU MAA 7646) in right lateral (1), dorsal (2), ventral (3), and anterior (4) views; mid-trunk vertebra (UU MAA 7647) in right lateral (5), dorsal (6), ventral (7), anterior (8), and posterior (9) views; mid-trunk vertebra (UU MAA 7649) in dorsal (10), ventral (11), and anterior (12) views. Abbreviations: ct, cotyle; hk, haemal keel; If, lateral foramen; Inhk, lateral notch of the haemal keel; na, neural arch; nc, neural canal; ns, neural spine; $p$, parapophysis; pctf, paracotylar foramen; po, postzygapophysis; scf, subcentral foramen; scg, subcentral grooves; scr, subcentral ridge; zg, zygantrum; zy, zygosphene.

to the holotype, in all vertebrae, the zygosphenal facet is oval, the interzygapophyseal ridge is moderately developed, short, and rather blunt, the lateral foramina are rather large, with their orifices usually situated within deep funnel-like depressions, and the subcentral ridges are always straight or slightly dorsally vaulted, moderately developed, and they are rather wide and blunt along their entire length. When preserved, synapophyses are well divided into diapophyses and parapophyses, with the former being always larger than the latter. In dorsal view, the zygosphene is almost straight in the largest mid-trunk vertebrae, with minute lateral lobes. However, in the smaller vertebrae, the zygosphene has developed distinct lateral and rather wide and indistinct medial lobes. It seems that both lateral and medial lobes of the zygosphene become even more prominent in the posterior middle trunk vertebrae in comparison with the mid-trunk ones (Figure 30.10). The shape of the prezygapophyseal articular facets varies from suboval to rhomboid and, when preserved, the prezygapophyseal accessory processes are distally pointed and anterolaterally directed (Figure 30.9). In ventral view, distinct narrow notches usually occur between the cotylar rim and both parapophyses. These distinct lateral notches of the haemal keel are present in all mid-trunk vertebrae (Figure 28). They are almost parallel to the haemal keel across much of its length, but in their anteriormost and especially the posteriormost portions, they incline significantly laterally. The base of the haemal keel becomes slightly wider in the posterior part of the centrum. There is a sharp keel situated 
in the midline of the haemal keel in the ventral surface of the mid-trunk vertebrae. However, this keel becomes rounded instead of sharp or even completely diminishes in the posterior middle and posterior trunk vertebrae, thus the ventral margin of the haemal keel of these vertebrae is usually rounded or slightly flattened (Figure 30.11). Distinct subcentral foramina occur within the anterior half of the centrum and, in some specimens, these foramina are doubled. The postzygapophyseal articular facets are rectangular in outline. The slender zygosphenal lip is vaulted dorsally. The laterally directed prezygapophyseal articular facets are situated slightly above the dorsal margin of the cotylar rim. Paracotylar foramina are always present in all vertebrae and they are unusually large. In some specimens, paracotylar foramina are doubled and situated within depressions on either side of the rounded cotyle. In posterior view, the neural arch is vaulted in all mid-trunk vertebrae, though it becomes much more arched in the posterior trunk vertebrae. The only known cloacal vertebra (UU MAA 7858) is rather incomplete, missing most of both prezygapophyses and the right postzygapophysis (Figure 30.12-13). That vertebra is short and possesses blunt subcentral ridges, whereas its neural arch is vaulted. In lateral view, the haemal keel is so thick that it even resembles a short hypapophysis. No haemapophyses are present. The caudal region is largely unknown, as only a single anterior caudal vertebra (UU MAA 7873) has been recovered (Figure 30.14-17). The specimen is rather complete, missing only the left prezygapophysis and parts of the haemapophyses. The neural spine is rather short. The lymphapophyses appear to have been enlarged and project lateroventrally. The bases of the haemapophyses extend across most of the posterior portion of the ventral surface of the centrum. Slightly distinct lateral lobes and a medial one are present on the zygosphene in dorsal view. The prezygapophyses are anterolaterally directed in dorsal view, forming a much smaller angle with the zygosphenal lateral lobes in comparison with that in the trunk vertebrae. The prezygapophyseal accessory processes are pointed.

Remarks. The gracile structure, the elongated centrum, the presence of distinct prezygapophyseal processes, the presence of paracotylar and lateral foramina, as well as the absence of hypapophysis in mid- and posterior trunk vertebrae are all indicative of a taxonomic assignment to the "colubrines" (Szyndlar, 1984, 1991a). The vertebrae, however, are rather characteristic owing to a combination of features, and principally the presence of a haemal keel with a distinct sharp crest extending along its midline in the mid-trunk vertebrae, a rather flattened haemal keel on the posterior trunk vertebrae (with no sharp crest in the midline), and most principally, the presence of distinctive lateral notches running along the lateral margins of the haemal keel throughout the trunk vertebrae. The shape of the haemal keel has been repeatedly considered as an important and potentially diagnostic character in the taxonomy of fossil "colubrines" (e.g., Auffenberg, 1963; Rage, 1984; Szyndlar, 1984; LaDuke, 1991; Szyndlar, 1991a; Holman, 2000). So far, such distinctive lateral notches of the haemal keel, similar to those that are herein described for Paraxenophis spanios gen. et sp. nov., have never been documented for any "colubrine" taxon, either extant or extinct. It should be pointed out that these lateral notches on either side of the haemal keel are totally different structures from the subcentral grooves, because they are developed above the base of the haemal keel (Figure 28). Therefore, these features, along with the combination of characters proposed above, warrant the establishment of a new genus and species, in order to accommodate this peculiar vertebral morphology. Furthermore, the presence of these features in multiple specimens and the fact that the lateral notches of the haemal keel are always symmetrical preclude the possibility that the unique vertebral anatomy of Paraxenophis spanios gen. et sp. nov. is due to pathology.

Among fossil and extant "colubrines", the haemal keel of Paraxenophis spanios gen. et sp. nov. is more similar to material described as Coronella cf. miocaenica from the late Miocene (MN 9) of Creţeşti, Romania (Codrea et al., 2018), and probably also to material referred to Coronella miocaenica Venczel, 1998, from the middle Miocene (MN 7/8) of Tauţ, Romania (Venczel and Ştiucă, 2008; Venczel, 2011). Besides the presence of distinctive lateral notches of the haemal keel, Paraxenophis spanios gen. et $\mathrm{sp}$. nov. also has rather blunt subcentral ridges, which is not the case for the Romanian specimens. On the basis of the few existing published figures of the Romanian specimens, it cannot be confirmed whether they have generic affinities with Paraxenophis gen. nov. Nevertheless, the genus level affinities of Coronella miocaenica seem to be problematic and the species is in need of revision, although at species level, the taxon appears to be distinctive. Indeed, we see no reason to assign the holotype vertebra (MFGI V20617) of Coronella miocaenica from the late Miocene (MN 13) of Polgárdi, Hungary (Venc- 
zel, 1998, figure 6a-e), to the genus Coronella. Vertebrae of extant Coronella are characterized by depressed or weakly vaulted neural arch as well as a rather low neural spine and a wide (in the midtrunk vertebrae even indistinct) haemal keel (Ivanov, 1997; MI and GLG pers. obs.). Instead, the type specimen of Coronella miocaenica has a distinct and thin haemal keel which is lanceolate at its posterior termination (Venczel, 1998). Also, the centrum length / neural arch width ratio is lower in C. miocaenica in contrast to other extant species of Coronella, where the centrum of the vertebrae is elongated (Bailon, 1991; Venczel, 1998, 2000; GLG and MI, pers. obs.). Furthermore, the neural spine is high in C. miocaenica, whereas the same structure is always rather short in all extant members of Coronella (MI and GLG, pers. obs.). Paraxenophis spanios gen. et sp. nov. can be readily distinguished from its sympatric Periergophis micros gen. et sp. nov. by their different characters provided in the diagnoses of the two taxa, and principally the absence of anteriorly directed tubercles on the haemal keel of the posterior trunk vertebrae. Furthermore, the two new Maramena "colubrines" differ significantly in terms of size, with the vertebrae of Paraxenophis spanios gen. et sp. nov. being much larger than those of Periergophis micros gen. et sp. nov. Similarly, Paraxenophis spanios gen. et sp. nov. differs from the other Maramena "colubrines", Hierophis cf. hungaricus and "Colubrinae" indet. (morphotype 1), by its overall shape and its unique feature of the lateral notches on either side of its haemal keel. The sharp crest on the midline of the haemal keel of mid-trunk vertebrae is also observed in"Colubrinae" indet. from the nearby Ano Metochi locality (Georgalis et al., 2017a, figure 7A-E). However, that Ano Metochi form differs from the Maramena specimens by the dorsally strongly vaulted zygosphenal roof in anterior view, instead of the almost straight zygosphene in Paraxenophis spanios gen. et sp. nov., and of course, the absence of lateral notches of the haemal keel. Furthermore, Paraxenophis spanios gen. et sp. nov. differs from the other "colubrine" from Ano Metochi, cf. Dolichophis $\mathrm{sp}$., by the distinctly shorter prezygapophyseal accessory processes and smaller overall dimensions (see Georgalis et al., 2017a, figure 6).

\section{?Paraxenophis spanios \\ Figure 32}

Material. M1: six trunk vertebrae of a young subadult individual (UU MAA 7648 and UU MAA 7651UU MAA 7655).
Description. These six vertebrae are incomplete, with the exception of UU MAA 7648, which is well preserved and missing only small parts of the prezygapophyses. As such, we are basing our description on that specimen (Figure 32). All vertebrae are rather small, with centrum lengths less than $3 \mathrm{~mm}$. In lateral view (Figure 32.2), the neural spine is much longer than high. The condyle is clearly situated on a condylar neck. The lateral foramina are distinctive and large. In dorsal view (Figure 32.1), the zygosphene is almost straight, bearing lateral lobes. The posterior notch of the neural arch is deep. In ventral view (Figure 32.3), the haemal keel possesses no lateral notches on either side. Distinct subcentral foramina are present on both sides of the haemal keel. In anterior view (Figure 32.4), the zygosphene is rather wide, being wider than the cotyle, and convex. The cotyle is elliptical and depressed, with rather deep and enlarged paracotylar foramina present on both sides. The parapophyses extend below the ventral surface of the cotyle. In posterior view (Figure 32.5), the zygantrum is rather wide. The neural spine is relatively thin and becomes progressively thinner towards its dorsal surface.

Remarks. These six trunk vertebrae slightly deviate from the morphology of Paraxenophis spanios gen. et sp. nov., most notably by the absence of the peculiar lateral notches of the haemal keel that characterizes the species. Taking into consideration these differences described above, there are two possibilities:

1) Their rather small size (centrum length less than 3 $\mathrm{mm}$ ) could indicate that these vertebrae pertain to a young (subadult, not juvenile) specimen of Paraxenophis spanios gen. et sp. nov. This hypothesis could be further supported by the fact that in young snake specimens, the zygosphene can be relatively wider and more dorsally vaulted, and the zygapophyses are small and generally do not extend laterally (LaDuke, 1991; Georgalis and Scheyer, in press). As such, the fact that these vertebrae do not possess the distinctive lateral notches of the haemal keel could be attributed to ontogenetic variation. In that case, the distinct lateral notches of the haemal keel of Paraxenophis spanios gen. et sp. nov. are clearly developed only in adult specimens.

2) Alternatively, these vertebrae could belong to an adult snake of a different, small-sized species. The diameter of the neural canal is comparable to that of the cotyle. This is in agreement with the fact that the neural canal /cotyle diameter ratio has been variously applied to distinguish adult from sub-adult and juvenile specimens (e.g., Szyndlar, 1991a; Head, 2005). 

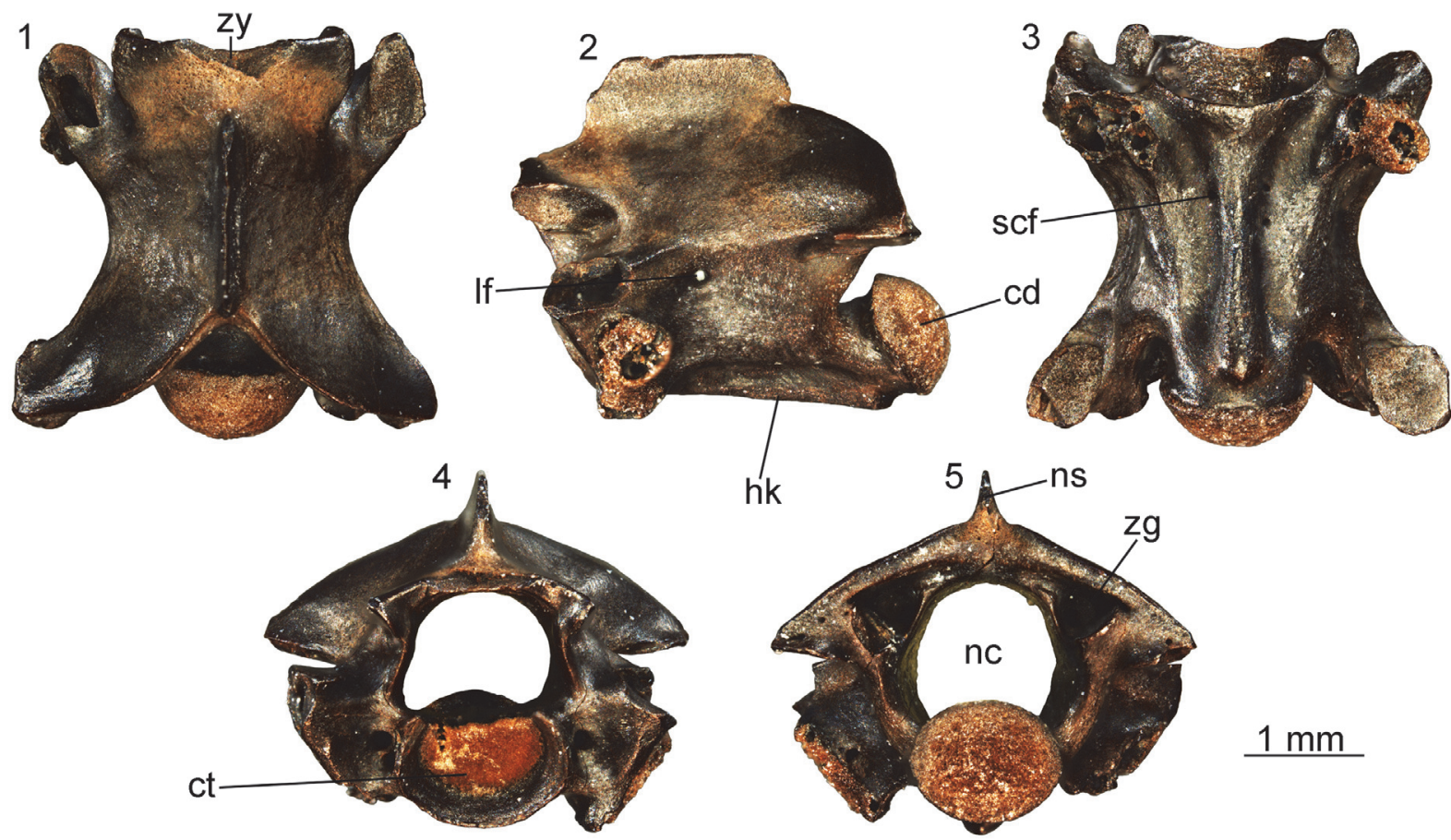

$1 \mathrm{~mm}$

FIGURE 32. ?Paraxenophis spanios, young individual from Maramena: mid-trunk vertebra (UU MAA 7648) in dorsal (1), left lateral (2), ventral (3), anterior (4), and posterior (5)views. Abbreviations: cd, condyle; ct, cotyle; hk, haemal keel; If, lateral foramen; nc, neural canal; ns, neural spine; scf, subcentral foramen; zg, zygantrum; zy, zygosphene.

We are here tentatively in favor of the first option and tend to regard these small vertebrae as pertaining to a young subadult (not juvenile) individual of Paraxenophis spanios gen. et sp. nov., though, of course, we cannot dismiss the possibility that they truly represent a distinct, small-sized taxon/morphotype.

\section{"Colubrinae" indet. (morphotype 1)}

Figure 33

Material. M1: four trunk vertebrae (UU MAA 7638, UU MAA 7639, UU MAA 7879, and UU MAA 7908).

Description. All vertebrae are incomplete and the description is herein based primarily on UU MAA 7638 , which is the best preserved one. Specimen UU MAA 7638 lacks zygosphene, neural spine, right prezygapophysis, and left postzygapophysis (Figure 33). The centrum is rather short and wide, with a centrum length of $3.36 \mathrm{~mm}$ and a neural arch width of $3.31 \mathrm{~mm}$. In lateral view (Figure 33.1, 33.4), large lateral foramina occur on both sides of the centrum, close below the distinct interzygapophyseal ridges. The completely preserved left synapophysis has the parapophysis twice as long as the diapophysis. The parapophysis has a rounded ventral surface and reaches clearly below the centrum of vertebra. The moderately developed subcentral ridges are blunt and rather short, reaching the half of the centrum length. There is a distinct ridge developed between the base of the neural arch and the base of the condyle. The condyle is developed on a short condylar neck. In dorsal view (Figure 33.2), the prezygapophyseal articular facets (only the left one is preserved) are rather wide, with an irregularly oval outline. The prezygapophyseal accessory process is brokenoff. The epizygapophyseal spines are underdeveloped. The medial notch at the posterior margin of the neural arch is rather narrow. In ventral view (Figure 33.3), subcotylar tubercles are indistinctly developed at the ventral margin of the cotylar rim. Slit-like furrows occur between the cotylar rim and the base of parapophyses. The haemal keel is distinctly wide, with a flat ventral surface. The subcentral foramina (the right one is doubled) are relatively small and are developed at the base of the haemal keel. No subcentral grooves are present. The incomplete right postzygapophyseal articular facet is relatively elongated in lateral direction. In anterior view (Figure 33.5), the prezygapophyses are dorsally inclined. The neural canal is rounded, with wide lateral sinuses. Paracotylar foramina occur on both sides of the cotyle. The 

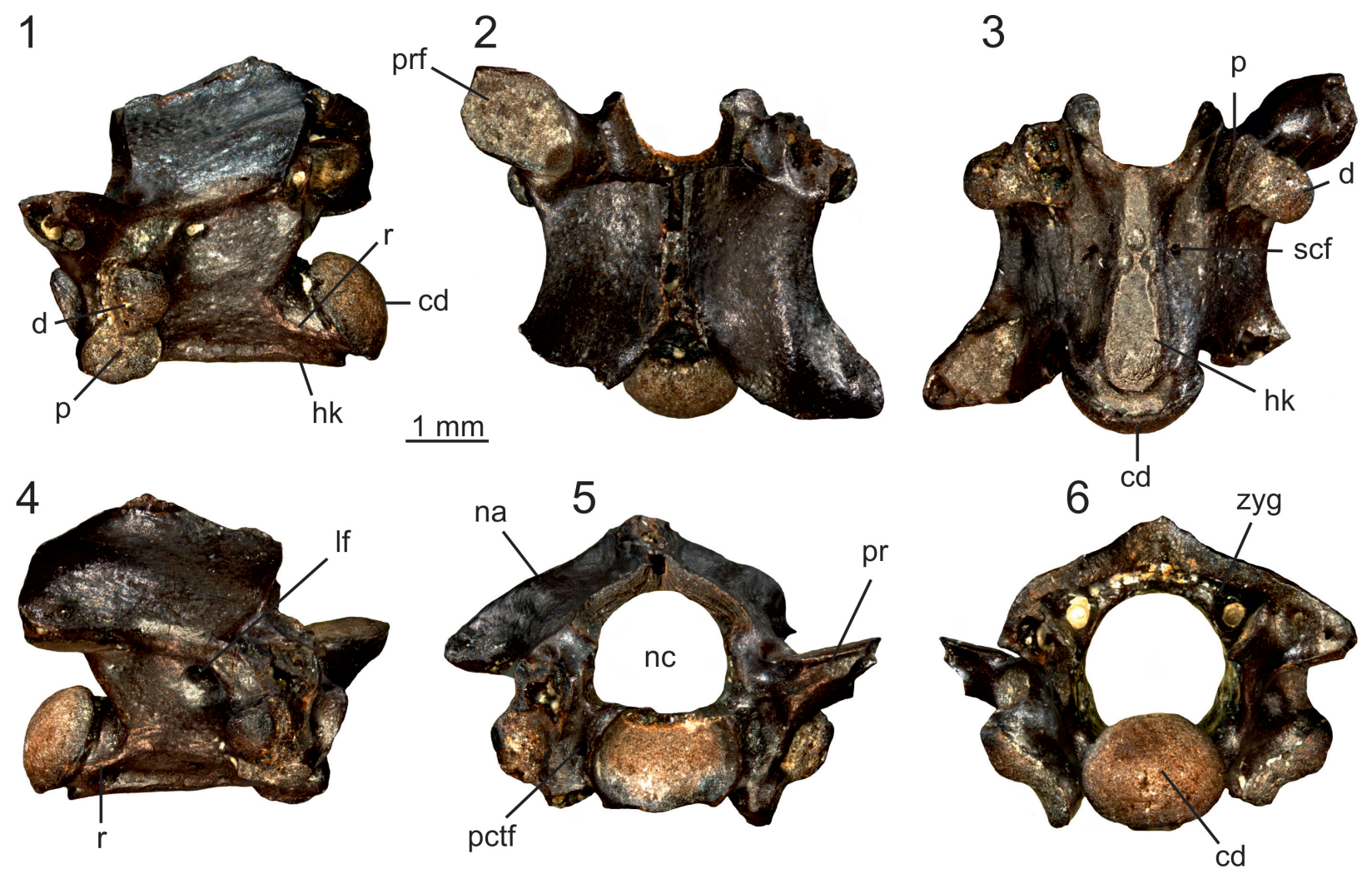

FIGURE 33. "Colubrinae" indet. (morphotype 1) from Maramena: mid-trunk vertebra (UU MAA 7638) in left lateral (1), dorsal (2), ventral (3), right lateral (4), anterior (5), and posterior (6) views. Abbreviations: cd, condyle; d, diapophysis; hk, haemal keel; If, lateral foramen; na, neural arch; nc, neural canal; p, parapophysis; pctf, paracotylar foramen;pr, prezygapophysis; prf, prezygapophyseal articular facet; r, ridge; scf, subcentral foramen; zg, zygantrum.

ventral base of the cotylar rim is flat. In posterior view (Figure 33.6), the neural arch is depressed. The zygantral area is wide. Distinct foramina are present inside the zygantrum. The base of the condyle is flattened.

Remarks. The low ratio of centum length / neural arch width (ratio $=1.02$ ), the indistinct subcentral ridges, as well as the absence of subcentral grooves, indicate that the vertebrae originate from the anterior or middle part of the trunk section. Although a more precise identification of this incomplete material is currently not possible, these vertebrae share certain features which are similar to Periergophis micros gen. et sp. nov., namely: 1) the parapophysis is rather large and about twice as long as the diapophysis; 2) the neural arch is depressed; 3) the prezygapophyses are inclined dorsally; and 4) the unusually large lateral foramina are situated within deep and wide depressions. However, "Colubrinae"indet. (morphotype 1) can still be differentiated from Periergophis micros gen. et sp. nov. by several features: 1) the absence of constriction of the haemal keel behind the synapophyses; 2) the absence of paired tubercles on the haemal keel; 3) its significantly larger dimensions; and 4) the presence of a distinct ridge developed between the base of the neural arch and the base of the condyle. Although we have never observed this kind of ridge in other known "colubrines", we cannot state with confidence whether this character falls within the range of the intraspecific variability or if it can be attributed to pathological development.

Among European extinct and extant "colubrines", the rather wide haemal keel of the Maramena form is reminiscent of Nanus planicarinatus Bachmayer and Szyndlar, 1985, from the late Miocene (MN 11) of Kohfidisch, Austria, which was recently referred to the extant genus Platyceps by Wallach et al. (2014). However, in that Austrian taxon, the centrum is more elongated and the shapes of the the prezygapophyseal and postzygapophyseal articular facets are different, whereas its synapophyses (and mainly its parapophyses) are significantly smaller. The Maramena "colubrine" (morphotype 1) shares also some resemblance with Hispanophis coronelloideus Szyndlar, 1985 from the late Miocene (MN 13) of Algora, Spain, 
but in the Spanish form, the neural arch is more vaulted and the prezygapophyses and the postzygapophyses are less massive than in the Greek snake. A rather wide haemal keel that narrows in the anterior portion of the ventral surface of the centrum, like in the Maramena material, is also present in the probable dipsadid from the middle Miocene of France, Paleoheterodon arcuatus (Rage and Holman, 1984). However, there are several vertebral features that are different in the Greek and French specimens, especially concerning the shape of their prezygapophyses. Interestingly, its North American supposed congener Paleoheterodon tiheni Holman, 1964, has similarly dorsally inclined prezygapophyses, as well as similar shape of the haemal keel, with the "Colubrinae" indet. (morphotype 1) from Maramena. The degree of dorsal inclination of the prezygapophyses may have some special value, as it appears to be rather uncommon within "colubrines". Vertebrae of Telescopus also share some resemblance with the Maramena vertebrae, principally in terms of the width of the haemal keel (especially in the extinct Telescopus bolkayi) and the large parapophyses, but the neural spine in Telescopus is significantly shorter in lateral view than the Greek specimens. The Maramena snake is also reminiscent of Texasophis meini Rage and Holman, 1984, from the early and middle Miocene of France (Rage and Holman, 1984; Rage and Bailon, 2005), especially in the width of the haemal keel, the shape of the neural arch, and the shape of the prezygapophyses. However, vertebrae of species of Texasophis Holman, 1977, are more elongated, their neural spines are significantly shorter in lateral view, and the haemal keel is equally wide along the whole length. In Eirenis modestus (Martin, 1838), an extant small-sized "colubrine" that inhabits southeastern Europe, the neural arch is also depressed, and the haemal keel significantly widens posteriorly (e.g., specimen MDHC 291), however, it differs from the Maramena form in its lesser degree of dorsal inclination of prezygapophyses, much smaller prezygapophyseal articular facets, and significantly shorter neural spine. Beyond "colubrines", an alternative taxonomic allocation of the Maramena fossil material would be that it pertains to the boid genus Bavarioboa Szyndlar and Schleich, 1993. Unlike most booids, paracotylar foramina are variously present in Bavarioboa, though this is relatively infrequent. The low centrum length I neural arch width, the wide haemal keel, and the distinct diapophyses and parapophyses seem to further hint for such booid affinities. However, in
Bavarioboa, the interzygapophyseal constriction is always less distinct and anteroposteriorly short (Szyndlar and Schleich, 1993; Szyndlar and Rage, 2003), whereas this is more prominent in "Colubrinae" indet. (morphotype 1). Furthermore, in ventral view, the centrum of the Maramena "colubrine" is not so distinctly triangulary enlarged towards the synapophyses, unlike the wide triangular base of the centrum observed in mid-trunk vertebrae of Bavarioboa (Szyndlar and Rage, 2003). Moreover, the zygantral area also seems to be more gracile in the Maramena specimens, in comparison with that of Bavarioboa (Szyndlar and Rage, 2003).

NATRICINAE Bonaparte, 1838 (sensu Szyndlar, 1991b)

Genus NATRIX Laurenti, 1768

Type species. Coluber natrix Linnaeus, 1758.

\section{NATRIX RUDABANYAENSIS Szyndlar, 2005 Natrix aff. rudabanyaensis}

Figure 34

Material. M1: 34 precloacal vertebrae (UU MAA 7656-UU MAA 7689) and seven caudal vertebrae (UU MAA 7690-UU MAA 7694, UU MAA 7893, and UU MAA 7904); M3: four precloacal vertebrae (UU MAA 7741-UU MAA 7744).

Description. Precloacal vertebrae (Figure 34.116): all preserved vertebrae are at least partially fragmentary with broken off neural spines, hypapophyses, and prezygapophyseal processes. In lateral view (Figure 34.1, 34.6, 34.13), the preserved base of the neural spine indicates that its dorsal margin rised in the posterior half of the zygosphenal length. The zygosphenal articular facets are oval. The interzygapophyseal ridges are well developed and usually rather sharp. Large lateral foramina occur close below these ridges, in the upper part of the distinct wide depression, which occurs on either lateral side of the vertebra between the subcentral ridges and interzygapophyseal ridges. The synapophyses are well divided into parapophyses and diapophyses, both having an almost equal length. The parapophyseal processes are long and directed anteriorly rather than anteroventrally. The strongly developed subcentral ridges are either straight or slightly vaulted dorsally, reaching two thirds of the vertebral centrum length. In dorsal view (Figure 34.2, 34.7, 34.11, 34.14), the prezygapophyseal articular facets are oval and narrow with a long axis oriented anterolaterally. The prezygapophyseal accessory processes are broken off at their base. The zygosphene is trilobated, with distinct lateral lobes and a wide medial lobe. The epizygapophyseal spines are 

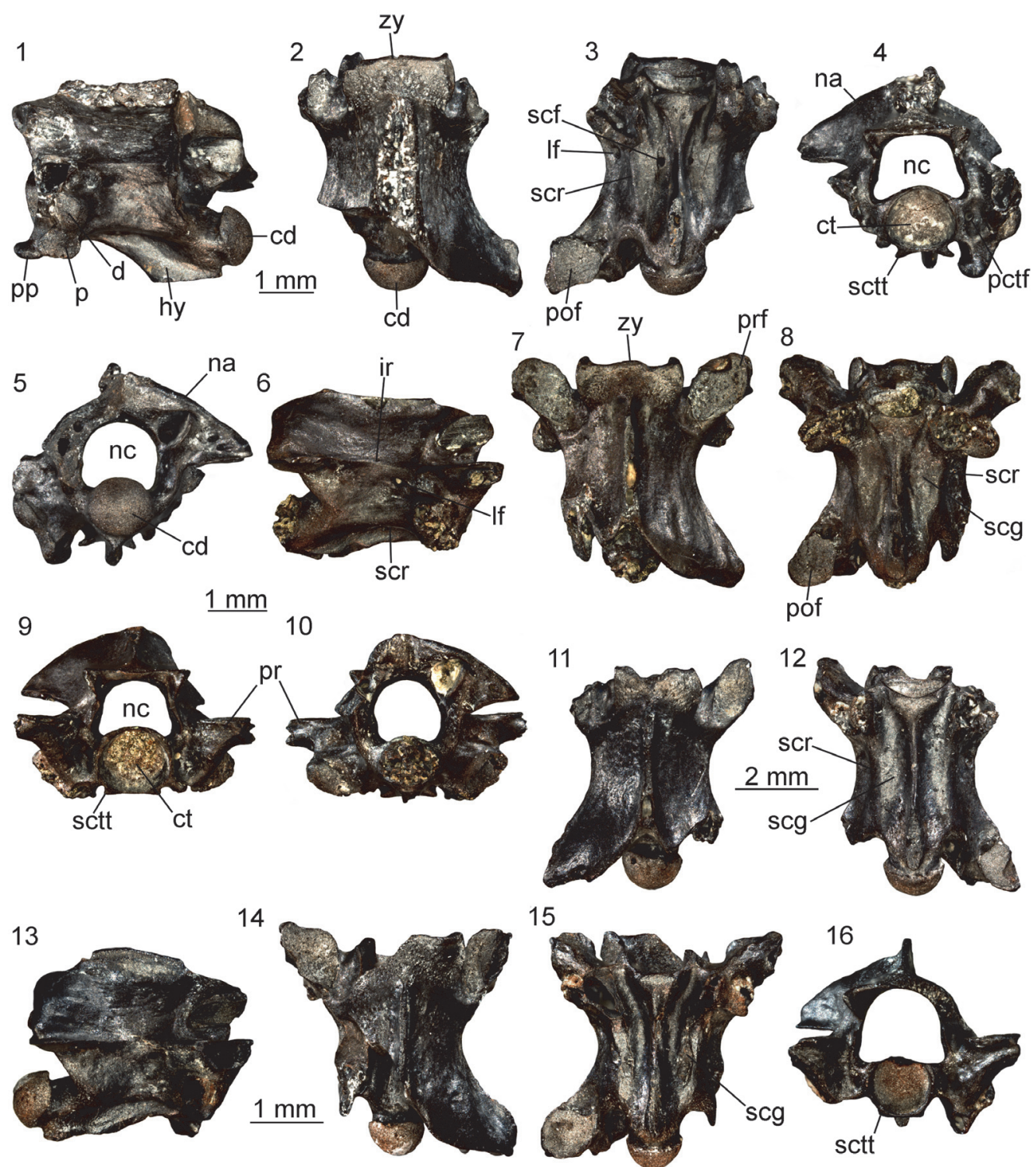

15
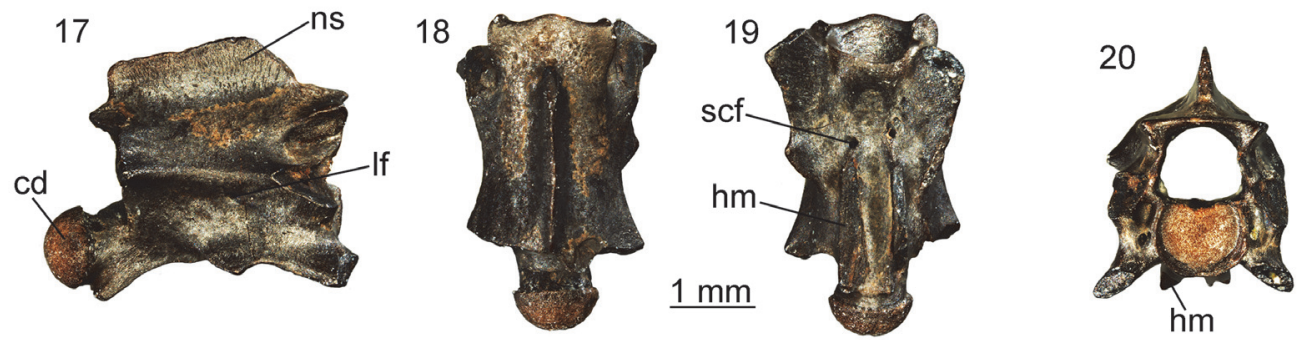

FIGURE 34. Natrix aff. rudabanyaensis from Maramena: anterior precloacal vertebra (UU MAA 7669) in left lateral (1), dorsal (2), ventral (3), anterior (4), and posterior (5) views; precloacal vertebra (UU MAA 7670) in right lateral (6), dorsal (7), ventral (8), anterior (9), and posterior (10) views; posterior trunk vertebra (UU MAA 7667) in dorsal (11) and ventral (12)views; posterior trunk vertebra (UU MAA 7668) in right lateral (13), dorsal (14), ventral (15), and anterior (16) views; caudal vertebra (UU MAA 7694) in right lateral (17), dorsal (18), ventral (19), and anterior (20) views. Abbreviations: cd, condyle; ct, cotyle; d, diapophysis; hy, hypapophysis; ir, interzygapophyseal ridge; If, lateral foramen; na, neural arch; nc, neural canal; $p$, parapophysis; pctf, paracotylar foramen; pof, postzygapophyseal articular facet; pp, parapophyseal process; pr, prezygapophysis; prf, prezygapophyseal articular facet; scf, subcentral foramen; scg, subcentral groove; scr, subcentral ridge; sctt, subcotylar tubercles; zy, zygosphene. 
moderately developed. In ventral view (Figure $34.3,34.8,34.12,34.15)$ the anterior keel of the hypapophysis is triangular with two distinct (in some specimens, rather long) subcotylar tubercles developed at the ventral margin of the cotylar rim. The vertebrae from the anterior and middle parts of the precloacal section possess wide subcentral grooves. In posterior precloacal vertebrae, the strongly built subcentral ridges are expressed by deep subcentral grooves. Subcentral ridges are almost parallel with the axis of the centrum and reach the posterior margin of the laterally expanded pedicle. Subcentral foramina are present and have a variable diameter among the vertebrae. They occur at the base of the thin hypapophysis. The postzygapophyseal articular facets are irregularly trapezoid in outline. In anterior view (Figure 34.4, 34.9, 34.16), the neural canal is rounded to subsquare, with distinct lateral sinuses. The prezygapophyses are directed laterally with their prezygapophyseal articular facets situated at about the level of the dorsal margin of the cotylar rim. The zygosphene is usually straight but in the posterior precloacal vertebrae, it can be moderately vaulted dorsally. Paracotylar foramina are present and occur within depressions on either side of the rounded cotyle. In posterior view (Figure $34.5,34.10$ ) the neural arch is moderately vaulted. The zygantrum is wide. The base of the pedicle is expanded laterally in posterior precloacal vertebrae. The condyle is rounded.

Caudal vertebrae (Figure 34.17-20): the vertebrae are fragmentary with pleurapophyses and haemapophyses broken off close to their bases. The only preserved neural spine seems to be about three times longer than high, with its posterior dorsal margin inclined posteriorly. The anterior margin of the neural spine is damaged. The interzygapophyseal ridges are distinct and rather sharp. Large lateral foramina occur close below these ridges. Pleurapophyses possess wide bases and they are directed anteroventrally and lateroventrally in lateral and anterior views, respectively (Figure 34.20). The distal tips of the pleurapophyses are broken off. The zygosphene is trilobated in dorsal view and vaulted dorsally in anterior view. The cotyle is rounded and rather large. The neural canal is semirounded with distinct lateral sinuses.

Remarks. The presence of well-developed hypapophyses in the whole precloacal region, the long parapophyseal processes directed anteriorly, and the vaulted neural arch clearly permit the assignment of the material to the genus Natrix (Szyndlar, $1984,1991 b)$. Although the neural spine is not fully preserved in any specimen, the following combination of features enable identification of the precloacal vertebrae as similar to Natrix rudabanyaensis Szyndlar, 2005, from the late Miocene (MN 9) of Rudabánya, Hungary: 1) the distinct subcentral ridges; 2) the wide and shallow subcentral grooves; 3) the elongated prezygapophyseal articular facets; and 4) the generally small overall size. However, the Maramena specimens still differ from Natrix rudabanyaensis by having more distinct and sharp subcentral ridges in middle trunk vertebrae (Szyndlar, 2005). The clearly lower centrum length I neural arch width ratio, the less elongated ventral surface of the centrum, as well as the small size enable to distinguish the Maramena Natrix aff. rudabanyaensis from Natrix merkurensis Ivanov, 2002 from the early Miocene of Merkur Nord. Moreover, Natrix aff. rudabanyaensis from Maramena further differs from both Natrix merkurensis and the French Natrix sansaniensis (Lartet, 1851) by possessing larger prezygapophyseal articular facets (Augé and Rage, 2000; Ivanov, 2002).

Natrix sp.
Figure 35

Material. M1: six precloacal vertebrae (UU MAA 7695-UU MAA 7700).

Description. The precloacal vertebrae are incomplete (Figure 35), with broken off hypapophyses and neural spines, and, in most cases, strongly damaged prezygapophyses. In lateral view (Figure $35.2,35.7$ ), the base of the anterior margin of the neural spine rises at the posterior margin of the zygosphene. Although the dorsal margin of the neural spine is absent in all these fragmentary vertebrae, its preserved base indicates that the neural spine was probably relatively narrow and high. The zygosphenal facets are narrow and oval. The interzygapophyseal ridges are moderately developed and rather blunt. Small lateral foramina occur close below the interzygapophyseal ridges. When preserved, the diapophyses are slightly larger than the parapophyses. The parapophyseal process is long and directed anteriorly. The subcentral ridges are only moderately developed in the anterior precaudal vertebrae. Distinct, slightly dorsally vaulted subcentral ridges occur in middle and posterior precloacal vertebrae. However, they are never sharp. The small condyle is developed on a short condylar neck. In dorsal view (Figure 35.1, 35.6), the vertebrae are cylindrical. The trilobated zygosphene is wide with distinct and pointed lateral lobes and a wide medial lobe. The prezygapophyseal articular facets are irregularly oval, and in some specimens, their outline is tear-like shaped. 
1

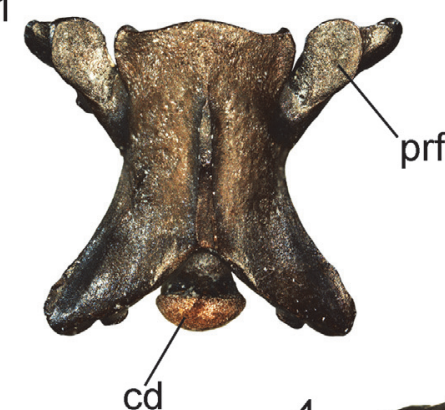

2

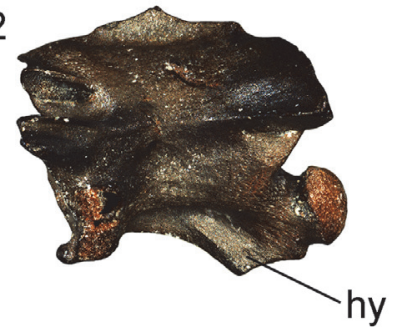

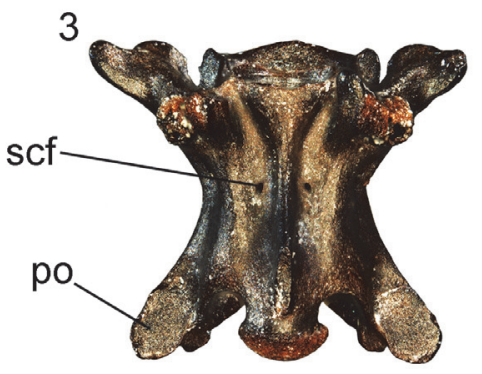

$1 \mathrm{~mm}$
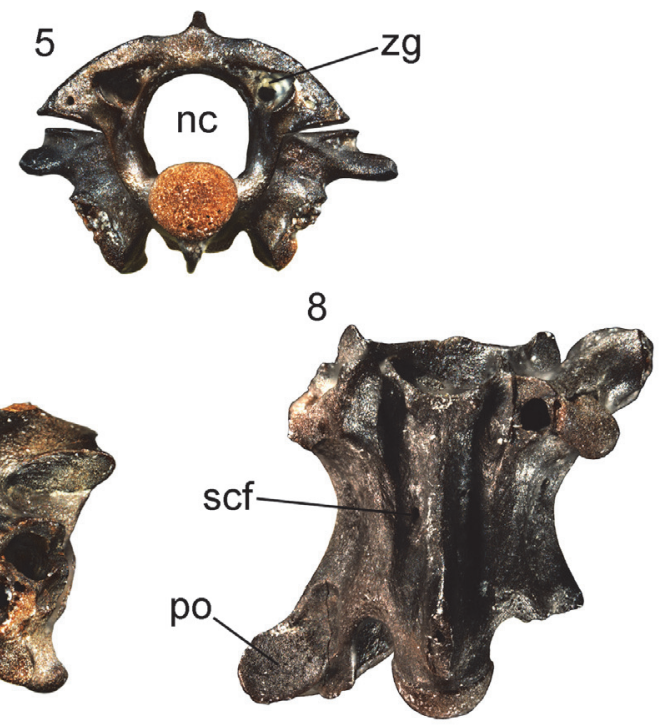

FIGURE 35. Natrix sp. from Maramena: precloacal vertebra (UU MAA 7699) in dorsal (1), left lateral (2), ventral (3), anterior (4), and posterior (5) views; posterior precloacal vertebra (UU MAA 7700) in dorsal (6), right lateral (7), and ventral (8) views. Abbreviations: cd, condyle; ct, cotyle; hy, hypapophysis; nc, neural canal; pctf, paracotylar foramen; po, postzygapophysis; prf, prezygapophyseal articular facet; prp, prezygapophyseal accessory process; scf, subcentral foramen; zg, zygantrum; zy, zygosphene.

The distally blunt prezygapophyseal accessory processes reach half of the prezygapophyseal facets length. In ventral view (Figure 35.3, 35.8), the anterior keel of the hypapophysis is triangular with two small subcotylar tubercles at the ventral margin of the cotylar rim. The subcentral ridges are rather short in anterior precloacal vertebrae. The subcentral grooves are wide and shallow in anterior precloacal vertebrae, whereas in posterior vertebrae these grooves become narrow. The postzygapophyseal articular facets are irregularly shaped. In anterior view (Figure 35.4), the neural canal is subsquare with wide lateral sinuses. The zygosphenal lip is moderately vaulted dorsally. The laterally directed prezygapophyseal facets are situated well above the dorsal margin of the cotyle. The prezygapophyseal accessory processes are directed laterally or slightly lateroventrally. The rounded cotyle is markedly smaller than the diameter of the neural canal. There are deep depressions on either side of the cotyle, with distinct paracotylar foramina situated close to the lateral margins of the cotyle. In posterior view (Figure 35.5), the neural arch is moderately vaulted. The zygantral area is rather wide and the base of the pedicle is expanded laterally. The rounded condyle is rather small.

Remarks. These precloacal vertebrae are assigned to Natricinae, and in particular the genus Natrix, on the basis of the presence of a hypapophysis and its shape (Szyndlar, 1991b; Ivanov, 2002). This material differs from Natrix aff. rudabanyaensis by possessing less distinct interzygapophyseal ridges, less distinct subcentral ridges in midprecloacal vertebrae, indistinct subcotylar tubercles, and a relatively wider zygosphene. In fact, it resembles more the extant Natrix natrix rather than the other Maramena natricine. However, this form can still be differentiated from the extant representatives of $N$. natrix by its relatively wide zygosphene with a rather wide medial lobe. Whatever its exact affinities may be, this material clearly 
denotes the presence of a second, though indeterminate, taxon of the genus Natrix in Maramena.

\section{Natricinae indet.}

Material. M1: 41 precaudal vertebrae (UU MAA 7258, UU MAA 7259, UU MAA 7534, UU MAA 7701-UU MAA 7709, UU MAA 7776, UU MAA 7778, UU MAA 7782, UU MAA 7788, UU MAA 7791, UU MAA 7819, UU MAA 7823, UU MAA 7831-UU MAA 7834, UU MAA 7836, UU MAA 7838, UU MAA 7844, UU MAA 7857, UU MAA 7861, UU MAA 7864, UU MAA 7877, UU MAA 7883, UU MAA 7891, UU MAA 7892, UU MAA 7895, UU MAA 7898, UU MAA 7901, UU MAA 7914, UU MAA 7917, UU MAA 7925, and UU MAA 7934), several fragmentary precaudal vertebrae (UU MAA 7261), and a caudal vertebra (UU MAA 7260); M2: five precaudal vertebrae (UU MAA 7189 and UU MAA 7190).

Description and remarks. All vertebrae are strongly damaged and fragmentary. They are assigned to indeterminate natricines because of the presence of a hypapophysis in all precloacal vertebrae. Although a more precise determination is impossible, it is probable that they belong to one of the two Natrix species described above. The vertebra from Maramena previously figured by Szyndlar (1995) is rather incomplete and fragmentary and is herein referred to Natricinae indet. as well. It is worth noting also that Szyndlar (1991b, 1995) reported that, among the then available natricine vertebral material, one vertebra possessed a rather low neural spine, prompting the author to suggest that it probably denoted its allocation to a non-Natrix natricine. Considering that this specimen was never figured and in our collection there is not any natricine with such low neural spine, we cannot further conclude about Szyndlar's (1991b, 1995) implication.

\section{Colubridae indet.}

Material. M1: six cervical vertebrae (UU MAA 7710-UU MAA 7715), 29 trunk vertebrae (UU MAA 7113, UU MAA 7114, UU MAA 7825, UU MAA 7828, UU MAA 7847, UU MAA 7852, UU MAA 7855, UU MAA 7856, UU MAA 7865, UU MAA 7870, UU MAA 7871, UU MAA 7885, UU MAA 7909, UU MAA 7913, UU MAA 7920, UU MAA 7930, UU MAA 7931, UU MAA 7935, UU MAA 7939, UU MAA 7941- UU MAA 7946, UU MAA 7948, UU MAA 7949, UU MAA 7954, and UU MAA 7965), four cloacal vertebrae (UU MAA 7768, UU MAA 7775, UU MAA 7902, and UU MAA 7932), and 29 caudal vertebrae (UU MAA 7716-UU MAA 7739, UU MAA 7840, UU MAA 7897, UU MAA
7900, UU MAA 7927, and UU MAA 7938); M3: four fragmentary caudal vertebrae (UU MAA 7745-UU MAA 7748).

Remarks. These vertebrae are rather incomplete. Their elongated centrum, the overall lightly built morphology, and the presence of haemal keel or hypapophysis on the trunk vertebrae, denote that they pertain to colubrids. However, due to their highly fragmentary preservation, it cannot be even determined whether they belong to "colubrines" or natricines.

\section{ELAPIDAE Boié, 1827}

Genus NAJA Laurenti, 1768

Type species. Coluber naja Linnaeus, 1758.

$$
\begin{gathered}
\text { Naja sp. } \\
\text { Figure } 36
\end{gathered}
$$

Material. M1: two mid-trunk vertebrae (UU MAA 7257 and UU MAA 7531).

Description. Specimen UU MAA 7531 is a rather large vertebra with a centrum length of $9.2 \mathrm{~mm}$, missing the hypapophysis, part of the neural spine, and most of the postzygapophyses, whereas the synapophyses are eroded (Figure 36). In fact, UU MAA 7531 represents by far the largest snake vertebra among all the herein described material from Maramena. Specimen UU MAA 7257 is a much smaller vertebra with a centrum length of $4.9 \mathrm{~mm}$, and misses the hypapophysis, the neural spine, both prezygapophyses, and the left postzygapophysis. In dorsal view (Figure 36.5), the zygosphene is concave in UU MAA 7531 and trilobate in UU MAA 7257. The prezygapophyseal articular facets are large, massive, and almost triangular shaped in dorsal view in UU MAA 7531, whereas they are totally not preserved in UU MAA 7257. The prezygapophyseal accessory processes are eroded. The postzygapophyses (preserved only in UU MAA 7257) extend laterally well beyond the level of the centrum. In ventral view (Figure 36.6), the centrum is triangular-shaped and distinct subcentral ridges and subcentral foramina are visible. Only the base of the hypapophysis is preserved. The postzygapophyseal articular facet (preserved only in UU MAA 7257) is obovate to triangular in shape. In lateral view (Figure 36.3-4), the neural spine is broken in both specimens, though it seems to have been relatively low, at least in the larger specimen (UU MAA 7531) where it is much better preserved. Large and deep lateral foramina are present in both vertebrae. In anterior view (Figure 36.1), the zygosphene is rather massive and thick in UU MAA 7531, whereas it is significantly smaller in UU MAA 7257 . The cotyle is robust and relatively oval- 


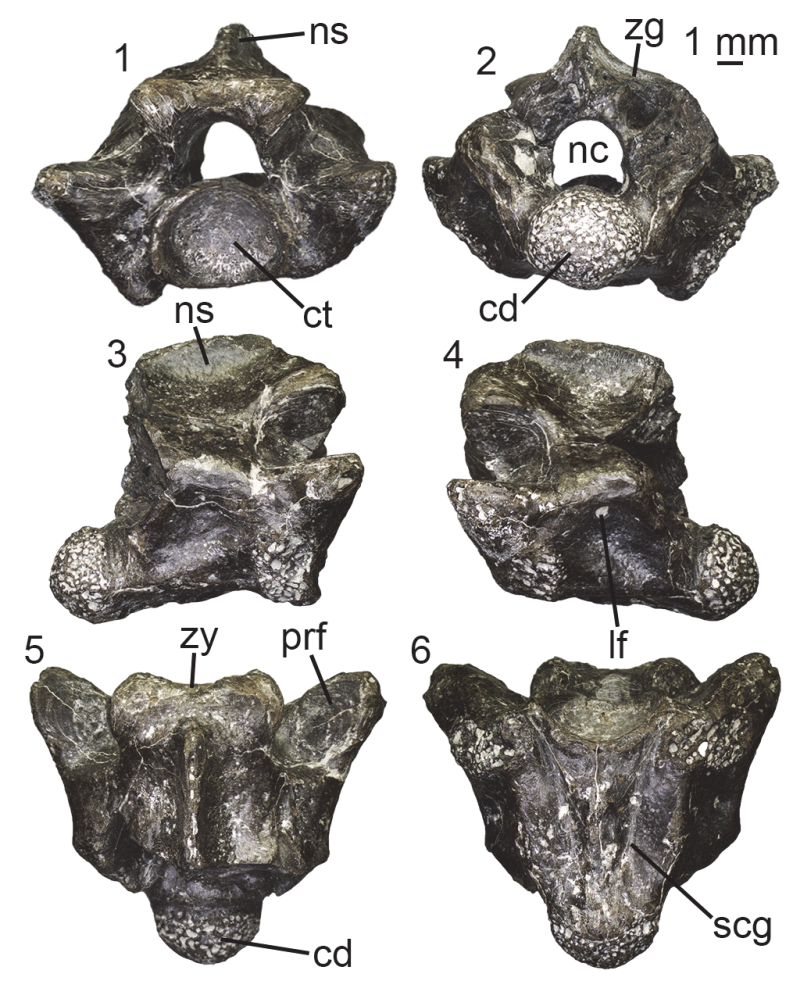

FIGURE 36. Naja sp. from Maramena: mid-trunk vertebra (UU MAA 7531) in anterior (1), posterior (2), right lateral (3), left lateral (4), dorsal (5), and ventral (6) views. Abbreviations: cd, condyle; ct, cotyle; If, lateral foramen; nc, neural canal; ns, neural spine; prf, prezygapophyseal articular facet; scg, subcentral grooves; zg, zygantrum; zy, zygosphene.

shaped in UU MAA 7531 (it is incomplete in UU MAA 7257). The prezygapophyses (preserved only in UU MAA 7531) are only slightly tilted dorsally from the upper level of the cotyle. The synapophyses extend below the level of the cotyle. In posterior view (Figure 36.2), the zygantrum is rather enlarged and the condyle is significantly robust. The neural arch is relatively depressed.

Remarks. Both vertebrae can be assigned to Elapidae on the basis of their non-lightly built general shape and the probable presence of a hypapophysis, the relatively low neural spine, the depressed neural arch, the well-developed subcentral ridges, and the short condylar neck (Szyndlar, 1991b; Scanlon et al., 2003; Ikeda, 2007; Ivanov and Böhme, 2011; Georgalis et al., 2018b). Among elapids, UU MAA 7257 and UU MAA 7531 can be attributed to the genus Naja on the basis of their absolute size and the relatively low ratio of centrum length / neural arch width (Ivanov and Böhme, 2011). The size, general shape, the absence of lymphapophyses, haemapophyses, and pleurapophyses, and the shape of the neural canal denote that the two vertebrae originate from the precloacal region, and more specifically for the larger one (UU MAA 7531), from the mid-trunk portion of the skeleton. The presence of Naja in the Maramena assemblage was already previously noted by Szyndlar (1995) who mentioned the presence of fragmentary vertebrae, among which he figured one in lateral and ventral views. Judging from the published figure of Szyndlar (1995: figure $1 \mathrm{H}-\mathrm{I}$ ), that material can be considered as conspecific with the new specimens described herein. In any case, on the basis of the existing material, it is not possible to determine whether the Maramena cobra belonged to the widespread species Naja romani (Hoffstetter, 1939) or a distinct form.

Genus MICRURUS Wagler, 1824

Type species. Micrurus spixii Wagler, 1824.

\section{cf. Micrurus sp.}

Figure 37

Material. M1: a mid-trunk vertebra (UU MAA 7535).

Description. Specimen UU MAA 7535 is an incomplete vertebra, missing the whole right side of the neural arch, the right portions of the zygosphene and zygantrum, the right prezygapophysis, the right postzygapophysis, the right paradiapophysis, both prezygapophyseal accessory processes, and part of the neural spine (Figure 37). In dorsal view (Figure 37.3), a distinct lateral lobe is present on the zygosphene. The prezygapophyseal articular facet is damaged but seems to extend only slightly laterally. In ventral view (Figure 37.4), the centrum is relatively triangular in shape. The subcentral ridges extend from the level of the synapophyses to the proximal margin of the condyle. A distinct, deep, and rather enlarged subcentral foramen is present at the left side of the centrum. The hypapophysis extends anteriorly until almost the level of the cotylar rim. In lateral view (Figure 37.2, 37.5), the vertebra is elongated; the hypapophysis is rather short and is directed more posteriorly than ventrally with its tip situated at the end of the condylar neck. The synapophyses are clearly divided into diapophyses and parapophyses. A rather large and deep lateral foramen is present. In anterior view (Figure 37.1), the cotyle is almost sphaerical in shape, being significantly less wide than the zygosphene. Two paracotylar foramina are present, one on each side of the cotyle. The zygosphene is poorly preserved, but it appears to have been relatively thick. In posterior view (Figure 37.6), the condyle is sphaerical and is much less wide in comparison with the zygantral area. 

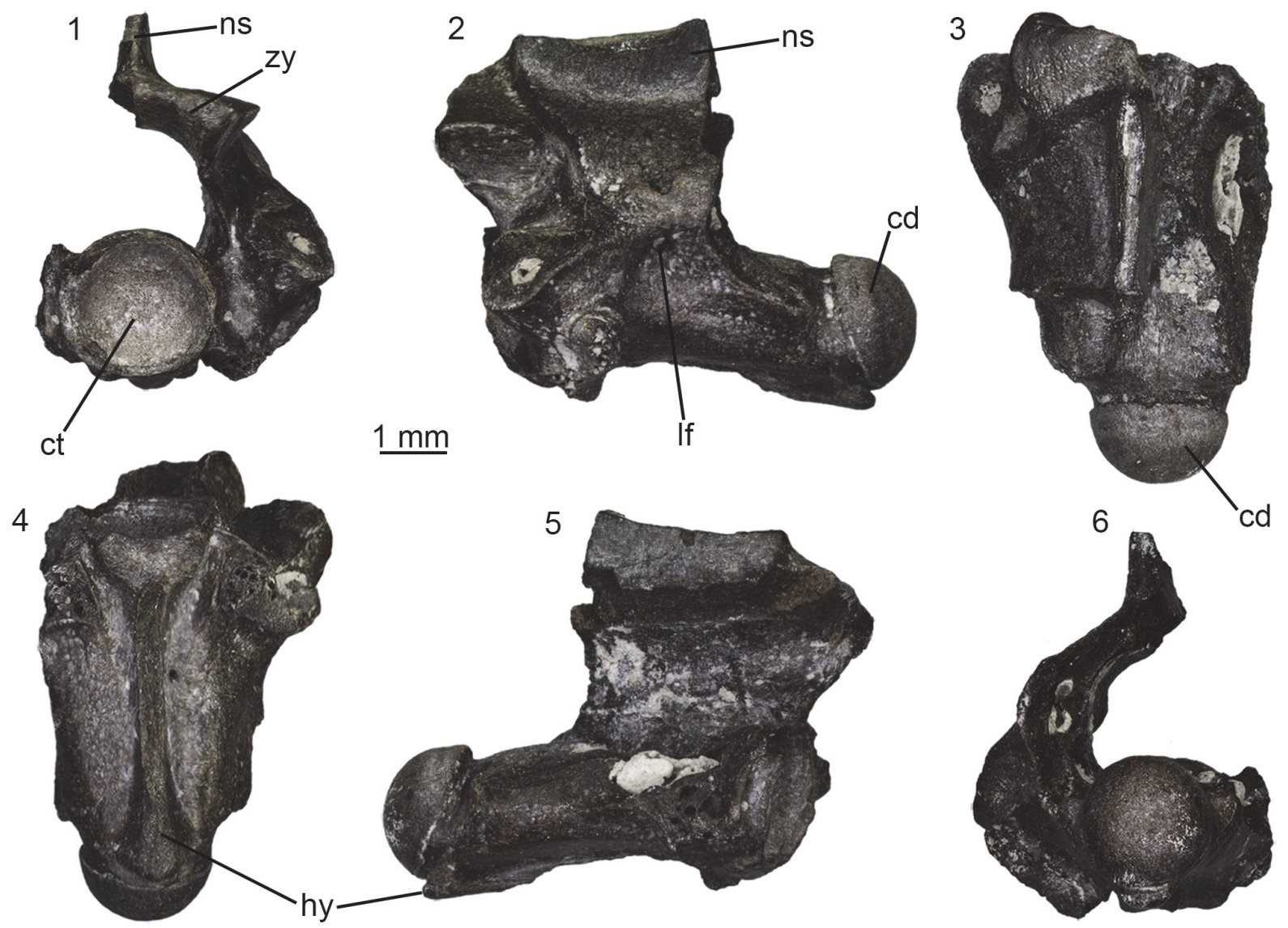

FIGURE 37. cf. Micrurus sp. from Maramena: mid-trunk vertebra (UU MAA 7535) in anterior (1), left lateral (2), dorsal (3), ventral (4), right lateral (5), and posterior (6) views. Abbreviations: cd, condyle; ct, cotyle; hy, hypapophysis; If, lateral foramen; ns, neural spine; zy, zygosphene.

Remarks. The single vertebra UU MAA 7535 can be tentatively attributed to Micrurus on the basis of its relatively small dimensions (centrum length), its elongated vertebral centrum, a short hypapophysis which is directed more posteriorly than ventrally (Ivanov and Böhme, 2011). The neural spine in UU MAA 7535 is not fully preserved but we assume it was relatively low, as is the case with other extinct and extant Micrurus spp. The size, general shape, the absence of lymphapophyses, haemapophyses, and pleurapophyses, and the shape of the neural canal denote that the vertebra originates from the precloacal region and most probably from the midtrunk portion of the skeleton. Due to the incomplete nature of UU MAA 7535, no further comparison of the Maramena form with the sole named European taxon of the genus, Micrurus gallicus Rage and Holman, 1984, from the middle Miocene of France, can be made.

Besides Micrurus, such short hypapophysis occurs also in the natricine genus Neonatrix Holman, 1973. This North American typified genus
(Holman, 1973) also has congeneric representatives in the Miocene of Europe (e.g., Rage and Holman, 1984; Szyndlar, 1987, 1991b; Augé and Rage, 2000; Ivanov, 2000; Rage and Bailon, 2005). However, the monophyletic status or even the validity of this genus, encompassing a large number of North American and European forms, has been doubted (e.g., Szyndlar and Schleich, 1993; Szyndlar, 2005). Whatever the case, judging from the published figures, the hypapophysis of the European Neonatrix spp. appears to be more enlarged in comparison with the Maramena vertebra (Rage and Holman, 1984; Szyndlar, 1987; Augé and Rage, 2000; Szyndlar, 2005), thus prompting us to consider that generic assignment unlikely.

\section{?Elapidae indet.}

Material. M1: two trunk vertebrae (UU MAA 7256 and UU MAA 7807).

Description and remarks. Specimens UU MAA 7256 and UU MAA 7807are rather fragmentary 
trunk vertebrae, preserving solely the condyle and the posteriormost portion of the centrum with remains of a hypapophysis. Due to the poor preservation of the specimens, it is not possible to precisely assess their exact affinities, but the relatively large size of the condyle and the overall size of the posteriormost preserved portion of the centrum are reminiscent of elapids, and particularly of cobras of the genus Naja. Therefore, it seems highly probable that both these specimens could pertain to the same taxon as the Naja specimens described above.

VIPERIDAE Oppel, 1811

VIPERINAE Oppel, 1811

Genus VIPERA Laurenti, 1768 (sensu Szyndlar and Rage, 1999)
Type species. Coluber aspis Linnaeus, 1758.

"ORIENTAL VIPERS" COMPLEX (sensu Szyndlar and Rage, 1999)

"Oriental Vipers" complex indet.

Figure 38

Material. M1: two fangs (UU MAA 7115 and UU MAA 7281).

Description. The two isolated fangs are rather large (Figure 38). Specimen UU MAA 7281 is complete (Figure 38.1-5), whereas the other specimen, UU MAA 7115, misses its dorsal and ventral tips (Figure 38.6-10). The apical termination is slightly curved, with a wide pulpal cavity and venom canal situated anteriorly in central position. In dorsal view (Figure 38.5, 38.10), the base of the entrance orifice, which is situated in the anteriormost proximal
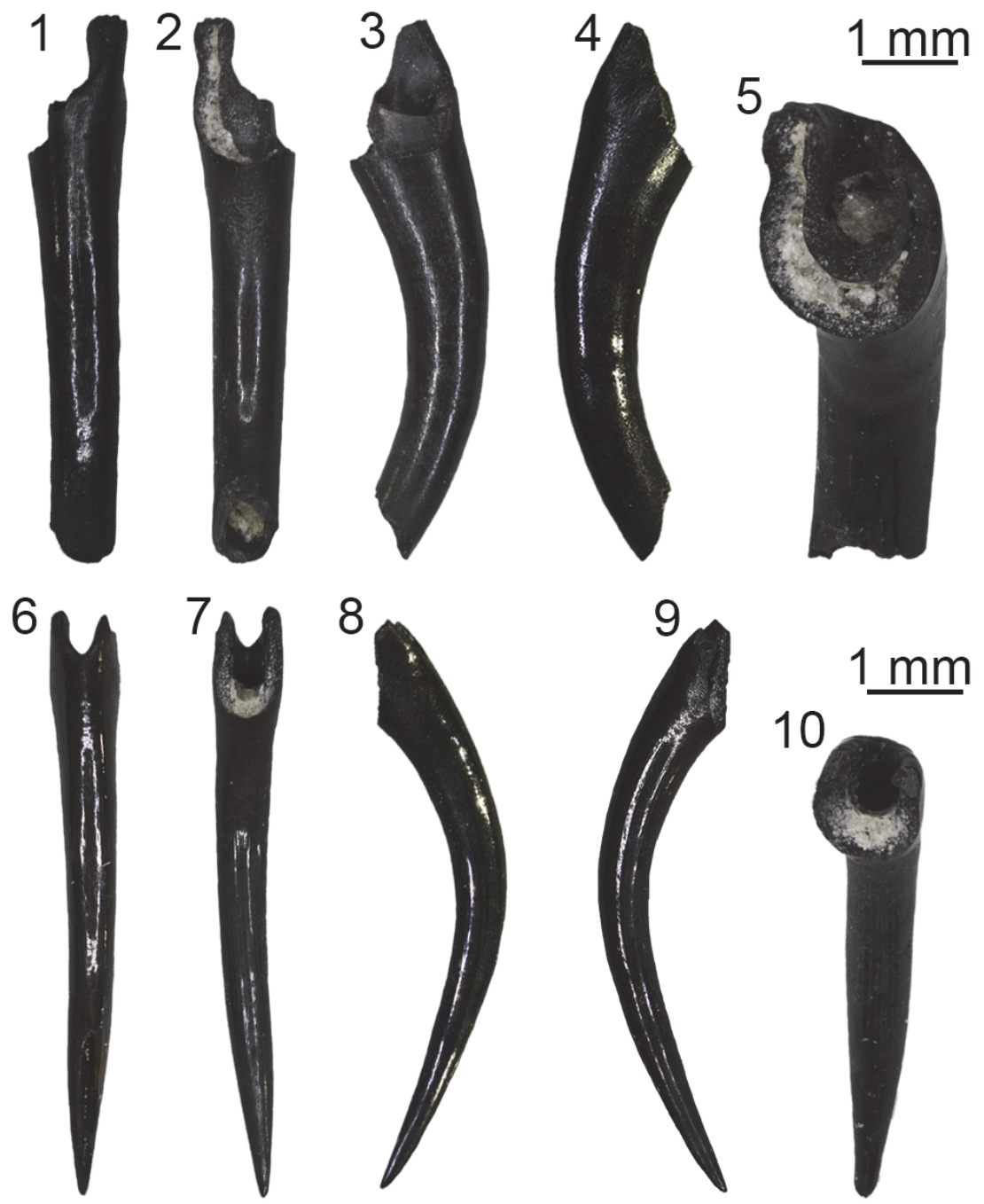

FIGURE 38. "Oriental vipers" complex indet. from Maramena: fang (UU MAA 7115) in anterior (1), posterior (2), right lateral (3), left lateral (4), and dorsal (5) views; fang (UU MAA 7281) in anterior (6), posterior (7), right lateral (8), left lateral (9), and dorsal (10) views. 
part of the element, is indicated by the separation of the dentine folds which form the anterior closure of the venom canal. In anterior view (Figure 38.1, 38.6), there is a distinct suture close to the distal termination of the element. This suture turns proximally into a narrow groove, which diminishes in front of the entrance orifice base where the fang surface is completely smooth. The discharge orifice is only preserved in UU MAA 7281. A wide groove occurs on both lateral sides of the fangs along their entire length.

Remarks. Both isolated fangs can be assigned to viperids on the basis of the presence of a closed venom canal which originated from the dentine folding throughout ontogeny. This mode of venom canal development is typical of viperids (Jackson, 2002; Zahradnicek et al., 2008). In elapid fangs, a distinct anterior groove extending from the entrance to the discharge orifice can be observed (Kuch et al., 2006; Broeckhoven and du Plessis, 2017; Vilakazi et al., 2018). Although this groove is usually well developed, it may be subjected to an important degree of variability. Indeed, one specimen of the extant African Naja melanoleuca Hallowell, 1857 (MDHC 138) possesses a distinct groove that runs transversely along the anterior surface of the fang, whereas in other specimens of the same species, this groove is (if present) rather narrow (e.g., see Bogert, 1943, figure 38). In viperid snakes, the anterior surface of fully developed fangs is usually completely smooth in the area between entrance and discharge orifices (Jackson, 2002; Zahradnicek et al., 2008). This is true not only for extant taxa but also for fossil viperids (Rage, 1976; Szyndlar, 1984; Ivanov, 1999; Bailon et al., 2002), including extinct representatives of the "Oriental Vipers" complex, e.g., Macrovipera burgenlandica (Bachmayer and Szyndlar, 1987) from the late Miocene of Kohfidisch, Austria (see Tempfer, 2005, figure 35). However, a thin line on the anterior fang surface can be observed in certain taxa, e.g., in the extant African viperid Bitis arietans Merrem, 1820 (specimen MDHC 136; see also Jackson, 2002, figure 2). The presence of a short and incompletely closed groove between the entrance and discharge orifices in the Maramena specimens indicates that development of both fangs was not finished yet (Zahradnícek et al., 2008). Therefore, most probably these fangs were not fully developed and the infolding tissue was not fully closed yet. The distinct lateral grooves stretching along the entire length of the fangs from Maramena are rather unusual in viperids although short lateral grooves frequently occur in both crotalines and viperines at the vicinity of the fang base (Georgalis et al., 2018d). No similar lateral grooves have been reported for elapids (Bogert, 1943). If our identification and referral to viperids is correct, the Maramena fangs are tentatively attributed to the "Oriental vipers" complex, mostly on the basis of their relatively large size and the fact that large vertebral material belonging to this group has been previously described from the same locality by Szyndlar (1995). In addition, isolated snake fangs from the nearby locality of Ano Metochi were recently described by Georgalis et al. (2017a) as Serpentes indet. One of these fangs (UU AM3 547) was figured in lateral view (Georgalis et al., 2017a, figure7Q), showing a slight hint of a groove in the anterior part. After further studying and comparing again the Ano Metochi and Maramena fangs, we tentatively attribute the above mentioned Ano Metochi isolated fang to Viperidae indet.

\section{Serpentes indet. \\ Figure 39}

Material. M1: a right dentary (UU MAA 7749), 16 trunk vertebrae (UU MAA 7773, UU MAA 7781, UU MAA 7783, UU MAA 7786, UU MAA 7796, UU MAA 7815, UU MAA 7816,UU MAA 7818, UU MAA 7846, UU MAA 7851, UU MAA 7866, UU MAA 7882, UU MAA 7953, UU MAA 7959, UU MAA 7960, and UU MAA 7966), two cloacal vertebrae (UU MAA 7771 and UU MAA 7795), two caudal vertebrae (UU MAA 7772 and UU MAA 7933), four series of fused caudal vertebrae (UU MAA 7414, UU MAA 7415, UU MAA 7422, and UU MAA 7964), and eight ribs (UU MAA 7764- UU MAA 7767, UU MAA 7793, UU MAA 7794, UU MAA 7956, and UU MAA 7957).

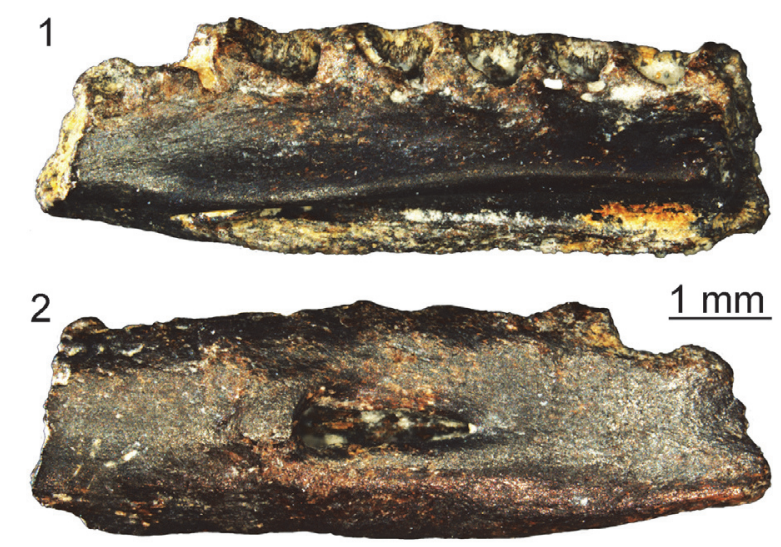

FIGURE 39. Serpentes indet. from Maramena: right dentary (UU MAA 7749) in lingual (1) and labial (2) views. 
Remarks. These specimens are either too incomplete or do not preserve any character for a more precise determination within snakes. Of special interest is a right dentary (UU MAA 7749), which, besides the viperid fangs described above, represents the sole known cranial material of snakes from Maramena (Figure 39). Nevertheless, this specimen is incomplete, with no teeth preserved, and cannot be assigned to a more precise taxonomic group.

\section{DISCUSSION}

\section{Diversity, Affinities, and Palaeobiogeography of the Maramena Herpetofauna}

The herpetofauna from the locality of Maramena, dated at the latest Miocene/earliest Pliocene (MN 13/14), represents the richest record of fossil amphibians and reptiles from Greece described so far. In fact, Maramena represents the most diverse Neogene assemblage of amphibians and reptiles not only from the country, but from the whole Eastern Mediterranean.

Previously, Neogene amphibians from Greece had only been described from the early Miocene localities of Aliveri (Euboea), Karydia (Thrace), and Lapsarna (Lesvos), and the late Miocene of Plakias (Crete) (Georgalis et al., 2016c; Vasileiadou et al. 2017; Georgalis et al., 2019) and were all significantly less abundant in both numbers of taxa and specimens. The amphibian assemblage from Maramena is represented by a diverse salamander (at least five taxa) and a poorer frog (at least three taxa) fauna. Urodelans include a giant salamander (Cryptobranchidae indet.), a small-sized Salamandrina, a medium and a small-sized newt of the genus Lissotriton (Lissotriton vulgaris group and Lissotriton sp. respectively), a larger-sized newt attributable to Ommatotriton, as well as a large salamander pertaining to the genus Salamandra. Indeterminate salamandrids are also present. The frog fauna includes taxa attributable to Latonia, Hyla, and Pelophylax, as well as additional specimens that cannot be confidently attributed to a certain group.

The palaeobiogeographic distribution of giant salamanders (Cryptobranchidae) in the European continent is nearly exclusively confined to Central Europe (Böhme et al., 2012). The cryptobranchid from Maramena represents the sole known fossil record of that clade in the Mediterranean region and, at the same time, their southernmost distribution. Furthermore, the Maramena cryptobranchid represents the earliest occurrence among the last phase of the expansion or the "reappearance" of giant salamanders in the European fossil record (Böhme et al., 2012). Considering their earlier (late Oligocene-early late Miocene) rich record in Central Europe and their absence from the southern portions of the continent, a dispersal from Central Europe to the southern Balkans appears to be probable.

The genus Salamandrina is nowadays distributed only in continental Italy (Sparreboom, 2014). The fossil record of this genus is rather poor, with scarce material known from the early Miocene of Oschiri in Sardinia, Italy (Venczel and Sanchíz, 2006), the late Miocene of Felsőtárkány 1, Hungary (Venczel and Hír, 2013), and the late Pliocene of Capo Mannu, Sardinia (Delfino et al., 2011). That scarce material nevertheless demonstrates a much wider distribution during the Neogene. Thus, the locality of Maramena lies well outside the former and present-day distribution range of Salamandrina, representing the easternmost occurrence of the genus. Taking into account the oldest occurrence of Salamandrina in the early Miocene of Sardinia (Venczel and Sanchíz, 2006), an origin of this lineage in the Mediterranean region cannot be excluded. However, that early Miocene Sardinian material was only briefly described and never figured, and as such, its exact affinities cannot be fully evaluated. In any case, the fossil record of Salamandrina is not known well enough to further conclude with certainty any exact palaeobiogeographic distribution patterns for that genus.

Salamanders of the Lissotriton vulgaris group, particularly the extant species Lissotriton vulgaris, currently have the widest distribution range among all known urodelans, ranging from Western Europe to Western Siberia (Sparreboom, 2014). The identification of fossil material attributable to the $L$. vulgaris group in the Maramena faunal assemblage is concordant with the wide Neogene distribution of this lineage (e.g., Estes, 1981; Tempfer, 2005; Böhme and Vasilyan, 2014) and also with the extant herpetofauna of northern Greece, where Lissotriton vulgaris is currently abundant (Valakos et al., 2008). The second Lissotriton taxon from Maramena represents an interesting find, since that vertebral material resembles in morphology a similar one referred to Lissotriton aff. rohrsi from the early Miocene of Mokrá-Western Quarry, 2/ 2003 Reptile Joint, Czech Republic (Ivanov, 2008). It is difficult to conclude whether the Greek and the Czech forms are truly related, as detailed skeletal studies of extant and extinct Lissotriton species are 
currently lacking. Furthermore, the exact affinities and the taxonomic content surrounding the taxon Lissotriton rohrsi (Herre, 1955) are as yet unresolved. Originally established as a species of the wastebasket genus Triturus Rafinesque, 1815 based on material from the middle Miocene (MN 6) of Devínska Nová Ves (= Neudorf = Neudorf a.d. March), Slovakia (Herre, 1955), its validity was only accepted with reluctance by Roček (1994a). Additional specimens have been referred to the same taxon from the latest Oligocene of Oberleichtersbach, Germany (Böhme, 2008), the early Miocene of Oberdorf, Austria (Sanchíz, 1998b), and the early late Miocene of Götzendorf, Austria (Miklas, 2002). The generic placement of $L$. rohrsi into Lissotriton was recently challenged by Martín et al. (2012), who suggested that this extinct species should be included into Ommatotriton, as they reported that it demonstrates a combination of vertebral features rather similar to the extant Ommatotriton vittatus. However, our observation of fossil specimens of Lissotriton rohrsi and comparison with recent individuals pertaining to Ommatotriton demonstrate the presence of significant differences in the vertebral morphology between these two taxa. Among the most important of these differences is the presence of dermal sculpture on the neural spine of $L$. rohrsi, whereas this feature is absent in members of Ommatotriton. Furthermore, a ventral lamina is absent on the ventral surface of the vertebrae of $L$. rohrsi, whereas this is present and triangular-shaped in Ommatotriton. As such, we herein consider $L$. rohrsi as a member of the genus Lissotriton and not Ommatotriton.

The genus Ommatotriton is represented in Maramena on the basis of vertebral and appendicular material, and this occurrence represents an interesting find. Extant species of this genus are currently distributed in the Middle East, eastern Anatolia, and the Caucasus (Riemsdijk et al., 2017), where the data on the palaeoherpetofauna are extremely scarce. As such, if our identification is correct, then the new Maramena specimens represent the first reliable finds of Ommatotriton in the fossil record and accordingly extend that lineage back to the latest Miocene/earliest Pliocene and widen its geographic distribution.

Currently, six extant species of the genus Salamandra are known in Europe, Northwest Africa and Middle East (Sparreboom, 2014). In Europe, the genus Salamandra has one of the most abundant fossil record among urodelans, ranging from the earliest Oligocene until the Quaternary (Estes, 1981; Roček, 1994a). The Salamandra material from Maramena described herein represents the first fossil occurrence of the genus in Greece and enlarges its Neogene European range to the southeast. It is also remarkable that during the latest Miocene, Salamandra is absent from other European localities. Salamandra salamandra is currently a common inhabitant of the modern ecosystems around the Maramena area (Valakos et al., 2008).

Among the frog fauna of Maramena, Latonia is by far the most abundant. Indeed, that genus is known to have achieved a rather broad geographic distribution across various Neogene and early Quaternary localities of Europe and Anatolia (Roček, 1994b, 2013; Vasilyan et al., 2014; Georgalis et al., 2019; Villa et al., 2019). So far, Latonia in Greece was known only by recently described finds from the early Miocene localities of Aliveri and Karydia (Georgalis et al., 2019). The new Maramena remains confirm that Latonia was probably present in the region throughout the Miocene.

Hyla and Pelophylax are currently widespread elements of the extant Greek amphibian fauna (Valakos et al., 2008), however, their fossil record from the area is practically unknown. In fact, the Hyla material from Maramena documents the first description of this genus from Greece. The genus Pelophylax was so far similarly totally absent from the Greek fossil record, with the only exception of much younger remains from the Pleistocene of Crete, and perhaps also Kos islands (Sanchíz, 1984). Nevertheless, the identification of both Hyla and Pelophylax in the latest Miocene or earliest Pliocene of Maramena documents that both these lineages were probably already present in the Greek area by the late Neogene.

Turtles are represented in the fossil herpetofauna of Maramena by the geoemydid Mauremys aristotelica and possibly also an indeterminate testudinid. The new specimens add to the previously described material from the same locality by Gad (1990), which is also herein referred to $M$. aristotelica. The new geoemydid remains further expand the known geographical distribution of this species, which was previously known from three northern Greek localities situated relatively near to Maramena (Vlachos et al., 2019). The new Maramena specimens confirm that the lineage of Mauremys was rather abundant and common in the Neogene of Greece taking into consideration that all previously described fossil specimens from the area pertain to this genus (Georgalis and Kear, 2013; Vlachos et al., 2015; Georgalis et al., 2016c; Vlachos and Tsoukala, 2016; Vlachos et al., 2019). 
This relatively low and seemingly monogeneric diversity of Greek Neogene geoemydids is further supported by the new Maramena finds, although we still agree with previous suggestions that at least two distinct species have been present in the area, judging from the fact that the older (MN 9) Mauremys sp. from Plakias, Crete (Georgalis et al., 2016c), is clearly distinct from the younger (MN 13-16) M. aristotelica (Vlachos et al., 2019). Interestingly, the phylogenetic analysis of Vlachos et al. (2019) recovered Mauremys aristotelica as the sister taxon of the slightly older late Miocene (MN 12) Italian species Mauremys campanii (Ristori, 1891), implying a possible dispersal from Italy to the Greek area during the MSC event. The abovementioned, so far undescribed, costal MGPT-PU 142091 from the early Pleistocene of Pirro Nord, southern Italy, could eventually indicate that the lineage of Mauremys campanii + Mauremys aristotelica could even have survived into the Quaternary, but this is of course a hypothesis that needs to be to be evaluated.

The isolated limb osteoderm of the probable testudinid does not offer important insight on its exact taxonomic affinities. Nevertheless, it documents the presence of a second chelonian clade in Maramena and is also fully consistent with the abundance of testudinids in the latest Miocene and earliest Pliocene of Greece (Georgalis and Kear, 2013). The extreme rarity of testudinids in the Maramena fossil material, solely represented by this isolated limb osteoderm, and not even by one shell remain, can be probably attributed to ecological or taphonomical factors, considering that the environmental reconstruction of the locality indicates the presence of a large lake, surrounded by a subtropical forest (Schmidt-Kittler et al., 1995).

Squamate remains from Maramena are by far the most abundant elements in the herpetofauna of the locality. Lizards are represented by agamine agamids, lacertids, another bizarre probable lacertid, the cordylid aff. Palaeocordylus sp., probable scincids, multiple anguines (Anguis, Pseudopus, and at least five morphotypes of Ophisaurus), the varanid Varanus (at least one species), and indeterminate forms. Snakes are represented by scolecophidians, the "colubrines" Periergophis micros gen. et sp. nov., Paraxenophis spanios gen. et sp. nov., Hierophis cf. hungaricus (not present in the material here described, but identified in Szyndlar's [1995] described material; see below), and at least one other different "colubrine" morphotype, the natricines Natrix aff. rudabanyaensis and a second indetrminate species of Natrix, the elapids Naja sp. and cf. Micrurus sp., viperids of the "Oriental Vipers" complex, and indeterminate forms. This high diversity and large amount of material renders the fauna of Maramena as by far the richest among all fossil squamate faunas from Greece and the Eastern Mediterranean as a whole.

Agamids are currently present in insular and few sporadic continental regions in Greece, all belonging to a single species, Stellagama stellio (Linnaeus, 1758) (Valakos et al., 2008; Baig et al., 2012). In fact, this rather patchy distribution in mainland Greece has been variously suggested to be the result of anthropogenic transportation of Stellagama stellio during historic times. The abundant agamid material from Maramena described herein, along with the previously reported maxilla from the same locality (Richter, 1995), documents that agamids were already present in northern mainland Greece by the latest Miocene/earliest Pliocene. Few studies have dealt with the skeletal anatomy of extant agamids, most of them conducted several decades ago (Siebenrock, 1895; Beddard, 1905; El-Toubi, 1945) or mostly focusing on Western and Central Asian (Zarevsky, 1929; Ananjeva, 1977, 1998; Fathinia et al., 2011) and Australian taxa (Covacevich et al., 1990; Stilson et al., 2017). Taking into consideration that the skeletal anatomy of the modern taxa is not adequately comprehended (e.g., Delfino et al., 2008; Villa et al., 2017), there cannot be reliable evidence whether the Maramena agamids and the extant Stellagama stellio pertain to the same single lineage. Furthermore, apart from the genus Stellagama Baig, Wagner, Ananjeva and Böhme, 2012, three other agamine genera (Paralaudakia Baig, Wagner, Ananjeva and Böhme, 2012, Phrynocephalus Kaup, 1825, and Trapelus Cuvier, 1817) currently inhabit eastern Anatolia, so it cannot be excluded that any of these lineages had achieved a wider range that also encompassed the Balkans during the Neogene. Nevertheless, affinities of the Maramena specimens with Phrynocephalus and Trapelus can be tentatively excluded, as the cranial anatomy of these genera is relatively well known (Zarevsky, 1929; Ananjeva, 1998; Fathinia et al., 2011), at least for agamid standards, and seem to be quite distinct. In any case, the Maramena fossil material cannot provide confident answers to the question whether agamid lizards were indeed continuously present in Greece since the latest Miocene/earliest Pliocene or if the modern populations were simply introduced during historical times. It is worth noting that a purported fossil agamid had also been reported (without any description or fig- 
ure) from the nearby locality of Ano Metochi (Delfino et al., 2008), however, this material was recently demonstrated to pertain to fish (Georgalis et al., 2017a). In any case, the Maramena agamids represent the sole confirmed described fossil occurrence of this clade from Greece.

Lacertids are currently the most diverse reptile group in modern Greek herpetofaunas, comprising also several endemic species (Arnold et al., 2007; Sindaco and Jeremčenko, 2008; Valakos et al., 2008). It seems that the Maramena lacertid assemblage was not diverse, probably comprising only two taxa, thus contrasting with modern herpetofaunas of the region (e.g., Sindaco and Jeremčenko, 2008; Sillero et al., 2014) but also with coeval European fossil localities, which are more speciose (e.g., Polgárdi; Venczel, 2006). In any case, the lacertids from Maramena add to the previously known records of that clade in the Miocene of Greece (Richter, 1995; Georgalis et al., 2017a; Vasileiadou et al., 2017; Georgalis et al., 2019). The current inadequate knowledge of the skeletal anatomy of most extant lacertid taxa (e.g., Villa et al., 2017) hinders the understanding of the exact affinities of the Greek fossil forms, and as such we cannot ascertain to which of the several lacertid lineages the Maramena specimens pertain. The tooth bearing bone UU MAA 7033, with its unusual tricuspid teeth, indicates the presence of an additional distinct lizard taxon in Maramena, however, its poor preservation precludes an exact taxonomic assignment. As such, affinities of that specimen with any of the fossil European tricuspid tooth bearing lineages (lacertids, teiids, and iguanids) cannot be evaluated, although on the basis of biogeographic and stratigraphic rationale, it seems more likely that it pertains to lacertids. Among European extinct lacertids, this Maramena form resembles most closely Miolacerta tenuis from the early Miocene (MN 4) of Dolnice, Czech Republic (Roček, 1984), but the two forms can be differentiated on the basis of certain features of their teeth.

As was pointed out by Georgalis et al. (2017a), the cordylids from Ano Metochi and Maramena represent the youngest occurrences of this lizard clade from the European continent. The new abundant cordylid specimens from Maramena further reinforce that previous taxonomic assignement, but also allow a more precise systematic determination by referring this (and also the Ano Metochi) material to aff. Palaeocordylus sp. Therefore, affinities of the Greek cordylids with that Central European genus imply indeed a southeastern range withdrawal and late survival of this lineage of
European girdled lizards. The Maramena cordylids are confirmed as the youngest European cordylids and, as such, the ultimate extinction date of that lizard clade from the continent should be placed around or after the Miocene/Pliocene transition (MN 13/14).

The fragmentary material of the new probable scincids from Maramena described herein does not afford any adequate further taxonomic assignement or comparison with any of the four extant scincid lineages (Ablepharus Fitzinger, 1824, Chalcides Laurenti, 1768, Heremites Gray, 1845, and Ophiomorus Duméril and Bibron, 1839) that currently inhabit Greece, or with Eumeces Wiegmann, 1834 , that is found in adjacent Anatolia (Kumlutas et al., 2007; Sindaco and Jeremčenko, 2008; Valakos et al., 2008). The only previously recorded mention of fossil scincids from Greece consisted of material from Late Pleistocene or Holocene caves: material from Vraona Cave, near Athens, that was attributed to the extant Ablepharus kitaibelii (Bibron and Bory de Saint-Vincent, 1833) by Rauscher (1995), and material from Sarakenos Cave, Boeotia, Sterea Hellas, which was tentatively referred to Chalcides by Wilczyński et al. (2016). However, this purported Ablepharus and Chalcides material has never been figured (and for the latter, not even collection numbers were provided), and as such, the validity of Rauscher's (1995) and Wilczyński's et al. (2016) taxonomic claims cannot be substantiated. Therefore, the new Maramena material probably represents the first known fossil material of scincids from Greece. Nevertheless, scincids are relatively poorly represented in the Neogene and Quaternary record of Europe and in fact, the only genera that have been reliably identified are Chalcides Laurenti, 1768, known from remains from the Miocene of Hungary (Venczel and Hír, 2013) and the Quaternary of Spain (Blain and Bailon, 2010; López-García et al., 2011; Bailon, 2014), Eumeces from the Holocene of Cyprus (Croft et al., 2017), and Heremites from the late Miocene of European Russia (Čerňanský and Syromyatnikova, in press). Tropidophorus bavaricus Böhme, 2010, a scincid taxon established from the middle Miocene (MN 5) of Sandelzhausen, Germany, was suggested by Böhme (2010) to belong to the extant Tropidophorus Duméril and Bibron, 1839, a genus of semiaquatic skinks, which currently inhabits southeastern Asia, Indonesia, and Philippines (Truong et al., 2010). However, we consider that any resemblance between $T$. bavaricus and the extant Tropidophorus spp. is only superficial, and these forms share only anatomical traits that are 
rather generalized among scincids. Accordingly, we provisionally discard the generic attribution of the Miocene German taxon to Tropidophorus and suggest that it should be referred to a different genus. It is of course beyond the scope of this paper to assess the validity or the generic assignment of this taxon and, pending a revision and redescription of the respective material, we suggest treating the genus name in quotation marks as "Tropidophorus" bavaricus.

Anguids are currently abundant and diverse in extant Greek herpetofaunas, pertaining to species belonging to two genera: the small-sized Anguis and the much larger Pseudopus (Valakos et al., 2008; Georgalis et al., 2017a). So far, anguid fossils from Greece had only been described from few early and late Miocene localities (Richter, 1995; Georgalis et al., 2018b, 2019), including also Ano Metochi (Georgalis et al., 2017a), whereas they have also been recovered from multiple localities in the Oligocene and Miocene of nearby Turkey (Čerňanský et al., 2017; Syromyatnikova et al., 2019). The new anguid material from Maramena is by far the most abundant and demonstrates that the anguid fauna of Greece during the latest Miocene/earliest Pliocene was rather diverse with multiple taxa belonging to Anguis, Ophisaurus, and Pseudopus. The large number of morphotypes (five) within Ophisaurus material from Maramena is truly remarkable, although it cannot be fully evaluated whether and how this diversity of morphs also reflects species level taxonomy or if it could simply be attributed to some kind of intraspecific (e.g., ontogenetic) variation, or tooth wear. Interestingly, similar numbers of different anguine taxa and/or morphotypes in the Neogene of Europe are only recorded in the early Miocene of Merkur-Nord (MN 3) (Klembara, 1981, 2012, 2015; Klembara and Rummel, 2018) and, to a lesser degree, Dolnice (MN 4) (Klembara, 1979, 1981; Roček, 1984; Klembara and Rummel, 2018), both in Czech Republic. This pattern of relatively similar morphotypes and diversity among the anguines of MerkurNord and Maramena is rather bizarre, considering the large chronological and geographic distance of the Czech and Greek localities. In any case, the Ophisaurus remains from Maramena represent the youngest occurrence of this genus from Eastern Europe. Regarding the Anguis and Pseudopus genera, currently present in Greece, remains from Maramena document their first fossil occurrences from Greece, extending their lineages back to the latest Miocene/earliest Pliocene. Note that a record of Pseudopus apodus from the Late Pleistocene-
Holocene of Vraona Cave, near Athens, was mentioned by Rauscher (1995) but was not accompanied by any figure and thus cannot be evaluated. Interestingly, the resemblance of the Pseudopus material from Maramena with that of Pseudopus pannonicus could hint for a potential geographic expansion of that species in the southern Balkan area.

The varanid material from Maramena, represented solely by isolated teeth and caudal vertebrae, does not provide any information about its exact species level affinities. The four different types of serration on the available teeth leave open the possibility that even more than one species of Varanus coexisted in the locality, though alternatively this could be attributed to, some as yet unresolved, intraspecific variation or even taphonomic reasons. Nevertheless, these new specimens add to the already known occurrences of monitor lizards from the country, which were so far described from the late Miocene of Thessaloniki area (MN 10; Georgalis et al., 2018b), Pikermi (MN 12; Gaudry, 1862-1867; Villa et al., 2018a), and Samos (MN 12; Conrad et al., 2012; Villa et al., 2018a), and the Middle Pleistocene of Tourkobounia-5 (Georgalis et al., 2017b), the latter being the youngest record of varanids from the whole Europe.

Scolecophidians generally constitute rather rare finds in fossil herpetofaunas, a fact apparently not reflecting genuine absence from Cenozoic ecosystems, but mostly caused due to the extremely small size and fragile nature of their remains (Vidal et al., 2009; Mead, 2013; Georgalis et al., 2017a). As such, apart from few scarce descriptions of scolecophidians from the Pliocene and Quaternary of various Greek localities (Szyndlar, 1991a) and a single, recently described Miocene record from Ano Metochi (Georgalis et al., 2017a), this clade is virtually unknown from the country. Furthermore, no fossil cranial remains have ever been found and, frustratingly, their vertebral anatomy is so conservative and similar among taxa that it does not permit distinguishing diagnostic taxonomic features. This taxonomic problem should be mostly attributed to the unfortunate fact that only few studies have dealt with the skeletal anatomy of extant scolecophidians, and that the rare studies focused on cranial features (e.g., List, 1966; Rieppel, 1979; Kraus, 2017; Chretien et al., 2019). As such, the two distinct scolecophidian clades that currently inhabit the northeastern Mediterranean, i.e., Typhlopidae (genera Letheobia Cope, 1869, and Xerotyphlops Hedges, Marion, Lipp, Marin, and Vidal, 2014), and Leptotyphlopidae (genus Myriop- 
holis Hedges, Adalsteinsson, and Branch in Adalsteinsson et al., 2009) cannot be reliably identified in the European fossil record. This is rather frustrating, given that typhlopids and leptotyphlopids are believed to have diverged from each other during the Mesozoic (Adalsteinsson et al., 2009; Vidal et al., 2009; Miralles et al., 2018). Taking into consideration all these aspects, it is currently impossible to determine whether the new Maramena scolecophidians pertain to any of these genera or even represent a now locally or totally extinct lineage.

Regarding the relatively diverse (at least four species) assemblage of "colubrines" from Maramena, they seem to provide contrasting biogeographic conclusions. The tiny "colubrine" Periergophis micros gen. et sp. nov. appears to be an abundant element of the Maramena herpetofauna. Its rather characteristic morphology (especially the anteroventrally directed tubercles on the wide haemal keel of the posterior trunk vertebrae) makes this snake readily distinctive among other European fossil and extant taxa. The same applies for the other distinctive "colubrine" from Maramena, Paraxenophis spanios gen. et sp. nov., as the lateral notches observed on the haemal keels of its vertebrae have never been described from other European taxa. Taking into consideration the total absence of related forms in Europe, the origin of Periergophis gen. nov. and Paraxenophis gen. nov. remains a mystery, and an origin from Africa or Asia cannot be excluded. Affinities of these two new snake genera from Maramena with other caenophidian lineages, such as dipsadids, lamprophiids, and psammophiids cannot be excluded.

A distinct morphotype/taxon of "colubrines" ("Colubrinae" indet. [morphotype 1]) also seems to have been present in Maramena, however, considering that its exact affinities are not resolved, it cannot offer any biogeographic insights.

Besides the above described "colubrines" found in our new material from Maramena, it seems that a further distinct taxon existed in the same locality, having affinities with Hierophis hungaricus (Bolkay, 1913). This Maramena material was originally described and figured by Szyndlar (1995) as an indeterminate "colubrine", but it was subsequently suggested to be probably referrable to Hierophis hungaricus by Venczel (1998). The latter view also later convinced Szyndlar (2005). Judging from the published figure of Szyndlar (1995, figure 1A-E), we here formally refer that material to Hierophis cf. hungaricus. Among Maramena "colubrines", Hierophis cf. hungaricus resembles most closely Paraxenophis spanios gen. et sp. nov. However, the former taxon still differs from the latter one, most prominently by the absence of lateral notches of its haemal keel and the shape of the anterior border of its zygosphenal roof, which possesses a rather distinct medial lobe, whereas that feature is usually absent or at least only slightly visible in Paraxenophis spanios gen. et sp. nov. Hierophis hungaricus was formerly known from the middle Miocene of Germany (Ivanov and Böhme, 2011), the late Miocene of Hungary (Bolkay, 1913; Venczel, 1998; Szyndlar, 2005), and the early Pliocene of Hungary (Venczel, 2001), with similar or conspecific forms also known from the middle Miocene of Hungary (Venczel and Hír, 2013), Romania (Venczel and Ştiucă, 2008), and even Kazakhstan (Ivanov et al., 2019). Thus, the referral of Szyndlar's (1995) "colubrine" to Hierophis cf. hungaricus extends to the south the geographic range of that Central European snake species and further adds an extra snake taxon to the Maramena herpetofauna. The fact that no other specimen of Hierophis cf. hungaricus was recovered among the new material herein and that the taxon is only known from Szyndlar's (1995) specimens could probably be attributed to the rarity of this snake or even ecological or taphonomical factors that did not favour its preservation.

Similarly, another taxon that was originally typified from the Neogene of Hungary, Natrix aff. rudabanyaensis, is now also described from Maramena. This species was only previously known from the late Miocene (MN 9) of Rudabánya, Hungary (Szyndlar, 2005) and other few tentatively referred occurrences from the middle and late Miocene of Hungary and Romania (Venczel and Ştiucă, 2008; Venczel, 2011; Venczel and Hír, 2013). On the basis of the available material, it is not easy to attest whether the Maramena form is indeed conspecific with the Hungarian taxon or simply bears some strong resemblance - if the former is the case, however, then this identification provides an interesting geographical and biochronological expansion for Natrix rudabanyaensis. A second, distinct, though indeterminate species of Natrix also exists in Maramena, denoting that natricines were more diverse in that locality, achieving a higher diversity in the latest Miocene/earliest Pliocene of southeastearn Europe.

Cobras of the genus Naja had already been described from Maramena (Szyndlar, 1995). In fact, cobras have been so far only rarely recorded from Greece and, besides Maramena, they were known only from the late Miocene (MN 10) of Ravin 
de la Pluie (Georgalis et al., 2018b) and the late Pliocene (MN 16) of Tourkobounia 1 (Szyndlar and Zerova, 1990; Szyndlar, 1991b). In any case, the presence of the cobra Naja in the late Miocene and Pliocene of Greece is fully concordant with the presence of that genus in approximately coeval deposits in Spain (Szyndlar, 1985; Szyndlar and Rage, 1990), France (Hoffstetter, 1939; Rage, 2013), and Turkey (Rage and Sen, 1976). The extant Neotropical elapid genus Micrurus has also sporadic occurrences in the Miocene of Europe. The only named fossil taxon, Micrurus gallicus, has been described from the early and middle Miocene of France (Rage and Holman, 1984; Augé and Rage, 2000; Rage and Bailon, 2005) and the early Miocene of Germany (Szyndlar and Schleich, 1993), but similar forms have also been reported from the early-middle Miocene of France (Ivanov, 2000) and the middle Miocene of Germany (Ivanov and Böhme, 2011). As such, if our identification of the single vertebra from Maramena is correct, then it consists by far the youngest record of Micrurus in Europe and the Old World in general, significantly extending the time-range of this lineage from the middle Miocene (MN 6) to the latest Miocene/earliest Pliocene (MN 13/14), and expanding its geographic distribution to the East of the continent.

The viperid fangs from Maramena further demonstrate the presence of the large-sized "Oriental Vipers" in Maramena, as was previouly reported by Szyndlar (1995) on the basis of vertebral elements. "Oriental Vipers" currently inhabit Greece and Anatolia, represented by the distinct genera Macrovipera Reuss, 1927, and Montivipera Nilson, Tuniyev, Andrén, Orlov, Joger, and Herrmann, 1999. However, the distinction among these two extant lineages has been exclusively made on the basis of either external morphology or molecular data (e.g., Nilson and Andrén, 1986; Herrmann et al., 1992). On the contrary, as fossils usually do not preserve external morphological or molecular data, palaeontologists have mostly used vertebral structural characteristics to refer large-sized viperid specimens to the "Oriental Vipers" complex, considering that it is not currently possible to precisely distinguish them at the genus level (Szyndlar, 1984, 1991b; Szyndlar and Rage, 1999, 2002; Georgalis et al., 2016a). On the other hand, Codrea et al. (2017a) recently stated that it could be possible to differentiate fossil vertebrae of Macrovipera from Montivipera. However, these authors provided no characters for Montivipera, except for the fact that its vertebrae are usually smaller than Macrovipera, whereas the vertebral characters they provided for Macrovipera were in fact mostly rather generalized features for viperids (Codrea et al., 2017a). In any case, distinctive features among vertebrae of Macrovipera and Montivipera seem to do indeed exist (GLG, pers. observ.), but pending a detailed and comprehensive analysis of their vertebral anatomy, which could assess the huge variation among the whole skeletal column, we herein provisionally follow previous workers and assign most European fossil occurrences of large-sized viperids to the "Oriental Vipers" complex. Laophis crotaloides Owen, 1857, from the early Pliocene (MN 15) of the Thessaloniki area in Greece, is one of the prominent exceptions to this rule, as this gigantic (centrum length more than $15 \mathrm{~mm}$ ) taxon is rather distinct from all other European related species and cannot be further assigned with confidence to any viperid subclade (Georgalis et al., 2016a). Anyway, the taxonomic uncertainty about the alpha taxonomy of fossil "Oriental Vipers" further hinders the understanding about the biogeography and evolutionary patterns of these large snakes, especially considering that divergence dates on the basis of molecular data between extant Macrovipera and Montivipera suggest that the two lineages had already diverged by around the middle Miocene (Langhian) (Stümpel et al., 2016).

Being represented by at least 30 different taxa (six salamander, three frog, two turtle, nine lizard, and 10 snake species), Maramena represents an extremely rich assemblage of amphibians and reptiles and ranks as the most diverse herpetofauna from the latest Miocene/earliest Pliocene (Messinian/Zanclean) of Europe, surpassing by far in species numbers the rich (or moderately rich) faunas of Ano Metochi (Greece, MN 13; Georgalis et al., 2017a), Moncucco Torinese (Italy, MN 13; Colombero et al., 2017), Monticino (Italy, MN 13; Rook et al., 2015), Verduno (Italy, MN 13; Colombero et al., 2014), Ciabòt Cagna (Italy, MN 13; Cavallo and Repetto, 1988; Cavallo et al., 1993), Polgárdi (Hungary, MN 13; Kormos, 1911; Bolkay, 1913; Fejérváry-Lángh, 1923; Szunyoghy, 1932; Szalai, 1934; Młynarski, 1966; Szyndlar, 1991b; Venczel, 1994, 1998; Venczel and Várdai, 2000; Venczel, 2006), Osztramos (Hungary, MN 14; Venczel, 2001), Solnechnodolsk (Russia, MN 13; Syromyatnikova, 2019; Čerňanský et al., 2018; Čerňanský and Syromyatnikova, 2019, in press), and Algora (Spain, MN 13; Szyndlar, 1985) (Table 1).Maramena is notable among these localities for uniquely possessing cryptobranchids, cordylids, and of course the two new bizarre "colubrines" 


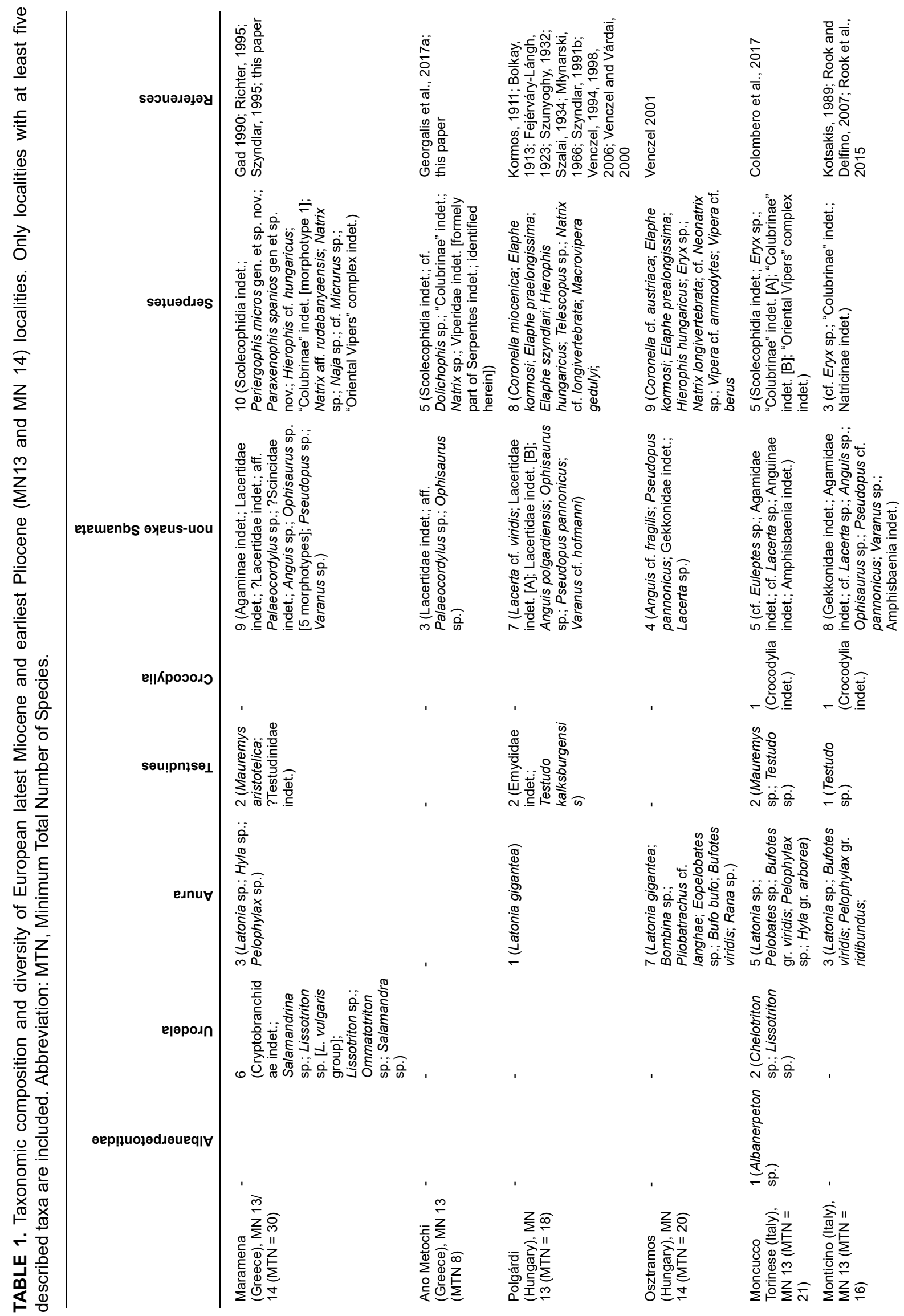




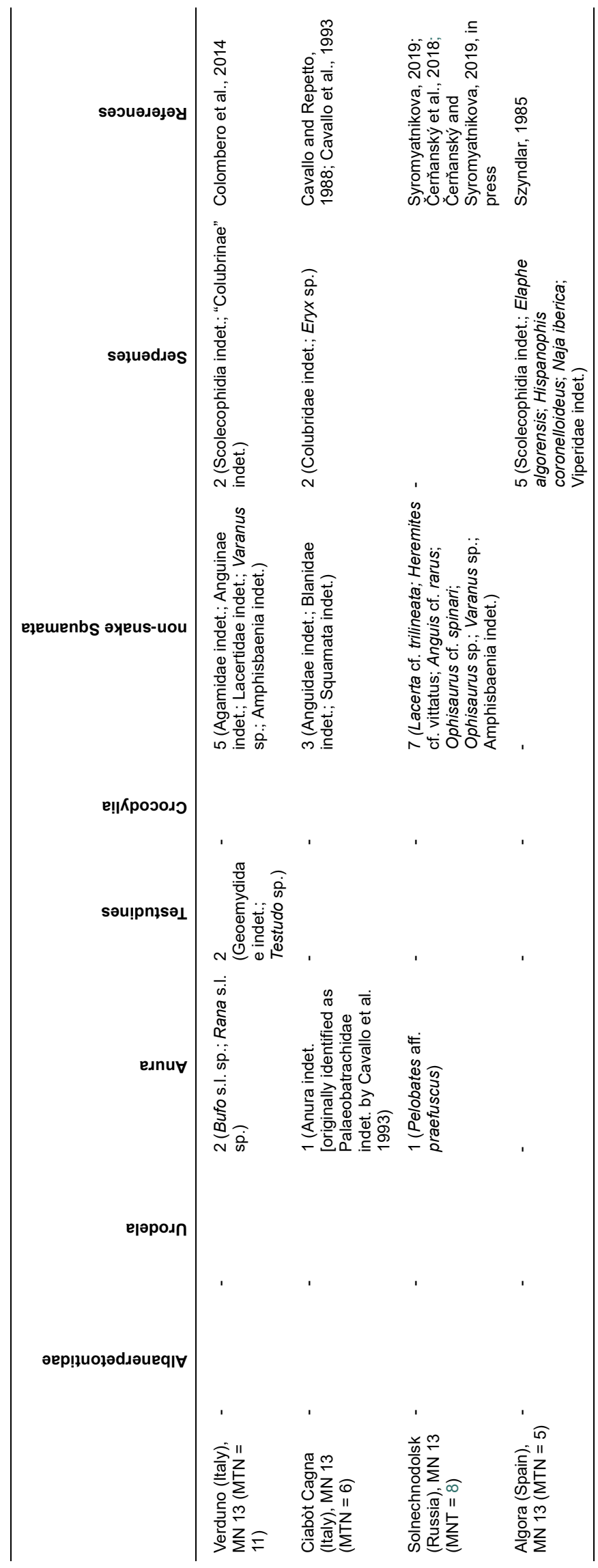


Periergophis gen. nov. and Paraxenophis gen. nov. It is also noticeable that the anuran genera Pelobates Wagler, 1830, Bufo Laurenti, 1768, Butofes Rafinesque, 1815, and Rana Linnaeus, 1758, that are widely distributed in the Neogene of Europe (Sanchíz, 1998a; Rage and Roček, 2003; Syromyatnikova, 2019), are completely missing from Maramena. Interestingly also, Maramena lacks gekkotans, amphisbaenians, and erycines, which are otherwise present in the Italian localities of Moncucco Torinese (Colombero et al., 2017) and Monticino (Rook et al., 2015), with amphisbaenians also present in Solnechnodolsk (Čerňanský et al., 2018). Furthermore, Maramena is characterized by the absence of certain "colubrine" genera such as Coronella, Elaphe (sensu lato), and Telescopus, which are otherwise present in Polgárdi (Venczel, 1998). In contrast, all the above mentioned frog, turtle, and squamate lineages that are absent as fossils from Maramena (except for amphisbaenians) are currently present in the extant fauna of northern Greece (Valakos et al., 2008), but nevertheless, amphisbaenians inhabit certain Greek islands and adjacent Anatolia and also have Miocene and Pliocene occurrences in both Greece and Turkey (Rage and Sen, 1976; Georgalis et al., 2016c, 2018a), including a Pliocene record from the locality of Spilia-4, which is situated only a few kilometers away from Maramena (Georgalis et al., 2018c). As such, this absence could probably be attributable to taphonomy or collection bias, although ecological settings could have also played a major role. The absence of pan-trionychids from Maramena could also be explained by ecological or taphonomical factors, as these turtles were present in the late Miocene and early Pliocene of the Northern Mediterranean (including Greece). However, at that time, they were already not frequent components of these faunal assemblages (Georgalis and Joyce, 2017). The record of the now extinct lineage of palaeobatrachids in the late Miocene (MN 13) of the Italian locality of Ciabòt Cagna (Cavallo et al., 1993) is probably erroneous as the figured synsacrum of Cavallo et al. (1993, figure 4A) clearly cannot pertain to that frog group (the centrum is circular, whereas it is compressed in palaeobatrachids) and can only be identified as an indeterminate anuran. What appears to be probably genuine is the absence from Maramena of albanerpetontids and crocodylians, which are known (although rare) in latest Miocene localities from Italy (Colombero et al., 2014, 2017). Indeed, the youngest crocodylians from southeastern Europe are only known from much older sedi- ments (MN 9, Plakias [Crete]; Georgalis et al., 2016c), whereas albanerpetontids have never been described from that portion of the continent, despite the fact that they went globally extinct as recently as the early Quaternary and their youngest records are known from nearby Italy (Delfino and Sala, 2007).

Certain herpetofaunal elements from Maramena imply Central European affinities of this Greek assemblage. Indeed, the cordylid aff. Palaeocordylus sp. and the multiple morphotypes of Ophisaurus from the latest Miocene/earliest Pliocene (MN 13/14) of Maramena suggest a striking and unexpected resemblance with the much older respective taxa/forms from the early Miocene (MN 3) of Merkur-Nord, Czech Republic. Could that imply a southeastern withdrawal range of these early Miocene taxa and their late local survival during the Miocene? Additional remains are certainly needed in order to adequately resolve the alpha taxonomy of all these forms. The Central European affinities of the Maramena herpetofauna are also further supported by the probable presence of Micrurus (or at least a related form) in the Greek locality, considering that that genus had been previously considered to have a relatively restricted geographic and stratigraphic distribution in Europe, spanning from the early Miocene (MN 4) to the middle Miocene (MN 7/8) of France and Germany (Rage and Holman, 1984; Szyndlar and Schleich, 1993; Ivanov, 2000; Rage and Bailon, 2005; Ivanov and Böhme, 2011). Interestingly, a faunal correlation between Hungarian and northern Greek localities had already been suggested on the basis of mammal finds, though this concerned coeval Tortonian sites (Rook et al., 2005). However, especially regarding snakes, the absence from Maramena of the extant Coronella and Telescopus and the extinct Texasophis is a striking difference with the Central European faunas, as these genera are represented in middle and late Miocene localities of the latter area (e.g., Codrea et al., 2018). In any case, a southward range constriction of Central European taxa during the Neogene has also been proposed for other Maramena taxa, such as agamids, cordylids, scolecophidians, Naja, and "Oriental Vipers" (Szyndlar and Rage, 1990; Szyndlar, 1991a; Szyndlar and Rage, 1999, 2002; Delfino et al., 2008; Georgalis et al., 2016a, 2017a, 2018a). Indeed, the Greek area has repeatedly served as a "refugium" for certain reptile lineages throughout the late Neogene and Quaternary (Georgalis et al., 2017a, 2017b, 2018c). On the other hand, the latest Miocene witnessed a rather 
important event, the so called Messinian Salinity Crisis (MSC), which tremendously affected the palaeoenvironmens of the Mediterranean (Krijgsman et al., 1999; Rouchy and Caruso, 2006; Carnevale et al., 2008; Ivanovic et al., 2014; Koufos and Vasileiadou, 2015; Carnevale et al., 2017, 2019). During this event that occurred at the latest Miocene, around 5.96-5.33 Ma, the Mediterranean Sea has significantly dried due to the closure of the Straight of Gibraltar at the west and its isolation from the Atlantic Ocean (Hsü, 1972; Krijgsman et al., 1999). As such, during the MSC, several areas in the Mediterranean (including also parts of the Aegean Sea and surrounding areas) that formerly formed a marine environment were now transformed into "extensive saline deserts or even saline/hypersaline lakes" (Poulakakis et al., 2015:19). Significant vegetation turnovers and habitat alterations took place at that time (Cerling et al., 1997). The effects of the MSC on Neogene faunal assemblages of the Mediterranean are not yet fully resolved, but nevertheless, it has been suggested that certain terrestrial micromammal taxa with African affinities had managed to disperse into southern Europe (also into the Balkans) during that time interval (Koufos and Vasileiadou, 2015), and even hominid primates were recently considered to have reached Crete from Africa, though the latter record is only based on fossilized footprints and should be considered with caution (Gierliński et al., 2017). Indeed, the various extended "saline deserts" that appeared in the Aegean region during the MSC could have facilitated dispersals of terrestrial taxa from northern Africa into Greece. Of course, such "saline deserts" could have selectively allowed only taxa with highly specialized ecologies or life history strategies to disperse from northern Africa into Europe, but if certain mammals managed to do so, then the same could also apply for certain reptiles and amphibians. It has been suggested on the basis of fossil evidence that amphibians indeed dispersed during the MSC, using potential existing water streams in the desert environments (Torres-Roig et al., 2017). Especially as it concerns the lizards, several of the Maramena taxa (e.g., agamids, cordylids, and varanids) pertain to clades that are known to contain forms which are fully adapted to arid environmens (Pianka et al., 2004; Pianka and Vitt, 2006; Čerňanský, 2012). Nevertheless, all these arid-adapted amphibian and reptile lineages also have a rich Miocene European fossil record, thus making an African origin of the Maramena specimens less plausible. Regarding snakes, on the basis of mtDNA and estimated divergence dates, it has been recently suggested that the MSC played a highly important role in the diversification and dispersal(s) of scolecophidians (Kornilios, 2017). Fossil evidence also suggests that the MSC has facilitated the dispersal of certain snake lineages from Northern Africa into southern Europe, particularly the Iberian Peninsula (e.g., erycines; Szyndlar and Schleich, 1994). The rather peculiar vertebral morphologies observed in Periergophis gen. nov. and Paraxenophis gen. nov., which are distinct among European snakes, prompt us to leave open the possibility that these two genera from Maramena represented short-lived lineages that could have eventually dispersed from Africa into southeastern Europe. Alternatively, certain European herpetofaunal elements could have taken advantage of the MSC and use the opposite direction and accordingly disperse from southern Europe into Africa. Frustratingly, the extremely scarce and inadequately known fossil record of the Neogene herpetofaunas of Africa (e.g., Delfino et al., 2004; Gardner and Rage, 2016; Bailon et al., 2017; Georgalis and Joyce, 2017; Delfino, in press) hinders significantly the current understanding of any such possible biogeographic pattern for herpetofaunal dispersals during the MSC. In any case, more sound data on latest Miocene and earliest Pliocene herpetofaunas are definitely needed from the Balkans and especially the southern portions of Greece, before we can conclude with certainty about any kind of dispersal from northeastern Africa into southeastern Europe (and vice versa) during the MSC. During the peak of the MSC, geographical fluctuations/transformations also took place to the north. Among the most important and relevant to the Maramena fauna, is the connection of the Mediterranean Sea, and more specifically the northern Aegean Sea, with the Paratethys Sea through a massive water drainage system that united the Dacic and Strymon Basins (practically where Maramena is situated), also accompanied by changes in the salinity level (Snel et al., 2006; Suc et al., 2015; Karakitsios et al., 2017). Finally, certain fossil mammal taxa from Maramena have been suggested to have clearly Asiatic affinities and origins, such as the sciurid Sinotamias atsali (Bruijn, 1995) with congeneric species known from older localities from Anatolia and China (Sinitsa, 2018). Taking all the above into consideration, it is obvious that the assemblage of Maramena was the product of multiple different dispersal events and a mosaic of faunal elements. 


\section{Palaeoenvironmental Considerations}

Based on the herpetofaunal assemblage of Maramena, the palaeoenvironment of the locality can be reconstructed as following: heliophilic taxa (Agaminae indet., Lacertidae indet., ?Lacertidae indet., aff. Palaeocordylus sp., ?Scincidae indet., Ophisaurus sp. [five morphotypes], Pseudopus sp., and Varanus sp. [at least one species / morphotype]) are dominant, suggesting the presence of open areas, with rocky surfaces and sunlight reaching the ground. A single heliophobic taxon (Salamandrina sp.) indicates the presence of forested areas with humid grounds. Two subterranean (fossorial) taxa (Anguis sp. and Scolecophidia indet.) suggest the presence of soft soil covered with mulch. The semiaquatic Pelophylax sp. indicates the presence of standing (temporary) water bodies, whereas the periaquatic Hyla sp., Latonia sp., Salamandra sp., Ommatotriton $\mathrm{sp} .$, Lissotriton sp. (Lissotriton vulgaris group), and Lissotriton sp. suggest the presence of humid swampy areas with dense vegetation near water bodies. Moreover, Salamandra sp. allows to envisage fast running rivulets with oxygenized water for their larval development (Duellman and Trueb, 1994). The aquatic giant salamander Cryptobranchidae indet. is an indicator of permanent water bodies (i.e., rivers) with highly oxygenized waters (Böhme et al., 2012), whereas the water terrapin Mauremys aristotelica has been inferred to have inhabited permanent ponds or lakes (Vlachos et al., 2019). The presence of a broad range of habitats can be assumed based on the presence of two species of the snake Natrix inhabiting diverse aquatic and nearshore environments (e.g., Vitt and Caldwell, 2014). Vipers are known to inhabit open habitats, whereas elapids are distributed in various warm open to closed habitats (Schuett et al., 2002). The two new "colubrines" Periergophis micros gen. et sp. nov. and Paraxenophis spanios gen. et sp. nov., and the indeterminate "colubrine" (morphotype 1) have no modern analogues and cannot offer any practical insight about their palaeoecology.

Estimation of the palaeoprecipitation value is based on the amphibian and reptile assemblage following the protocol of Böhme et al. (2006). The calculation showed a mean annual precipitation (MAP) value of $632 \mathrm{~mm} \pm 252 \mathrm{~mm}$ (Table 2). This value is slightly higher than the present-day precipitation of the Serres region. The result of palaeoprecipitation values disagrees with the assumption of Böhme et al. (2012) that the occurrence of a giant salamander indicates humid to rather humid climates with MAP exceeding $900 \mathrm{~mm}$. Taking into account that the herpetofauna can be still underrepresented, at least due the absence of certain frog clades (see above), the estimated value can be considered as biased. If that is not the case, then Maramena will be so far the only exception from the suggested palaeoclimatic distribution pattern.

\section{CONCLUSIONS}

We herein describe in detail the herpetofauna of the latest Miocene/earliest Pliocene (MN 13/14) locality of Maramena in northern Greece. The locality has yielded an extremely diverse amphibian and reptile assemblage, including at least 30 different taxa. Six taxa of urodelans are known, comprising the giant salamander Cryptobranchidae indet., Salamandrina sp., Lissotriton sp. (Lissotriton vulgaris group), Lissotriton sp., Ommatotriton sp., Salamandra sp., as well as indeterminate forms. Anurans are less diverse, including Latonia sp., Hyla sp., Pelophylax sp., as well as indeterminate forms. Two turtle taxa are known from Maramena, the geoemydid Mauremys aristotelica and an indeterminate probable testudinid. Lizards and especially snakes are rather diverse. At least nine taxa of lizards are known, including Agaminae indet., Lacertidae indet., ?Lacertidae indet., aff. Palaeocordylus sp., ?Scincidae indet., Anguis sp., five morphotypes of Ophisaurus, Pseudopus sp., at least one species of Varanus, and indeterminate forms that cannot be assigned with confidence to any of these clades. The extremely speciose snake assemblage, with at least 10 distinct taxa, comprises Scolecophidia indet., Hierophis cf. hungaricus, two new species in two new genera of "colubrines" (Periergophis micros gen. et sp. nov. and Paraxenophis spanios gen. et sp. nov.), another distinct "colubrine" morphotype, Natrix aff. rudabanyaensis and another distinct species of Natrix, Naja sp., cf. Micrurus sp., a member of the "Oriental Vipers" complex, and indeterminate forms. Cryptobranchids, scincids, cf. Micrurus, and, of course, the new "colubrine" genera, represent new fossil occurrences for Greece and the whole southeastern Europe. The same applies for extant taxa that currently inhabit the area, such as several of the amphibian genera (e.g., Lissotriton, Ommatotriton, and Hyla), Anguis, and Pseudopus, which are here recognized in the fossil assemblage of Maramena. The unique vertebral morphology and diagnostic features of Periergophis micros gen. et sp. nov., Paraxenophis spanios gen. et sp. nov. are highly distinctive among both extinct and 
TABLE 2. List of amphibian and reptile taxa from Maramena including ecophysiological indices for applicable taxa and mean annual precipitation. The indices are coloured from dark blue to dark yellow according to the ecological adaptation of the animals, from aquatic to terrestrial, respectively. ${ }^{*}$ The recent mean annual precipitation value is given according to The World Bank Group (http://data.worldbank.org; accessed at 2017 under a Creative Commons Attribution 4.0 International Licence). Index: 1, aquatic; 0.9768, heliophobic; 0.513, semiaquatic; 0.3918, periaquatic; 0.0917 , subterranean; 0 , heliophilic.

\begin{tabular}{|c|c|c|}
\hline & Taxon & Index \\
\hline \multirow[t]{6}{*}{ Urodela } & Cryptobranchidae indet. & 1 \\
\hline & Salamandrina sp. & 0,9768 \\
\hline & Lissotriton sp. (Lissotriton vulgaris group) & 0,3918 \\
\hline & Lissotriton sp. & 0,3918 \\
\hline & Ommatriton sp. & 0,3918 \\
\hline & Salamandra sp. & 0,3918 \\
\hline \multirow[t]{3}{*}{ Anura } & Latonia sp. & 0,3918 \\
\hline & Hyla sp. & 0,3918 \\
\hline & Pelophylax sp. & 0,513 \\
\hline \multirow[t]{2}{*}{ Testudines } & Mauremys aristotelica & 1 \\
\hline & ?Testudinidae indet. & 0 \\
\hline \multirow{13}{*}{$\begin{array}{l}\text { non-snake } \\
\text { Squamata }\end{array}$} & Agaminae indet. & 0 \\
\hline & Lacertidae indet. & 0 \\
\hline & ?Lacertidae indet. & - \\
\hline & aff. Palaeocordylus sp. & 0 \\
\hline & ?Scincidae indet. & 0 \\
\hline & Anguis sp. & 0,0917 \\
\hline & Ophisaurus sp. (morphotype 1) & 0 \\
\hline & Ophisaurus sp. (morphotype 2) & + \\
\hline & Ophisaurus sp. (morphotype 3) & + \\
\hline & Ophisaurus sp. (morphotype 4) & + \\
\hline & Ophisaurus sp. (morphotype 5) & + \\
\hline & Pseudopus sp. & 0 \\
\hline & Varanus sp. & 0 \\
\hline \multirow[t]{16}{*}{ Serpentes } & Scolecophidia indet. & 0,0917 \\
\hline & Periergophis micros gen. et sp. nov. & - \\
\hline & Paraxenophis spanios gen. et sp. nov. & - \\
\hline & Hierophis cf. hungaricus & - \\
\hline & "Colubrinae" indet. (morphotype 1) & - \\
\hline & Natrix aff. rudabanyaensis & - \\
\hline & Natrix sp. & - \\
\hline & Naja sp. & - \\
\hline & cf. Micrurus sp. & 0,0917 \\
\hline & "Oriental Vipers" complex indet. & - \\
\hline & Ecophysiological index of the assemblage & 0,28 \\
\hline & MAP (in mm) & 632 \\
\hline & MAPrecent* (in mm) & 534 \\
\hline & MAP/MAPrecent (in \%) & 118 \\
\hline & Error \pm (in mm) & 252 \\
\hline & Climate station & Serres \\
\hline
\end{tabular}


extant "colubrines". The multiple serration patterns observed on the varanid teeth from Maramena are intriguing, however, on the basis of the current evidence it is not possible to decipher whether they truly have taxonomic utility or simply reflect some kind of intraspecific variation. The overall high abundance of different amphibian and reptile taxa at Maramena makes it the most diverse European locality across the latest Miocene and earliest Pliocene. On the basis of the ecology of the herpetofaunal elements, a palaeoprecipitation estimation of the locality is provided. The assemblage comprises several taxa, which were previously known from the early and middle Miocene of Central Europe, providing further implications that the Greek area has repeatedly acted as a "refugium" for several Neogene herpetofaunal clades. However, the biogeographic affinities for several taxa of the Maramena assemblage remain unresolved, and its herpetofauna was the product of a much complex biogeographic pattern. Taking into consideration the great abundace of amphibian and reptile remains and the high diversity of co-occurring taxa, Maramena has to be regarded as a reference point for all European Neogene herpetofaunas.

\section{ACKNOWLEDGEMENTS}

We would like to acknowledge W. Wessels and $\mathrm{H}$. de Bruijn (UU) for the loan of the specimens described in this paper, and B. Sanchíz (MNCN) for having facilitated its study. We thank the late J-C. Rage (MNHN) for insightful discussions concerning the anatomy of Periergophis micros gen. et sp. nov. We also thank D. Kostopoulos and G. Koufos (Aristotle University of Thessaloniki), I. Danilov
(Zoological Institute of the Russian Academy of Sciences, Saint Petersburg), R. Biton (University of Torino), W. Joyce and R. Garbin (University of Fribourg), K. Smith (SMF), E. Vlachos (CONICET and Museo Paleontologico Egidio Feruglio, Trelew), and $\mathrm{A}$. Čerňanský, and J. Klembara (Comenius University of Bratislava) for several comments that improved the quality of the manuscript. $\mathrm{H}$. de Bruijn also provided additional information on the collection history and collectors of the material and the geological settings of the locality. Study of comparative skeletal material of extant taxa was enhanced through funding by SYNTHESYS: Museo Nacional de Ciencias Naturales, Madrid (SYNTHESYS ESTAF-5910 to GLG and SYNTHESYS ES-TAF-1975 to MD), Naturhistorisches Museum, Vienna (SYNTHESYS AT-TAF-5911 to GLG, SYNTHESYS ATTAF-4591 to AV, and SYNTHESYS AT-TAF-1281 to MD), Hungarian Natural History Museum (SYNTHESYS HU-TAF-6145 to GLG), and Muséum national d'Histoire naturelle, Paris (SYNTHESYS FR-TAF-5007 to AV), and the curators of these institutions, respectively $M$. Calvo-Revuelta, $H$. Grillitsch, J. Vörös, and S. Bailon, are also acknowledged here. We also thank J. Moravec (NMP) and Z. Szyndlar (ZZSiD) for access to specimens under their care. This work was further supported by Fondi di Ateneo dell'Università di Torino (2018-2019), Generalitat de Catalunya (CERCA Program), and Spanish Agencia Estatal de Investigación (CGL2016-76431-P, AEI/FEDER, EU) to $M D$. The quality of this manuscript was improved by the useful comments of the two reviewers, J. Müller and an anonymous one, and the editor $\mathrm{A}$. Souron.

\section{REFERENCES}

Adalsteinsson, S.A., Branch, W.R., Trape, S., Vitt, L.J., and Hedges, S.B. 2009. Molecular phylogeny, classification, and biogeography of snakes of the Family Leptotyphlopidae (Reptilia, Squamata). Zootaxa, 2244:1-50.

Ananjeva, N.B. 1977. [The taxonomic differences in the skull structure and dentition of agamid lizards (Sauria, Agamidae) of USSR fauna]. Zoologicheskiy Zhurnal (Moscow), 56:10621070. (In Russian)

Ananjeva, N.B. 1998. The skull structure of some arid Asian agamids of Phrynocephalus genus (Agamidae, Sauria). Russian Journal of Herpetology, 5:29-35.

Arnold, E.N., Arribas, O., and Carranza, S. 2007. Systematics of the Palaearctic and Oriental lizard tribe Lacertini (Squamata: Lacertidae: Lacertinae), with descriptions of eight new genera. Zootaxa, 1430:1-86. https://doi.org/10.11646/zootaxa.1430.1.1

Auffenberg, W. 1963. The fossil snakes of Florida. Tulane Studies in Zoology, 10:131-216. https:/ /doi.org/10.5962/bhl.part.4641 
Augé, M.L. 2005. Evolution des lézards du Paléogène en Europe. Mémoires du Muséum National d'Histoire Naturelle, 192:3-369.

Augé, M.L.and Pouit, D. 2012. Presence of iguanid lizards in the European Oligocene. Lazarus taxa and fossil abundance. Bulletin de la Société Géologique de France, 183:653-660. https:/ /doi.org/10.2113/gssgfbull.183.6.653

Augé, M.L. and Rage, J.-C. 2000. Les Squamates (Reptilia) du Miocène moyen de Sansan. Mémoires du Muséum National d'Histoire Naturelle, 183:263-313.

Bachmayer, F. 1967. Eine Riesenschildkröte aus den altpliozäne Schichten von Pikermi (Griechenland). Annales Géologiques des Pays Helléniques, 19:512-526.

Bachmayer, F. and Szyndlar, Z. 1985. Ophidians (Reptilia: Serpentes) from the Kohfidisch fissures of Burgenland, Austria. Annalen des Naturhistorischen Museums Wien, A, 87:79100.

Bachmayer, F. and Szyndlar, Z. 1987. A second contribution to the ophidian fauna (Reptilia: Serpentes) of Kohfidisch, Austria. Annalen des Naturhistorischen Museums Wien, A, 88:2539.

Baig, K.J., Wagner, P., Ananjeva, N.B., and Böhme, W. 2012. A morphology-based taxonomic revision of Laudakia Gray, 1845 (Squamata: Agamidae). Vertebrate Zoology, 62:213-260.

Bailon, S. 1991. Amphibiens et Reptiles du Pliocène et du Quaternaire de France et d'Espagne: Mise en Place et Évolution des Faunes. PhD dissertation, Université de Paris VII, Paris, France.

Bailon, S. 1999. Différenciation Ostéologique des Anoures (Amphibia, Anura) de France. APDCA, Antibes.

Bailon, S. 2014. Herpetofauna tardiglaciar y holocena de Santa Catalina (Lekeito, Vizcaya). Bizkaiko Arkeologi Indusketak - Excavaciones Arqueologicas en Bizkaia, 4:103-118. Bizkaiko Foru Aldundia-Diputación Foral de Bizkaia. Bilbao.

Bailon, S. and Augé, M. 2012. Un nouveau genre, Ragesaurus (Squamata, Anguidae, Anguinae), du Pléistocène inférieur des îles Medas (Catalogne, Espagne). Bulletin de la Société Géologique de France, 183:683-688. https://doi.org/10.2113/gssgfbull.183.6.683

Bailon, S., Garcia-Porta, J., and Quintana-Cardona, J. 2002. The first record of viperid snakes (Reptilia, Serpentes) from the Balearic Islands (Spain): fossils from the Neogene, with description of a new species from the Pliocene. Comptes Rendus Palevol, 1:227-234.

Bailon, S., Hossini, S., and Rage, J.-C. 2017. Les amphibiens et lépidosauriens du Cénozoïque du Maroc. Mémoires de la Société Géologique de France, Nouvelle Série, 180:453-484.

Baird, S.F. and Girard, C. 1853. Catalogue of North American Reptiles in the Museum of the Smithsonian Institution. Part I. Serpents. Smithsonian Institution, Washington.

Barahona, F. and Barbadillo, L.J. 1997. Identification of some Iberian lacertids using skull characters. Revista Española de Herpetología, 11:47-62.

Barahona, F. and Barbadillo, L.J. 1998. Inter- and intraspecific variation in the post-natal skull of some lacertid lizards. Journal of Zoology, 245:393-405. https://doi.org/10.1111/j.14697998.1998.tb00114.x

Batsch, A.J.G.K. 1788. Versuch einer Anleitung, zur Kenntniß und Geschichte der Thiere und Mineralien, für akademische Vorlesungen entworfen, und mit den nöthigsten Abbildungen versehen, Erster Theil. Allgemeine Geschichte der Natur; besondre der Saügthiere, Vögel, Amphibien und Fische. Akademische Buchhandlung, Jena.

Batsch, A.J.G.K. 1796. Umriß der gesammten Naturgeschichte: ein Auszug aus den frühern Handbüchern des Verfassers für seine Vorfesungen. Christian Ernst Gabler, Jena and Leipzig.

Beddard, F.E. 1905. Some notes on the cranial osteology of the Mastigure lizard, Uromastix. Proceedings of the Zoological Society of London, 75:2-9. https://doi.org/10.1111/j.14697998.1905.tb08351.x

Bell, T. 1839. A History of British Reptiles. John van Voorst, London.

Berthold, A.A. 1846. Über das Vorkommen von Tritonen am Kaukasus mit. Nachrichten von der Georg-Augusts-Universität und der Königl. Gesellschaft der Wissenschaften zu Göttingen, 1846:188-190.

Bibron, G. and Bory de Saint-Vincent, J.B. 1833. Vertébrés à sang froid. Reptiles et poissons. Reptiles, p. 57-76. In Levrault, F.G., Expédition Scientifique de Morée, Tome III. 1re partie, Zoologie, Strasbourg. 
Biton, R., Boistel, R., Rabinovich, R., Gafny, S., Brumfeld, V., and Bailon, S. 2016. Osteological observations on the alytid anuran Latonia nigriventer with comments on functional morphology, biogeography, and evolutionary history. Journal of Morphology, 277:1131-1145. https://doi.org/10.1002/jmor.20562

Blain, H.-A. and Bailon, S. 2010. Anfibios y escamosos del Pleistoceno inferior de Barranco León y de Fuente Nueva 3 (Orce, Andalucía, España), p. 165-183. In Toro, I., MartínezNavarro, B. and Agustí, J. (eds.), Ocupaciones Humanas Durante el Pleistoceno Inferior y Medio de la Cuenca de Guadix-Baza. Arqueología Monografías. Junta de Andalucía, Sevilla.

Blain, H.-A., Bailon, S., Agustí, J., Piñero-García, P., Lozano-Fernández, I., Sevilla, P., LópezGarcía, J.M., Romero, G., and Mancheño, M.A. 2014. Youngest agamid lizards from Western Europe (Sierra de Quibas, Spain, late Early Pleistocene). Acta Palaeontologica Polonica, 59:873-878. https://doi.org/10.4202/app.2012.0141

Blanchard, É. 1871. Note sur une nouvelle Salamandre gigantesque (Sieboldia davidiana Blanch.) de la Chine occidentale. Comptes Rendus Hebdomadaires des Séances de l'Académie des Sciences. Paris, 73:79-80.

Blyth, E. 1860. Report of Curator, Zoological Department. Proceedings of the Asiatic Society of Bengal (Natural History), Calcutta, 29:87-115.

Boda, A. 1927. Clemmydopsis sopronensis, n. g. n. sp. aus der unteren pannonischen Stufe von Sopron in Ungarn. Centralblatt für Mineralogie, Geologie und Paläontologie B, 9:375-383.

Bogert, C.M. 1943. Dentitional phenomena in cobras and other elapids with notes on adaptive modifications of fangs. Bulletin of the American Museum of Natural History, 81:285-360.

Bogert, C.M. 1964. Snakes of the genera Diaphorolepis and Synophis and the colubrid subfamily Xenoderminae (Reptilia, Colubridae). Senckenbergiana Biologica, 45:509-531.

Böhme, G. 1977. Zur bestimmung quartärer anuren europas an hand von skelettelementen. Wissenschaftliche Zeitschrift der Humboldt-Universität zu Berlin, MathematischNaturwissenschaftliche Reihe, 26:283-299.

Böhme, M. 2008. Ectothermic vertebrates (Teleostei, Allocaudata, Urodela, Anura, Testudines, Choristodera, Crocodylia, Squamata) from the upper Oligocene of Oberleichtersbach (northern Bavaria, Germany). Courier Forschungsinstitut Senckenberg, 260:161-183.

Böhme, M. 2010. Ectothermic vertebrates (Actinopterygii, Allocaudata, Urodela, Anura, Crocodylia, Squamata) from the Miocene of Sandelzhausen (Germany, Bavaria) and their implications for environment reconstruction and palaeoclimate. Paläontologische Zeitschrift, 84:3-41. https://doi.org/10.1007/s12542-010-0050-4

Böhme, M., Ilg, A., Ossig, A., and Küchenhoff, H. 2006. New method to estimate paleoprecipitation using fossil amphibians and reptiles and the middle and late Miocene precipitation gradients in Europe. Geology, 34:425-428. https://doi.org/10.1130/g22460.1

Böhme, M. and Vasilyan, D. 2014. Ectothermic vertebrates from the late Middle Miocene of Gratkorn (Austria, Styria). Palaeobiodiversity Palaeoenvironments, 94:21-40. https://doi.org/ 10.1007/s12549-013-0143-7

Böhme, M., Vasilyan, D., and Winklhofer, M. 2012. Habitat tracking, range dynamics and palaeoclimatic significance of Eurasian giant salamanders (Cryptobranchidae) — indications for elevated Central Asian humidity during Cenozoic global warm periods. Palaeogeography, Palaeoclimatology, Palaeoecology, 342-343:64-72. https://doi.org/10.1016/ j.palaeo.2012.04.032

Boié, F. 1827. Bemerkungen über Merrem's Versuch eines Systems der Amphibien, 1-ste Lieferung: Ophidier. Isis von Oken, Leipzig, 20:508-566.

Bolkay, J. 1913. Additions to the fossil herpetology of Hungary from the Pannonian and Praeglacial periode (sic). Mittheilungen aus dem Jahrbuche der königlichen Ungarischen geologischen Reichsanstalt, 21:216-230.

Bonaparte, C.L. 1832-1841. Iconographia della Fauna Italica per le Quattro Classi degli Animali Vertebrati. Tomo II. Anfibi. Dalla Tipografia Salviucci, Roma.

Boscá, E. 1916. Un género nuevo para la fauna herpetológica de España y especie nueva o poco conocida. Boletín de la Real Sociedad Española de Historia Natural, 16:294-297.

Boulenger, G.A. 1880. Sur une forme intéressante de Triton provenant de Moldavie et observations sur le genre Pelonectes Lataste. Bulletin de la Société Zoologique de France, 5:37-40.

Boulenger, G.A. 1905. A contribution to the knowledge of the varieties of the wall-lizard (Lacerta muralis) in Western Europe and North Africa. Transactions of the Zoological Society of London, 17:351-420. https://doi.org/10.5962/bhl.title.12643 
Boulenger, G.A. 1916. On the lizards allied to Lacerta muralis with an account of Lacerta agilis and L. parva. Transactions of the Zoological Society of London, 21:1-104. https://doi.org/ 10.5962/bhl.title.12083

Broeckhoven, C. and du Plessis, A. 2017. Has snake fang evolution lost its bite? New insights from a structural mechanics viewpoint. Biology Letters, 13:20170293. https://doi.org/10.1098/ rsbl.2017.0293

Cantor, T.E. 1842. General features of Chusan, with remarks on the flora and fauna of that island. Animals observed at Chusan. Annals and Magazine of Natural History, London, 9:265-278. https://doi.org/10.5962/bhl.title.6704

Caputo, V. 2004. The cranial osteology and dentition in the scincid lizards of the genus Chalcides (Reptilia, Scincidae). Italian Journal of Zoology, 71(S2):35-45. https://doi.org/10.1080/ 11250000409356604

Carnevale, G., Dela Pierre, F., Natalicchio, M., and Landini, W., 2017. Fossil marine fishes and the 'Lago Mare' Event: has the Mediterranean ever transformed into a brackish lake? Newsletters on Stratigraphy, 51:57-72. https://doi.org/10.1127/nos/2016/0343

Carnevale, G., Gennari, R., Lozar, F., Natalicchio, M., Pellegrino, L., and Dela Pierre, F., 2019. Living in a deep desiccated Mediterranean Sea: An overview of the Italian fossil record of the Messinian salinity crisis. Bolletino della Società Paleontologica Italiana, 58:109-140.

Carnevale, G., Longinelli, A., Caputo, D., Barbieri, M., and Landini,W. 2008. Did the Mediterranean marine reflooding precede the Mio-Pliocene boundary? Paleontological and geochemical evidence from upper Messinian sequences of Tuscany, Italy. Palaeogeography, Palaeoclimatology, Palaeoecology, 257:81-105. https://doi.org/10.1016/j.palaeo.2007.09.005

Cavallo, O.and Repetto, G., 1988. Un nuovo giacimento della facies a Congerie nell'Albese. Rivista Piemontese di Storia Naturale, 9:43-62.

Cavallo, O., Sen, S., Rage, J.-C., and Gaudant, J., 1993. Vertébrés messiniens du faciès à Congéries de Ciabòt Cagna, Cornelliano d'Alba (Piémont, Italie). Rivista Piemontese di Storia Naturale, 14:3-22.

Cerling, T.E., Harris, J.M., MacFadden, B.J., Leakey, M.G., Quade, J., Eisenmann, V., and Ehleringer, J.R. 1997. Global vegetation change through the Miocene/Pliocene boundary. Nature, 389:153-158. https://doi.org/10.1038/38229

Čerňanský, A. 2012. The oldest known European Neogene girdled lizard fauna (Squamata, Cordylidae), with comments on Early Miocene immigration of African taxa. Geodiversitas, 34:837-848. https://doi.org/10.5252/g2012n4a6

Čerňanský, A., Klembara, J., and Müller, J. 2016a. The new rare record of the late Oligocene lizards and amphisbaenians from Germany and its impact on our knowledge of the European terminal Palaeogene. Palaeobiodiversity and Palaeoenvironments, 96:559-587. https:// doi.org/10.1007/s12549-015-0226-8

Čerňanský, A., Klembara, J., and Smith, K.T., 2016b. Fossil lizard from central Europe resolves the origin of large body size and herbivory in giant Canary Island lacertids. Zoological Journal of the Linnean Society, 176:861-877. https://doi.org/10.1111/zoj.12340

Čerňanský, A. and Syromyatnikova, E.V. 2019. The first Miocene fossils of Lacerta cf. trilineata (Squamata, Lacertidae) with a comparative study of the main cranial osteological differences in green lizards and their relatives. PLoS ONE, 14:e0216191. https://doi.org/10.1371/ journal.pone.0216191

Čerňanský, A. and Syromyatnikova, E.V. In press. The first pre-Quaternary fossil record of the clade Mabuyidae with a comment on the enclosure of the meckelian canal in skinks. Papers in Palaeontology, https://doi.org/10.1002/spp2.1279

Černanský, A., Syromyatnikova, E.V., and Jablonski, D. 2018. The first record of amphisbaenian and anguimorph lizards (Reptilia, Squamata) from the upper Miocene Solnechnodolsk locality in Russia. Historical Biology, https://doi.org/10.1080/08912963.2018.1539973

Čerňanský, A., Vasilyan, D., Georgalis, G.L., Joniak, P., Mayda, S., and Klembara, J. 2017. First record of fossil anguines (Squamata; Anguidae) from the Oligocene and Miocene of Turkey. Swiss Journal of Geosciences, 110:741-751. https://doi.org/10.1007/s00015-017-0272-5

Čerňanský, A., Yaryhin, O., Ciceková, J., Werneburg, I., Hain, M., and Klembara, J. 2019. Vertebral comparative anatomy and morphological differences in anguine lizards with a special reference to Pseudopus apodus. The Anatomical Record, 302:232-257. https:// doi.org/10.1002/ar.23944 
Chesi, F., Delfino, M., and Rook, L. 2009. Late Miocene Mauremys (Testudines, Geoemydidae) from Tuscany (Italy): evidence of terrapin persistence after a mammal turnover. Journal of Paleontology, 83:379-388. https://doi.org/10.1666/08-134.1

Chretien, J., Wang-Claypool, C.Y., Glaw, F., and Scherz, M.D. 2019. The bizarre skull of Xenotyphlops sheds light on synapomorphies of Typhlopoidea. Journal of Anatomy, 234:637655. https://doi.org/10.1111/joa.12952

Clarke, B.T. 1981. Comparative osteology and evolutionary relationships in the African Raninae (Anura, Ranidae). Monitore Zoologico Italiano, Supplemento, 15:285-331. https://doi.org/ 10.1080/03749444.1981.10736638

Codrea, V., Venczel, M., and Solomon, A. 2017b. A new family of teiioid lizards from the Upper Cretaceous of Romania with notes on the evolutionary history of early teiioids. Zoological Journal of the Linnean Society, 181:385-399. https://doi.org/10.1093/zoolinnean/zlx008

Codrea, V., Venczel, M., and Ursachi, L. 2018. Amphibians and squamates from the early Vallesian of Crețești (Vaslui County, E-Romania). Nymphaea Folia Naturae Bihariae, 44:3755.

Codrea, V., Venczel, M., Ursachi, L., and Răţoi, B. 2017a. A large viper from the early Vallesian (MN 9) of Moldova (Eastern Romania) with notes on the palaeobiogeography of late Miocene "Oriental vipers". Geobios, 50:401-411. https://doi.org/10.1016/j.geobios.2017.07.001

Colombero, S., Alba, D.M., D’Amico, C., Delfino, M., Esu, D., Giuntelli, P., Harzhauser, M., Mazza, P.P.A., Mosca, M., Neubauer, T.A., Pavia, G., Pavia, M., Villa, A., and Carnevale, G. 2017. Late Messinian mollusks and vertebrates from Moncucco Torinese, north-western Italy. Paleoecological and paleoclimatological implications. Palaeontologia Electronica, 20.1.10A:1-66. https://doi.org/10.26879/658 palaeo-electronica.org/content/2017/1749-moncucco-torinese-paleoecology

Colombero, S., Angelone, C., Bonelli, E., Carnevale, G., Cavallo, O., Delfino, M., Giuntelli, P., Mazza, P., Pavia, G., Pavia, M., and Repetto, G. 2014. The Messinian vertebrate assemblages of Verduno (NW Italy): another brick for a latest Miocene bridge across the Mediterranean. Neues Jahrbuch für Geologie und Paläontologie Monatschefte, 272:287-324. https://doi.org/10.1127/0077-7749/2014/0408

Conrad, J.L., Balcarcel, A.M., and Mehling, C.M. 2012. Earliest example of a giant monitor lizard (Varanus, Varanidae, Squamata). PLoS ONE, 7:e41767. https://doi.org/10.1371/ journal.pone.0041767

Cope, E.D. 1860. Catalogue of the Colubridae in the Museum of the Academy of Natural Sciences of Philadelphia, with notes and descriptions of new species. Part 2. Proceedings of the Academy of Natural Sciences of Philadelphia, 12:241-266.

Cope, E.D. 1864. On the characters of the higher groups of Reptilia Squamata - and especially of Diploglossa. Proceedings of the Academy of Natural Sciences of Philadelphia, 15:224231.

Cope, E.D. 1869. Observations on reptiles of the Old World. Art. II. Proceedings of the Academy of Natural Sciences of Philadelphia, 20:316-323.

Covacevich, J., Couper, P., Molnar, R.E., Witten, G., and Young, W. 1990. Miocene dragons from Riversleigh: new data on the history of the family Agamidae (Reptilia: Squamata) in Australia. Memoirs of the Queensland Museum, 29:339-360.

Croft, P., Ceron-Carrasco, R., Peltenburg, E., Bailon, S., Cucchi, T., Mano, L., Colledge, S., Deckers, K., Lorentz, K.O., and Ridout-Sharpe, J. 2017. Neolithic Kisonerga-Myloudia, 20002006: the bioarchaeology, pp. 189-217. In Report of the Department of Antiquities, Cyprus, 2011-12. Department of Antiquities, Nicosia.

Cuvier, G. 1817. Le Règne Animal Distribué d'après son Organisation, pour Servir de Base à I'Histoire Naturelle des Animaux et d'Introduction à l'Anatomie Comparée. Tome II, Contenant les Reptiles, les Poissons, les Mollusques et les Annélides. Déterville, Paris.

D’Amore, D.C., Clulow, S., Doody, J.S., Rhind, D., and McHenry, C.R. 2018. Claw morphometrics in monitor lizards: Variable substrate and habitat use correlate to shape diversity within a predator guild. Ecology and Evolution, 8:6766-6778. https://doi.org/ 10.1002/ece3.4185

Danilov, I.G. 2005. Die fossilen Schildkröten Europas, p. 329-448. In Fritz, U. (ed.), Handbuch der Reptilien und Amphibien Europas, Part 3/IIIB: Schildkröten (Testudines) II. Aula-Verlag, Wiebelsheim, Germany. 
Daudin, F.M. 1802. Histoire Naturelle, Génerale et Particulièredes Reptiles, Ouvrage faisant suiteà l'Histoire Naturelle Générale et Particulière, Composée par Leclerc De Buffon, et Rédigée par C. S. Sonnini, Membre de Plusieurs Sociétés Savantes. Tome troisième. F. Dufart, Paris.

Daudin, F.M. 1803. Histoire Naturelle, Générale et Particulière des Reptiles, Ouvrage faisant suite à l'Histoire Naturelle Générale et Particulière, Composée par Leclerc de Buffon, et Rédigée par C.S. Sonnini, Membre de Plusieurs Sociétés Savantes. Tome septième. F. Dufart, Paris.

de Bruijn, H. 1989. Smaller mammals from the Upper Miocene and Lower Pliocene of the Strimon Basin, Greece. Part 1. Rodentia and Lagomorpha. Bollettino Della Societa Paleontologica Italiana, 28:189-195.

de Bruijn, H. 1995. The vertebrate locality Maramena (Macedonia, Greece) at the TurolianRuscinian boundary (Neogene). 8. Sciuridae, Petauristidae and Eomyidae (Rodentia, Mammalia). Münchner Geowissenschaftliche Abhandlungen A, 28:87-102.

de Garsault, F.A. 1764. Les Figures des Plantes et Animaux d'Usage en Medecine, Décrits dans la Matiere Medicale de Mr. Geoffroy Medecin, Dessinés d'après Nature. Chez l'auteur, Paris. https://doi.org/10.5962/bhl.title.49481

Delfino, M. In press. Early Pliocene anuran fossils from Kanapoi, Kenya, and the first fossil record for the African burrowing frog Hemisus (Neobatrachia: Hemisotidae). Journal of Human Evolution. https://doi.org/10.1016/j.jhevol.2017.06.008

Delfino, M. and Atzori, M. 2013. An update on the Early Pleistocene herpetofauna from Pirro Nord. Palaeontographica Abteilung A, Palaeozoology - Stratigraphy, 298:19-29. https:// doi.org/10.1127/pala/298/2013/19

Delfino, M. and Bailon, S. 2000. Early Pleistocene herpetofauna from Cava Dell'Erba and Cava Pirro (Apulia, Southern Italy). Herpetological Journal, 10:95-110.

Delfino, M., Bailon, S., and Pitruzzella, G. 2011. The Late Pliocene amphibians and reptiles from "Capo Mannu D1 Local Fauna" (Mandriola, Sardinia, Italy). Geodiversitas, 33:357-382. https://doi.org/10.5252/g2011n2a10

Delfino, M., Kotsakis, T., Arca, M., Tuveri, C., Pitruzzella, G., and Rook, L. 2008. Agamid lizardsfrom the Plio-Pleistocene of Sardinia (Italy) and an overview of the European fossil record of the family. Geodiversitas, 30:641-656.

Delfino, M., Rage, J.-C., Bolet, A., and Alba, D.M. 2013. Early Miocene dispersal of the lizard Varanus into Europe: reassessment of vertebral material from Spain. Acta Palaeontologica Polonica, 58:731-735. https://doi.org/10.4202/app.2012.0025

Delfino, M. and Sala, B. 2007. Late Pliocene Albanerpetontidae (Lissamphibia) from Italy. Journal of Vertebrate Paleontology, 27:716-719. https://doi.org/10.1671/02724634(2007)27[716:LPALFI]2.0.CO;2

Delfino, M., Segid, A., Yosief, D., Shoshani, J., Rook, L., and Libsekal, Y. 2004. Fossil reptiles from the Pleistocene Homo-bearing locality of Buia (Eritrea, Northern Danakil Depression). Rivista Italiana di Paleontologia e Stratigrafia, 110(supplement):51-60.

de Razoumovsky, G. 1789. Histoire Naturelle du Jorat et de ses Environs; et celle de Trois Lacs de Neuchâtel, Morat et Bienne. Volume 1. Jean Mourer, Lausanne. https://doi.org/10.5962/ bhl.title.37043

Dubois, A. 1984. Miscellanea nomenclatorica batrachologica (IV). Alytes, 3:103-110.

Duellman, W.E. and Trueb, L. 1994. Biology of Amphibians. The Johns Hopkins University Press, Baltimore, London.

Duméril, A.M.C. 1806. Zoologie Analytique, ou Méthode Naturelle de Classification des Animaux, Rendue plus Facile à l'Aide de Tableaux Synoptiques. Allais, Paris. https://doi.org/ 10.5962/bhl.title.44835

Duméril, A.M.C. and Bibron, G. 1839. Erpétologie Générale ou Histoire Naturelle Complète des Reptiles. Tome cinquième. Librairie Encyclopédique de Roret, Paris.

Duméril, A.M.C. and Bibron, G. 1844. Erpétologie Générale ou Histoire Naturelle Complète des Reptiles. Tome sixième, Comprenant l'Histoire Générale des Ophidiens, la Description des Genres et des Espèces de Serpents Non Venimeux, Savoir : la Totalité des Vermiformes ou des Scolécophides, et Partie des Cicuriformes ou Azémiophides; en tout Vingt-cinq genres et Soixante-cinq espèces. Librairie Encyclopédique de Roret, Paris.

El-Toubi, M.R. 1945. Notes on the cranial osteology of Uromastyx aegyptia (Forskal). Bulletin of the Faculty of Science, Cairo University, 25:1-10. 
Ernst, C.H. and Barbour, R.W. 1989. Turtles of the World. Smithsonian Institution Press, Washington, D.C.

Estes, R. 1981. Encyclopedia of Paleoherpetology: Gymnophiona, Caudata, Part 2. Gustav Fischer, Stuttgart, New York.

Estes, R. 1983. Encyclopedia of Paleoherpetology: Sauria Terrestria, Amphisbaenia, Part 10A. Gustav Fischer, Stuttgart, New York.

Estes, R. and Hoffstetter, R. 1976. Les urodèles du Miocène de La Grive-Saint-Alban (Isère, France). Bulletin du Muséum National d'Histoire Naturelle, Série 3, 57:298-343.

Estes, R., Queiroz, K. de, and Gauthier, J.A. 1988. Phylogenetic relationships within Squamata, p. 119-281. In Estes, R. and Pregill, G.K. (eds.), Phylogenetic Relationships of the Lizard Families: Essays Commemorating C.L. Camp. Stanford University Press, Stanford, California.

Evans, S.E. 2008. The skull of lizards and tuatara, p. 1-347. In Gans, C., Gaunt, A., and Adler, K. (eds.), Biology of the Reptilia. Volume 21. Morphology I. The Skull and Appendicular Locomotor Apparatus of Lepidosauria. Society for the Study of Amphibians and Reptiles, Ithaca, New York.

Evans, S.E., Prasad, G.V.R., and Manhas, B.K. 2002. Fossil lizards from the Jurassic Kota Formation of India. Journal of Vertebrate Paleontology, 22:299-312. https://doi.org/10.1671/ 0272-4634(2002)022[0299:flftjk]2.0.co;2

Farlow, J.O., Brinkman, D.L., Abler, W.L., and Currie, P.K. 1991. Size, shape and serration density of theropod dinosaur lateral teeth. Modern Geology, 16:161-198.

Fathinia, B., Rastegar-Pouyani, N., Bahrami, A.M., and Abdali, G. 2011. Comparative skull anatomy and dentition of Trapelus lessonae and T. ruderatus (Sauria: Agamidae) from llam Province, Iran. Russian Journal of Herpetology, 18:83-92.

Fejérváry, de G.J. 1918. Contributions to a monography on fossil Varanidae and on Megalanidae. Annales Historico-Naturales Musei Nationalis Hungarici, 16:341-467.

Fejérváry, de G.J. 1935. Further contributions to a monograph of the Megalanidae and fossil Varanidae, with notes on recent varanians. Annales Historico-Naturales Musei Nationalis Hungarici , Pars Zoologica, 29:1-130.

Fejérváry-Lángh, A.M. 1923. Beiträge zu einer Monographie der fossilen Ophisaurier. Palaeontologia Hungarica, 1:123-220.

Fischer von Waldheim, G. 1813. Zoognosia. Tabulis Synopticis Illustrata, in Usum Prælectionum Academiæ Imperialis Medico-Chirurgicæ Mosquensis Edita. Editio tertia, volumen primum. Nicolai Sergeidis Vsevolozsky, Moscow. https://doi.org/10.5962/bhl.title.42225

Fitzinger, L.J.F.J. 1824. Über den Ablepharus pannonicus, eine neue Eidechse aus Hungarn. Verhandlungen der Naturforschenden Gesellschaft Berlin, 1:297-302.

Fitzinger, L.J.F.J. 1826. Neue Classification der Reptilien nach ihren natürlichen Verwandtschaften nebst einer Verwandschafts-Tafel und einem Verzeichnisse der ReptilienSammlung des K. K. Zoologischen Museums zu Wien. J.G. Heubner, Wien.

Fitzinger, L.J.F.J. 1843. Systema Reptilium. Fasciculus Primus. Braumüller et Seidel, Wien.

Fleischmann, F.L. 1831. Dissertatio inauguralis sistens Dalmatiae Nova Serpentum Genera quam gratiosi medicorum ordinis auctoritate in Regia Literarum Universitate FridericoAlexandrina pro impetrandis Doctoris Medicinae, Chirurgiae atque Artis obstetriciae Summis honoribus et privileglis eruditorum examini submittit.Commissis C. Heyderi, Erlangae (= Erlangen).

Fortelius, M., Eronen, J., Liu, L., Pushkina, D., Tesakov, A., Vislobokova, I., and Zhang, Z. 2006. Late Miocene and Pliocene large land mammals and climatic changes in Eurasia.

Palaeogeography, Palaeoclimatology, Palaeoecology, 238:219-227. https://doi.org/10.1016/ j.palaeo.2006.03.042

Friant, M. 1944. Caractères anatomiques d'un batracien oligocène de la Limagne, le Prodiscoglossus vertaizoni nov. gen. nov. spec. Comptes Rendus Hebdomadaires des Séances de l'Académie des Sciences de Paris, 219:561-562.

Fritts, T.H. and Smith, H.N. 1969. A new genus and species of snake from western Ecuador. Transactions of the Kansas Academy of Science, 72:60-66. https://doi.org/10.2307/3627049

Fürbringer, M. 1900. Zur vergleichenden anatomie des Brustschulterapparates und der Schultermuskeln. Jenaische Zeitschrift, 34:215-718. https://doi.org/10.5962/bhl.title.52377

Gad, J. 1990. Nachweis einer Schildkröte des Mauremys-Ocadia-Komplexes aus dem Obermiozän von Nordgriechenland. Salamandra, 26:311-313. 
Gardner, J.D. and Rage, J.-C. 2016. The fossil record of lissamphibians from Africa, Madagascar, and the Arabian Plate. Palaeobiodiversity and Palaeoenvironments, 96:169220. https://doi.org/10.1007/s12549-015-0221-0

Gaudry, A. 1862-1867. Animaux Fossiles et Géologie de l'Attique. F. Savy, Paris.

Gauthier, J.A., Kearney, M., Maisano, J.A., Rieppel, O., and Behlke, A.D.B. 2012. Assembling the squamate tree of life: perspectives from the phenotypeand the fossil record. Bulletin of the Peabody Museum of Natural History, 53:3-308. https://doi.org/10.3374/014.053.0101

Georgalis, G.L., Halaçlar, K., Mayda, S., Kaya, T., and Ayaz, D. 2018a. First fossil find of the Blanus strauchi complex (Amphisbaenia, Blanidae) from the Miocene of Anatolia. Journal of Vertebrate Paleontology, 38:e1437044. https://doi.org/10.1080/02724634.2018.1437044

Georgalis, G.L. and Joyce, W.G. 2017. A review of the fossil record of Old World turtles of the clade Pan-Trionychidae. Bulletin of the Peabody Museum of Natural History, 58:115-208. https://doi.org/10.3374/014.058.0106

Georgalis, G. L. and Kear, B.P. 2013. The fossil turtles of Greece: an overview of taxonomy and distribution. Geobios, 46:299-311. https://doi.org/10.1016/j.geobios.2013.05.001

Georgalis, G.L., Rage, J.-C., de Bonis, L., and Koufos, G.D. 2018b. Lizards and snakes from the late Miocene hominoid locality of Ravin de la Pluie (Axios Valley, Greece). Swiss Journal of Geosciences, 111:169-181. https://doi.org/10.1007/s00015-017-0291-2

Georgalis, G.L. and Scheyer, T.M. in press. A new species of Palaeopython (Serpentes) and other extinct squamates from the Eocene of Dielsdorf (Zurich, Switzerland). Swiss Journal of Geosciences. https://doi.org/10.1007/s00015-019-00341-6

Georgalis, G.L., Szyndlar, Z., Kear, B.P., and Delfino, M. 2016a. New material of Laophis crotaloides, an enigmatic giant snake from Greece, with an overview of the largest fossil European vipers. Swiss Journal of Geosciences, 109:113-116. https://doi.org/10.1007/ s00015-016-0210-y

Georgalis, G.L., Villa, A., and Delfino, M. 2016b. First description of a fossil chamaeleonid from Greece and its relevance for the European biogeographic history of the group. The Science of Nature, 103:12. https://doi.org/10.1007/s00114-016-1336-5

Georgalis, G.L., Villa, A., and Delfino, M. 2017a. Fossil lizards and snakes from Ano Metochi - a diverse squamate fauna from the latest Miocene of northern Greece. Historical Biology, 29:730-742. https://doi.org/10.1080/08912963.2016.1234619

Georgalis, G.L., Villa, A., and Delfino, M. 2017b. The last European varanid: demise and extinction of monitor lizards (Squamata, Varanidae) from Europe. Journal of Vertebrate Paleontology, 37:e1301946. https://doi.org/10.1080/02724634.2017.1301946

Georgalis, G.L., Villa, A., and Delfino, M. 2018c. The last amphisbaenian (Squamata) from continental Eastern Europe. Annales de Paléontologie, 104:155-159. https://doi.org/10.1016/ j.annpal.2018.03.002

Georgalis, G.L., Villa, A., Ivanov, M., Roussiakis, S., Skandalos, P., and Delfino, M. 2019. Early Miocene herpetofaunas from the Greek localities of Aliveri and Karydia - bridging a gap in the knowledge of amphibians and reptiles from the early Neogene of southeastern Europe. Historical Biology, 31:1045-1064. https://doi.org/10.1080/08912963.2017.1417404

Georgalis, G.L., Villa, A., Vlachos, E., and Delfino, M. 2016c. Fossil amphibians and reptiles from Plakias, Crete: a glimpse into the earliest late Miocene herpetofaunas of southeastern Europe. Geobios, 49:433-444. https://doi.org/10.1016/j.geobios.2016.09.004

Gierliński, G.D., Niedźwiedzki, G., Lockley, M.G., Athanassiou, A., Fassoulas, C., Dubicka, Z., Boczarowski, A., Bennett, M.R., and Ahlberg, P.E. 2017. Possible hominin footprints from the late Miocene (c. 5.7 Ma) of Crete? Proceedings of the Geologists' Association, 128:697-710. https://doi.org/10.1016/j.pgeola.2017.07.006

Gilmore, C.W. 1938. Fossil snakes of North America. Geological Society of North America, Special Papers, 9:1-96. https://doi.org/10.1130/spe9-p1

Gistel, J.N.F.X. 1868. Die lurche Europas. Ein Beitrag zur Lehre von der geographischen Verbreitung derselben, p. 144-167. In Gistel, J. (ed.), Blicke in das Leben der Natur und des Menschen. Verlag von Ed. Wartig, Leipzig.

Gmelin, J.F. 1789. Caroli a Linne...Systema naturae per regna tria natural, secundum classes, ordines, genera, species, cum characteribus differentilis, synonymis, locis. Tomus I, Editio decima tertia, aucta, reformata. Pars III. Amphibia et Pisces, p. 103-1516. Georg. Emanuel Beer, Lipsiae (= Leipszig). 
Gmelin, S.G. 1774. Reise durch Russland zur Untersuchung der drey Natur-Reiche. Dritter Theil. Reise durch nordliche Persien, in den Jahren 1770, 1771, bis im April 1772. Kayserliche Academie der Wissenschaften, St. Pétersbourg (= St. Petersburg).

Goldfuss, G.A. 1820. Handbuch der Zoologie. J. L. Schrag, Nürnberg.

Gray, J.E. 1825. A synopsis of the genera of Reptiles and Amphibia, with a description of some new species. Annals of Philosophy, Series 2, 10:193-217.

Gray, J.E. 1827. A synopsis of the genera of saurian reptiles, in which some new genera are indicated and others reviewed by actual examination. The Philosophical Magazine, or Annals of Chemistry, Mathematics, Astronomy, Natural History, and General Science, 2:54-58. https://doi.org/10.1080/14786442708675620

Gray, J.E. 1845. Catalogue of the Specimens of Lizards in the Collection of the British Museum. British Museum (Natural History), London. https://doi.org/10.5962/bhl.title.5499

Gray, J.E. 1850. Catalogue of the Specimens of Amphibia in the Collection of the British Museum. Part II. Batrachia Gradientia, etc. British Museum (Natural History), London. https:/ /doi.org/10.5962/bhl.title.64048

Gray, J.E. 1860. Description of a new species of Emys lately living in the gardens of the Zoological Society. Proceedings of the Zoological Society of London, 28:232-233.

Gray, J.E. 1869. Description of Mauremys laniaria, a new freshwater tortoise. Proceedings of the Zoological Society of London, 37:499-500. https://doi.org/10.1111/j.14697998.1869.tb07358.x

Günther, A. 1873. Description of a new Saurian (Hyalosaurus) allied to Pseudopus. The Annals and Magazine of Natural History, Series 4, 11:351. https://doi.org/10.1080/ 00222937308696828

Gvoždík, V., Benkovský, N., Crottini, A., Bellati, A., Moravec, J., Romano, A., Sacchi, R., and Jandzik, D. 2013. An ancient lineage of slow worms, genus Anguis (Squamata: Anguidae), survived in the Italian Peninsula. Molecular Phylogenetics and Evolution, 69:1077-1092. https://doi.org/10.1016/j.ympev.2013.05.004

Gvoždík, V., Jandzik, D., Lymberakis, P., Jablonski, D., and Moravec, J. 2010. Slow worm, Anguis fragilis (Reptilia: Anguidae) as a species complex: genetic structure reveals deep divergences. Molecular Phylogenetics and Evolution, 55:460-472. https://doi.org/10.1016/ j.ympev.2010.01.007

Hallowell, E. 1857. Notice of a collection of reptiles from the Gaboon country, West Africa, recently presented to the Academy of Natural Sciences of Philadelphia, by Dr. Henry A. Ford. Proceedings of the Academy of Natural Sciences of Philadelphia, 9:48-72.

Harzhauser, M., Neubauer, T.A., Georgopoulou, E., Esu, D., D’Amico, C., Pavia, G., Giuntelli, P., and Carnevale, G. 2015. Late Messinian continental and Lago-Mare gastropods from the Tertiary Piedmont Basin, NW Italy. Bollettino della Società Paleontologica Italiana, 54:1-53.

He, M., Feng, J.C., Liu, S.Y., Guo, P., and Zhao, E.M. 2009. The phylogenetic position of Thermophis (Serpentes: Colubridae), an endemic snake from the Qinghai?Xizang Plateau, China. Journal of Natural History, 43:479-488. https://doi.org/10.1080/00222930802389825

Head, J.J. 2005. Snakes of the Siwalik Group (Miocene of Pakistan): systematics and relationship to environmental change. Palaeontologia Electronica, 8:18A:1-33. palaeo-electronica.org/2005_1/head18/issue1_05.htm

Head, J.J., Mahlow, K., and Müller, J. 2016. Fossil calibration dates for molecular phylogenetic analysis of snakes 2: Caenophidia, Colubroidea, Elapoidea, Colubridae. Palaeontologia Electronica, 19.2.2FC:1-21. https://doi.org/10.26879/625 palaeo-electronica.org/content/fc-9

Hedges, S.B., Marion, A.B., Lipp, K.M., Marin, J., and Vidal, N. 2014. A taxonomic framework for typhlopid snakes from the Caribbean and other regions (Reptilia, Squamata). Caribbean Herpetology, 49:1-61. https://doi.org/10.31611/ch.49

Helfenberger, N. 2001. Phylogenetic relationships of Old World ratsnakes based on visceral organ topography, osteology, and allozyme variation. Russian Journal of Herpetology, Supplement, 8:1-62.

Herre, W. 1955. Die fauna der Miozänen spaltenfüllung von Neudorf a.D. March (Črs): Amphibia (Urodela). Österreichische Akademie der Wissenschaften, MathematischNaturwissenschaftliche Klasse Abteilung I, Sitzungsberichte, 164:783-803. 
Herrmann, H.-W., Joger, U., and Nilson, G. 1992. Phylogeny and systematics of Viperinae snakes. III: Resurrection of the genus Macrovipera (Reuss, 1927) as suggested by biochemical evidence. Amphibia-Reptilia, 13:375-392. https://doi.org/10.1163/ $156853892 \times 00076$

Hervet, S. 2000. Tortues du Quaternaire de France: critères de détermination, répartitions chronologique et géographique. Mésogéé, 58:3-47.

Hervet, S. 2004. Systématique du groupe "Palaeochelys sensu lato - Mauremys" (Chelonii, Testudinoidea) du Tertiaire d'Europe occidentale: principaux résultats. Annales de Paléontologie, 90:13-78. https://doi.org/10.1016/j.annpal.2003.12.002

Hirayama, R. 1985. Cladistic analysis of batagurine turtles (Batagurinae: Emydidae: Testudinoidea); a preliminary result. Studia Geologica Salmanticensia, Volumen Especial, 1:141-157.

Hocknull, S.A., Piper, P.J., van den Bergh, G.D., Due, R.A., Morwood, M.J., and Kurniawan, I. 2009. Dragon's paradise lost: palaeobiogeography, evolution and extinction of the largestever terrestrial lizards (Varanidae). PLoS ONE, 4:e7241. https://doi.org/10.1371/ journal.pone.0007241

Hodrová, M. 1984. Salamandridae of the upper Pliocene Ivanovce locality (Czechoslovakia). Acta Universitatis Carolinae - Geologica, 4:331-352.

Hoffstetter, R. 1939. Contribution à l'étude des Elapidæ actuels et fossiles et de l'ostéologie des Ophidiens. Archives du Muséum d'Histoire Naturelle de Lyon, 15:1-78.

Hoffstetter, R. 1943. Varanidæ et Necrosauridæ fossiles. Bulletin du Muséum National d'Histoire Naturelle, Série 2, 15:134-141.

Hoffstetter, R. 1946. Les Typhlopidae fossiles. Bulletin du Muséum National d'Histoire Naturelle, Paris, Série 2, 18:309-315.

Hoffstetter, R. 1962. Observations sur les ostéodermes et la classification desanguidés actuels et fossiles (Reptiles, Sauriens). Bulletin du Muséum National d'Histoire Naturelle, 34:149157.

Hoffstetter, R. 1968. A review of "A contribution to the classification of snakes, by G. Underwood". Copeia, 1968:201-213. https://doi.org/10.2307/1441587

Holbrook, J.E. 1842. North American Herpetology; or, a Description of the Reptiles Inhabiting the United States. Vol. IV. Second edition. J. Dobson, Philadelphia. https://doi.org/10.5962/ bhl.title.12492

Holman, J.A. 1964. Fossil snakes from the Valentine Formation of Nebraska. Copeia, 4:631-637. https://doi.org/10.2307/1441438

Holman, J.A. 1968. Upper Pliocene snakes from Idaho. Copeia, 1968:152-158. https://doi.org/ $10.2307 / 1441561$

Holman, J.A. 1973. Reptiles of the Egelhoff local fauna (upper Miocene) of Nebraska. Contributions from the Museum of Paleontology, University of Michigan, 24:125-134.

Holman, J.A. 1976. Snakes of the Split Rock formation (middle Miocene), central Wyoming. Herpetologica, 32:419-426.

Holman, J.A. 1977. Amphibians and reptiles from the Gulf Coast Miocene of Texas. Herpetologica, 33:391-403.

Holman, J.A. 1995. On the identification of emydid (Reptilia: Testudines) shell bones in the Pleistocene of Britain. British Herpetological Society Bulletin, 53:37-40.

Holman, J.A. 2000. Fossil Snakes of North America: Origin, Evolution, Distribution, Paleoecology. Indiana University Press, Bloomington and Indianapolis, USA.

Hossini, S. 1993. A new species of Latonia (Anura, Discoglossidae) from the lower Miocene of France. Amphibia-Reptilia, 14:237-245. https://doi.org/10.1163/156853893x00435

Hsü, K.J. 1972. Origin of saline giants: a critical review after the discovery of the Mediterranean evaporates. Earth-Science Review, 8:371-396. https://doi.org/10.1016/0012-8252(72)900621

Huang, S., Liu, S.Y., Guo, P., Zhang, Y.P., and Zhao, E.M. 2009. What are the closest relatives of the hot-spring snakes (Colubridae, Thermophis), the relict species endemic to the Tibetan Plateau? Molecular Phylogenetics and Evolution, 51:438-446. https://doi.org/10.1016/ j.ympev.2009.02.013

[ICZN] International Commission on Zoological Nomenclature. 1999. International Code of Zoological Nomenclature. 4th ed. International Trust for Zoological Nomenclature, London. 
Ikeda, T. 2007. A comparative morphological study of vertebrae of snakes occurring in Japan and adjacent regions. Current Herpetology, 26:13-34. https://doi.org/10.3105/13455834(2007)26[13:acmsot]2.0.co;2

Ivanov, M. 1997. Old Biharian reptiles of Żabia Cave (Poland). Acta Zoologica Cracoviensia, 40:249-267.

Ivanov, M. 1999. The first European pit viper from the Miocene of Ukraine. Acta Palaeontologica Polonica, 44:327-334.

Ivanov, M. 2000. Snakes of the lower/middle Miocene transition at Vieux Collonges (Rhône, France), with comments on the colonisation of western Europe by colubroids. Geodiversitas, 22:559-588.

Ivanov, M. 2002. The oldest known Miocene snake fauna from Central Europe: Merkur-North locality, Czech Republic. Acta Palaeontologica Polonica, 47:513-534.

Ivanov, M. 2008. Early Miocene amphibians (Caudata, Salientia) from the Mokrá-Western Quarry (Czech Republic) with comments on the evolution of early Miocene amphibian assemblages in Central Europe. Geobios, 41:465-492. https://doi.org/10.1016/ j.geobios.2007.11.004

Ivanov, M. and Böhme, M. 2011. Snakes from Griesbeckerzell (Langhian, Early Badenian), North Alpine Foreland Basin (Germany), with comments on the evolution of snake faunas in Central Europe during the Miocene Climatic Optimum. Geodiversitas, 33:411-449. https:// doi.org/10.5252/g2011n3a2

Ivanov, M., Rage J.-C., Szyndlar, Z., and Venczel, M. 2000. Histoire et origine géographique des faunes de serpents en Europe. Bulletin de la Société Herpétologique de France, 96:15-24.

Ivanov, M., Ruta, M., Klembara, J., and Böhme, M.2018. A new species of Varanus (Anguimorpha: Varanidae) from the early Miocene of the Czech Republic, and its relationships and palaeoecology. Journal of Systematic Palaeontology, 16:767-797. https:// doi.org/10.1080/14772019.2017.1355338

Ivanov, M., Vasilyan, D., Böhme, M., and Zazhigin, V.S. 2019. Miocene snakes from northeastern Kazakhstan: new data on the evolution of snake assemblages in Siberia. Historical Biology, 31:1284-1303. https://doi.org/10.1080/08912963.2018.1446086

Ivanovic, R.F., Valdes, P.J., Flecker, R., and Gutjahr, M. 2014. Modelling global-scale climate impacts of the late Miocene Messinian Salinity Crisis. Climate of the Past, 10:607-622. https:/ /doi.org/10.5194/cpd-9-4807-2013

Jackson, K. 2002. How tubular venom conducting fangs are formed. Journal of Morphology, 252:291-297. https://doi.org/10.1002/jmor.1106

Jan, G. 1863. Prodromo della Iconographie générale degli ofidi II. Parte. VI. Gruppo. Coronellidae. Eredi Soliani, Modena.

Jenyns, L. 1835. A Manual of British Vertebrate Animals. Pitt Press, Cambridge. https://doi.org/ 10.5962/bhl.title.152814

Joyce, W.G.and Bell, C.J. 2004. A review of the comparative morphology of extant testudinoid turtles (Reptilia: Testudines). Asiatic Herpetological Research, 10:53-109.

Joyce, W.G., Parham, J.F., and Gauthier, J.A. 2004. Developing a protocol for the conversion of rank-based taxon names to phylogenetically defined clade names, as exemplified by turtles. Journal of Paleontology, 78:989-1013. https://doi.org/10.1666/00223360(2004)078<0989:dapftc>2.0.co;2

Kamermans, M. and Vences, M. 2009. Terminal phalanges in ranoid frogs, morphological diversity and evolutionary correlation with climbing habits. Alytes, 26:117-152.

Karakitsios, V., Cornée, J.-J., Tsourou, T., Moissette, P., Kontakiotis, G., Agiadi, K., Manoutsoglou, E., Triantaphyllou, M., Koskeridou, E., Drinia, H., and Roussos, D. 2017. Messinian salinity crisis record under strong freshwater input in marginal, intermediate, and deep environments: the case of the North Aegean. Palaeogeography, Palaeoclimatology, Palaeoecology, 485:316-335. https://doi.org/10.1016/j.palaeo.2017.06.023

Karystineos, N. 1984. [Palaeogeographic evolution of the Serres Basin. Lithostromatography, biostromatography and tectonics]. PhD dissertation, Aristotle University of Thessaloniki, Thessaloniki, Greece. (In Greek, with English abstract)

Kaup, J.J. 1825. Einige Bemerkungen zu Merrems Handbuch. Isis von Oken, 16:589-593.

Kearney, M. and Rieppel, O. 2006. An investigation into the occurrence of plicidentine in the teeth of squamate reptiles. Copeia, 2006:337-350. https://doi.org/10.1643/00458511(2006)2006[337:aiitoo]2.0.co;2 
Klembara, J. 1979. Neue funde der Gattungen Ophisaurus und Anguis (Squamata, Reptilia) aus dem Untermiozan Westbohmens (CSSR). Vestnık Ustrednıho ustavu geologickeho, 54:163169.

Klembara, J. 1981. Beitrag zur kenntnis der subfamilie Anguinae (Reptilia, Anguidae). Acta Universitatis Carolinae, Geologica, 2:121-168.

Klembara, J. 2012. A new species of Pseudopus (Squamata, Anguidae) from the early Miocene of Northwest Bohemia (Czech Republic). Journal of Vertebrate Paleontology, 32:854-866. https://doi.org/10.1080/02724634.2012.670177

Klembara, J. 2015. New finds of anguines (Squamata, Anguidae) from the early Miocene of Northwest Bohemia (Czech Republic). Paläontologische Zeitschrift, 89:171-195. https:// doi.org/10.1007/s12542-014-0226-4

Klembara, J., Böhme, M., and Rummel, M. 2010. Revision of the anguine lizard Pseudopus laurillardi (Squamata, Anguidae) from the Miocene of Europe, with comments on paleoecology. Journal of Paleontology, 84:159-196. https://doi.org/10.1666/09-033r1.1

Klembara, J., Hain, M., and Dobiašová, K. 2014. Comparative anatomy of the lower jaw and dentition of Pseudopus apodus and the interrelationships of species of subfamily Anguinae (Anguimorpha, Anguidae). The Anatomical Record, 297:516-544. https://doi.org/10.1002/ ar.22854

Klembara, J.and Rummel, M. 2018. New material of Ophisaurus, Anguis and Pseudopus (Squamata, Anguidae, Anguinae) from the Miocene of the Czech Republic and Germany and systematic revision and palaeobiogeography of the Cenozoic Anguinae. Geological Magazine, 155:20-44. https://doi.org/10.1017/s0016756816000753

Kormos, T. 1911. A Polgárdi pliocén csontlelet. Földtani Közlöny, 41:48-64.

Kornilios, P. 2017. Polytomies, signal and noise: revisiting the mitochondrial phylogeny and phylogeography of the Eurasian blindsnake species complex (Typhlopidae, Squamata). Zoologica Scripta, 46:665-674. https://doi.org/10.1111/zsc.12243

Kosma, R. 2004. The Dentitions of Recent and Fossil Scincomorphan Lizards (Lacertilia, Squamata) - Systematics, Functional Morphology, Palecology (sic). PhD dissertation. University of Hannover, Hannover, Germany.

Koufos, G.D. 2006. The Neogene mammal localities of Greece: faunas, chronology, and biostratigraphy. Annales Géologiques des Pays Helléniques, 4:183-214.

Koufos, G.D., Kostopoulos, D.S., and Vlachou, T.D. 2005. Neogene/Quaternary mammalian migrations in Eastern Mediterranean. Belgian Journal of Zoology, 135:181-190.

Koufos, G.D. and Vasileiadou, K. 2015. Miocene/Pliocene mammal faunas of southern Balkans: implications for biostratigraphy and palaeoecology. Palaeobiodiversity and Palaeoenvironments, 95:285-303. https://doi.org/10.1007/s12549-015-0201-4

Kraus, F. 2017. New species of blindsnakes (Squamata: Gerrhopilidae) from the offshore islands of Papua New Guinea. Zootaxa, 4299:75-94. https://doi.org/10.11646/zootaxa.4299.1.3

Krijgsman, W, Hilgen, F.J., Raffi, I., Sierro, F.J., and Wilson, D.S. 1999. Chronology, causes and progression of the Messinian Salinity Crisis. Nature, 400:652-655. https://doi.org/10.1038/ 23231

Kuch, U., Müller, J., Mödden, C., and Mebs, D. 2006. Snake fangs from the Lower Miocene of Germany: evolutionary stability of perfect weapons. Naturwissenschaften, 93:84-87. https:// doi.org/10.1007/s00114-005-0065-y

Kumlutas, Y., Arikan, H., Ilgaz, Ç., and Kaska, Y. 2007. A new subspecies, Eumeces schneiderii barani n. ssp (Reptilia: Sauria: Scincidae) from Turkey. Zootaxa, 1387:27-38.

LaDuke, T.C. 1991. The fossil snakes of Pit 91, Rancho la Brea, California. Contributions in Science, Natural History Museum of Los Angeles County, 424:1-28.

Lantz, L.A. 1927. Quelques observations nouvelles sur l'herpétologie des Pyrénées Centrales. Extrait de la Revue d'Histoire Naturelle Appliquée Première Partie, No. E, 2:1-14.

Lanza, B., Caputo, V., Nascetti, G., and Bullini, L. 1995. Morphologic and genetic studies of the European plethodontid salamanders: taxonomic inferences (genus Hydromantes). Monografia Museo Regionale di Scienze Naturali di Torino, 16:1-366.

Lapparent de Broin, F. de. 2002. A giant tortoise from the Late Pliocene of Lesvos Island (Greece) and its possible relationships. Annales Géologiques des Pays Helléniques, 39:99130.

Lartet, E. 1851. Notice sur la Colline de Sansan, Suivie d'une Récapitulation des Diverses Espèces d'Animaux Vertébrés Fossiles, Trouvés soit à Sansan, soit dans d'autres Gisements du Terrain Tertiaire Miocène dans le Bassin Sous-Pyrénéen. J.-A. Portes, Auch. 
Latreille, P.A. 1800. Histoire Naturelle des Salamandres de France: Précédée d'un Tableau Méthodique des Autres Reptiles Indigènes. Villier, Paris. https://doi.org/10.5962/bhl.title.5045

Laurenti, J.N. 1768. Austriaci Viennensis specimen medicum, exhibens synopsin reptilium emendatam cum experimentis circa Venena et antidota reptilium Austriacorum quod authoritate et consensu. Joannis Thomae de Trattnern, Caes. Reg. Maj. Aulae Typographi et Bibliopolae, Wien. https://doi.org/10.5962/bhl.title.5108

Leidy, J. 1870. Descriptions of Emys jeanesi, E. haydeni, Baena arenosa, and Saniwa ensidens. Proceedings of the Academy of Natural Science, Philadelphia, 1870:123-124.

Lichtenstein, H. 1823. Verzeichniss der Doubletten des Zoologischen Museums der Königl. Universität zu Berlin nebst Beschreibung vieler bisher unbekannter Arten von Säugethieren, Vögeln, Amphibien und Fröschen. Trautwein, Berlin. https://doi.org/10.5962/bhl.title.40281

Linnaeus, C. 1758. Systema naturæ per regna tria naturae, secundum classes, ordines, genera, species cum characteribus, differentiis, synonymis, locis. Tomus 1., Pars 1. Laurentii Salvius, Stockholm. https://doi.org/10.5962/bhl.title.542

Linnaeus, C. 1766. Systema naturæ per regna tria naturæ, secundum classes, ordines, genera, species, cum characteribus, differentiis, synonymis, locis. Tomus I. Editio duodecima, reformata. Laurentii Salvii, Stockholm. https://doi.org/10.5962/bhl.title.68927

List, J.C., 1966. Comparative osteology of the snake families Typhlopidae and Leptotyphlopidae. Illinois Biological Monographs, 36:1-112. https://doi.org/10.5962/bhl.title.50341

López-García, J.M., Blain, H.-A., Cuenca-Bescós, G., Alonso, C., Alonso, S., and Vaquero, M. 2011. Small vertebrates (Amphibia, Squamata, Mammalia) from the late PleistoceneHolocene of the Valdavara-1 cave (Galicia, northwestern Spain). Geobios, 44:253-269. https://doi.org/10.1016/j.geobios.2010.10.001

Lopez-Seoane, V. 1885. Identidad de Lacerta schreiberi (Bedriaga) y Lacerta viridis var. Gadovii (Boulenger), é Investigaciones Herpetologicas de Galicia. Imp. Y Est. De Vicente Abad, La Coruña, Spain.

Macey, J.R., Shulte, J.A., Larson, A., Ananjeva, N.B., Wang, Y., Pethiyagoda, R., RastegarPouyani, N., and Papenfuss, T.J. 2000. Evaluating trans-Tethys migration: an example using acrodont lizard phylogenetics. Systematic Biology, 49:233-256. https://doi.org/10.1093/ sysbio/49.2.233

Malnate, E.V. 1953. The taxonomic status of the Tibetan colubrid snake Natrix baileyi. Copeia, 1953:92-96. https://doi.org/10.2307/1440132

Malnate, E.V. 1972. Observations on the vertebral hypapophyses and associated musculature in some snakes, with special reference to the Colubridae. Zoologische Mededelingen, 47:225239.

Martin, W.C.L. 1838. On some snakes collected during the Euphrates expedition. Proceedings of the Zoological Society of London, 6:81-84.

Martín, C., Alonso-Zarazaga, M.A., and Sanchíz, B. 2012. Nomenclatural notes on living and fossil amphibians. Graellsia, 68:159-180.

Maul, L.C., Smith, K.T., Barkai, R., Barash, A., Karkanas, P., Shahack-Gross, R., and Gopher, A. 2011. Microfaunal remains at Middle Pleistocene Qesem Cave, Israel: preliminary results on small vertebrates, environment and biostratigraphy. Journal of Human Evolution, 60:464480. https://doi.org/10.1016/j.jhevol.2010.03.015

McCartney, J.A., Stevens, N.J., and O'Connor, P.M. 2014. The earliest colubroid-dominated snake fauna from Africa: perspectives from the Late Oligocene Nsungwe Formation of Southwestern Tanzania. PLoS ONE, 9:e90415. https://doi.org/10.1371/ journal.pone.0090415

Mead, J. 2013. Scolecophidia (Serpentes) of the Late Oligocene and Early Miocene, North America, and a fossil history overview. Geobios, 46:225-231. https://doi.org/10.1016/ j.geobios.2012.10.016

Mendelssohn, H. and Steinitz, H. 1943. A new frog from Palestine. Copeia, 1943:231-233. https:/ /doi.org/10.2307/1438135

Merrem, B. 1820. Versuch eines Systems der Amphibien I (Tentamen Systematis Amphibiorum).J. C. Kriegeri, Marburg. https://doi.org/10.5962/bhl.title.5037

Miklas, P.M. 2002. Die amphibienfauna (Amphibia: Caudata, Anura) der obermiozänen fundstelle Götzendorf an der Leitha (südliches Wiener Becken, Niederösterreich). Annalen des Naturhistorischen Museums in Wien, 103A:161-211. 
Miralles, A., Marin, J., Markus, D., Herrel, A., Hedges, B.S., and Vidal, N. 2018. Molecular evidence for the paraphyly of Scolecophidia and its evolutionary implications. Journal of Evolutionary Biology, 31:1782-1793. https://doi.org/10.1111/jeb.13373

Młynarski, M. 1966. Die fossilen Schildkröten in den ungarischen Sammlungen. Acta Zoologica Cracoviensa, 11:224-288.

Montanucci, R.R. 1968. Comparative dentition in four iguanid lizards. Herpetologica, 24:305315.

Müller, J., Hipsley, C.A., Head, J.J., Kardjilov, N., Hilger, A., Wuttke, M., and Reisz, R. 2011. Eocene lizard from Germany reveals amphisbaenian origins. Nature, 473:364-367. https:// doi.org/10.1038/nature09919

Müller, L. and Hellmich, W. 1937. Mitteilungen über die Herpetofauna der Iberischen Halbinsel. II. Zur Kenntnis der Lacerta monticola. Zoologischer Anzeiger, 117:65-73.

Nilson, G. and Andrén, C. 1986. The mountain vipers of the Middle East - the Vipera xanthina complex (Reptilia, Viperidae). Bonner Zoologische Monographien, 20:1-90.

Nilson, G., Tuniyev, B., Andrén, C., Orlov, N., Joger, U., and Herrmann, H.-W. 1999. Taxonomic position of the Vipera xanthina complex. Kaupia, Darmstädter Beiträge zur Naturgeschichte, 8:99-102.

Nopcsa, F. 1908. Zur Kenntnis der fossilen Eidechsen. Beitrage zur Paläontologie und Geologie Osterreich-ungarns und des Orients, 21:33-62.

Nopcsa, F. 1923. Eidolosaurus und Pachyophis. Zwei neue Neocom-Reptilien. Palaeontographica, 65:99-154.

Oppel, M. 1811. Die Ordnungen, Familien und Gattungen der Reptilien als Prodom einer Naturgeschichte derselben. Joseph Lindauer Verlag, München. https://doi.org/10.5962/ bhl.title.4911

Ouwens, P.A. 1912. On a large Varanus species from the Island of Komodo. Bulletin du Jardin Botanique de Buitenzorg, 6(series 2):1-3.

Owen, R. 1857. On the fossil vertebræ of a serpent (Laophis crotaloïdes, Ow.) discovered by Capt. Spratt, R.N., in a Tertiary Formation at Salonica. Quarterly Journal of the Geological Society of London, 13:196-199. https://doi.org/10.1144/gsl.jgs.1857.013.01-02.28

Owen, R. 1859. Description of some remains of a gigantic land-lizard (Megalania prisca, Owen) from Australia. Philosophical Transactions of the Royal Society, 1860:43-48. https://doi.org/ 10.1098/rstl.1859.0002

Pallas, P.S. 1775. Lacerta apoda descripta. Novi Commentarii Academiae Scientiarum Imperialis Petropolitanae, 19:435-454.

Pérez-García, A. and Vlachos, E. 2014. New generic proposal for the European Neogene large testudinids (Cryptodira) and the first phylogenetic hypothesis for the medium and large representatives of the European Cenozoic record. Zoological Journal of the Linnean Society, 172:653-719. https://doi.org/10.1111/zoj.12183

Pianka, E.R., King, D., and King, R.A. 2004. Varanoid Lizards of the World. Indiana University Press, Bloomington. https://doi.org/10.2307/j.ctt2005wjp

Pianka, E.R. and Vitt, L.J. 2006. Lizards: Windows to the Evolution of Diversity. University of California Press, Berkeley, California.

Pictet, F.J. and Humbert, A. 1856. Monographie des chéloniens de la Molasse suisse. Matériaux pour la Paléontologie Suisse, 1:1-71.

Pitruzzella, G., Delfino, M., Böhme, M., and Rook, L. 2008. Osteology of genus Salamandrina: preliminary observation from a paleontological perspective. Herpetologia Sardiniae, 8:412415.

Poulakakis, N., Kapli, P., Lymberakis, P., Trichas, A., Vardinoyiannis, K., Sfenthourakis, S., and Mylonas, M. 2015. A review of phylogeographic analyses of animal taxa from the Aegean and surrounding regions. Journal of Zoological Systematics and Evolutionary Research, 53:18-32. https://doi.org/10.1111/jzs.12071

Pyron, R.A., Burbrink, F.T., and Wiens, J.J. 2013. A phylogeny and revised classification of Squamata, including 4161 species of lizards and snakes. BMC Evolutionary Biology, 13:93. https://doi.org/10.1186/1471-2148-13-93

Rafinesque, C.S. 1815. Analyse de la Nature ou Tableau de l'Univers et des Corps Organisés. Jean Barravecchia, Palermo. https://doi.org/10.5962/bhl.title.106607

Rage, J.-C. 1976. Les squamates du Miocène de Béni Mellal, Maroc. Géologie Méditerranéene, 2:57-70. https://doi.org/10.3406/geolm.1976.962 
Rage, J.-C. 1984. Encyclopedia of Paleoherpetology: Serpentes, Part 11. Gustav Fischer, Stuttgart, New York.

Rage, J.-C. 2013. Mesozoic and Cenozoic squamates of Europe. Palaeobiodiversity and Palaeoenvironments, 93:517-534. https://doi.org/10.1007/s12549-013-0124-x

Rage, J.-C. and Augé, M. 2010. Squamate reptiles from the middle Eocene of Lissieu (France). A landmark in the middle Eocene of Europe. Geobios, 43:253-268. https://doi.org/10.1016/ j.geobios.2009.08.002

Rage, J.-C.and Bailon, S. 2005. Amphibians and squamate reptiles from the late early Miocene (MN 4) of Béon 1 (Montréal-du-Gers, southwestern France). Geodiversitas, 27:413-441.

Rage, J.-C. and Bailon, S. 2011. Amphibia and Squamata, p. 467-478. In Harrison, T. (ed.), Paleontology and Geology of Laetoli: Human Evolution in Context. Volume 2: Fossil Hominins and the Associated Fauna. Springer, Dodrecht, Netherlands.

Rage, J.-C.and Holman, J.A. 1984. Des serpents (Reptilia, Squamata) de type nord-américain dans le Miocène français. Evolution parallèle ou dispersion? Geobios, 17:89-104. https:// doi.org/10.1016/s0016-6995(84)80007-8

Rage J.-C. and Roček, Z. 2003. Evolution of anuran assemblages in the Tertiary and Quaternary of Europe, in the context of palaeoclimate and palaeogeography. Amphibia-Reptilia, 24:133177. https://doi.org/10.1163/156853803322390408

Rage, J.-C. and Sen, S. 1976. Les amphibiens et les reptiles du Pliocène supérieur de Çalta (Turquie). Géologie Méditerranéenne, 3:127-134. https://doi.org/10.3406/geolm.1976.969

Ratnikov, V.Y. 2004. Identification of some Eurasian species of Elaphe (Colubridae, Serpentes) on the basis of vertebrae. Russian Journal of Herpetology, 11:91-98.

Rauscher, K.L. 1995. Die herpetofauna der Vraona-Holhe (Attika) in Griechenland. Annales Géologiques des Pays Helléniques, 36:39-41.

Reeder, T.W., Townsend, T.M., Mulcahy, D.G., Noonan, B.P., Wood, P.L., Jr., Sites, J.W., Jr., and Wiens, J.J. 2015. Integrated analyses resolve conflicts over squamate reptile phylogeny and reveal unexpected placements for fossil taxa. PLoS ONE, 10:e0118199. https://doi.org/ 10.1371/journal.pone.0118199

Reuss, A.F.T. 1927. Sechs europäische Giftschlangengattungen. Zoologischer Anzeiger, Leipzig, 73:124-129.

Richter, A. 1995. The vertebrate locality Maramena (Macedonia, Greece) at the TurolianRuscinian Boundary (Neogene). 3. Lacertilia (Squamata, Reptilia). Münchner Geowissenchaften Abhandlungen, 28:35-38.

Rieppel, O. 1979. The braincase of Typhlops and Leptotyphlops (Reptilia: Serpentes). Zoological Journal of the Linnean Society, 65:161-176. https://doi.org/10.1111/j.10963642.1979.tb01088.x

Ristori, G. 1891. I cheloniani fossili di Montebamboli e Casteani (Maremma, Toscana). Atti della Società Toscana di Scienze Naturali, Processi Verbali, 7:304-307.

Roček, Z. 1984. Lizards (Reptilia: Sauria) from the Lower Miocene locality Dolnice (Bohemia, Czechoslovakia). Rozpravy Československé Akademie Věd - Řada Matematických a Prírodních Věd, 94:1-69.

Roček, Z. 1994a. A review of the fossil Caudata of Europe. Abhandlungen und Berichte für Naturkunde, 17:51-56.

Roček, Z. 1994b. Taxonomy and distribution of Tertiary discoglossids (Anura) of the genus Latonia v. Meyer, 1843. Geobios, 27:717-751. https://doi.org/10.1016/s0016-6995(94)800588

Roček, Z. 2013. Mesozoic and Tertiary Anura of Laurasia. Palaeobiodiversity and Palaeoenvironments, 93:397-439. https://doi.org/10.1007/s12549-013-0131-y

Rook, L., Bernor, R.L., and Kordos, L. 2005. Rudabánya: a reference Late Miocene (Vallesian, MN9) vertebrate fauna from Middle Europe. Palaeontographia Italica, 90:309-313.

Rook, L. and Delfino, M. 2007. La fauna preistorica di Brisighella e i popolamenti continentali del Mediterraneo nel Miocene superiore, p. 97-121. In Sami, M. (ed.), II Parco Museo Geologico Cava Monticino, Brisighella. Una Guida e una Storia. Tipografia Carta Bianca, Faenza.

Rook, L., Delfino, M., and Sami, M. 2015. I vertebrati fossili della cava del Monticino di Brisighella: una finestra sui popolamenti continentali del Mediterraneo nel Miocene superiore. I gessi di Brisighella e Rontana. Memorie dell'Istituto Italiano di Speleologia, Series II, 28:79-100. 
Rouchy, J.M. and Caruso, A. 2006. The Messinian salinity crisis in the Mediterranean basin: a reassessment of the data and an integrated scenario. Sedimentary Geology, 188:35-67. https://doi.org/10.1016/j.sedgeo.2006.02.005

Sánchez-Vialas, A., Calvo-Revuelta, M., and García-París, M. 2019. Taxonomic and nomenclatural status of Iberian Algyroides (Lacertidae). Amphibia-Reptilia, 40:91-102. https:/ /doi.org/10.1163/15685381-20181016

Sanchíz, B. 1984. Algunas batracofaunas pleistocénicas de islas del Mediterráneo oriental, p. 59-69. In Castroviejo, J. (ed.), Actas II Reunión Iberoamericana sobre Conservación y Zoología de Vertebrados. Publicaciones Estación Biológica de Doñana CSIC, Sevilla.

Sanchíz, B. 1998a. Salientia. Part 4. Encyclopedia of Paleoherpetology. Verlag Dr. Friedrich Pfeil, München.

Sanchíz, B. 1998b. Vertebrates from the Early Miocene lignite deposits of the opencast mine Oberdorf (Western Styrian Basin, Austria). 2. Amphibia. Annalen des Naturhistorischen Museums in Wien, 99A:13-29.

Sanchíz, B. and Młynarski, M. 1979. Pliocene salamandrids (Amphibia, Caudata) from Poland. Acta Zoologica Cracoviensia, 24:175-188.

Savi, P. 1821. Descrizione (inedita) di una nuova specie di salamandra terrestre, Salamandra perspicillata. Biblioteca Italiana, Ossia Giornale di Letteratura, Scienze ed Arti, 22:228-230.

Scanlon, J.D., Lee, M.S.Y., and Archer, M. 2003. Mid-Tertiary elapid snakes (Squamata, Colubroidea) from Riversleigh, northern Australia: early steps in a continent-wide adaptive radiation. Geobios, 36:573-601. https://doi.org/10.1016/s0016-6995(03)00056-1

Schmidt-Kittler, N., de Bruijn, H., and Doukas, C. 1995. The vertebrate locality Maramena (Macedonia, Greece) at the Turolian/Ruscinian boundary (Neogene). 1. General introduction. Münchner Geowissenschaftliche Abhandlungen, 28:9-18.

Schoepff, I.D. 1792. Historia Testudinum Iconibus IIlustrata. [part 1]. J.J. Palm, Erlangae (= Erlangen). https://doi.org/10.5962/bhl.title.5109

Schuett, G., Hoggren, M., Douglas, M., and Greene, H. 2002. Biology of the Vipers. Eagle Mountain Publishing, Eagle Mountain.

Siebenrock, F. 1895. Das skelet der Agamidae. Sitzungsberichte der Kaiserlichen Akademie der Wissenschaftenin Wien, Mathematisch-Naturwissenschaftliche Klasse. Abt. 1, Mineralogie, Krystallographie, Botanik, Physiologie der Pflanzen, Zoologie, Paläontologie, Geologie, physische Geographie und Reisen, 104:1089-1196.

Sillero, N., Campos, J., Bonardi, A., Corti, C., Creemers, R., Crochet, P.-A., Crnobrnja Isailović, J., Denoël, M., Ficetola, G.F., Gonçalves, J., Kuzmin, S., Lymberakis, P., de Pous, P., Rodríguez, A., Sindaco, R., Speybroeck, J., Toxopeus, B., Vieites, D.R., and Vences, M. 2014. Updated distribution and biogeography of amphibians and reptiles of Europe. Amphibia-Reptilia, 35:1-31. https://doi.org/10.1163/15685381-00002935

Sindaco, R. and Jeremčenko, V. 2008. The Reptiles of the Western Palearctic Vol. 1: Annotated Checklist and Distributional Atlas of the Turtles, Crocodiles, Amphisbaenians and Lizards of Europe, North Africa, Middle East and Central Asia. Monografie della Societas Herpetologica Italica I, Belvedere.

Sinitsa, M.V. 2018. Phylogenetic position of Sinotamias and the early evolution of Marmotini (Rodentia, Sciuridae, Xerinae). Journal of Vertebrate Paleontology, 38:e1419251. https:// doi.org/10.1080/02724634.2017.1419251

Smith, K.T. 2006. A diverse new assemblage of late Eocene squamates (Reptilia) from the Chadron Formation of North Dakota, USA. Palaeontologia Electronica, 9.2.5A:1-44. https:// palaeo-electronica.org/2006_2/dakota/index.html

Smith, K.T. 2009. Eocene lizards of the clade Geiseltaliellus from Messel and Geiseltal, Germany, and the early radiation of Iguanidae (Reptilia: Squamata). Bulletin of the Peabody Museum of Natural History, 50:219-306. https://doi.org/10.3374/014.050.0201

Smith, K.T., Bhullar, B.-A.S., and Holroyd, P.A. 2008. Earliest African record of the Varanus stem-clade (Squamata: Varanidae) from the early Oligocene of Egypt. Journal of Vertebrate Paleontology, 28:909-913. https://doi.org/10.1671/0272-4634(2008)28[909:earotv]2.0.co;2

Snel, E., Mărunţeanu, M., and Meulenkamp, J.E. 2006. Calcareous nannofossil biostratigraphy and magnetostratigraphy of the upper Miocene and lower Pliocene of the Northern Aegean (Orphanic Gulf-Strimon Basin areas), Greece. Palaeogeography, Palaeoclimatology, Palaeoecology, 238:125-150. https://doi.org/10.1016/j.palaeo.2006.03.022 
Sonnini de Manoncourt, C.S. and Latreille, P.A. 1801 An. X. Histoire Naturelle des Reptiles, avec Figures Dessinées d'après Nature. Volume 4. Deterville, Paris. https://doi.org/10.5962/ bhl.title.4688

Sparreboom, M. 2014. Salamanders of the Old World: the Salamanders of Europe, Asia and Northern Africa. First edition. KNNV Publishing, Zeist. https://doi.org/10.1163/ 9789004285620

Steindachner, F. 1870. Herpetologische notizen (II). Reptilien gesammelt Während einer reise in Sengambien. Sitzungsberichte der Kaiserlichen Akademie der Wissenschaften in Wien, 62:326-348.

Stejneger, L.H. 1890. On a new genus and species of colubrine snakes from North America. Proceedings of the United States National Museum, 13:151-155. https://doi.org/10.5479/ si.00963801.13-802.151

Stilson, K.T., Bell, C.J., and Mead, J.I. 2017. Patterns of variation in the cranial osteology of three species of endemic Australian lizards (Ctenophorus: Squamata: Agamidae): implications for the fossil record and morphological analyses made with limited sample sizes. Journal of Herpetology, 51:316-329. https://doi.org/10.7934/p1262

Streicher, J.W. and Wiens, J.J. 2016. Phylogenomic analyses reveal novel relationships among snake families. Molecular Phylogenetics and Evolution, 100:160-169. https://doi.org/10.1016/ j.ympev.2016.04.015

Stümpel, N., Rajabizadeh, M., Avci, A., Wüster, W., and Joger, U. 2016. Phylogeny and diversification of mountain vipers (Montivipera, Nilson et al., 2001) triggered by multiple PlioPleistocene refugia and high-mountain topography in the Near and Middle East. Molecular Phylogenetics and Evolution, 101:336-351. https://doi.org/10.1016/j.ympev.2016.04.025

Suc, J.-P., Popescu, S.-M., Do Couto, D., Clauzon, G., Rubino, J.-L., Melinte-Dobrinescu, M.C., Quillévéré, F., Brun, J.-P., Dumurdžanov, N., Zagorchev, I., Lesić, V., Tomić, D., Sokoutis, D., Meyer, B., Macalet, R., and Rifelj, H. 2015. Marine gateway vs. fluvial stream within the Balkans from 6 to $5 \mathrm{Ma}$. Marine and Petroleum Geology, 66:231-245. https://doi.org/10.1016/ j.marpetgeo.2015.01.003

Sumida, S.S. and Murphy, R.W. 1987. Form and function of the tooth crown structure in gekkonid lizards (Reptilia, Squamata, Gekkonidae). Canadian Journal of Zoology, 65:28862892. https://doi.org/10.1139/z87-438

Syromyatnikova, E.V. 2019. Redescription of Pelobates praefuscus Khosatzky, 1985 and new records of Pelobates from the late Miocene-Pleistocene of Eastern Europe. Historical Biology, 31:888-897. https://doi.org/10.1080/08912963.2017.1402015

Syromyatnikova, E., Georgalis, G.L., Mayda, S., Kaya, T., and Saraç, G. 2019. A new early Miocene herpetofauna from Kilçak, Turkey. Russian Journal of Herpetology, 26:205-224.

Szalai, T. 1934. Die fossilen Schildkröten Ungarns. Folia Zoologica et Hydrobiologica, 6:97-142.

Szunyoghy, J. von. 1932. Beiträge zur vergleichenden formenlehre des colubridenschädels, nebst einer kraniologischen synopsis der fossilenschlangen ungarns mit nomenklatorischen, systematischen und phyletischen bemerkungen. Acta Zoologica, Stockholm, 13:1-56. https:// doi.org/10.1111/j.1463-6395.1932.tb00484.x

Szyndlar, Z. 1984. Fossil snakes from Poland. Acta Zoologica Cracoviensia, 28:1-156.

Szyndlar. Z. 1985. Ophidian fauna (Reptilia, Serpentes) from the uppermost Miocene of Algora (Spain). Estudios Geológicos, 41:447-465. https://doi.org/10.3989/egeol.85415-6725

Szyndlar, Z. 1987. Snakes from the Lower Miocene locality of Dolnice (Czechoslovakia). Journal of Vertebrate Paleontology, 7:55-71. https://doi.org/10.1080/02724634.1987.10011637

Szyndlar, Z. 1991a. A review of Neogene and Quaternary snakes of Central and Eastern Europe. Part I: Scolecophidia, Boidae, Colubrinae. Estudios Geológicos, 47:103-126.

Szyndlar, Z. 1991b. A review of Neogene and Quaternary snakes of Central and Eastern Europe. Part II: Natricinae, Elapidae, Viperidae. Estudios Geológicos, 47:237-266.

Szyndlar, Z. 1995. The vertebrate locality Maramena (Macedonia, Greece) at the TurolianRuscinian Boundary (Neogene). 4. Serpentes (Squamata, Reptilia). Münchner Geowissenschaftliche Abhandlungen, 28:35-39.

Szyndlar, Z. 2005. Snake fauna from the Late Miocene of Rudabánya. Palaeontographia Italica, 90:31-52.

Szyndlar, Z. 2012. Early Oligocene to Pliocene Colubridae of Europe: a review. Bulletin de la Société Géologique de France, 183:661-681. https://doi.org/10.2113/gssgfbull.183.6.661 
Szyndlar, Z. and Rage, J.-C. 1990. West Palearctic cobras of the genus Naja (Serpentes: Elapidae): interrelationships among extinct and extant species. Amphibia-Reptilia, 11:385400. https://doi.org/10.1163/156853890x00078

Szyndlar, Z. and Rage, J.-C. 1999. Oldest fossil vipers (Serpentes: Viperidae) from the Old World. Kaupia, 8:9-20.

Szyndlar, Z. and Rage, J.-C. 2002. Fossil record of the true vipers, p. 419-441. In Schuett, G., Hoggren, M., Douglas, M., and Greene, H. (eds.), Biology of the Vipers. Eagle Mountain Publishing, Eagle Mountain.

Szyndlar, Z. and Rage, J.-C. 2003. Non-erycine Booidea from the Oligocene and Miocene of Europe. Institute of Systematics and Evolution of Animals, Polish Academy of Sciences, Kraków.

Szyndlar, Z. and Schleich, H.-H. 1993. Description of Miocene snakes from Petersbuch 2 with comments on the lower and middle Miocene ophidian faunas of southern Germany. Stuttgarter Beiträge zur Naturkunde B, 192:1-47.

Szyndlar, Z. and Schleich, H.-H. 1994. Two species of the genus Eryx (Serpentes; Boidae; Erycinae) from the Spanish Neogene with comments on the past distribution of the genus in Europe. Amphibia-Reptilia, 15:233-248. https://doi.org/10.1163/156853894×00010

Szyndlar, Z. and Zerova, G. 1990. Neogene cobras of the genus Naja (Serpentes: Elapidae) of East Europe. Annalen des Naturhistorischen Museums in Wien, 91A:53-61.

Temminck, C.J. 1836. Coup-d'oeil sur la Faune des îles de la Sonde et de l'Empire du Japon. Discours Préliminaire Destiné à Servir d'Introduction à la Faune du Japon. Müller, Amsterdam. https://doi.org/10.5962/bhl.title.119899

Tempfer, P.M. 2005. The herpetofauna (Amphibia: Caudata, Anura; Reptilia: Scleroglossa) of the Upper Miocene locality Kohfidisch (Burgenland, Austria). Beiträge zur Paläontologie, 29:145253.

Theobald, W., Jr. 1868. Catalogue of reptiles in the Museum of the Asiatic Society of Bengal. Journal of the Asiatic Society, Extra Number, 37:1-88. https://doi.org/10.5962/bhl.title.5477

Torres-Roig, E., Bailon, S., Bover, P., and Alcover, J.A. 2017. An early Pliocene anuran assemblage from Mallorca (Balearic Islands, Western Mediterranean): palaeobiogeographic and palaeoenvironmental implications. Palaeobiodiversity and Palaeoenvironments, 97:315327. https://doi.org/10.1007/s12549-017-0273-4

Tourneville, A. 1879. Description d'une nouvelle espèce de batracien urodèle d'Espagne (Pelonectes boscai Lataste). Bulletin de la Société Zoologique de France, 4:69-87.

Townsend, V.R., Jr., Akin, J.A., Felgenhauer, B.E., Dauphine, J., and Kidder, S.A. 1999. Dentition of the ground skink, Scincella lateralis (Sauria, Scincidae). Copeia, 1999:783-788. https://doi.org/10.2307/1447615

Truong, N.Q., Van Sang, N., Orlov, N., Thao, H.N., Böhme, W., and Ziegler, T. 2010. A review of the genus Tropidophorus (Squamata, Scincidae) from Vietnam with new species records and additional data on natural history. Zoosystematics and Evolution, 86:5-19. https://doi.org/ 10.1002/zoos.200900020

Valakos, E.D., Pafilis, P., Sotiropoulos, K., Lymberakis, P., Maragou, P., and Foufopoulos, J. 2008. Amphibians and Reptiles of Greece. Chimaira, Frankfurt.

Valverde, J.A. 1958. Una nueva lagartija del género Algiroides Bribron procedente de la Sierra de Cazorla (Sur de España). Archivos del Instituto de Aclimatación de Almería, 7:127-134.

Vasileiadou, K., Böhme, M., Neubauer, T.A., Georgalis, G.L., Syrides, G.E., Papadopoulou, L., and Zouros, N. 2017. Early Miocene gastropod and ectothermic vertebrate remains from the Lesvos Petrified Forest (Greece). Paläontologische Zeitschrift, 91:541-564. https://doi.org/ 10.1007/s12542-017-0352-x

Vasilyan, D., Böhme, M., Chkhikvadze, V.M., Semenov, Y.A., and Joyce, W.G. 2013. A new giant salamander (Urodela, Pancryptobrancha) from the Miocene of eastern Europe (Grytsiv, Ukraine). Journal of Vertebrate Paleontology, 33:301-318. https://doi.org/10.1080/ 02724634.2013 .722151

Vasilyan, D., Schneider, S., Bayraktutan, M.S., and Şen, Ş. 2014. Early Pleistocene freshwater communities and rodents from the Pasinler Basin (Erzurum Province, north-eastern Turkey). Turkish Journal of Earth Sciences, 23:293-307. https://doi.org/10.3906/yer-1307-16

Venczel, M. 1994. Late Miocene snakes from Polgárdi (Hungary). Acta Zoologica Cracoviensia, 37:1-29.

Venczel, M. 1998. Late Miocene snakes (Reptilia: Serpentes) from Polgárdi (Hungary): a second contribution. Acta Zoologica Cracoviensia, 4:1-22. 
Venczel, M. 2000. Quaternary Snakes from Bihor (Romania). Publishing House of the Tarii Crisurilor Museum, Oradea.

Venczel, M. 2001 Anurans and squamates from the lower Pliocene (MN 14) Osztramos 1 locality (Northern Hungary). Fragmenta Palaeontologica Hungarica, 19:79-90.

Venczel, M. 2006. Lizards from the Late Miocene of Polgárdi (W. Hungary). Nymphaea, Folia naturae Bihariae, 33:25-38.

Venczel, M. 2011. Middle-Late Miocene snakes from the Pannonian basin. Acta Palaeontologica Romaniae, 7:343-349.

Venczel, M. and Hír, J. 2013. Amphibians and squamates from the Miocene of Felsötárkány basin, N-Hungary. Palaeontographica Abteilung A, 300:117-147. https://doi.org/10.1127/pala/ 300/2013/117

Venczel, M. and Hír, J. 2015. Lissamphibians and squamate reptiles from the early middle Miocene of Litke, northern Hungary. Geobios, 48:491-504. https://doi.org/10.1016/ j.geobios.2015.09.001

Venczel, M., Hír, J., Huza, R.R., Popa, E., and Golban, D. 2005. A new Middle Miocene vertebrate fauna from Subpiatrã (Bihor County, Romania). Nymphaea, Folia Naturae Bihariae, 32:23-38.

Venczel, M. and Sanchíz, B. 2006. Lower Miocene amphibians and reptiles from Oschiri (Sardinia, Italy). Hantkeniana, 5:72-75.

Venczel, M. and Ştiucă, E. 2008. Late middle Miocene amphibians and squamate reptiles from Tauţ, Romania. Geodiversitas, 30:731-763.

Venczel, M. and Várdai, G. 2000. The genus Elaphe in the Carpathian basin: fossil record. Nymphaea, Folia Naturae Bihariae, 28:65-82.

Vidal, N. and Hedges, B.S. 2005. The phylogeny of squamate reptiles (lizards, snakes, and amphisbaenians) inferred from nine nuclear protein-coding genes. Comptes Rendus Biologies, 328:1000-1008. https://doi.org/10.1016/j.crvi.2005.10.001

Vidal, N.and Hedges, B.S. 2009. The molecular evolutionary tree of lizards, snakes, and amphisbaenians. Comptes Rendus Biologies, 332:129-139. https://doi.org/10.1016/ j.crvi.2008.07.010

Vidal, N., Rage, J.-C., Couloux, A., and Hedges, S.B. 2009. Snakes (Serpentes), p. 390-397. In Hedges, S.B. and Kumar, S. (eds.), The Timetree of Life. Oxford University Press, New York.

Vilakazi, N., Gommery, D., and Kgasi, L. 2018. First fossil record of the spitting Elapidae in the Cradle of Humankind, South Africa. South African Archaeological Bulletin, 73:35-40.

Villa, A., Abella, J., Alba, D.M., Almécija, S., Bolet, A., Koufos, G.D., Knoll, F., Luján, À.H., Morales, J., Robles, J.M., Sánchez, I.M., and Delfino, M. 2018a. Revision of Varanus marathonensis (Squamata, Varanidae) based on historical and new material: morphology, systematics, and paleobiogeography of the European monitor lizards. PLoS ONE, 13:e0207719. https://doi.org/10.1371/journal.pone.0207719

Villa, A., Andreone, F., Boistel, R., and Delfino, M. 2014. Skull and lower jaw osteology of the Lanza's salamander, Salamandra lanzai (Amphibia, Caudata), p. 171-200. In Capula, M.and Corti, C. (eds.), Scripta Herpetologica. Studies on Amphibians and Reptiles in Honour of Benedetto Lanza. Monografie della Societas Herpetologica Italica - III. Edizioni Belvedere, Latina, "le scienze".

Villa, A., Daza, J.D., Bauer, A.M., and Delfino, M. 2018b. Comparative cranial osteology of European gekkotans (Reptilia, Squamata). Zoological Journal of the Linnean Society, 184:857-895. https://doi.org/10.1093/zoolinnean/zlx104

Villa, A., Delfino, M., Luján, À.H., Almécija, S., and Alba, D.M. 2019. First record of Latonia gigantea (Anura, Alytidae) from the Iberian Peninsula. Historical Biology, 31:371-382. https:// doi.org/10.1080/08912963.2017.1371712

Villa, A., Kosma, R., Čerňanský, A., and Delfino, M. 2018c. Taxonomical assessment of 'Bavaricordylus' Kosma, 2004 (Reptilia, Squamata). Journal of Vertebrate Paleontology, e1487844. https://doi.org/10.1080/02724634.2018.1487844

Villa, A., Tschopp, E., Georgalis, G.L., and Delfino, M. 2017. Osteology, fossil record and palaeodiversity of the European lizards. Amphibia-Reptilia, 38:79-88. https://doi.org/10.1163/ 15685381-00003085

Vitt, L.J. and Caldwell, J.P. 2014. Herpetology. An Introductory Biology of Amphibians and Reptiles. 4th Edition. Academic Press, Elsevier, Amsterdam. 
Vlachos, E., Tsoukala, E., and Corsini, J. 2014. Cheirogaster bacharidisi, sp. nov., a new species of a giant tortoise from the Pliocene of Thessaloniki (Macedonia, Greece). Journal of Vertebrate Paleontology, 34:560-575. https://doi.org/10.1080/02724634.2013.821409

Vlachos, E., Kotsakis, T., and Delfino, M. 2015. The chelonians from the latest Miocene-earliest Pliocene locality of Allatini and Pylea (east Thessaloniki, Macedonia, Greece). Comptes Rendus Palevol, 14:187-205. https://doi.org/10.1016/j.crpv.2015.01.005

Vlachos, E., Sterli, J., Vasileiadou, K., and Syrides, G. 2019. A new species of Mauremys (Testudines, Geoemydidae) from the late Miocene - Pliocene of Central Macedonia (Northern Greece) with exceptionally wide vertebral scutes. Papers in Palaeontology, 5:177195. https://doi.org/10.1002/spp2.1235

Vlachos, E. and Tsoukala, E. 2016. The diverse fossil chelonians from Milia (late Pliocene, Grevena, Greece) with a new species of Testudo Linnaeus, 1758 (Testudines: Testudinidae). Papers in Palaeontology, 2:71-86. https://doi.org/10.1002/spp2.1031

von Meyer, H. 1843. Mittheilungen an professor Bronn gerichtet. Neues Jahrbuch für Geologie und Paläontologie, Geognasie, Geologie und Petrefactenkunde, 1843:579-590.

van Riemsdijk, I., Arntzen, J.W., Bogaerts, S., Franzen, M., Litvinchuk, S.N., Olgun, K., and Wielstra, B. 2017. The Near East as a cradle of biodiversity: a phylogeography of banded newts (genus Ommatotriton) reveals extensive inter- and intraspecific genetic differentiation. Molecular Phylogenetics and Evolution, 114:73-81. https://doi.org/10.1016/ j.ympev.2017.05.028

von Spix, J.B. 1825. Animalia nova sive species nova lacertarum quas in itinere per Brasiliam annis MDCCCXVII-MDCCCXX jussu et auspicius Maximiliani Josephi I Bavariae Regis suscepto collegit et descripsit Dr. J.B. de Spix. T.O. Weigel and F.S. Hübschmanni, Lipsiae (Leipzig) and Monachii (Munich). https://doi.org/10.5962/bhl.title.5117

Wagler, J.G. 1824. Serpentum brasiliensium species novae ou Histoire Naturelle des Espèces Nouvelles de Serpens, Recueillies et Observées pendant le Voyage dans I'Intérieur du Brésil dans les Années 1817, 1818, 1819, 1820, Exécuté par Ordre de Sa Majesté le Roi de Bavière, Publiée par Jean de Spix,... Ecrite d'après les Notes du Voyageur. Seraph. Hübschmanni, Monachii, Franc. https://doi.org/10.5962/bhl.title.4269

Wagler, J.G. 1830. Natürliches system der amphibien, mit vorangehender classification der saugthiere und vogel. Ein beitrag zur vergleichenden Zoologie. J.G. Cotta schen Buchhandlung. Munchen, Stuttgart und Tubingen. https://doi.org/10.5962/bhl.title.58730

Wagler, J.G. 1833. Descriptiones et icones amphibiorum. Sumtibus J.G. Cottae, Monachii (= Munich), Stuttgartiae (= Stuttgart) and Tubingae (= Tübingen). https://doi.org/10.5962/ bhl.title.77350

Wallach, V., Williams, K.L., and Boundy, J. 2014. Snakes of the World: a Catalogue of Living and Extinct species. CRC Press, Boca Raton, London and New York.

Weithofer, A. 1888. Beiträge zur kenntniss der fauna von Pikermi bei Athen. Beiträge zur Paläontologie Österreich-Ungarns, 6:225-292.

Westphal, F. 1958. Die tertiären und rezenten eurasiatischen riesensalamander (genus Andrias, Urodela, Amphibia). Palaeontographica A, 110:20-92.

White, J. 1790. Journal of a Voyage to New South Wales, with Sixty-five Plates of Non Descript Animals, Birds, Lizards, Serpents, Curious Cones of Trees and Other Natural Productions. Debrett, London. https://doi.org/10.5962/bhl.title.118604

Wiegmann, A.F.A. 1834. Herpetologia Mexicana, seu descriptio amphibiorum Novae Hispaniae, quae itineribus comitis de Sack, Ferdinandi Deppe et Chr. Guil. Schiede in Museum Zoologicum Berolinense Pervenerunt, C. G. Lüderitz, Berlin. https://doi.org/10.5962/ bhl.title.119131

Wiens, J.J., Hutter, C.R., Mulcahy, D.G., Noonan, B.P., Townsend, T.M., Sites, J.W., and Reeder, T.W. 2012. Resolving the phylogeny of lizards and snakes (Squamata) with extensive sampling of genes and species. Biology Letters, 8:1043. https://doi.org/10.1098/ rsbl.2012.0703

Wilczyński, J., Tomek, T., Nadachowski, A., Miękina, B., Rzebik-Kowalska, B., Pereswiet-Soltan, A., Stworzewicz, E., Szyndlar, Z., Marciszak, A., and Lõugas, L. 2016. Chapter 5. Faunal record and enviromental changes during Holocene and Pleistocene, p. 63-80. In Kaczanowska, M., Kozłowski, J.K., and Sampson, A. (eds.), The Sarakenos Cave at Akraephnion, Boeotia, Greece. Vol. II. The Early Neolithic, the Mesolithic and the Final Palaeolithic (Excavations in Trench A). The Polish Academy of Arts and Sciences, Kraków. 
Williams, E.E. 1954. Clemmydopsis Boda a valid lineage of emydine turtles from the European Tertiary. Breviora, 28:1-9.

Zahradnicek, O., Horacek, I., and Tucker, A.S. 2008. Viperous fangs: development and evolution of the venom canal. Mechanisms of Development, 125:786-796. https://doi.org/10.1016/ j.mod.2008.06.008

Zarevsky, S.F. 1929. Contribution to the classification and distribution of the lizards of the genus Phrynocephalus. Comptes Rendus de l'Académie des Sciences de l'URSS, 1929:415-419.

Zheng, Y. and Wiens, J.J. 2016. Combining phylogenomic and supermatrix approaches, and a time?calibrated phylogeny for squamate reptiles (lizards and snakes) based on 52 genes and 4162 species. Molecular Phylogenetics and Evolution, 94:537-547. https://doi.org/10.1016/ j.ympev.2015.10.009 